Yonathan Ferreira Bizzo

\title{
Avaliação dos Efeitos das Propriedades dos Fluidos e das Rochas na Simulação Geomecânica de Reservatórios do Campo de Namorado
}

Dissertação apresentada ao Programa de Pósgraduação em Engenharia Mecânica da PUC-Rio como requisito parcial para obtenção do grau de Mestre em Engenharia Mecânica.

Orientador: Prof. Arthur Martins Barbosa Braga Coorientador: Prof. Nelson Inoue 


\section{Avaliação dos Efeitos das Propriedades dos Fluidos e das Rochas na Simulação Geomecânica de Reservatórios do Campo de Namorado}

Dissertação apresentada como requisito parcial para obtenção do grau de Mestre pelo Programa de Pósgraduação em Engenharia Mecânica do Centro Técnico Científico da PUC-Rio. Aprovada pela Comissão Examinadora abaixo assinada.

Prof. Arthur Martins Barbosa Braga

Orientador

Departamento de Engenharia Mecânica - PUC-Rio

Prof. Nelson Inoue

Coorientador

Departamento de Engenharia Civil - PUC-Rio

Dr. Luiz Otávio Schmall dos Santos Petróleo Brasileiro

Dra. Flávia de Oliveira Lima Falcão

Petróleo Brasileiro

Prof. Sergio Augusto Barreto da Fontoura

Departamento de Engenharia Civil - PUC-Rio

Prof. Márcio da Silveira Carvalho

Coordenador Setorial do Centro

Técnico Científico - PUC-Rio

Rio de Janeiro, 28 de abril de 2017 
Todos os direitos reservados. É proibida a reprodução total ou parcial deste trabalho sem autorização da universidade, do autor e do orientador.

\section{Yonathan Ferreira Bizzo}

Graduou-se em Engenharia de Petróleo na Pontifícia Universidade Católica do Rio de Janeiro em 2014. No ano de 2015, ingressou no curso de Mestrado em Engenharia Mecânica na Pontifícia Universidade Católica do Rio de Janeiro, na área de Petróleo e Energia.

Ficha Catalográfica

Bizzo, Yonathan Ferreira

Avaliação dos efeitos das propriedades dos fluidos e das rochas na simulação geomecânica de reservatórios do Campo de Namorado / Yonathan Ferreira Bizzo ; orientador: Arthur Martins Barbosa Braga ; co-orientador: Nelson Inoue. - 2017.

173 f. : il. color. ; $30 \mathrm{~cm}$

Dissertação (mestrado)-Pontifícia Universidade Católica do Rio de Janeiro, Departamento de Engenharia Mecânica, 2017. Inclui bibliografia

1. Engenharia Mecânica - Teses. 2. Simulação geomecânica. 3. Simulação de reservatórios. 4. Acoplamento parcial de duas vias. 5. Poroelasticidade. I. Braga, Arthur Martins Barbosa. II. Inoue, Nelson. III. Pontifícia Universidade Católica do Rio de Janeiro. Departamento de Engenharia Mecânica. IV. Título. 


\section{Agradecimentos}

Aos meus orientadores, Arthur Braga e Dr. Nelson Inoue por todo o suporte na decisão e no desenvolvimento de um tema tão atual na indústria do petróleo.

Ao CNPq pela bolsa de incentivo com duração de dois anos que permitiu o desenvolvimento do trabalho com dedicação exclusiva.

Aos colegas de GTEP sempre prestativos em tirar dúvidas e dar palavras de incentivo.

A meus pais, Iran e Rosana, por me apoiarem durante todos esses anos e garantirem um ambiente familiar regido por valores e atenção.

A meu avô, Hugo, por ter sido a pessoa que moldou parte da minha personalidade e de quem sinto imensas saudades.

A Deus, por ter posto obstáculos em minha vida que sempre me ensinaram o direcionamento correto e a gratidão por ver a conquista concretizada. 


\section{Resumo}

Bizzo, Yonathan Ferreira; Braga, Arthur Martins Barbosa; Inoue, Nelson. Avaliação dos Efeitos das Propriedades dos Fluidos e das Rochas na Simulação Geomecânica de Reservatórios do Campo de Namorado. Rio de Janeiro, 2017. 173 p. Dissertação de Mestrado - Departamento de Engenharia Mecânica, Pontifícia Universidade Católica do Rio de Janeiro.

Em uma simulação de reservatório convencional, geralmente o modelo de fluxo de fluido de uma área de interesse recebe mais atenção do que o modelo geomecânico. Nos estudos de fluxo, são analisadas as variações de pressão de poros, saturação de fluidos e temperatura no reservatório, resultantes da produção e injeção de fluidos durante a fase de explotação do campo. Porém, o comportamento mecânico da rocha também chamado, na indústria do petróleo, de efeito geomecânico é aproximado em uma simulação convencional de reservatórios através de apenas um único parâmetro mecânico: a compressibilidade da rocha, insuficiente para avaliar de maneira adequada, o efeito que a variação do estado de tensão nas rochas reservatório e adjacentes exercem sobre a pressão de poros no reservatório. Em função disso, um dos objetivos deste trabalho é analisar como a variação de propriedades das rochas e dos fluidos pode impactar na produção de hidrocarbonetos e na ordem de grandeza da compactação e subsidência. Outro objetivo igualmente importante é a criação de um fluxo de informações que permite estimar as propriedades mecânicas das rochas a partir de dados provenientes de perfilagem, de maneira a dar maior acurácia aos dados utilizados. Dessa forma, as análises feitas utilizaram a metodologia desenvolvida pelo GTEP/PUC-Rio, a qual permite que sejam feitas simulações parcialmente acopladas de duas vias entre o simulador de fluxo IMEX e o programa de análise de tensões CHRONOS. Os resultados obtidos permitiram concluir que o início da liberação de gás dentro do reservatório tem impacto não só na explotação de fluidos, como também na desaceleração do processo de compactação do reservatório. Além disso, mudanças de propriedades nas rochas adjacentes não geram comportamentos semelhantes de deslocamentos para todos os horizontes observados.

\section{Palavras-chave}

Simulação geomecânica; simulação de reservatórios; acoplamento parcial de duas vias; poroelasticidade 


\section{Abstract}

Bizzo, Yonathan Ferreira; Braga, Arthur Martins Barbosa; Inoue, Nelson (Advisor). Evaluation of the Effects of Fluid and Rock Properties on Geomechanical Simulations of Reservoirs from the Namorado Field. Rio de Janeiro, 2017. 173 p. Dissertação de Mestrado - Departamento de Engenharia Mecânica, Pontifícia Universidade Católica do Rio de Janeiro.

In a conventional reservoir simulation, usually the fluid flow model of an area of interest receives more attention than the geomechanics model. In these studies, the pore pressure, fluid saturation and reservoir temperature variations resulting from the production and injection of fluids during the field exploitation phase are analyzed. However, less attention is given to the mechanical behavior of rock, also called geomechanical effects in the petroleum industry, which is approximated in a conventional reservoir simulation using only a single mechanical parameter: the compressibility of the rock, which is insufficient to adequately evaluate the effect that the variation of the stress state in the reservoir and in the adjacent rocks exerts on the pore pressure in the reservoir. Because of that, this work aims at analyzing how the variations of rocks and fluids properties may affect the production of hydrocarbons and the order of magnitude of compaction and subsidence. Another equally important objective is the creation of an information flow that allows the estimation of the mechanical properties of the rocks, based on $\log$ data, in order to give greater accuracy to the data used. Thus, the analyses were performed using a methodology developed by the GTEP / PUC-Rio, which makes it possible to perform two way partially coupled simulations between the conventional flow simulator (IMEX) and the stress analysis program (CHRONOS). The obtained results indicate that the initiation of the gas released inside the reservoir has an impact not only on the exploitation of fluids, but also on the deceleration of the reservoir compaction process. In addition, changes in the properties of adjacent rocks do not generate a similar displacement behavior for all observed horizons.

\section{Keywords}

Geomechanics simulation; reservoir simulation; two way partial coupling; poroelasticity 


\section{Sumário}

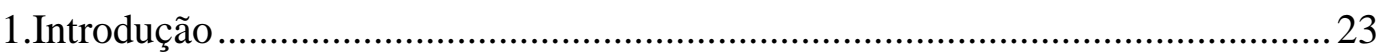

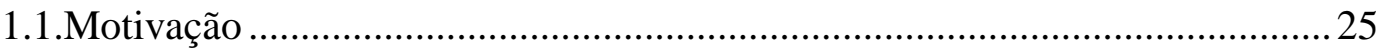

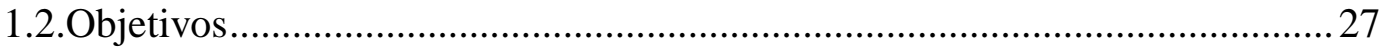

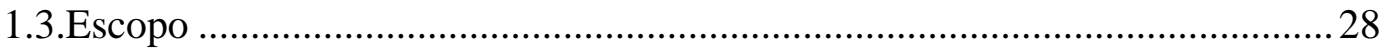

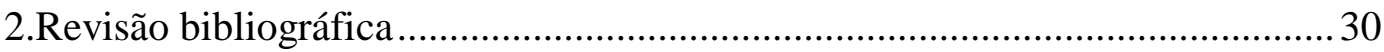

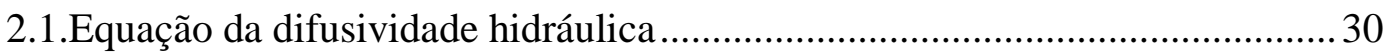

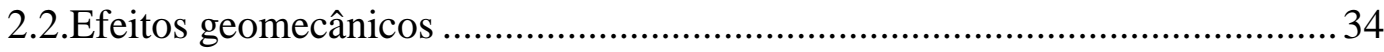

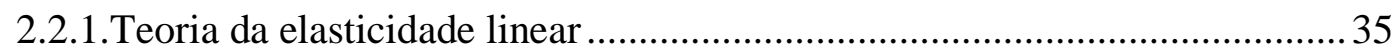

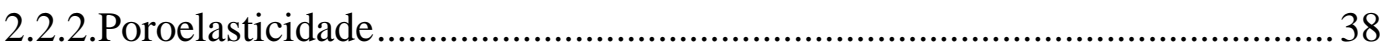

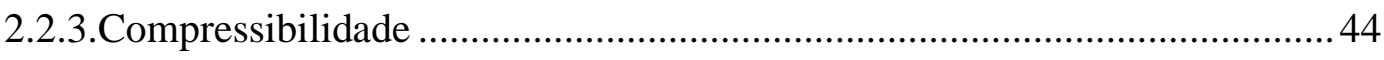

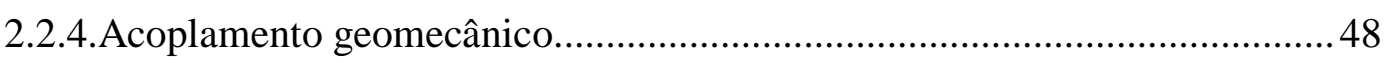

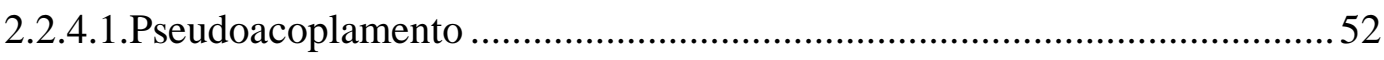

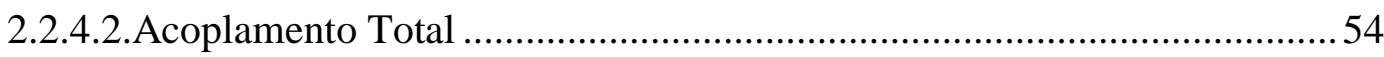

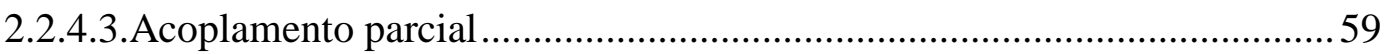

2.2.5.Metodologia de acoplamento GTEP - PUC-Rio......................................... 63

3.Medições diretas e indiretas dos módulos de elasticidade e compressibilidade. 69

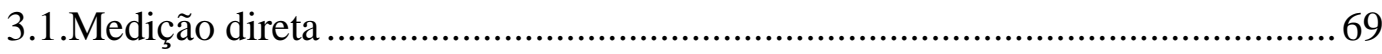

3.2.Medição indireta por meio de ondas compressionais e cisalhantes..................72

3.3.Medição indireta por meio de perfis............................................................... 76

3.3.1.Determinação de Ks e Gs ....................................................................... 78

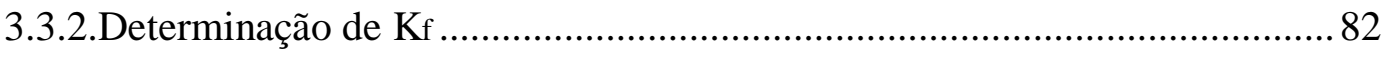

4.Construção do Modelo Geomecânico................................................................... 86 


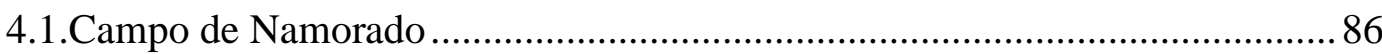

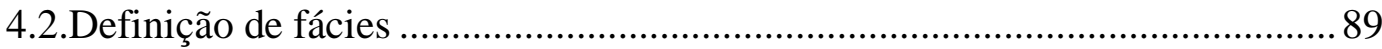

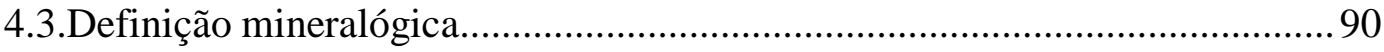

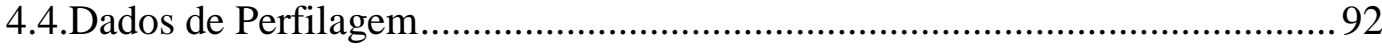

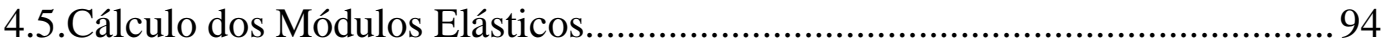

4.6.Construção da Malha de Elementos Finitos ................................................. 108

4.7.Distribuição das Propriedades Mecânicas no Modelo em Estudo.................. 110

5.Estudo de Casos

5.1.Comparação de resultados de fluxo gerados entre método de acoplamento

GTEP/PUC-Rio e simulação sem acoplamento para o cenário R A

5.2.Análise de resultados geomecânicos gerados pelo método de acoplamento

GTEP/PUC-Rio para o cenário RA

5.3.Comparação de resultados entre o cenário R A e outros cenários com diferentes propriedades mecânicas nas rochas adjacentes................................. 128

5.3.1.Definição dos cenários analisados ........................................................... 128

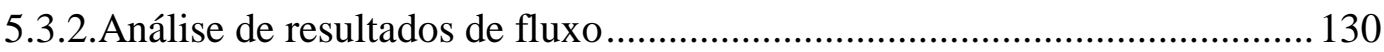

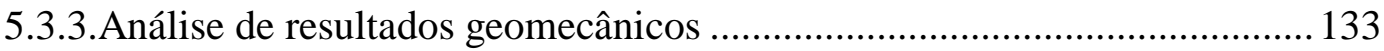

5.4.Comparação de resultados entre o cenário acoplado original e outros cenários com diferentes propriedades mecânicas na rocha reservatório

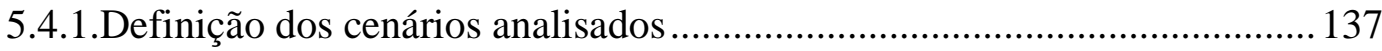

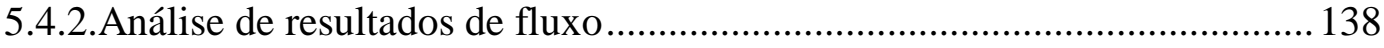

5.4.3.Análise de resultados geomecânicos ........................................................ 142

5.5.Comparação de resultados entre o cenário acoplado original e outros cenários com hidrocarbonetos de graus API distintos....................................... 145

5.5.1.Definição dos cenários analisados ........................................................... 145

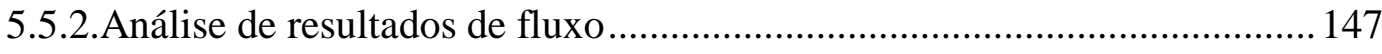

5.5.3.Análise de resultados geomecânicos ........................................................ 151 


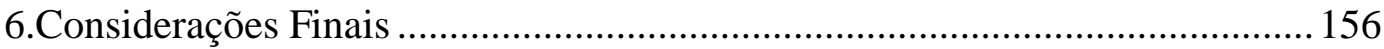

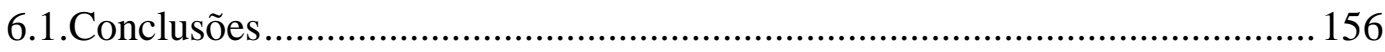

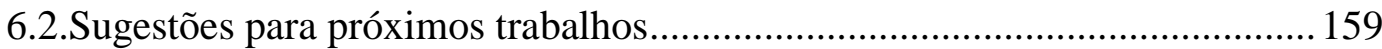

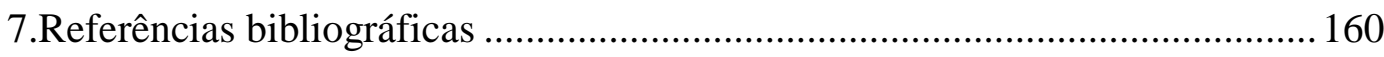

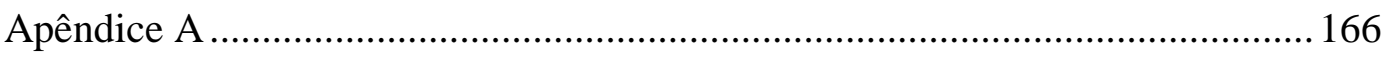

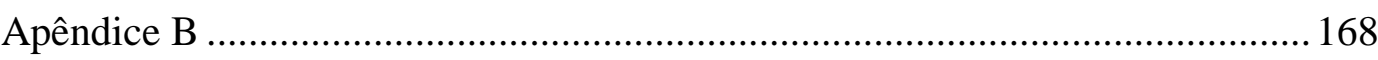

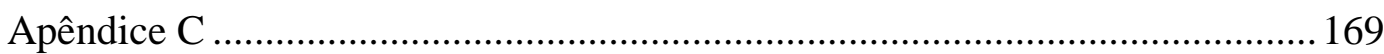




\section{Lista de figuras}

Figura 1.1: Modelo global simplificado utilizado para validações da implementação ABAQUS-IMEX no trabalho de Lautenschlager [7] 26

Figura 2. 1: Fluxo de fluido através de volume de controle cúbico.

Adaptado de Inoue \& Fontoura [4] 31

Figura 2.2: Algumas relações entre módulos elásticos (Fjaer et al. [13]) .............. 38

Figura 2. 3: Representação esquemática de um sistema petrolífero .49

Figura 2. 4: Esquema de interação entre geomecânica e fluxo em um reservatório deformável. 50

Figura 2. 5: Variação da porosidade com a tensão efetiva e a pressão de poros nos regimes elástico e plástico. Modificado de Falcão [10].

Figura 2.6: Relação dos multiplicadores em função da pressão. Pressão de

poros original (p0) é de $322 \mathrm{kgf} / \mathrm{cm}^{2}$

Figura 2.7: Relação linear (à esquerda) e não-linear (à direita) entre porosidade e pressão de poros ( Tran et al. [25] ). .55

Figura 2. 8: Esquema de acoplamento parcial explícito. 60

Figura 2. 9: Esquema de acoplamento parcial iterativo 62

Figura 2. 10: Esquema com as equações que governam o acoplamento

parcial. Modificado de Lautenschläger [7]

Figura 2. 11: Fluxo de processamento de dados no acoplamento parcial iterativo nos programas do pacote Olympus Suite

Figura 2. 12: Aproximação da equação de fluxo do simulador

convencional de reservatórios através da pseudo-compressibilidade

da rocha e da porosidade (adaptado de Inoue \& Fontoura [4])

para o caso isotérmico.

Figura 2. 13: Esquema de processos, realizados pelo Hermes, entre simulador de fluxo e programa de análise de tensões 68

Figura 3. 1: Representação esquemática do ensaio triaxial .70

Figura 3. 2: Esquemas dos testes de compressibilidade com e

jaqueta. Modificado de Chen et al. [30]

Figura 3. 3: Correlação entre módulos de Young estáticos e dinâmicos 
para arenitos.

Figura 3. 4: Correlação entre módulos de Young estáticos e

dinâmicos para folhelhos.

Figura 3.5: Workflow para modelo petroelástico Adaptado de

Emerick et al. [38].

Figura 3. 6: Assinaturas gamaespectométricas típicas dos principais

litotipos sedimentares (Adaptado de Rider, 1990)

Figura 3. 7: Limites de Reuss, Voigt e média de Voigt-Reuss-Hill

para módulo de compressibilidade em um sistema hipotético formado

de argila e quartzo.

Figura 3. 8: Limites de módulo de compressibilidade de Reuss, Voigt

e de Hashin-Shtrikman para um sistema hipotético formado de argila

e calcita.

Figura 4.1: Carta estratigráfica da Bacia de Campos 87

Figura 4. 2: Estrutura do Campo de Namorado com os 9 poços de

produção e legenda em função da profundidade no programa Results

da CMG. a) Visão superior do Campo de Namorado; b) Visão lateral

do Campo de Namorado 88

Figura 4. 3: Mapa do Campo de Namorado com a localização

dos poços de perfilagem utilizados neste trabalho.

Figura 4.4: Fácies classificadas a partir dos critérios da Tabela 4.2 para

cinco poços de perfilagem.

Figura 4. 5: Percentual médio de argila nas litologias identificadas como

arenito em cada poço perfilado.

Figura 4. 6: Módulo de compressibilidade da estrutura mineral

dos pontos identificados como arenito

Figura 4.7: Modelo de contorno de Reuss-Voigt dos módulos de compressibilidade mineral e cisalhamento para as 3 litologias.

Figura 4. 8: Porosidade média obtida por meio de dos do perfil de

densidade para as 3 fácies dos cinco poços perfilados

Figura 4.9: Saturação média de óleo nos arenitos classificados como

reservatórios

Figura 4.10: Módulo de compressibilidade bulk saturado em função 
da porosidade para arenitos, folhelhos e carbonatos.

100

Figura 4. 11: Módulo de compressibilidade bulk saturado e drenado

em relação à porosidade para os pontos classificados como arenito.

Figura 4. 12: Relação entre parâmetro de consolidação e razão de

velocidade (linha sólida) e relação entre parâmetro de consolidação

e parâmetro $\xi$ (linha pontilhada). (Adaptado de Lee [50])

Figura 4. 13: Módulos de compressibilidade e cisalhamento bulk

saturado e drenado em relação à porosidade para os pontos classificados

como arenito.

Figura 4.14: Módulos de compressibilidade e cisalhamento bulk drenado

em relação à porosidade obtidos nesta dissertação e no trabalho de

Emerick et al. [38]

Figura 4.15: Módulos de compressibilidade e cisalhamento bulk saturado

e drenado em relação à porosidade para os pontos classificados como

folhelho e carbonato.

Figura 4.16: Módulo de Young em relação à porosidade para as três

fácies nos cincos poços perfilados

Figura 4. 17: Coeficiente de Poisson em relação à porosidade para as

três fácies nos cincos poços perfilados

Figura 4. 18: (A) Distribuição da porosidade nas regiões ativas do grid

em diferenças finitas do Campo de Namorado no Results3D da CMG;

(B) Distribuição da porosidade nas regiões ativas na malha de elementos

finitos gerados no GOCAD; (C) Malha de elementos finitos com

as regiões inativas inseridas

Figura 4. 19: Visão do reservatório anexado ao sideburden. A legenda

de cores da porosidade refere-se apenas ao reservatório.

Figura 4. 20: Visão lateral do modelo com a presença do overburden,

sideburden e underburden com o reservatório apresentado ao centro.

Figura 4. 21: Histograma de porosidade do arenito que compõe o

reservatório.

Figura 4. 22: Visualização do reservatório dividido em 4 regiões de

porosidade com os 9 poços produtores.

Figura 4. 23: Curvas de módulo de Young estático e dinâmico geradas

pelos dados de arenitos obtidos dos cincos poços perfilados. 
Figura 4. 24: Representação das rochas adjacentes com seus respectivos módulos de elasticidade estáticos, coeficientes de Poisson e porosidades.

Figura 4.25: Curvas de módulo de Young estático e dinâmico geradas pelos dados de folhelhos obtidos dos cincos poços perfilados

Figura 4. 26: Relação entre porosidade e profundidade para regiões

formadas por arenito e folhelho (modificado de Stuart [52])

Figura 5. 1: Representação do reservatório e rochas adjacentes com seus respectivos módulos de Young e coeficientes de Poisson para o cenário R A. .. 118 Figura 5. 2: Curvas de volume acumulado de óleo explotado do Campo de Namorado com e sem acoplamento geomecânico.

Figura 5. 3: Curva de vazão de gás em condições standard para cenários com e sem acoplamento geomecânico.

Figura 5. 4: Curva de liberação de gás dentro do reservatório para cenários com e sem acoplamento geomecânico.

Figura 5. 5: Queda da pressão média do reservatório para cenários com e sem acoplamento geomecânico.

Figura 5. 6: Curva de liberação de gás dentro do reservatório para cenários com e sem acoplamento geomecânico para o período de junho de 2016 a maio de 2017.

Figura 5. 7: Localização dos cincos horizontes selecionados para análise.

Figura 5. 8: Evolução dos deslocamentos dos cinco horizontes

selecionados ao fim de 1,3 e 15 anos de simulação

Figura 5. 9: Taxa de liberação de gás no reservatório e velocidades de deslocamento do leito marinho e topo do reservatório para o período de 15 anos de simulação.

Figura 5.10: Comparação entre deslocamentos para 3 horizontes no cenário R A refinado no overburden e no cenário com overburden totalmente homogêneo.

Figura 5.11: Representação das rochas adjacentes com seus respectivos módulos de Young, coeficientes de Poisson e porosidades para o cenário $\mathrm{R} \mathrm{A}+$. 129

Figura 5.12: Representação das rochas adjacentes com seus respectivos 
módulos de elasticidade, coeficientes de Poisson e porosidades para o cenário R A-

Figura 5. 13: Curva de volume acumulado de óleo produzido para cenários com mudanças de propriedades nas rochas adjacentes

Figura 5. 14: Curva de liberação de gás dentro do reservatório para cenários R A, R A+ e R A- no período de junho de 2016 a janeiro de 2017. .... 131 Figura 5.15: Diferença de pressão média no reservatório dos cenários

R A- e R A+ em relação ao cenário R A ao longo dos 15 anos simulados.

Figura 5. 16: Diferença percentual de entre volume total de óleo produzido nos cenários $\mathrm{R} A-$ e $\mathrm{R} A+$ em relação ao cenário $\mathrm{R}$ A.

Figura 5. 17: Deslocamentos dos cinco horizontes selecionados após

15 anos de simulação para o caso R A-

Figura 5.18: Deslocamentos dos cinco horizontes selecionados após

15 anos de simulação para o caso R A+.

Figura 5.19: Diferença de deslocamentos entre os cenários R A- e R A+ para o cenário R A no horizonte de leito marinho ao fim de 15 anos.

Figura 5. 20: Diferença de deslocamentos entre os cenários R A- e R A+ para o cenário R A no horizonte de topo do reservatório ao fim de 15 anos.

Figura 5. 21: Comparação entre deslocamentos dos horizontes no cenário R A- em relação ao cenário R A

Figura 5. 22: Comparação entre deslocamentos dos horizontes no

cenário $\mathrm{R}$ A+ em relação ao cenário $\mathrm{R} A$.

Figura 5.23: Curva de volume acumulado de óleo produzido para

cenários com mudanças de propriedades no reservatório.

Figura 5.24: Queda da pressão média do reservatório para cenários R A,

$\mathrm{R}+\mathrm{A}$ e $\mathrm{R}-\mathrm{A}$

Figura 5. 25: Diferença de pressão média no reservatório dos cenários

R A- e RA+ em relação ao cenário R A ao longo dos 15 anos simulados.

Figura 5.26: Curva de liberação de gás dentro do reservatório para cenários simulados no período de junho de 2016 a maio de 2017 .

Figura 5. 27: Deslocamentos dos cinco horizontes selecionados após

15 anos de simulação para o caso $\mathrm{R}+\mathrm{A}$.

Figura 5. 28: Comparação entre deslocamentos dos horizontes no

cenário $\mathrm{R}+\mathrm{A}$ em relação ao cenário $\mathrm{R} A$. 
Figura 5. 29: Deslocamentos dos cinco horizontes selecionados após

15 anos de simulação para o caso R-A.

Figura 5. 30: Comparação entre deslocamentos dos horizontes no

cenário R-A em relação ao cenário $\mathrm{R} A$.

Figura 5.31: Deslocamento vertical ao longo da profundidade do

ambiente rochoso para os cenários $\mathrm{R}+\mathrm{A}, \mathrm{R}-\mathrm{A}$ e $\mathrm{R} \mathrm{A}$.

Figura 5. 32: Curvas de volume acumulado de óleo do Campo de

Namorado para cenários de óleo leve, médio e pesado com e sem

acoplamento geomecânico.

Figura 5.33: Curvas de queda pressão de poros para cenários de óleo

leve, médio e pesado com e sem acoplamento geomecânico.

Figura 5. 34: Análise de volume de óleo produzido para os cenários com

óleo leve, médio e pesado relativos aos casos R A e R-A- ao fim de 15

anos de simulação.

Figura 5. 35: Histórico de vazão de óleo dos cenários R A e R-A- de

óleo leve, médio e pesado

Figura 5. 36: Evolução dos deslocamentos do horizonte do topo do

reservatório para cenários $\mathrm{R}$ A e R-A- com óleo leve, médio e

pesado ao fim de 1, 3 e 15 anos de simulação.

Figura 5. 37: Histórico do deslocamento vertical e taxa de liberação

de gás para o cenário R A com óleo leve, médio e pesado.

Figura 5. 38: Evolução dos deslocamentos do horizonte do leito

marinho para cenários R A e R-A- com óleo leve, médio e pesado

ao fim de 1, 3 e 15 anos de simulação.

Figura 6.1: Percentual de deslocamento do topo do overburden em

relação ao topo do reservatório para 8 cenários simulados ao fim de

15 anos.

Figura 6.2: Deslocamento do topo do overburden para 8 cenários

simulados ao fim de 15 anos

Figura A. 1: Fluxograma de definição dos módulos de

compressibilidade e cisalhamento para as três fácies a partir de

dados de bibliografia e de perfilagem de poços. 
Figura A.2: Fluxograma de definição dos módulos elásticos e

compressibilidades a partir de dados obtidos do fluxograma anterior. ............... 167 


\section{Lista de tabelas}

Tabela 4. 1: Associação das fácies com suas respectivas

composições mineralógicas.

Tabela 4. 2: Critérios para classificação das fácies em função

dos dados de perfilagem.

Tabela 4.3: Quadro de módulo de compressibilidade, módulo de

cisalhamento e densidade para cada mineral que compõe as fácies definidas. .....95

Tabela 4.4: Quadro de módulo de compressibilidade e módulo de

compressibilidade para cada fluido presente na formação.

Tabela 4.5: Resultados médios obtidos a partir dos perfis e premissas

utilizados ao longo desse capítulo.

Tabela 4. 6: Dados obtidos a partir do arquivo de simulação de fluxo

do IMEX do Campo de Namorado.

Tabela 4. 7: Módulo de Young estático e coeficiente de Poisson em

função da faixa de porosidade utilizados para distribuição

de propriedades mecânicas na malha de elementos finitos.

Tabela 4. 8: Gradiente de tensão em função da camada do overburden

Tabela 5. 1: Módulo de Young estático e coeficiente de Poisson para as fácies definidas neste trabalho. Modificado de Read \& Stacey [53] (com base em dados de Jaeger \& Cook (1979), Goodman (1989), Bell (2000) e Gonzalez de Vallejo (2002)). 138

Tabela 5. 2: Módulo de Young e coeficiente de Poisson para as faixas

de porosidade dos cenários $\mathrm{R}+\mathrm{A}$ e $\mathrm{R}-\mathrm{A}$.

Tabela 5. 3: Excedente de óleo explotado para cenários com rochas

adjacentes mais compressíveis. A nomenclatura EXT se refere a

cenário extra, inserido apenas para análises pontuais,

Tabela 5. 4: Volume de fluido no momento que antecede a

simulação para os 3 cenários com óleos de diferentes graus API.

Tabela 5. 5: Análise de volume de óleo produzido para os cenários R A

com óleo leve, médio e pesado com e sem acoplamento.

Tabela 5. 6: Comparação entre deslocamentos do cenário R-A- e cenário $\mathrm{R}$ A para o horizonte de topo do reservatório.

Tabela B.1: Relação das fácies encontradas em cada poço perfilado.

Adaptado de Passarella [34] 


\section{Lista de Símbolos}
A Área
a Coeficiente litológico
$a_{c} \quad$ Fator de conversão para volume (relativo ao sistema de unidades)
$B_{l} \quad$ Fator volume-formação do fluido da fase $l$
c Compressibilidade para material sem poros
$c_{b p} \quad$ Compressibilidade pseudo-bulk
$c_{D} \quad$ Compressibilidade bulk drenado
$c_{P C} \quad$ Compressibilidade do volume poroso em relação à pressão

confinante

$c_{\mathrm{b}} \quad$ Compressibilidade da formação definido em simuladores de fluxo

$c_{\emptyset} \quad$ Compressibilidade do volume poroso em relação à pressão de poros

$c_{f} \quad$ Compressibilidade do fluido

$c_{f l} \quad$ Compressibilidade da fase $l$ do fluido

$c_{S} \quad$ Compressibilidade dos grãos

$c_{p} \quad$ Pseudo-compressibilidade

E $\quad$ Módulo de elasticidade

$E_{D} \quad$ Módulo de elasticidade dinâmico

$E_{S} \quad$ Módulo de elasticidade estático

$f \quad$ Fração volumétrica de mineral

G Módulo de cisalhamento

$G_{D} \quad$ Módulo de cisalhamento da estrutura sólida drenada

$G_{\text {sat }} \quad$ Módulo de cisalhamento bulk saturado

$G R_{\log }$ Gamma Ray medido na formação

$G R_{\min }$ Gamma Ray mínimo

$G R_{\text {máx }}$ Gamma Ray máximo

HS - Limite mínimo de Hashin e Shtrikman

$H S+\quad$ Limite máximo de Hashin e Shtrikman

$I_{G R} \quad$ Índice de perfil Gamma Ray

$I_{P} \quad$ Impedância compressional 


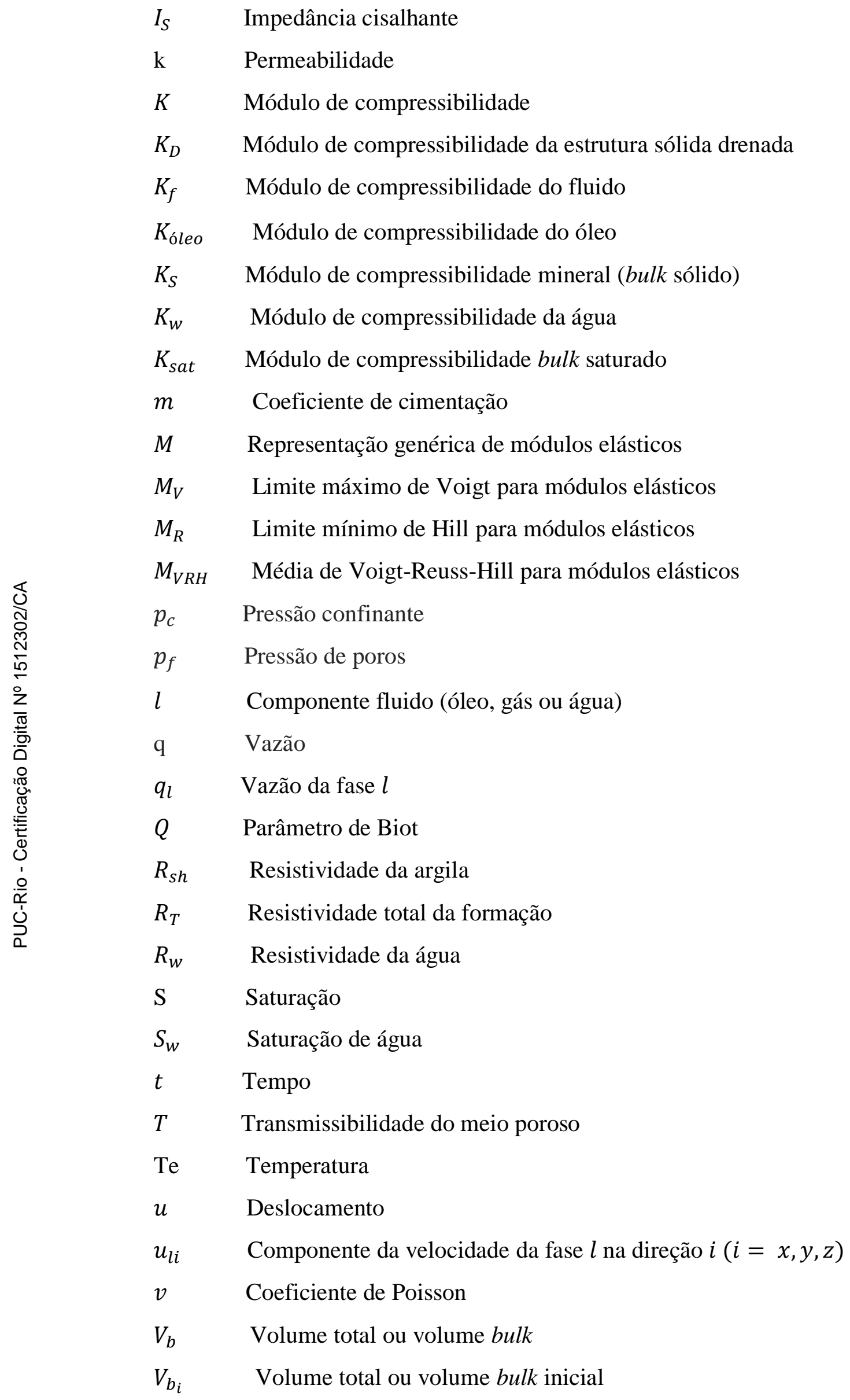


$V_{f} \quad$ Volume do fluido

$V_{p} \quad$ Volume poroso

$V_{r c} \quad$ Volume de fluido em condições de reservatório

$V_{s} \quad$ Volume de sólido

$V_{s c} \quad$ Volume de fluido em condições padrão

$V_{s h} \quad$ Volume de argila

$W_{P} \quad$ Velocidade de onda compressional

$W_{S} \quad$ Velocidade de onda cisalhante

$\mathrm{Z} \quad$ Altura em relação a uma referência dada

$\alpha \quad$ Parâmetro de Biot

$\sigma^{\prime} \quad$ Tensão efetiva

$\sigma \quad$ Tensão

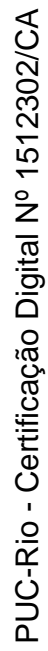

$\sigma_{c} \quad$ Tensão confinante

$\sigma_{p} \quad$ Tensão hidrostática

$\beta \quad$ Fator de consolidação da equação de Lee

$\beta_{c} \quad$ Fator de conversão para transmissibilidade (relativo ao sistema de unidades)

$\Delta x \quad$ Comprimento ao longo da direção $\mathrm{x}$

$\Delta y \quad$ Comprimento ao longo da direção y

$\Delta z \quad$ Comprimento ao longo da direção z

$\varepsilon \quad$ Deformação

$\varepsilon_{v o l} \quad$ Deformação volumétrica bulk

$\xi \quad$ Parâmetro de Lee dependente do fator de consolidação $\beta$

$\mu \quad$ Viscosidade

$\varnothing \quad$ Porosidade absoluta

$\emptyset_{c} \quad$ Porosidade crítica

$\emptyset_{e} \quad$ Porosidade efetiva

$\rho \quad$ Densidade

$\rho_{b} \quad$ Densidade medida do perfil RHOB

$\rho_{f} \quad$ Densidade do fluido

$\rho_{s} \quad$ Densidade da matriz sólida mineral

$\rho_{s h} \quad$ Densidade da argila 


$\begin{array}{ll}\lambda & \text { Parâmetro de Lamé } \\ \zeta & \text { Deformação volumétrica do fluido } \\ \Phi & \text { Potencial } \\ \tau & \text { Tensão cisalhante } \\ \Gamma_{l} & \text { Termo de acumulação para a fase } l \\ \Gamma & \text { Deformação cisalhante } \\ \gamma & \text { Peso específico }\end{array}$

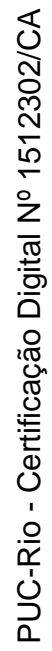


"Se você quer ser bem sucedido, precisa ter dedicação total, buscar seu último limite e dar o melhor de si." 


\section{1 \\ Introdução}

Esta dissertação aborda o relacionamento entre escoamento multifásico de hidrocarbonetos no reservatório e a deformação volumétrica das rochas envolvidas. Essa interação é amplamente reconhecida no estudo do fraturamento hidráulico, no qual é identificada a importância da fratura induzida in situ nas mudanças de tensão e deformação do reservatório e na forma como a fratura hidráulica pode ser acoplada aos simuladores de reservatório. No entanto, em outras aplicações, a geomecânica, se não inteiramente negligenciada, ainda é tratada como um aspecto separado do fluxo dentro da rocha reservatório. Essa abordagem tradicional para relacionar fluxo acoplado à mecânica utiliza uma estratégia de divisão, em que os sistemas de fluxo e mecânico são resolvidos separadamente e relacionados tanto vagamente ou através de iterações. Isso também significa dizer que ao tratar as duas áreas como questões separadas, gera-se uma tendência de busca por simplificações e aproximações para interrelacioná-las. Esta estratégia de simulação em separado é motivada em parte pela disponibilidade comercial de softwares estáveis e específicos para cada uma das áreas, além da complexidade de abordar estes dois assuntos como processos acoplados.

Na simulação convencional de fluxo, é a rocha reservatório que recebe um maior enfoque nos estudos de viabilidade técnica e econômica de uma área de interesse. Resultados obtidos como volume de fluidos produzidos, vazões de cada fase presente no reservatório, variações na pressão de poros, temperatura e saturação de fluidos determinam não só a aprovação para início de desenvolvimento de um campo, como também a estratégia que será utilizada para obtenção de maior fator de recuperação de hidrocarbonetos. Em função disso, segundo Rosa et al. [1], é primordial entender que a produção de fluidos é consequência de dois efeitos:

- Descompressão dos fluidos na rocha reservatório que gera a expansão destes e a contração do volume poroso;

- Deslocamento de um fluido pelo outro, como nos casos em que ocorre influxo de água de um aquífero na zona de óleo.

Como visto anteriormente, o processo de depleção induz deformações na rocha que deveriam ser levadas em consideração na modelagem do reservatório. 
Porém, segundo Inoue et al. [2], os efeitos geomecânicos são aproximados em uma simulação convencional através de apenas um único parâmetro mecânico: a compressibilidade da rocha. Tal parâmetro é medido hidrostaticamente para diferentes níveis de confinamento, porém é normalmente considerado constante ao longo de todo o processo de simulação. Ainda segundo os autores, é uma abordagem de acoplamento muito simplificada que não permite uma análise detalhada dos efeitos geomecânicos, além de não representar aspectos relacionados ao comportamento da rocha tais como a trajetória das tensões e dilatância. Por sua vez, as mudanças de pressão de poros, também resultantes dos carregamentos aplicados a partir das rochas adjacentes, não conseguem ser corretamente dimensionadas somente com a compressibilidade rochosa.

A resposta geomecânica ao fluxo de fluido é de importância para diversas aplicações de subsuperfície. Historicamente, a subsidência geológica tem sido vista como uma resposta para a produção de petróleo (como no caso do campo Ekofisk no Mar do Norte), bem como a produção de águas subterrâneas (exemplos mais famosos são a subsidência do Vale de San Joaquin e Veneza). Segundo Doster \& Nordbotten [3], o acoplamento de fluxo e geomecânica tem recebido uma atenção renovada recentemente, tanto no contexto de elevação do nível do solo associado ao local de armazenamento de $\mathrm{CO}_{2} \mathrm{em}$ In Salah, mas também no contexto da fratura hidráulica para os fins de sistemas avançados geotérmicos e de produção de gás em xisto. Ao mesmo tempo que há uma tendência de considerar sistemas onde há uma resposta geomecânica já diretamente no projeto de engenharia, há também uma necessidade para algoritmos mais robustos que lidem com sistemas hidromecânicos fortemente acoplados.

$\mathrm{Na}$ simulação de fluxo convencional, não é possível extrair dados de compactação e variação da tensão na rocha reservatório, nem resultados a respeito da subsidência de superfícies. Estas informações podem ser extremamente importantes tanto para a previsão e definição de estratégias de produção, quanto para a prevenção de graves acidentes ambientais. Significa dizer que as tensões no reservatório e rochas circundantes não pode estar em equilíbrio com a pressão de poro, uma vez que o comportamento geomecânico não é considerado integralmente.

Inoue et al. [2] propõem uma metodologia na qual são feitas simulações parcialmente acopladas de duas vias entre o simulador de fluxo IMEX e o programa de análises tensões CHRONOS. Nos trabalhos de Inoue \& Fontoura [4] e 
Albuquerque [5], é demonstrado em detalhes a construção do modelo de simulação de um campo a partir de um pacote de programas integrados chamado Olympus Suite. Este pacote opera em ambiente $\mathrm{GOCAD}^{\odot}$, onde o fluxo de trabalho de análise geomecânica é desenvolvido por meio de um plugin, denominado Gaia. Além da proposição de parâmetros de acoplamento que tornam a solução próxima do acoplamento total, uma das recentes e maiores contribuições desta metodologia é a utilização de processamento em GPU com o objetivo reduzir de forma significativa o tempo das simulações acopladas. Ao longo deste trabalho, esta metodologia de acoplamento geomecânico será chamada de metodologia GTEP/PUC-Rio.

\section{1}

\section{Motivação}

Com base em equações inicialmente desenvolvidas por Biot [6] para o fluxo multifásico em meios porosos deformáveis, argumenta-se que a deformação da rocha e o fluxo de múltiplas fases são processos totalmente acoplados que devem ser representados simultaneamente.

Para consideração do efeito geomecânico global, a deformação das rochas que circundam o reservatório também devem ser consideradas a fim de avaliar os seus efeitos sobre o sistema petrolífero. A partir do momento que a produção de hidrocarbonetos tem início, a pressão de poros tende a diminuir com a consequente elevação da tensão efetiva. Parte do carregamento do overburden, que antes era suportada pelo fluido, passa a agir na matriz da rocha que irá se deformar no sentido de compactação e redução de porosidade. Dessa forma, a deformação da rocha reservatório afeta a porosidade, a permeabilidade e a compressibilidade dos poros da rocha. Por sua vez, as pressões de fluido nos poros variam devido as alterações na porosidade.

Esse efeito é especialmente importante em reservatórios de óleo subsaturado e que não apresentam aquíferos associados que gerem entrada de grandes massas de água como fonte de manutenção de energia para o sistema. Segundo Rosa et al. [1], como não existe a possibilidade de interferência do meio externo em um reservatório com essas características, toda a energia disponível para a produção se encontra armazenada dentro da própria zona de óleo. Conforme os fluidos são produzidos, a pressão de poros do reservatório tende a cair, como explicado acima. 
Ao mesmo tempo, a deformação do reservatório tem um papel de destaque na tentativa de manutenção de pressão do sistema até que se atinja a pressão de bolha e haja liberação de gás. A partir desse ponto, o mecanismo de gás em solução passa a agir de forma efetiva.

No trabalho de Lautenschlager [7], já é evidenciado de forma superficial que a liberação de gás dentro do reservatório tem impactos na pressão média dos poros e na deformação volumétrica do reservatório. O seu objetivo era estabelecer uma comparação entre os resultados obtidos pela simulação parcialmente acoplada de uma via (com uso do simulador de fluxo IMEX) com a simulação parcialmente acoplada de duas vias (com uso do simulador de fluxo IMEX e do programa de análise de tensões ABAQUS). O autor faz uso de um modelo prismático de simulação de reservatório (Figura 1.1) idealizado por Dean et al.[8]. O modelo simulado pelo autor é composto por um reservatório com módulo de Young de 0,069 GPa e coeficiente de Poisson igual a 0,25. As rochas adjacentes são consideradas homogêneas, independentemente de suas profundidades, e apresentavam coeficiente de Poisson semelhante ao do reservatório e módulo de Young de 6,9 GPa.
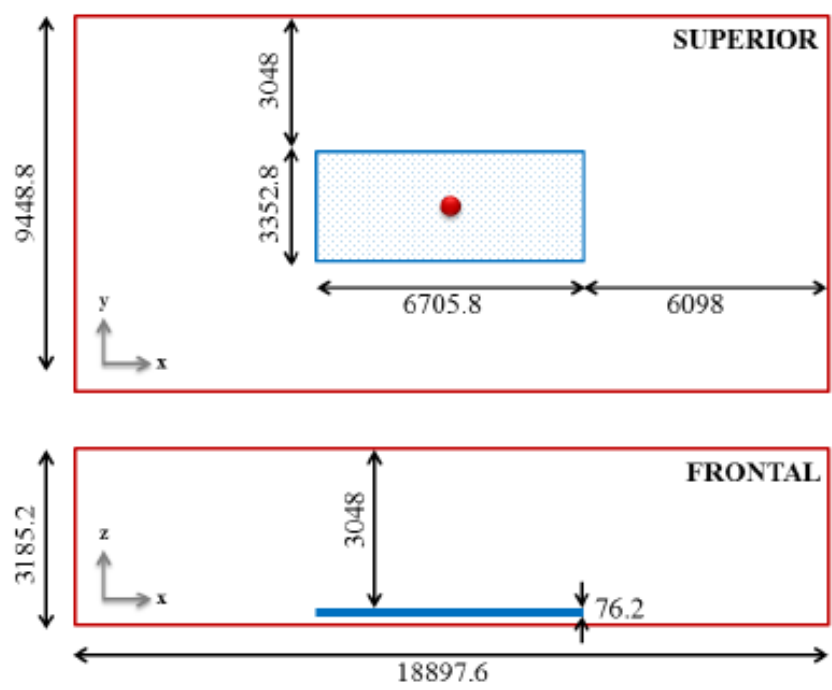

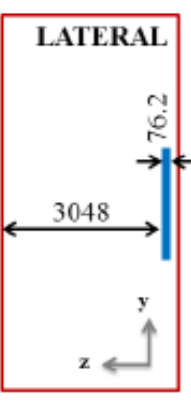

3185.2

Reservatório

Adjacèncias

Poço Produtor

Figura 1.1: Modelo global simplificado utilizado para validações da implementação ABAQUS-IMEX no trabalho de Lautenschlager [7] 


\section{2 \\ Objetivos}

Esta dissertação apresenta quatro grandes objetivos. O primeiro deles é realizar a simulação acoplada iterativa de duas vias do Campo de Namorado. A escolha do objeto de estudo se deu em função da ausência de gás livre neste campo no momento inicial de produção. Ou seja, é um reservatório que apresenta o mecanismo de gás em solução como fonte de energia associada à produção de fluidos. Foi feita também a opção de não inserir poços injetores como forma de recuperação secundária de óleo. Os resultados de fluxo e geomecânicos obtidos serão comparados aos da simulação convencional de reservatórios.

O segundo objetivo é realizar uma análise paramétrica relacionada não só ao reservatório, como também às rochas adjacentes. Dois parâmetros mecânicos serão mais explorados: o módulo de Young e o coeficiente de Poisson. São dois parâmetros de entrada essenciais para a metologia de acoplamento geomecânico GTEP/PUC-Rio. Serão analisados diferentes cenários ao tornar o reservatório e rochas adjacentes mais ou menos rígidos. Além disso, será realizada uma posterior análise das consequências no que se refere à explotação de fluidos, deformação do reservatório e deslocamentos de horizontes de interesse.

A terceira meta é realizar uma análise paramétrica relacionada aos fluidos. Serão simulados três cenários com diferentes graus API para, mais uma vez, observar as consequências na explotação de fluidos, deformação do reservatório e deslocamentos de horizontes para simulações acopladas de reservatório.

Em busca de maior relevância e acurácia para os resultados provenientes dos três objetivos elencados acima, esta dissertação também objetiva gerar um fluxo de informações que permita estimar as propriedades mecânicas das rochas a partir de dados indiretos. Nesta dissertação, estes dados serão provenientes de perfis de poços de exploração do Campo de Namorado. Gerar estimativas de módulos elásticos trata-se de uma necessidade atual em virtude da escassez de dados de módulo de Young e coeficiente de Poisson não só dos reservatórios, como também de praticamente toda estrutura rochosa do overburden, sideburden e underburden. $\mathrm{Na}$ área acadêmica, tal dificuldade em encontrar dados referentes a reservatórios marítimos da costa brasileira, mais especificamente de campos ainda em produção, é reflexo da necessidade de proteção e confidencialidade dos dados dessas rochas 
por parte das empresas. Quando se trata das rochas adjacentes, em muitas ocasiões, a escassez de detalhamento de dados é reflexo de uma maior dificuldade em mobilizar recursos para a realização de testes em tantos quilômetros de testemunhos.

Ainda assim, na bibliografia, os trabalhos que apresentem um fluxograma completo desde a estimativa de parâmetros indiretamente advindos dos perfis (por exemplo, saturação de fluidos, porosidade, argilosidade e densidade da rocha) até as estimativas finais de módulos elásticos e compressibilidades são bastante raros. Dessa forma, os resultados apresentados nesta dissertação e provenientes de uma Bacia brasileira, não são facilmente encontrados na bibliografia atual.

\section{3 \\ Escopo}

No Capítulo 2, são exibidas as referências bibliográficas a respeito dos temas abordados nesse trabalho, como as equações utilizadas na simulação convencional de reservatórios, a importância de considerar os efeitos geomecânicos e como podem ser atuantes com a apresentação de diversas metodologias de acoplamento. Também no Capítulo 2, é exibida a teoria da poroelasticidade, parte fundamental não só na metodologia de acoplamento, como também na obtenção dos módulos elásticos que são utilizados nas simulações desta dissertação.

No Capítulo 3, são relatados métodos para obtenção de módulos elásticos e outras propriedades das rochas e fluidos que compõem o ambiente em estudo por meio de ensaios laboratoriais e, principalmente, por via indireta através da utilização de perfis de poços.

Por sua vez, o Capítulo 4 oferece uma descrição detalhada do objeto de simulação deste trabalho, o Campo de Namorado. São apresentadas também as premissas para composição mineralógica das fácies consideradas, além da apresentação dos módulos elásticos calculados para cada horizonte a partir do workflow desenvolvido nesta dissertação. Por fim, com todos os dados de entrada disponíveis para o acoplamento geomecânico, é exibido o fluxo de trabalho da metodologia parcialmente acoplada do GTEP/PUC-Rio para a geração de um modelo de simulação acoplado. 
O Capítulo 5 apresenta os resultados de fluxo e geomecânicos para o cenário descrito no capítulo anterior. Além disso, são criados cenários a partir da variação das propriedades mecânicas da rocha reservatório e das rochas adjacentes para análise dos efeitos gerados na produção de fluidos e deslocamento de horizontes selecionados. Por fim, as mesmas consequências são avaliadas para cenários com mudança do peso do óleo, sendo analisados casos com óleo leve, médio e pesado.

O sexto capítulo é destinado às conclusões obtidas a partir da dissertação e a sugestões de trabalhos futuros relacionados ao tema. 


\section{2 Revisão bibliográfica}

Os simuladores numéricos de reservatório têm como objetivo permitir o estudo do comportamento do fluxo de fluidos em reservatórios de petróleo por meio do emprego de uma solução numérica. No modelo de simulador black oil, também conhecido como Beta ou volumétrico, a resolução matemática engloba funções de pressão do ambiente simulado. Além disso, admite-se que cada uma das várias fases (água, óleo e/ou gás) eventualmente presentes no reservatório seja constituída de um único componente, embora se saiba que o óleo, por exemplo, é constituído por diversos hidrocarbonetos com pesos moleculares distintos (Rosa et al. [1]).

A fim de gerar aproximação das equações diferenciais, em razão de não possuírem solução analítica, excetuando casos extremamente simples, tradicionalmente os simuladores de reservatórios de petróleo utilizam o método das diferenças finitas. O reservatório é dividido em blocos (grade de simulação) e as equações diferenciais, que representam o escoamento de fluidos, são discretizadas e escritas em função de variáveis definidas em cada bloco.

A análise de fluxo de fluidos através de meios porosos tem como ponto central a equação de difusividade hidráulica, a partir da qual são desenvolvidas soluções para as diversas situações em que os reservatórios podem se encontrar (Rosa et al. [1]).

\section{1}

\section{Equação da difusividade hidráulica}

A equação da difusividade hidráulica, em uma formulação isotérmica, é obtida a partir da equação da continuidade, equação de transporte (lei de Darcy) e equação de estado.

A equação da continuidade descreve a variação de massa dentro do meio poroso em virtude do fluxo de fluido neste meio. Para um volume de controle cúbico em um meio poroso (Figura 2.1), temos:

$$
-\frac{\partial}{\partial x}\left(A_{x} \frac{u_{l x}}{B_{l}}\right)-\frac{\partial}{\partial y}\left(A_{y} \frac{u_{l y}}{B_{l}}\right)-\frac{\partial}{\partial z}\left(A_{z} \frac{u_{l z}}{B_{l}}\right)=\frac{V_{b}}{a_{c}} \frac{\partial}{\partial t}\left(\frac{\emptyset}{B_{l}}\right)-q_{l}
$$


Onde, fator volume-formação $B$ pode ser definido pelo volume ocupado por uma dada massa de fluido em condições de pressão e temperatura do reservatório $V_{r c} \mathrm{e}$ pelo volume ocupado pelo mesmo componente em condições padrão $V_{s c}$ (pressão $=$ 14,7 psia e temperatura $\left.=60^{\circ} \mathrm{C}\right)$, como a seguir:

$$
B_{l}=\frac{V_{r c}}{V_{s c}}
$$

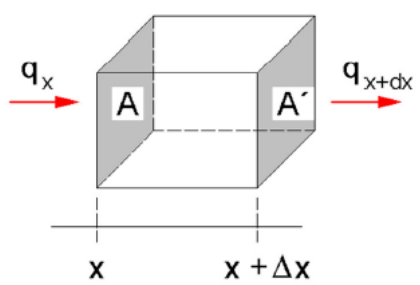

Figura 2. 1: Fluxo de fluido através de volume de controle cúbico. Adaptado de Inoue \& Fontoura [4].

O próximo passo na dedução da equação da difusividade é a associação da equação da continuidade com uma lei que descreva o transporte de fluido no ambiente poroso. Esta lei relaciona a velocidade aparente do fluido com os gradientes de pressão, ou ainda de forma mais genérica com os gradientes de potencial, através da seguinte equação para um escoamento monofásico.

$$
\vec{u}=-\beta_{c} \frac{k}{\mu} \vec{\nabla} \Phi
$$

Onde,

$$
\vec{\nabla} \Phi=\quad \vec{\nabla} \mathrm{p}-\gamma \vec{\nabla} \mathrm{Z}
$$

Introduzindo as expressões das velocidades aparentes nas três direções de fluxo na equação da continuidade, obtém-se uma nova forma para a equação diferencial de escoamento monofásico de fluido.

$$
\begin{gathered}
\frac{\partial}{\partial x}\left(\beta_{c} \frac{k_{x}}{\mu_{l}} \frac{A_{x}}{B_{l}}\left(\frac{\partial p}{\partial x}-\gamma_{1} \frac{\partial Z}{\partial x}\right)\right) \Delta x+\frac{\partial}{\partial y}\left(\beta_{c} \frac{k_{y}}{\mu_{l}} \frac{A_{y}}{B_{l}}\left(\frac{\partial p}{\partial y}-\gamma_{1} \frac{\partial Z}{\partial y}\right)\right) \Delta y \\
+\frac{\partial}{\partial z}\left(\beta_{c} \frac{k_{z}}{\mu_{l}} \frac{A_{z}}{B_{l}}\left(\frac{\partial p}{\partial z}-\gamma_{l} \frac{\partial Z}{\partial z}\right)\right) \Delta z=\frac{V_{b}}{a_{c}} \frac{\partial}{\partial t}\left(\frac{\emptyset}{B_{l}}\right)-q_{l}
\end{gathered}
$$

Dessa forma, a equação diferencial parcial é de segunda ordem no espaço e de primeira ordem no tempo. A fim de resolvê-la, é utilizado o método das 
diferenças finitas com a aproximação pela diferença central (Inoue \& Fontoura [4]). Para dois passos de tempo distintos temos:

$$
\begin{gathered}
T_{l x_{i+\frac{1}{2}, j, k}}\left(p_{i+1, j, k}^{n+1}-p_{i, j, k}^{n+1}\right)-T_{l x_{i-\frac{1}{2}, j, k}}\left(p_{i, j, k}^{n+1}-p_{i-1, j, k}^{n+1}\right)+ \\
T_{l y}{ }_{i, j+\frac{1}{2}, k}\left(p_{i, j+1, k}^{n+1}-p_{i, j, k}^{n+1}\right)-T_{l y}{ }_{i, j-\frac{1}{2}, k}\left(p_{i, j, k}^{n+1}-p_{i, j-1, k}^{n+1}\right)+ \\
T_{l z}{ }_{i, j, k+\frac{1}{2}}\left(p_{i, j, k+1}^{n+1}-p_{i, j, k}^{n+1}\right)-T_{l z_{i, j, k-\frac{1}{2}}}\left(p_{i, j, k}^{n+1}-p_{i, j, k-1}^{n+1}\right)=\frac{V_{b}}{a_{c}} \frac{\partial}{\partial t}\left(\frac{\emptyset}{B_{l}}\right)-q_{l_{i}}
\end{gathered}
$$

Onde os termos de aproximação por diferenças finitas são:

$$
\begin{aligned}
& T_{l x_{i \pm \frac{1}{2}, j, k}}=\left(\frac{k_{x} A_{x}}{\mu_{l} B_{l} \Delta x}\right)_{i \pm \frac{1}{2}, j, k} \\
& T_{l y_{i, j \pm \frac{1}{2}, k}}=\left(\frac{k_{y} A_{y}}{\mu_{l} B_{l} \Delta y}\right)_{i, j \pm \frac{1}{2}, k} \\
& T_{l z}{ }_{i, j, k \pm \frac{1}{2}}=\left(\frac{k_{z} A_{z}}{\mu_{l} B_{l} \Delta z}\right)_{i, j, k \pm \frac{1}{2}}
\end{aligned}
$$

O desenvolvimento do termo à direita da equação 2.6 deve ser realizado cuidadosamente para garantir que haja o balanço de material no volume de controle. Segundo Aziz \& Settari [9], no escoamento de fluidos pouco compressíveis é possível assumir a compressibilidade do fluido, definida por:

$$
c_{f}=-\left.\frac{1}{V_{f}} \frac{\partial V_{f}}{\partial p}\right|_{T e}=\left.\frac{1}{\rho_{f}} \frac{\partial \rho_{f}}{\partial p}\right|_{T e}
$$

Integrando a equação acima ao longo do intervalo de interesse, obtém-se:

$$
\rho_{f}^{n+1}=\rho_{f}^{n} \exp \left[c_{f}\left(p^{n+1}-p^{n}\right)\right]
$$

onde $\rho_{f}^{n}$ é a densidade na pressão de referência $p^{n}$.

A partir da definição na equação 2.2 , nota-se que:

$$
\frac{\rho_{f}^{n+1}}{\rho_{f}^{n}}=\frac{B_{l}{ }^{n}}{B_{l}{ }^{n+1}}=\exp \left[c_{f}\left(p^{n+1}-p^{n}\right)\right]=1+c_{f l}\left(p^{n+1}-p^{n}\right)+\frac{1}{2 !} c_{f}{ }^{2}\left(p^{n+1}-p^{n}\right)^{2}+\cdots
$$

onde $B_{l}{ }^{n}$ é o fator volume de formação em $p^{n}$. 
Considerando apenas os dois primeiros termos da expansão acima, visto que $c_{f l}$ é pequeno (na ordem de $10^{-6} \mathrm{psi}^{-1}$ ), é possível dizer que:

$$
B_{l}{ }^{n+1}=\frac{B_{l}{ }^{n}}{1+c_{f}\left(p^{n+1}-p^{n}\right)}
$$

Além disso, é possível definir a variação da porosidade com a pressão de poros da seguinte forma (Inoue \& Fontoura [4]):

$$
\emptyset^{n+1}=\emptyset^{n}\left[1+c_{b}\left(p^{n+1}-p^{n}\right)\right]
$$

onde $c_{b}$ é a compressibilidade da formação utilizada em simulações tradicionais de fluxo e pode ser definida por $c_{b}=\frac{1}{V_{P}} \frac{\partial V_{P}}{\partial p}=\frac{1}{\emptyset} \frac{\partial \emptyset}{\partial p}$.

Com as equações 2.11 e 2.12, a aproximação por diferenças finitas da derivada do tempo pode ser escrita como:

$$
\begin{gathered}
V_{b} \frac{\partial}{\partial t}\left(\frac{\emptyset}{B_{l}}\right) \approx \frac{\Gamma_{l}^{n+1}}{\Delta t}\left(p_{i}^{n+1}-p_{i}^{n}\right) \\
\Gamma_{l}^{n+1}=V_{b}\left(\frac{\emptyset^{n} c_{b}}{B_{l}^{n+1}}+\frac{\emptyset^{n} c_{f}}{B_{l}^{n}}\right)
\end{gathered}
$$

onde, $\Gamma_{l}$ é o termo de acumulação da fase líquida.

A partir disso, chega-se à forma final da equação de diferenças finitas para simulação convencional de reservatórios:

$$
\begin{gathered}
T_{l x_{i+\frac{1}{2}, j, k}}\left(p_{i+1, j, k}^{n+1}-p_{i, j, k}^{n+1}\right)-T_{l x_{i-\frac{1}{2}, j, k}}\left(p_{i, j, k}^{n+1}-p_{i-1, j, k}^{n+1}\right)+ \\
+T_{l y}{ }_{i, j+\frac{1}{2}, k}\left(p_{i, j+1, k}^{n+1}-p_{i, j, k}^{n+1}\right)-T_{l y}{ }_{i, j-\frac{1}{2}, k}\left(p_{i, j, k}^{n+1}-p_{i, j-1, k}^{n+1}\right)+ \\
+T_{l z}{ }_{i, j, k+\frac{1}{2}}\left(p_{i, j, k+1}^{n+1}-p_{i, j, k}^{n+1}\right)-T_{l z}{ }_{i, j, k-\frac{1}{2}}\left(p_{i, j, k}^{n+1}-p_{i, j, k-1}^{n+1}\right)+q_{l_{i}}= \\
=\frac{V_{b}}{\Delta t}\left(\frac{\emptyset^{n} c_{b}}{B_{l}^{n+1}}+\frac{\emptyset^{n} c_{f}}{B_{l}^{n}}\right)\left(p_{i}^{n+1}-p_{i}^{n}\right)
\end{gathered}
$$

Por fim, a equação de estado é uma relação matemática que relaciona pressão, temperatura e volume específico para um sistema em equilíbrio termodinâmico. Dessa forma, para definição da densidade e compressibilidade dos fluidos, a maior 
parte dos simuladores comerciais black-oil permite a inserção de tabelas PVT para descrever o comportamento dos fluidos. As tabelas PVT expressam uma relação funcional do tipo $f(P, V, T)$, que relaciona as três principais propriedades de um gás (pressão, volume e temperatura).

\section{2}

\section{Efeitos geomecânicos}

O primeiro estudo de geomecânica de reservatórios no Brasil foi desenvolvido ao longo da década de 80 sob supervisão da Petrobras, comprovando que a preocupação com o comportamento mecânico da rocha, durante a produção de fluidos, na engenharia de reservatórios é relativamente recente. $\mathrm{O}$ objetivo principal do estudo era verificar o risco de ocorrência de subsidência nas principais bacias produtoras do país. Segundo Falcão [10], apenas no início do século XXI foram retomados os estudos geomecânicos, desta vez trazendo uma análise acoplada à simulação de reservatórios. Os principais enfoques das pesquisas estão atualmente relacionados à compactação do reservatório e à reativação de falhas.

Segundo Settari \& Vikram [11], sob a égide da geomecânica, pode-se incluir todos os problemas que apresentem algum componente de mecânica das rochas, do solo ou da fratura. Na indústria petrolífera, a geomecânica é encontrada em uma variedade de situações diferentes que envolvem perfuração, completação, estimulação, produção e engenharia de reservatórios. Normalmente, a resolução dessas questões deveria envolver a solução combinada de variáveis hidráulicas e mecânicas, muitas vezes acompanhadas por variáveis térmicas. Entre os exemplos práticos com aplicação no campo da geomecânica apresentados pelo autor estão:

1) Engenharia de perfuração e completação - a principal preocupação é com a estabilidade do poço durante a perfuração e sua integridade durante a vida de produção deste poço. O primeiro ponto sempre foi a preocupação tradicional da geomecânica, enquanto o segundo tem recebido maior atenção recentemente em campos mais antigos;

2) Compactação de reservatórios e subsidência resultante - são exemplos bem conhecidos de comportamento geomecânico. Durante a depleção, a pressão do reservatório tende a cair e tensões efetivas a aumentar. As rochas se deformam 
através de uma combinação de tensão elástica (recuperável) e plástica (permanente), com deformação plástica ocorrendo principalmente a medida que a tensão aumenta para além do limite de compactação ou tensão de "colapso". A deformação tende a criar uma pressão de suporte adicional no reservatório que pode inclusive melhorar a recuperação de hidrocarbonetos. No entanto, deve-se também lidar com os efeitos indesejáveis - o impacto ambiental de subsidência, a redução da permeabilidade, a possível reativação de falhas e integridade dos poços próximos a falhas;

3) Mecânica da fratura em rochas - considerada também uma parte da geomecânica de reservatórios que constitui a base teórica para o design convencional e modelagem de tratamentos de estimulação;

4) Mesmo reservatórios que não sofrem compactação significativa durante a depleção podem apresentar porosidade e permeabilidade com dependência nãolinear em relação à tensão efetiva e à deformação. Os exemplos típicos incluem rochas micro e macrofraturadas, areias que apresentam baixa permeabilidade, etc. Com a diminuição da pressão (devido à produção de fluidos), o aumento da tensão efetiva gera uma diminuição na permeabilidade. O oposto se observa com a injeção de fluidos, com a diminuição da tensão efetiva. Modelos convencionais de reservatórios que tratam a permeabilidade como uma propriedade de campo estático, tendem a superestimar a produtividade do poço e subestimar sua injetividade. A solução simultânea de geomecânica e fluxo de fluido é necessária ao objetivo de geração de respostas mais realistas em tais cenários.

É sobre os temas abordados neste subcapítulo 2.2 que este trabalho tem como objetivo abordar com maior profundidade. As seções seguintes têm como objetivo justamente prover maior detalhamento do comportamento de uma rocha que sofre alterações no campo de tensões e na pressão de poros.

\subsection{1}

\section{Teoria da elasticidade linear}

A teoria da elasticidade linear lida com situações onde existem relações lineares entre as tensões presentes no corpo em estudo e as deformações resultantes. Enquanto a maior parte das rochas apresenta comportamento não linear quando submetidas a tensões elevadas, seu comportamento pode normalmente ser descrito 
por relações lineares para pequenas mudanças de tensões. Tal relação é conhecida como Lei de Hooke. Para uma tensão uniaxial $\sigma_{x}$ aplicada numa amostra cilíndrica, temos:

$$
\sigma_{x}=E \varepsilon_{x}
$$

Onde:

$\varepsilon_{x}$ é a deformação na direção $\mathrm{x}$;

$E$ é o módulo de elasticidade ou módulo do Young.

Dessa forma, o módulo de Young é considerado uma medida da rigidez da amostra quando submetida a um processo compressivo de tensão uniaxial. Para este exemplo, além da deformação na direção $\mathrm{x}$, há também uma deformação lateral de expansão da amostra que permite o cálculo do parâmetro elástico conhecido como coeficiente de Poisson. Em materiais que obedecem à teoria da elasticidade linear, incluindo formações rochosas, o coeficiente de Poisson não deve exceder o valor de 0,5 ou ser inferior a zero (Lacy [12]).

$$
v=-\frac{\varepsilon_{y}}{\varepsilon_{x}}
$$

As equações acima se referem a apenas um componente de tensão $\left(\sigma_{x} \neq\right.$ $0 ; \sigma_{y}=0 ; \sigma_{z}=0$ ). Porém, cada componente da deformação é função linear de todos os componentes de tensão. Dito isso, para um material isotrópico, as relações abaixo se aplicam:

$$
\begin{gathered}
\varepsilon_{x}=\frac{\sigma_{x}-v\left(\sigma_{y}+\sigma_{z}\right)}{E} \\
\varepsilon_{y}=\frac{\sigma_{y}-v\left(\sigma_{x}+\sigma_{z}\right)}{E} \\
\varepsilon_{z}=\frac{\sigma_{z}-v\left(\sigma_{x}+\sigma_{y}\right)}{E} \\
\Gamma_{\mathrm{yz}}=\frac{\tau_{y z}}{2 G}
\end{gathered}
$$




$$
\begin{gathered}
\Gamma_{\mathrm{xz}}=\frac{\tau_{x z}}{2 G} \\
\Gamma_{\mathrm{xy}}=\frac{\tau_{x y}}{2 G}
\end{gathered}
$$

Onde:

$G$ é o módulo de cisalhamento;

$\Gamma$ é a deformação cisalhante;

$\tau$ é a tensão cisalhante.

O módulo de cisalhamento $(G)$ é uma medida de rigidez da amostra a deformações cisalhantes. É parte integrante da definição do módulo bulk $(K)$, também conhecido como módulo de compressibilidade (ou ainda, módulo de incompressibilidade nas áreas de geociências), que se trata de uma medida de rigidez da amostra a compressão hidrostática. Para determinar $K$, um teste sem jaquetas pode ser realizado, como descrito na seção 3.1 .

$$
K=\frac{\sigma_{p}}{\varepsilon_{v o l}}=\lambda+\frac{2}{3} G
$$

Onde:

$\sigma_{p}$ é a tensão hidrostática definida como $\sigma_{p}=\sigma_{x}=\sigma_{y}=\sigma_{z}$ enquanto que $\tau_{x y}=\tau_{y z}=\tau_{x z}=0$;

$\varepsilon_{v o l}$ é a deformação volumétrica;

$\lambda$ é um parâmetro de Lamé.

É possível ainda definir o módulo de elasticidade $E$ e o coeficiente de Poisson a partir de $G$ e $\lambda$ :

$$
\begin{gathered}
E=G \frac{3 \lambda+2 G}{\lambda+G} \\
v=\frac{\lambda}{2(\lambda+G)}
\end{gathered}
$$

Várias outras relações podem ser geradas a partir das relações acima e são mostradas na Figura 2.2.

Por fim, o módulo bulk tem importância na definição da compressibilidade da amostra, como mostra relação a seguir: 


$$
c_{\text {amostra }}=\frac{1}{K}
$$

\begin{tabular}{rlrl}
$E=3 K(1-2 v)$ & $K=\lambda \frac{1+v}{3 v}$ & $\frac{\lambda}{\lambda+G}=2 v$ \\
$E=2 G(1+v)$ & $K=\frac{2}{3} G \frac{1+v}{1-2 v}$ & $\frac{G}{\lambda+G}=1-2 v$ \\
$E=\frac{9 K G}{3 K+G}$ & $K=\lambda+\frac{2}{3} G$ & $\frac{\lambda+2 G}{\lambda+G}=2(1-v)$ \\
$E=G \frac{3 \lambda+2 G}{\lambda+G}$ & $K=\frac{G E}{9 G-3 E}$ & $\frac{3 \lambda+2 G}{\lambda+G}=2(1+v)$ \\
$E=\frac{\lambda}{v}(1+v)(1-2 v)$ & $\frac{\lambda}{G}=\frac{2 v}{1-2 v}$ & $\frac{3 \lambda+4 G}{\lambda+G}=2(2-v)$ \\
$H=\lambda+2 G$ & $H=K+\frac{4}{3} G$ & $v=\frac{3 K-2 G}{2(3 K+G)}$ \\
$H=E \frac{1-v}{(1+v)(1-2 v)}$ & $H=2 G \frac{1-v}{1-2 v}$ & $H=3 K \frac{1-v}{1+v}$ \\
\hline
\end{tabular}

Figura 2.2: Algumas relações entre módulos elásticos (Fjaer et al. [13])

\subsection{2}

\section{Poroelasticidade}

Até este ponto, a amostra foi tratada como homogênea em sua constituição. Entretanto, as rochas que constituem reservatórios de petróleo apresentam mais de um componente em suas estruturas sólidas com poros preenchidos por fases líquida e gasosa. Em virtude disso, será levado em consideração que o espaço poroso, além de ser parte essencial para a produção de óleo, tem papel importante no comportamento mecânico da rocha.

Como descrito na seção anterior, o módulo bulk $(K)$ é obtido pela equação 2.19 para um teste sem jaqueta (ver seção 3.1). Levando em consideração que a amostra apresenta diferentes componentes, deve-se considerar uma característica chave da resposta do material poroso preenchido com fluido que é a diferença entre a deformação drenada e não drenada (Detournay \& Cheng [14]). Em função disso, o módulo bulk a partir desse ponto passa a ser denominado módulo bulk saturado e identificado por $K_{\text {sat }}$ :

$$
K_{\text {sat }}=\frac{\sigma_{p}}{\varepsilon_{\text {vol }}}
$$


A deformação volumétrica deve então ser igual à soma da deformação de cada componente, ponderada pela fração de cada fase em relação ao volume total, como mostrado a seguir:

$$
\varepsilon_{v o l}=\frac{V_{s}}{V_{b}} \varepsilon_{v o l, s}+\frac{V_{f}}{V_{b}} \varepsilon_{v o l, f}
$$

onde $s$ e $f$ referem-se a sólido e fluido, respectivamente.

Considerando que porosidade é o volume ocupado por fluido em relação ao volume total:

$$
\begin{gathered}
\varnothing=\frac{V_{f}}{V_{b}} \\
1-\emptyset=\frac{V_{s}}{V_{b}}
\end{gathered}
$$

Além disso, é possível definir a deformação volumétrica dos grãos sólidos $\left(\varepsilon_{v o l, S}\right)$ pelo módulo bulk sólido ou mineral $\left(K_{S}\right)$ e a deformação volumétrica da fase fluida $\left(\varepsilon_{v o l, f}\right)$ pelo módulo bulk do fluido $\left(K_{f}\right)$, permitindo reescrever a equação 2.24:

$$
\varepsilon_{v o l}=(1-\emptyset) \frac{\sigma_{p}}{K_{S}}+\emptyset \frac{\sigma_{p}}{K_{f}}
$$

Combinando a equação 2.23 com a equação 2.27 é possível relacionar o módulo bulk saturado com os módulos dos componentes da seguinte forma:

$$
\frac{1}{K_{\text {sat }}}=\frac{1-\emptyset}{K_{S}}+\frac{\emptyset}{K_{f}}
$$

A equação acima exemplifica um material poroso particularmente simples. Portanto, é preciso generalizar levando em consideração o fato de que uma rocha consiste de uma estrutura sólida e fluidos nos poros que não podem ser tratados de maneira independente.

\section{Parâmetros de Biot}

Considerando um meio poroso, permeável e isotrópico formado por um componente sólido e um líquido, podemos dizer que a deslocamento da fase sólida 
é identificada por $\vec{u}_{S}$ e o deslocamento da fase fluida por $\vec{u}_{f}$. Para um elemento de volume conectado ao sólido, as deformações são dadas pelas derivadas dos componentes de $\vec{u}_{S}$.

$$
\varepsilon_{v o l}=\nabla \cdot \vec{u}_{S}
$$

Para a fase fluida, é definido um parâmetro $\zeta$, que descreve a deformação volumétrica do fluido relativa à fase sólida:

$$
\zeta=\emptyset \nabla \cdot\left(\vec{u}_{S}-\vec{u}_{f}\right)
$$

A mudança na massa de fluido em um elemento volumétrico conectado ao sólido pode ser dividida em duas partes:

- A mudança do volume poroso em função de mudanças de tensões externas e/ou da pressão de poros $\left(p_{f}\right)$;

- A compressão/descompressão do fluido com a mudança de pressão de poros.

Isso significa dizer que:

$$
\zeta=-\varnothing\left(\frac{\Delta V_{p}}{V_{p}}+\frac{p_{f}}{K_{f}}\right)
$$

A presença de fluido nos poros adiciona termos extras à energia de deformação do material. Consequentemente, as relações tensão-deformação também serão modificadas. De acordo com Biot [6], as relações lineares de tensãodeformação para um sistema de duas fases podem ser expressas em termos da deformação volumétrica $\varepsilon_{v o l}$, dos elementos do tensor de tensões (como mostrado no conjunto de equações 2.18), além da adição da deformação volumétrica do fluido relativa à fase sólida $\zeta$ e da pressão de poros $p_{f}$ :

$$
\begin{gathered}
\sigma_{x}=2 G\left(\varepsilon_{x}+\frac{v}{1-2 v} \varepsilon_{v o l}\right)-Q \alpha \zeta \\
\sigma_{y}=2 G\left(\varepsilon_{y}+\frac{v}{1-2 v} \varepsilon_{v o l}\right)-Q \alpha \zeta \\
\sigma_{z}=2 G\left(\varepsilon_{z}+\frac{v}{1-2 v} \varepsilon_{v o l}\right)-Q \alpha \zeta \\
\tau_{y z}=2 G \Gamma_{\mathrm{yz}}
\end{gathered}
$$




$$
\begin{aligned}
& \tau_{x z}=2 G \Gamma_{\mathrm{xz}} \\
& \tau_{x y}=2 G \Gamma_{\mathrm{xy}} \\
& p_{f}=Q \alpha \varepsilon_{v o l}-Q \zeta
\end{aligned}
$$

$Q$ e $\alpha$ são chamados parâmetros de Biot que serão descritos a seguir. Ao observar o conjunto de equações acima, quando $\zeta=0$, significa dizer que não há movimento de fluido na amostra, ou seja, o material não é drenado como descrito na seção 3.1 .

Para melhor entendimento do significado físico do parâmetro $Q$, considera-se o caso de $\varepsilon_{v o l}=0$ na equação anterior de pressão de poros. Inserindo a equação 2.30 na equação 2.38 , temos:

$$
p_{f}=Q \varnothing \nabla \cdot \vec{u}_{f}
$$

A equação acima mostra que $Q \emptyset$ é uma medida de quanto a pressão de poros é elevada com o acréscimo na quantidade de fluido no elemento volumétrico. Se o sólido for completamente rígido, $Q \emptyset$ seria igual a $K_{f}$.

Definindo a tensão normal principal como $\bar{\sigma}=\left(\sigma_{x}+\sigma_{y}+\sigma_{z}\right) / 3$ e recordando que $K_{\text {sat }}$ é medido numa condição onde não é permitido ao fluido presente nos poros escapar, podemos reescrever as equações 2.32, 2.33 e 2.34 como:

$$
\bar{\sigma}=K_{\text {sat }} \varepsilon_{v o l}-Q \alpha \zeta
$$

Com o objetivo de relacionar $K_{\text {sat }}$ e $Q$ aos módulos constituintes da rocha, deve-se levar em consideração nesse ponto um meio poroso confinado em uma jaqueta impermeável e submetido a uma pressão hidrostática externa $\sigma_{p}$. Maiores detalhes deste teste drenado são dados na seção 3.1.

Como o fluido dos poros é capaz de escapar durante o carregamento do teste, a pressão de poros tende a se manter constante e, como consequência, a tensão é inteiramente repassada à estrutura sólida do meio. Por meio equações 2.38 e 2.39, encontra-se que: 


$$
\frac{\sigma_{p}}{\varepsilon_{v o l}}=K_{s a t}-Q \alpha^{2}=K_{D}
$$

Dado que este teste permite dimensionar a rigidez da parte sólida da rocha, $K_{D}$ é denominado de módulo da estrutura drenada (do inglês, modulus of the dry framework). Uma vez que não há forças cisalhantes associadas com o fluido, podese dizer que o módulo de cisalhamento da estrutura drenada é igual ao módulo de cisalhamento do sistema poroso saturado:

$$
G_{D}=G_{s a t}
$$

A seguir volta-se a considerar um teste sem jaquetas (ver seção 3.1), no qual a amostra rochosa está embebida em um fluido de maneira que a pressão hidrostática na amostra é igualada a pressão de poros $\left(\sigma_{p}=p_{f}\right)$. Por meio das equações 2.38 e 2.40 , encontra-se que:

$$
\frac{\sigma_{p}}{\varepsilon_{v o l}}=\frac{p_{f}}{\varepsilon_{v o l}}=\frac{K_{D}}{1-\alpha}
$$

Como há uma tensão uniforme agindo na amostra $\left(p_{f}=\sigma_{p}\right)$, a estrutura da rocha se deforma uniformemente. Ou seja, a deformação do volume total, do volume poroso e do volume dos grãos sólidos deve ser igual.

$$
\frac{\Delta V_{S}}{V_{S}}=\frac{\Delta V_{p}}{V_{p}}=\frac{\Delta V_{T o t}}{V_{T o t}}=-\varepsilon_{v o l}=-\frac{p_{f}}{K_{S}}
$$

Substituindo a equação 2.44 na equação 2.43 , temos que $K_{D}$ é sempre menor que $K_{S}$ :

$$
K_{S}=\frac{K_{D}}{1-\alpha}
$$

Logo, o parâmetro $\alpha$ de Biot é igual a:

$$
\alpha=1-\frac{K_{D}}{K_{S}}
$$

Já a partir das equações 2.31 e 2.44 , temos a seguinte representação para a deformação volumétrica do fluido relativa à fase sólida: 


$$
\zeta=\varnothing\left(\frac{1}{K_{S}}-\frac{1}{K_{f}}\right) p_{f}
$$

Por outro lado, ao combinar as equações 2.38 com 2.40 e ao considerar $p_{f}=$ $\sigma_{p}$, torna-se possível dizer que:

$$
\zeta=\frac{Q \alpha-K_{\text {sat }}}{Q K_{\text {sat }}-Q^{2} \alpha^{2}} p_{f}=\varnothing\left(\frac{1}{K_{S}}-\frac{1}{K_{f}}\right) p_{f}
$$

Gassmann, em seu trabalho em 1951, apud Wang [15], propôs uma relação que é consagrada para o estudos de substituição de fluidos e que, embora sua versão original envolvesse as compressibilidades dos constituintes, normalmente sua versão apresentada na equação 2.49 é a mais utilizada. A partir das relações acima, é possível expressar as constantes elásticas $K_{\text {sat }}$ e $Q$ em função dos módulos elásticos dos componentes da rocha $\left(K_{S} e K_{f}\right)$, da porosidade e do módulo estrutural drenado $K_{D}$ :

$$
\begin{gathered}
K_{\text {sat }}=K_{D}+\frac{K_{f}}{\emptyset} \frac{\left(1-\frac{K_{D}}{K_{S}}\right)^{2}}{1+\frac{K_{f}}{\emptyset K_{S}}\left(1-\emptyset-\frac{K_{D}}{K_{S}}\right)} \\
Q=\frac{K_{f}}{\emptyset} \frac{1}{1+\frac{K_{f}}{\emptyset K_{S}}\left(1-\emptyset-\frac{K_{D}}{K_{S}}\right)}
\end{gathered}
$$

Isso significa dizer fisicamente que para o caso de um rocha rígida, onde a estrutura sólida é incompressível comparada ao fluido $\left(K_{S} \gg K_{f}\right)$ :

$$
K_{D}, G_{D}, K_{S} \gg K_{f}
$$

O uso da equação de Gassmann, de acordo com Wang [15] parte dos seguintes pressupostos:

- A rocha é macroscopicamente homogênea e isotrópica;

- O sistema rocha-fluido é fechado, implicando não existir fluxo de fluido em qualquer sentido nos limites do reservatório;

- O fluido e a rocha não interagem entre si de maneira a modificar as propriedades do meio rochoso, implicando a ausência de reação química entre rocha 
e fluido. Esta premissa é violada principalmente em rochas carbonáticas ou argilosas nas quais pode ser efetiva essa interação.

Algumas das premissas para o emprego da equação de Gassmann não ocorrem em parte dos reservatórios de petróleo, o que não impede a sua aplicabilidade com resultados satisfatórios.

À luz de Gassmann é possível determinar como as velocidades e impedâncias sísmicas dependem dos fluidos e da tensão efetiva e a solução do problema passa pelo entendimento de que forma os módulos da rocha mudam com o sistema porofluido. Esses pontos serão melhor explicitados no próximo capítulo, onde são analisados os métodos de medição de módulos elásticos por métodos indiretos.

\subsection{3}

\section{Compressibilidade}

Zimmerman [16] define que compressibilidade é um parâmetro que quantifica a relação entre a pressão exercida sobre um corpo e a mudança resultante em seu volume. Para um material não poroso, a compressibilidade é definida como:

$$
c=-\frac{1}{V_{b_{i}}} \frac{d V_{b}}{d p}
$$

Em contraste com a relação acima, a análise torna-se mais complexa quando envolve um corpo poroso, uma vez que envolve, além de uma tensão externa e confinante $\left(\sigma_{c}\right)$, uma poropressão que age sobre a superfície da parede interna do poro. O volume bulk ou ainda volume total da amostra, pode ser definido em função do volume poroso e do volume de sólidos presentes:

$$
V_{b}=V_{P}+V_{S}
$$

Ainda segundo Zimmerman [16], uma vez que há dois volumes independentes e duas tensões variáveis, é possível definir quatro compressibilidades associadas a um corpo poroso. Tais parâmetros são detalhados em seguida.

Compressibilidade bulk drenado $\left(c_{D}\right)$ : pode ser interpretada como a derivada parcial do volume bulk em relação à tensão confinante, com a poropressão 
mantida constante. As pressões de poro e confinante são aqui assumidas variáveis matematicamente independentes. Fisicamente, isso corresponde a uma compressão drenada, onde a variação da tensão confinante não provoca mudanças de poropressão (seção 3.1).

$$
c_{D}=-\frac{1}{V_{b_{i}}}\left[\frac{d V_{b}}{d \sigma_{c}}\right]_{p_{f}}
$$

Por meio da equação 2.22, pode-se dizer que:

$$
c_{D}=\frac{1}{K_{D}}
$$

Compressibilidade pseudo-bulk $\left(c_{b p}\right)$ : parâmetro útil no cálculo de subsidência e reflete a influência da poropressão no volume bulk.

$$
c_{b p}=-\frac{1}{V_{b_{i}}}\left[\frac{d V_{b_{i}}}{d p_{f}}\right]_{\sigma_{c}}
$$

Pela equação 2.41 e dados apresentados na seção anterior, é possível escrever que:

$$
K_{\text {sat }}=K_{D}+Q \alpha^{2}
$$

Pela relação abaixo é descrito o módulo pseudo-bulk $\left(\mathrm{K}_{\mathrm{bp}}\right)$ :

$$
\mathrm{K}_{\mathrm{bp}}=-\frac{p_{f}}{\varepsilon_{v o l}}=\frac{K_{D}}{\alpha}
$$

Com o uso da equação 2.18, a compressibilidade pseudo-bulk é descrita como:

$$
\mathrm{c}_{\mathrm{bp}}=\frac{1}{\mathrm{~K}_{\mathrm{bp}}}=\frac{\alpha}{K_{D}}=\left(\frac{1}{K_{D}}-\frac{1}{K_{S}}\right)
$$

Compressibilidade do volume poroso em relação à tensão confinante $\left(c_{P C}\right)$ : esse parâmetro tem relevância para análises em laboratório do volume poroso in situ da rocha reservatório. Hall [17] inclusive refere-se ao $c_{P C}$ como coeficiente de compactação da formação. Como a amostra rochosa tem a tensão confinante do overburden e do sideburden relaxada quando trazida à superfície, é importante 
reproduzir as condições originais para determinação do volume poroso desta amostra. Essa compressibilidade pode ser expressa como:

$$
c_{P c}=-\frac{1}{V_{P_{i}}}\left[\frac{d V_{P}}{d \sigma_{c}}\right]_{p_{f}}
$$

Por meio das equações $2.38,2.40$ e inserindo a expressão resultante para $\zeta$ na equação 2.31 com os parâmetros $K_{\text {sat }}$ e $Q$ das equações 2.49 e 2.50, temos após alguma álgebra que:

$$
\frac{\Delta V_{P}}{V_{P}}=-\frac{1}{\emptyset}\left(\frac{1}{K_{D}}-\frac{1}{K_{S}}\right) \sigma_{c}+\frac{1}{\emptyset}\left(\frac{1}{K_{D}}-\frac{1+\emptyset}{K_{S}}\right) p_{f}
$$

Combinando as 2 últimas equações, temos:

$$
\frac{1}{K_{P c}}=\frac{1}{\emptyset}\left(\frac{1}{K_{D}}-\frac{1}{K_{S}}\right)
$$

Portanto, a compressibilidade $c_{P c}$ com o uso da equação 2.22 se resume a:

$$
c_{P C}=\frac{1}{\emptyset}\left(\frac{1}{K_{D}}-\frac{1}{K_{S}}\right)
$$

\section{$\underline{\text { Compressibilidade do volume poroso em relação à pressão de poros }}$} $\left(c_{\emptyset}\right)$ : é utilizada na análise de reservatórios por refletir o excesso de volume de fluido no poro que pode ser armazenado no espaço poroso em virtude de um aumento na pressão de poros. Essa compressibilidade é acrescida à compressibilidade do fluido $\left(c_{f}\right)$ de forma a representar o termo da “compressibilidade do poro" que é utilizado na simulação de fluxo convencional. A compressibilidade $c_{\emptyset}$ é definida como mostrado a seguir:

$$
c_{\varnothing}=-\frac{1}{V_{P_{i}}}\left[\frac{d V_{P}}{d p_{f}}\right]_{\sigma_{c}}
$$

Por meio da equação acima e da equação 2.61, define-se seu módulo, e por consequência, $c_{\varnothing}$ :

$$
c_{\varnothing}=\frac{1}{K_{\varnothing}}=-\frac{1}{V_{P}} \frac{d V_{P}}{d \sigma_{c}}=\frac{1}{\emptyset}\left(\frac{1}{K_{D}}-\frac{1+\emptyset}{K_{S}}\right)
$$


Através das quatro compressibilidades identificadas acima, são estabelecidas três relações:

$$
\begin{gathered}
c_{b p}=c_{D}-\frac{1}{K_{S}} \\
c_{p c}=\frac{c_{D}-\frac{1}{K_{S}}}{\emptyset}=\frac{c_{b p}}{\emptyset} \\
c_{\varnothing}=\frac{c_{D}-\left(\frac{1+\emptyset}{K_{S}}\right)}{\emptyset}=c_{p c}-\frac{1}{K_{S}}
\end{gathered}
$$

A abordagem de compressibilidade apresentada acima que envolve trabalhos de Biot [18], Fjaer et al.[13] e Zimmerman [16] não é unânime.

Li et al.[19], em seu trabalho defende uma a equação própria para definição da compressibilidade do volume poroso. Segundo o autor, sua nova abordagem se opõe especialmente à correlação do trabalho de Hall [17] representada na equação 2.70. Segundo essa correlação, a compressibilidade do volume poroso diminui a medida que a porosidade aumenta.

$$
c_{\varnothing}=\frac{2,587 \times 10^{-4}}{\emptyset^{0,4358}}
$$

onde $c_{\varnothing}$ é medido em MPa.

Li et al.[19] também inclui a rigidez da estrutura da rocha, porém a compressibilidade tende a aumentar com o aumento da porosidade, como observado a seguir. Maiores detalhes da dedução não serão descritos neste trabalho.

$$
c_{\varnothing}=\frac{\emptyset}{1-\emptyset} \frac{3(1-2 v)}{\frac{E}{1-\varnothing}}
$$

onde $c_{\varnothing}$ é medido em MPa. 


\subsection{4}

\section{Acoplamento geomecânico}

Um reservatório encontra-se em um ambiente rochoso que exerce grande influência em sua constituição, principalmente ao longo de sua depleção, com mudanças na pressão que levam as rochas adjacentes e o próprio reservatório para um novo cenário de equilíbrio de tensões. Segundo Samier \& De Gennaro [20], de acordo com o posicionamento das rochas circundantes, influências específicas sobre o reservatório são observadas.

O overburden, ou seja, as diversas rochas e camadas de solo que se encontram entre o leito marinho ou a superfície (para campos terrestres) e o topo do reservatório, determina o grau de transmissão da compactação do reservatório para a superfície na forma de subsidência. Como trata-se de um carregamento relacionado ao peso, esse processo irá variar em função da geometria, espessura e propriedades constitutivas dessas estruturas sobrepostas ao reservatório. Inserido no overburden está a rocha capeadora, que por meio de um mecanismo de selagem hidráulica ou mecânica impediu a migração do hidrocarboneto para a superfície.

As armadilhas, também conhecidas por trapas, são arranjos estruturalgeométricos (dobras, falhas ou fraturas) de rochas que impedem que o óleo migre para superfície, como observado na Figura 2. 3. A formação de uma armadilha envolve frequentemente deformações da rocha reservatório também. Com base nisso, para que seja possível a formação de uma jazida petrolífera, é fundamental que a formação de uma armadilha ou trapa seja contemporânea ou anteceda a migração do hidrocarboneto.

As rochas lateralmente adjacentes ao reservatório (sideburden) influenciam predominantemente na trajetória das tensões e na grandeza de compactação que ocorre no reservatório. No caso de um sideburden de maior rigidez, uma parte da carga do overburden é transferida para o sideburden, gerando um efeito de arqueamento. Como consequência, a tensão vertical da camada de overburden não é inteiramente e nem uniformemente aplicada sobre o reservatório. Da mesma forma, a rocha situada abaixo do reservatório (underburden) também tem grande influência no processo de compactação do reservatório e subsidência. Como o sideburden está diretamente apoiado pelo underburden, uma maior rigidez permite 
um arqueamento mais evidente do que um underburden menos rígido (Samier \& De Gennaro [20]).

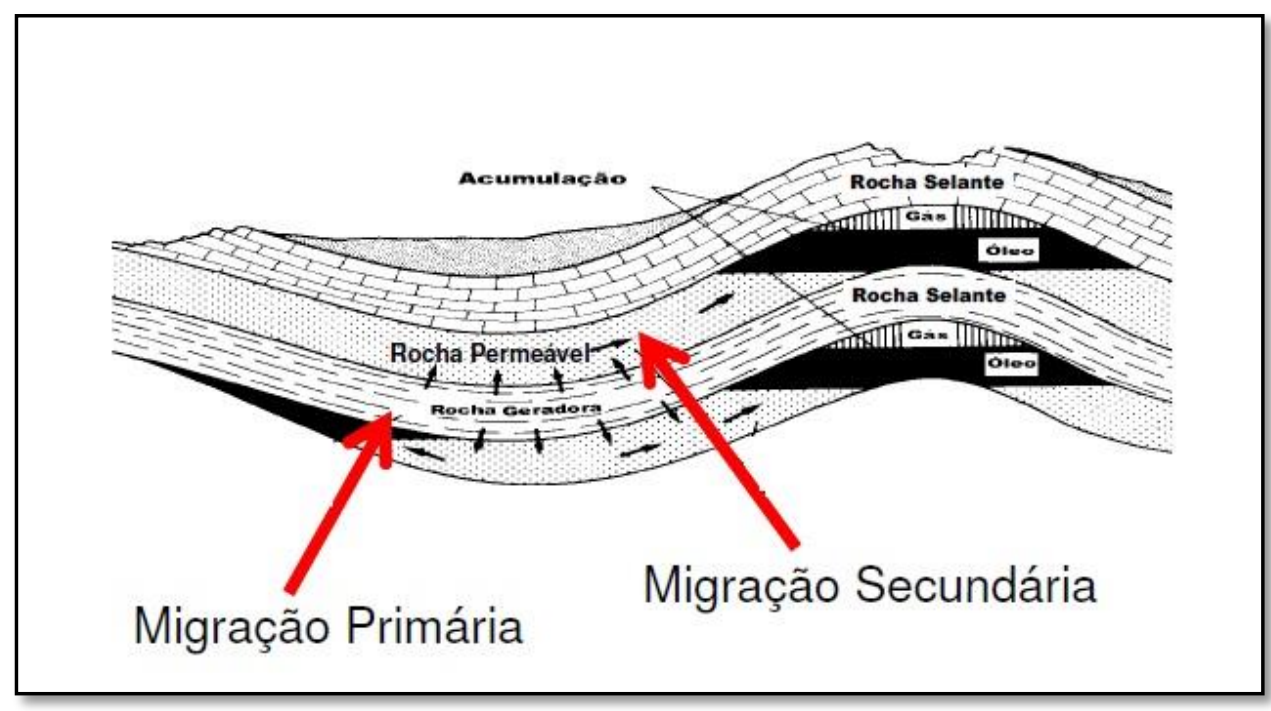

Figura 2. 3: Representação esquemática de um sistema petrolífero (Pires, UENF)

Hofman et al.[21] relatam o conceito de tensão efetiva, definido por Terzagui em 1936. A tensão efetiva seria a diferença entre a tensão confinante e a poropressão. Ou seja, para solos e rochas não consolidadas tensão efetiva governava a deformação do solo e dessas rochas.

$$
\begin{gathered}
\sigma^{\prime}=\sigma_{c}-p_{f} \\
\sigma^{\prime}=E \varepsilon
\end{gathered}
$$

Entretanto, Biot e Willis (1957) mostrariam que a deformação para o caso de uma rocha consolidada não é dependente somente da tensão efetiva. Observando a equação 2.41, obtida em um teste drenado e por meio da equação 2.74 (obtida de um teste saturado), chega-se à equação 2.75 :

$$
\begin{gathered}
p_{f}=Q \alpha \varepsilon_{v o l} \\
K_{s a t}=K_{D}+Q \alpha^{2}=K_{D}+\alpha \frac{p_{f}}{\varepsilon_{v o l}}
\end{gathered}
$$

Levando em consideração que $K_{s a t}=\sigma / \varepsilon_{v o l}$ e rearranjando a equação acima, temos:

$$
\sigma_{c}-\alpha p_{f}=K_{D} \varepsilon_{v o l}
$$


A equação anterior informa que a deformação é proporcional à tensão efetiva $\left(\sigma^{\prime}\right)$. A seguinte equação é então gerada com a presença do parâmetro $\alpha$ de Biot:

$$
\sigma^{\prime}=\sigma_{c}-\alpha p_{f}
$$

A partir disso, a mudança na pressão de poros altera o estado de tensões efetivas sugerindo duas formas de acoplamento do escoamento de fluido com a deformação da rocha:

- Acoplamento deformação-poropressão: forma de acoplamento no qual a deformação da rocha afeta a pressão de poros e vice-versa. Nesse caso, a elevação da tensão efetiva gera uma diminuição do espaço poroso e, no caso de o fluido ficar retido, haverá um aumento de poropressão. Este fenômeno apresenta vantagens para a explotação de hidrocarbonetos visto que permitiu armazenar, ao longo de milhares de anos, energia no reservatório que irá impactar na vida produtiva desse campo. A partir do momento que a produção de hidrocarboneto inicia, a pressão de poros começa a reduzir com a consequente elevação da tensão efetiva. Parte do carregamento do overburden que antes era suportada pelo fluido passa a agir na matriz da rocha que irá se deformar no sentido de compactação e redução de porosidade.

- Acoplamento tensão-permeabilidade: a deformação da rocha ocasiona mudanças na estrutura dos poros, afetando a permeabilidade e o escoamento. Em função disso, há um impacto direto na explotação do campo.

As relações descritas anteriormente podem ser observadas na figura a seguir:

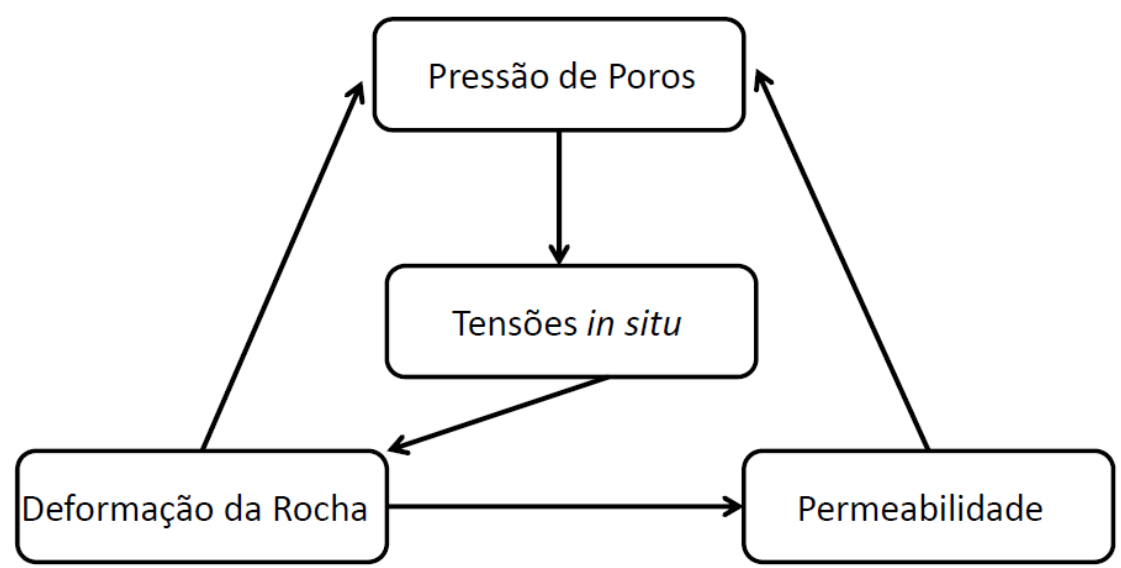

Figura 2. 4: Esquema de interação entre geomecânica e fluxo num reservatório deformável. 
Como detalhado nas equações 2.12, 2.14 e 2.15, em uma simulação convencional os efeitos geomecânicos são frequentemente aproximados apenas através da compressibilidade da rocha. Para Inoue \& Fontoura [4], significa dizer que nesse tipo de simulação, onde são consideradas apenas as equações de continuidade, de estado e lei de Darcy, a variação da porosidade é dependente apenas da variação do campo de pressão e de uma compressibilidade constante da formação. Ainda segundo os autores, não se contempla em tal hipótese a dependência da variação volumétrica, sendo somente validada em casos onde o reservatório e as rochas adjacentes apresentam baixíssima compressibilidade.

Outro fato importante a considerar é em relação à medição da compressibilidade da rocha em laboratório. Geralmente o procedimento envolve uma pequena amostra de rocha reservatório sujeita a condições de contorno nas quais as tensões de cisalhamento são negligenciadas e a deformação plástica ocorre em apenas uma direção. Em geral, um simulador convencional não consegue prever resultados precisos sem a ajuda da geomecânica quando materiais não lineares, trajetórias complexas de tensão, cargas externas, múltiplas dimensões e condições de contorno não-triviais são levadas em conta (Tran et al. [22]).

Ainda é necessário atentar que a compressibilidade é um bom parâmetro de ajuste da variação da porosidade quando a rocha encontra-se no regime elástico (Sen \& Settari [23]). Isso significa dizer que, de acordo com a teoria do préadensamento e citada por Falcão [10] em seu trabalho, quando no regime plástico as deformações são mais acentuadas (Figura 2.5). Dessa forma, simulações que fazem uso de um valor de compressibilidade constante durante todo o processo de simulação tendem a negligenciar grande parte dos efeitos geomecânicos.

Essas simplificações relatadas nos dois parágrafos acima implicam em dizer que as tensões no reservatório e rochas circundantes não podem estar em equilíbrio com a pressão de poros, uma vez que o acoplamento geomecânico não é considerado integralmente.

O mesmo se observa em relação à permeabilidade, onde a equação da difusividade hidráulica (equação 2.15) não contempla sua variação com as alterações de poropressão e variação volumétrica do meio ao longo do tempo. 

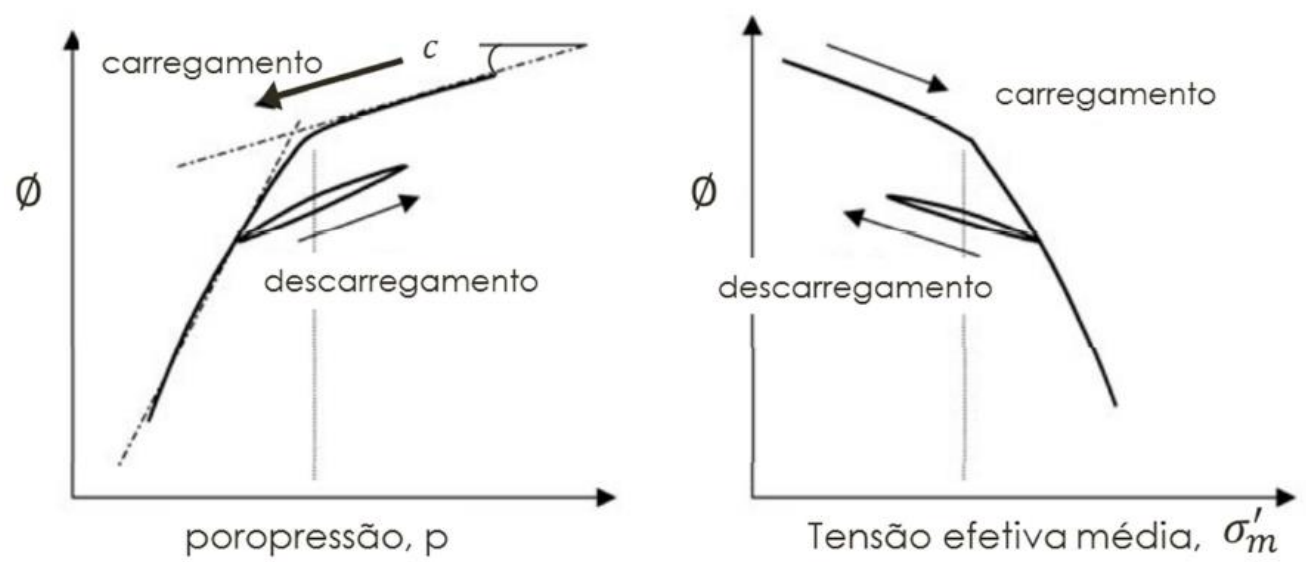

Figura 2. 5: Variação da porosidade com a tensão efetiva e a pressão de poros nos regimes elástico e plástico. Modificado de Falcão [10].

Como forma de resolução das questões apresentadas acima, três principais esquemas são apresentados em fontes bibliográficas para promover o acoplamento do problema de fluxo e tensão: pseudoacoplamento, acoplamento total, acoplamento parcial. Cada tipo de acoplamento tem vantagens e desvantagens que serão analisadas a seguir.

\subsubsection{1}

\section{Pseudoacoplamento}

A maior vantagem dessa implementação refere-se à economia de tempo e esforço computacional por não necessitar de um módulo geomecânico de simulação.

A porosidade e a permeabilidade absolutas podem ser calculadas e atualizadas a partir de um modelo empírico, sendo dependente apenas do campo de pressão. Desta forma, o modelo empírico é implementado no simulador na forma de tabelas de multiplicadores de porosidade e permeabilidade versus pressão (Samier \& De Gennaro [20]). Outros autores incluem funções ou tabelas baseadas em dados de laboratório para considerar algumas respostas geomecânicas no simulador de reservatório. Segundo Tran et al.[22], apesar deste tipo de acoplamento não produzir informações geomecânicas (por exemplo, campo de tensões), ele tem sido amplamente utilizado para fazer ajustes de histórico para fluxo e pressão.

Quando não há dados do reservatório, a tabela de multiplicadores de porosidade pode ser formada a partir da equação 2.12 e representada como: 


$$
\text { mult. porosidade }=\frac{\emptyset}{\emptyset^{0}}=1+c_{b}\left(p-p^{0}\right)
$$

Onde:

- $\quad \emptyset^{0}$ é a porosidade absoluta média inicial do reservatório;

- $\varnothing$ é a porosidade absoluta média do reservatório associada a um diferencial de pressão;

- $\quad p^{0}$ é a pressão de poros inicial.

No caso do simulador IMEX da empresa CMG, o próprio manual do fabricante sugere o trabalho científico de Espinoza [24] para o cálculo dos multiplicadores de permeabilidade. $\mathrm{O}$ autor faz uso da correlação de Kozeny e os resultados tabelados podem ser observados em um exemplo ilustrado na Figura 2.6.

$$
\text { multiplicador permeabilidade }=\frac{k}{k^{0}}=\left(\frac{\emptyset}{\emptyset^{0}}\right)^{r} *\left(\frac{1-\emptyset^{0}}{1-\emptyset}\right)^{2}
$$

onde:

- $\quad r$ é um parâmetro ajustável que depende da litologia e que varia de 3,5 para arenitos não consolidados até 4,5 para arenitos bem cimentados.

\begin{tabular}{|ccc|}
\hline pressure & porosity multiplier & permeability multiplier \\
50 & 0.9864 & 0.939054721 \\
100 & 0.9889 & 0.950023594 \\
150 & 0.9914 & 0.961097087 \\
200 & 0.9939 & 0.972276 \\
250 & 0.9964 & 0.983561141 \\
300 & 0.9989 & 0.994953321 \\
350 & 1.0014 & 1.006453356 \\
400 & 1.0039 & 1.018062068 \\
450 & 1.0064 & 1.029780285 \\
500 & 1.0089 & 1.041608837 \\
\hline
\end{tabular}

Figura 2. 6: Relação dos multiplicadores em função da pressão. Pressão de poros original $\left(\boldsymbol{p}_{\mathbf{0}}\right)$ é de $322 \mathrm{kgf} / \mathrm{cm}^{2}$.

No caso da equação 2.79 , como o multiplicador de permeabilidade também é dependente de uma estimativa fidedigna da atualização da porosidade, que deveria contemplar também as mudanças no campo de tensões, os efeitos geomecânicos voltam a não ser considerados de maneira integral na simulação. Para estimar o efeito da variação de tensões na produção são necessários estudos aprofundados, sempre com a realização de ensaios laboratoriais, atrelados ou não a ensaios em programas de análise de tensões. Soma-se a isso, a ausência de informação da 
variação de tensões nas camadas adjacentes ao reservatório. Apesar disso, caso sejam utilizados bons dados de entrada, o pseudoacoplamento tenderá a apresentar resultados melhores que a simulação convencional de reservatórios.

Segundo Falcão [10], além das correlações, a permeabilidade pode ser atualizada através de tabelas que relacionam seus multiplicadores com a tensão média total, tensão média efetiva ou com a deformação volumétrica. O ponto vantajoso dessa abordagem é levar o comportamento medido em laboratório de forma direta e simples para o modelo numérico.

\subsubsection{2}

\section{Acoplamento Total}

O uso do acoplamento total apresenta vantagens em função das variáveis de fluxo (pressão, saturação e temperatura) e geomecânicas (tensões, deslocamentos) serem resolvidas simultaneamente por meio de um único sistema de equações em um simulador. Tal arranjo permite maior confiabilidade e precisão nos resultados obtidos e que podem vir a servir de referência para outras abordagens de acoplamento (Tran et al.[22]).

Outra vantagem é a resolução por meio de iterações implícitas pelas quais não são necessárias iterações de acoplamento entre o modelo geomecânico e o modelo de reservatório, como na abordagem de acoplamento parcial iterativo.

Segundo Inoue \& Fontoura [4], a diferença básica entre a equação de fluxo do sistema totalmente acoplado e da simulação convencional se encontra na abordagem da equação da porosidade (equação 2.12). Na simulação convencional, a porosidade está relacionada com a pressão de poros através da compressibilidade da rocha por meio de uma relação linear.

A Figura 2.7 demonstra que o acoplamento geomecânico permite que a relação da porosidade com a poropressão assuma um comportamento não-linear, antes omitido pela simulação convencional. A equação de difusividade hidráulica descrita na seção 2.1 pode ser escrita da seguinte forma:

$$
\left(\emptyset^{n} c_{f}+\emptyset^{n} c_{b}\right) \frac{\partial p}{\partial t}-\frac{k}{\mu} \nabla^{2} p=0
$$




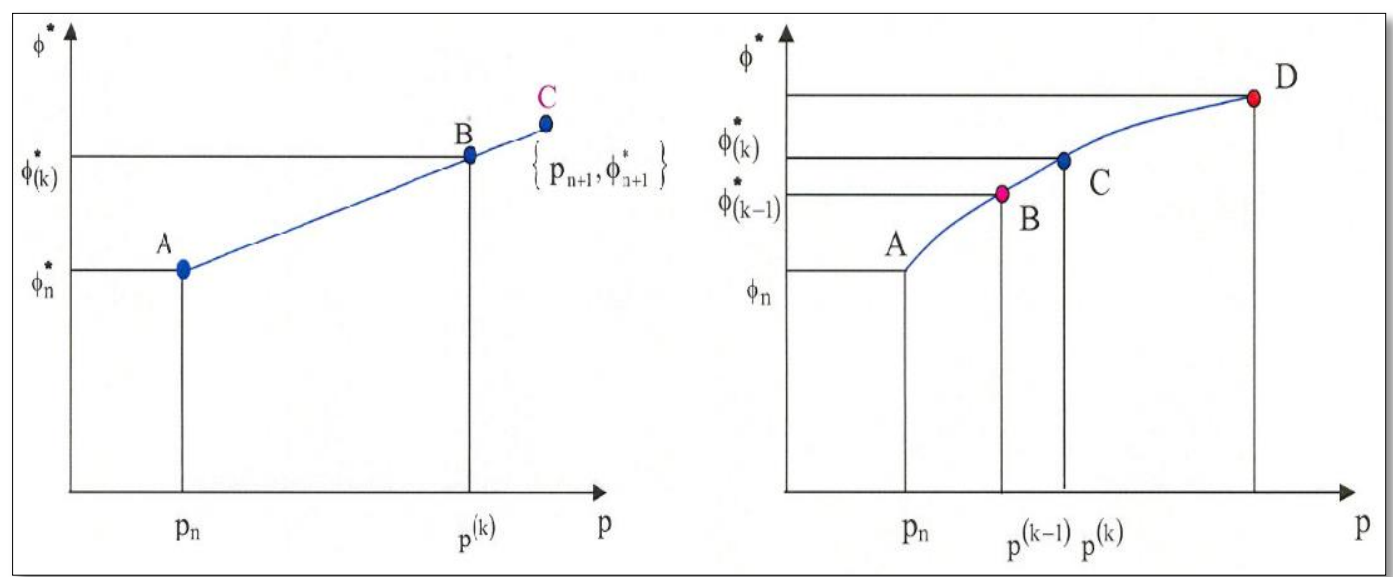

Figura 2. 7: Relação linear (à esquerda) e não-linear (à direita) entre porosidade e pressão de poros ( Tran et al. [25] ).

No acoplamento total, também conhecido como acoplamento implícito, são honradas simultaneamente a equação da continuidade, equação de fluxo de Darcy, equação de equilíbrio, equação da tensão efetiva, relação tensão-deformação e as condições de contorno. Segundo Zienkiewicz et al.[26], considerando um material linearmente elástico e isotrópico, a abordagem da equação da porosidade é composta de quatro componentes que contribuem para o termo de acumulação de fluido:

1) Componente devido à taxa de deformação volumétrica da rocha:

$$
\Delta \varepsilon_{v}
$$

2) Componente devido à compressão do sólido em função da pressão de poros:

$$
c_{s}(1-\emptyset) \Delta p \quad \text { ou } \quad(1-\emptyset) \frac{\Delta p}{K_{s}}
$$

3) Componente devido à compressão do sólido pela tensão efetiva:

$$
-c_{s} K_{D}\left(\Delta \varepsilon_{v}+c_{s} \Delta p\right) \quad \text { ou } \quad-\frac{K_{D}}{K_{s}}\left(\Delta \varepsilon_{v}+\frac{\Delta p}{K_{s}}\right)
$$

4) Componente devido à mudança volumétrica do fluido presente nos poros:

$$
\emptyset c_{f} \Delta p \quad \text { ou } \quad \emptyset \frac{\Delta p}{K_{f}}
$$

A equação da porosidade é gerada a partir da soma dos 4 componentes descritos acima:

$$
\emptyset^{n+1}=\emptyset^{n}+\left[\Delta \varepsilon_{v}+\left(1-\emptyset^{n}\right) \frac{\Delta p}{K_{S}}-\frac{K_{D}}{K_{S}}\left(\Delta \varepsilon_{v}+\frac{\Delta p}{K_{S}}\right)+\emptyset^{n} \frac{\Delta p}{K_{f}}\right]
$$


Rearranjado as variáveis temos:

$$
\emptyset^{n+1}=\emptyset^{n}+\left(1-\frac{K_{D}}{K_{S}}\right) \Delta \varepsilon_{v}+\left[\frac{\emptyset^{n}}{K_{f}}+\left(\frac{1-\frac{K_{D}}{K_{S}}}{K_{S}}\right)-\frac{\emptyset^{n}}{K_{S}}\right] \Delta p
$$

O trabalho de Zienkiewicz et al.[26] faz uso dos 2 parâmetros de Biot descritos na seção 2.2.2 e representados a seguir:

$$
\begin{gathered}
\alpha=1-\frac{K_{D}}{K_{S}} \\
\frac{1}{Q}=\frac{\emptyset^{n}}{K_{f}}+\frac{\alpha-\emptyset^{n}}{K_{S}}=c_{f} \emptyset^{n}+c_{S}\left(\alpha-\emptyset^{n}\right)
\end{gathered}
$$

As equações 2.83 e 2.84 são então inseridas na equação da porosidade (equação 2.82):

$$
\emptyset^{n+1}=\emptyset^{n}+\alpha\left(\varepsilon_{v}^{n+1}-\varepsilon_{v}^{n}\right)+\frac{1}{Q}\left(p^{n+1}-p^{n}\right)
$$

A próxima etapa passa pela introdução da equação acima no termo de acumulação do fluxo (primeiro termo à direita na equação 2.4) de forma similar ao que foi realizado nas equações 2.13 e 2.14 . O resultado é mostrado a seguir:

$$
V_{b} \frac{\partial}{\partial t}\left(\frac{\emptyset}{B_{l}}\right) \approx \frac{V_{b}}{\Delta t}\left[\frac{\alpha}{B_{l}^{n+1}}\left(\varepsilon_{v}^{n+1}-\varepsilon_{v}^{n}\right)+\left(\frac{1}{B_{l}^{n+1} Q}+\frac{\emptyset^{n} c_{f}}{B_{l}^{n}}\right)\left(p_{i}^{n+1}-p_{i}^{n}\right)\right]
$$

A partir disso, chega-se à forma final da equação de fluxo por diferenças finitas para simulação totalmente acoplada de um reservatório:

$$
\begin{aligned}
& T_{l x_{i+\frac{1}{2}, j, k}}\left(p_{i+1, j, k}^{n+1}-p_{i, j, k}^{n+1}\right)-T_{l x_{i-\frac{1}{2}, j, k}}\left(p_{i, j, k}^{n+1}-p_{i-1, j, k}^{n+1}\right)+ \\
& +T_{l y}{ }_{i, j+\frac{1}{2}, k}\left(p_{i, j+1, k}^{n+1}-p_{i, j, k}^{n+1}\right)-T_{l y}{ }_{i, j-\frac{1}{2}, k}\left(p_{i, j, k}^{n+1}-p_{i, j-1, k}^{n+1}\right)+ \\
& +T_{l z}{ }_{i, j, k+\frac{1}{2}}\left(p_{i, j, k+1}^{n+1}-p_{i, j, k}^{n+1}\right)-T_{l z}{ }_{i, j, k-\frac{1}{2}}\left(p_{i, j, k}^{n+1}-p_{i, j, k-1}^{n+1}\right)+q_{l s c_{i}}= \\
& =\frac{V_{b}}{\Delta t}\left[\frac{\alpha}{B_{l}^{n+1}}\left(\varepsilon_{v}^{n+1}-\varepsilon_{v}^{n}\right)+\left(\frac{1}{B_{l}^{n+1} Q}+\frac{\phi^{n} c_{f}}{B_{l}^{n}}\right)\left(p_{i}^{n+1}-p_{i}^{n}\right)\right]
\end{aligned}
$$


Ou ainda,

$$
\left[c_{f} \emptyset^{n}+c_{S}\left(\alpha-\emptyset^{n}\right)\right] \frac{\partial p}{\partial t}-\frac{k}{\mu} \nabla^{2} p=-\alpha \frac{\partial \varepsilon_{v}}{\partial t}
$$

Já a formulação para o problema poroelástico é detalhada a partir das relações lineares de tensão-deformação que foram descritas na seção 2.2 .2 e reescritas a seguir:

$$
\begin{gathered}
\sigma_{x}=2 G\left(\varepsilon_{x}+\frac{v}{1-2 v} \varepsilon_{v o l}\right)-\alpha p_{f} \\
\sigma_{y}=2 G\left(\varepsilon_{y}+\frac{v}{1-2 v} \varepsilon_{v o l}\right)-\alpha p_{f} \\
\sigma_{z}=2 G\left(\varepsilon_{z}+\frac{v}{1-2 v} \varepsilon_{v o l}\right)-\alpha p_{f} \\
\tau_{y z}=2 G \Gamma_{\mathrm{yz}} \\
\tau_{x z}=2 G \Gamma_{\mathrm{xz}} \\
\tau_{x y}=2 G \Gamma_{\mathrm{xy}}
\end{gathered}
$$

Portanto, as tensões totais devem obedecer às condições de equilíbrio:

$$
\begin{aligned}
& \frac{\partial \sigma_{x}}{\partial x}+\frac{\partial \tau_{y x}}{\partial y}+\frac{\partial \tau_{z x}}{\partial z}=0 \\
& \frac{\partial \tau_{x y}}{\partial x}+\frac{\partial \sigma_{y}}{\partial y}+\frac{\partial \tau_{z y}}{\partial z}=0 \\
& \frac{\partial \tau_{x z}}{\partial x}+\frac{\partial \tau_{y z}}{\partial y}+\frac{\partial \sigma_{z}}{\partial z}=0
\end{aligned}
$$

Inserindo o conjunto de equações (2.89-2.94) nas condições de equilíbrio mostradas anteriormente, temos:

$$
\begin{gathered}
\frac{\partial}{\partial x}\left[2 G\left(\varepsilon_{x}+\frac{v}{1-2 v} \varepsilon_{v o l}\right)-\alpha p_{f}\right]+\frac{\partial}{\partial y}\left[2 G \Gamma_{\mathrm{xy}}\right]+\frac{\partial}{\partial z}\left[2 G \Gamma_{\mathrm{xz}}\right]=0 \\
\frac{\partial}{\partial x}\left[2 G \Gamma_{\mathrm{xy}}\right]+\frac{\partial}{\partial y}\left[2 G\left(\varepsilon_{y}+\frac{v}{1-2 v} \varepsilon_{v o l}\right)-\alpha p_{f}\right]+\frac{\partial}{\partial z}\left[2 G \Gamma_{\mathrm{yz}}\right]=0 \\
\frac{\partial}{\partial x}\left[2 G \Gamma_{\mathrm{xz}}\right]+\frac{\partial}{\partial y}\left[2 G \Gamma_{\mathrm{yz}}\right]+\frac{\partial}{\partial z}\left[2 G\left(\varepsilon_{z}+\frac{v}{1-2 v} \varepsilon_{v o l}\right)-\alpha p_{f}\right]=0
\end{gathered}
$$


Nesse ponto, faz-se uso da relação entre deformações e deslocamentos $\varepsilon=$ $\frac{1}{2}\left[\nabla u+(\nabla u)^{T}\right]$, inserindo-as no sistema de equações acima e chega-se a:

$$
\begin{gathered}
2 G \frac{\partial}{\partial x}\left[\left(\frac{\partial \eta}{\partial x}+\frac{v}{1-2 v}\left(\frac{\partial \eta}{\partial x}+\frac{\partial \vartheta}{\partial y}+\frac{\partial w}{\partial z}\right)\right)-\alpha p_{f}\right]+ \\
+2 G \frac{\partial}{\partial y}\left[\frac{1}{2}\left(\frac{\partial \eta}{\partial y}+\frac{d \vartheta}{d x}\right)\right]+2 G \frac{\partial}{\partial z}\left[\frac{1}{2}\left(\frac{\partial w}{\partial x}+\frac{\partial \eta}{\partial z}\right)\right]=0 \\
2 G \frac{d}{d x}\left[\frac{1}{2}\left(\frac{\partial \eta}{\partial y}+\frac{\partial \vartheta}{\partial x}\right)\right]+2 G \frac{\partial}{\partial y}\left[\left(\frac{\partial \vartheta}{\partial y}+\frac{v}{1-2 v}\left(\frac{\partial u}{\partial x}+\frac{\partial \vartheta}{\partial y}+\frac{\partial w}{\partial z}\right)\right)-\alpha p_{f}\right]+ \\
+2 G \frac{\partial}{\partial z}\left[\frac{1}{2}\left(\frac{\partial \vartheta}{\partial z}+\frac{\partial w}{\partial y}\right)\right]=0 \\
2 G \frac{\partial}{\partial x}\left[\frac{1}{2}\left(\frac{\partial w}{\partial x}+\frac{\partial \eta}{\partial z}\right)\right]+2 G \frac{\partial}{\partial y}\left[\frac{1}{2}\left(\frac{\partial \vartheta}{\partial z}+\frac{\partial w}{\partial y}\right)\right]+ \\
+2 G \frac{\partial}{\partial z}\left[\left(\frac{\partial w}{\partial z}+\frac{v}{1-2 v}\left(\frac{\partial \eta}{\partial x}+\frac{\partial \vartheta}{\partial y}+\frac{\partial w}{\partial z}\right)\right)-\alpha p_{f}\right]=0
\end{gathered}
$$

Por meio de manipulação algébrica, o sistema de equações pode ser identificado como:

$$
\begin{aligned}
& G \frac{\partial^{2} \eta}{d x^{2}}++\frac{G}{1-2 v} \frac{\partial}{\partial x}\left(\frac{\partial \eta}{\partial x}+\frac{\partial \vartheta}{\partial y}+\frac{\partial w}{\partial z}\right)-\alpha \frac{\partial p_{f}}{\partial x}=0 \\
& G \frac{\partial^{2} \vartheta}{\partial y^{2}}++\frac{G}{1-2 v} \frac{\partial}{\partial y}\left(\frac{\partial \eta}{\partial x}+\frac{\partial \vartheta}{\partial y}+\frac{\partial w}{\partial z}\right)-\alpha \frac{\partial p_{f}}{\partial y}=0 \\
& G \frac{\partial^{2} w}{\partial z^{2}}++\frac{G}{1-2 v} \frac{\partial}{\partial z}\left(\frac{\partial \eta}{\partial x}+\frac{\partial \vartheta}{\partial y}+\frac{\partial w}{\partial z}\right)-\alpha \frac{\partial p_{f}}{\partial z}=0
\end{aligned}
$$

A equação que governa o problema geomecânico pode então ser escrita convenientemente na forma apresentada a seguir, em função dos valores de pressão:

$$
G \nabla^{2} u+\frac{G}{1-2 v} \nabla(\nabla \cdot u)=\alpha \nabla p
$$


A formulação da parte geomecânica utiliza o método de elementos finitos para conseguir uma solução aproximada do problema de valor de contorno (BVP). Dessa forma, leva em consideração as equações de equilíbrio, relações tensãodeformação-deslocamento, interação entre rocha e fluido (por meio da introdução do princípio tensão efetiva do Terzaghi - equação 2.72) e condições de contorno.

A resolução do sistema totalmente acoplado de equações, em função da sua complexidade, é o responsável pelas maiores desvantagens desse método de solução. Entre os pontos desfavoráveis estão:

- A simulação de fluxo é simplificada (geralmente utiliza-se fluxo de um único fluido);

- Alto custo computacional com tempo de resolução muito longo especialmente nos casos de campos de grandes dimensões ou com alto refinamento do grid;

- Em geral, é mais lento que o acoplamento parcial em função do tamanho das matrizes geradas.

\subsubsection{3}

\section{Acoplamento parcial}

O acoplamento parcial é caracterizado pela resolução do escoamento de fluido e das variáveis das equações geomecânicas de maneira separada. Pode ser classificado como iterativo ou explícito a depender da forma com que os simuladores se comunicam entre os intervalos de tempo.

Acoplamento parcial explícito

O acoplamento parcial explícito, também conhecido como acoplamento parcial de uma via (em inglês, one way coupling), fornece o grau de comunicação mais fraco entre o fluxo do reservatório e a análise geomecânica. O simulador convencional de reservatórios envia as informações (pressão de poros, saturação) para o programa geomecânico realizar as análises de tensões. Entretanto, as informações de tensão não são enviadas de volta para o simulador de fluxo. Logo, o efeito geomecânico do reservatório e das rochas adjacentes não atuam nos 
resultados obtidos na seção de fluxo. O fluxograma desse método é mostrado a seguir:

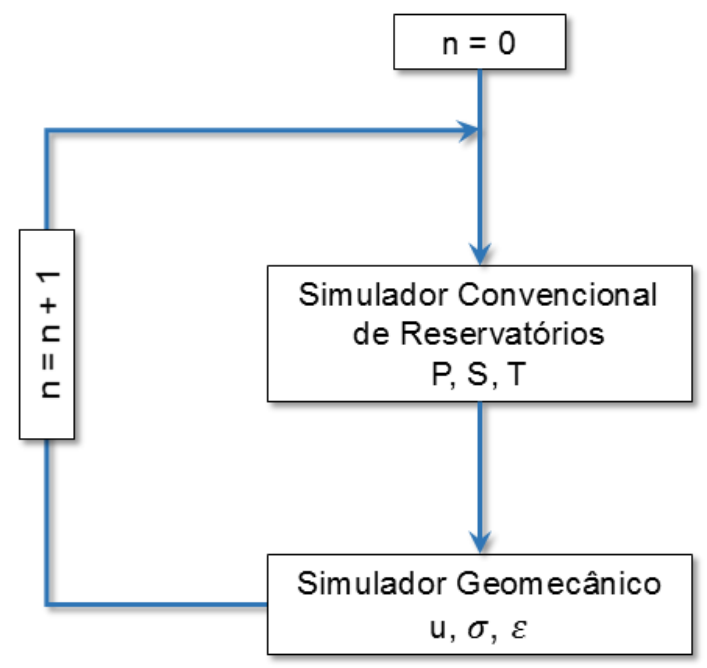

Figura 2. 8: Esquema de acoplamento parcial explícito (Inoue \& Fontoura [4]).

Apesar da não consideração dos efeitos geomecânicos na simulação de fluxo, esse método apresenta suas vantagens:

- O esquema de acoplamento explícito pode ser empregado em reservatórios de gás, sem grandes erros uma vez que a compressibilidade do gás geralmente é dominante sobre a compressibilidade da rocha. Em função disso, o balanço de massa neste tipo de reservatório é controlado principalmente pela pressão do gás ao invés da variação do estado de tensão na rocha (Tran et al.[25]);

- Para os casos em que o volume poroso muda pouco entre os intervalos de tempo, poucas atualizações geomecânicas são necessárias. Em função disso, é possível selecionar intervalos de tempo mais distantes de simulação de mecânica da rocha e reduzir assim o tempo de simulação. A justificativa se encontra no fato de que o cálculo das deformações é a parte mais custosa nesse processo;

- É uma técnica mais simples que permite usar qualquer simulador de fluxo existente com qualquer simulador geomecânico.

Acoplamento parcial iterativo

O acoplamento parcial iterativo (conhecido como acoplamento em duas vias ou, em inglês, two way coupling) também é caracterizado pela resolução das variáveis separada e sequencialmente. Essa abordagem faz uso de um simulador de 
fluxo em reservatórios e de um simulador geomecânico que trocam informações em ambos os sentidos ao final de cada intervalo de tempo.

As iterações são controladas por um critério de convergência que normalmente é baseado na pressão ou variações nas tensões entre as duas últimas iterações da solução (Tran et al.[22]). As repetições também podem ser cessadas quando é atingido o número máximo permitido destas.

Dessa forma, o sucesso deste método depende fortemente da seleção de variáveis para troca de informações entre os dois simuladores, bem como o número permitido de iterações. É um método capaz de chegar a resultados com precisão próxima aos obtidos com o acoplamento total e com a vantagem de uma melhor velocidade de funcionamento, a depender do grau de não-linearidade (Tran et al. [22]).

Settari \& Vikram [11] relatam que diferentes estratégias de acoplamento iterativo podem ser empregadas com consequências no tempo de resolução e precisão dos resultados.

Um dos primeiros estudos dessa abordagem foi realizada por Settari e Mourits [27]. Os autores propuseram um algoritmo iterativo para o acoplamento parcial, utilizando como parâmetro de acoplamento os valores de porosidade no reservatório, calculada através da variação da pressão de poros e da tensão normal média. Segundo Inoue \& Fontoura [4], embora a dedução dessa formulação seja diferente daquelas frequentemente encontradas na literatura, a expressão da porosidade é semelhante à da teoria da poroelasticidade de Biot.

O processo de transferência de dados entre os simuladores no método parcial iterativo pode ser exemplificado como na Figura 2. 9. Para cada intervalo de tempo $n$, o simulador interage $n_{g}$ vezes até que se atinja a convergência. Isso garante que houve o acoplamento dos problemas de fluxo e tensão dentro desse intervalo de tempo. Dessa forma, o simulador de fluxo em diferenças finitas calcula a variação de pressão em função da pressão inicial, saturação e transmissibilidade. A variação de pressão é então aplicada ao simulador geomecânico em elementos finitos para que se obtenha tensões, deformações e deslocamentos. O simulador geomecânico envia de volta uma nova configuração de compressibilidade ou porosidade ou permeabilidade para o simulador de fluxo. Se não houver convergência, uma nova iteração é gerada utilizando as novas propriedades obtidas dentro do mesmo intervalo de tempo até que se atinja a convergência desejada. Como dito 
anteriormente, o critério de convergência normalmente é baseado na pressão ou variações nas tensões. Uma vez chegado ao objetivo, os parâmetros são calculados para um novo intervalo de tempo.

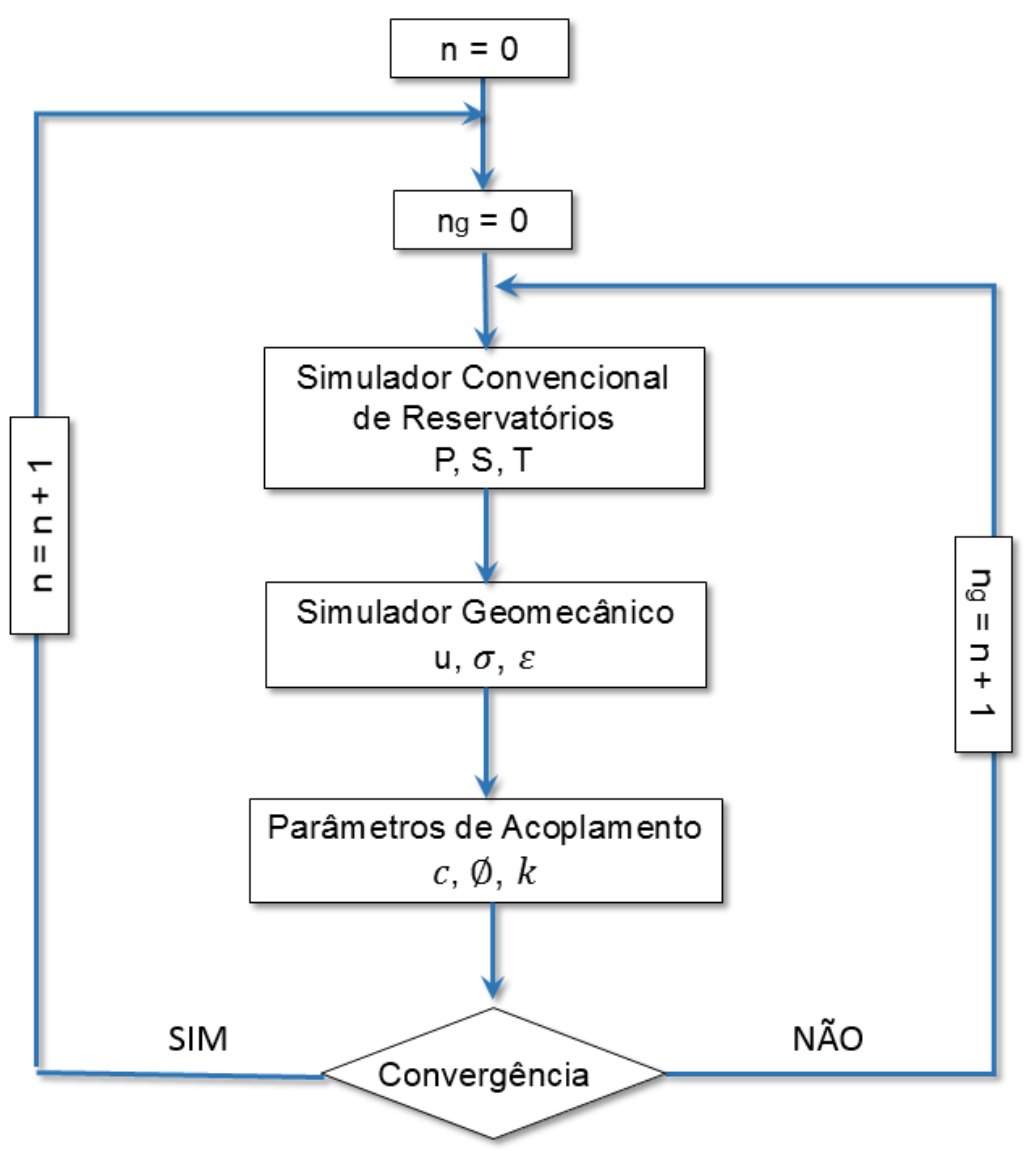

Figura 2. 9: Esquema de acoplamento parcial iterativo (adaptado de Inoue \& Fontoura [4])

O método parcial em duas vias apresenta também pontos que demandam atenção específica. Por exemplo, a maior parte dos modelos acoplados usam um simulador de reservatório de diferenças finitas em comunicação com um software geomecânico de elementos finitos. Esse fato cria um desafio adicional no qual o grid de diferenças finitas deve transferir com eficiência as variáveis desejadas para a malha de elementos finitos e vice-versa. Além disso, o método é desafiador para problemas que exigem um grande número de iterações por causa da convergência entre os módulos, gerando um tempo computacional elevado para estes casos. Em função disso, a exatidão dos resultados depende fortemente da escolha da formulação para estabelecer o acoplamento.

$\mathrm{Na}$ abordagem GTEP/PUC-Rio utilizada neste trabalho e implementada por Inoue \& Fontoura [4], também buscou-se obter, a partir da equação de fluxo da 
simulação convencional de reservatórios com acoplamento, a mesma resposta da equação de fluxo do esquema de acoplamento total. A Figura 2.10 retrata essa abordagem baseada no acoplamento parcial e na simulação convencional de reservatórios. A descrição em detalhes se encontra na seção a seguir.

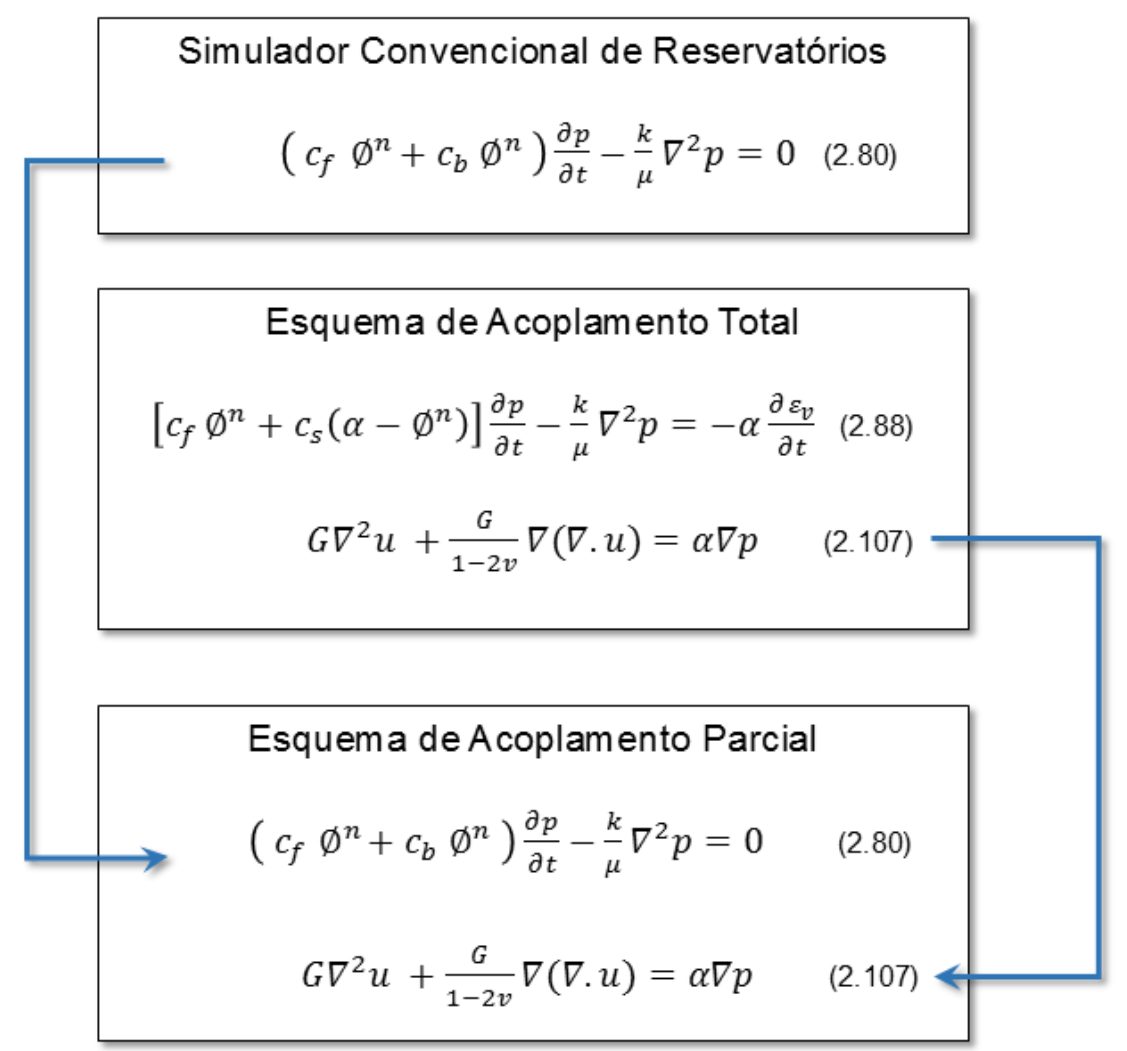

Figura 2. 10: Esquema com as equações que governam o acoplamento parcial. Modificado de Lautenschläger [7].

\subsection{5}

\section{Metodologia de acoplamento GTEP - PUC-Rio}

A metodologia de acoplamento iterativo descrita a seguir foi desenvolvida pelo Grupo de Geomecânica Computacional do GTEP, situado no campus da Pontifícia Universidade Católica do Rio de Janeiro (PUC-Rio). O projeto conta com a parceria da Petrobras e o objetivo principal da metodologia desenvolvida é a contribuição de maneira mais rigorosa e aplicada aos estudos dos efeitos geomecânicos provenientes da consideração de rochas adjacentes acopladas aos reservatórios ao longo do processo de depleção. 
A concepção teórica da metodologia de acoplamento parcial utilizada será apresentada resumidamente aqui com base nos trabalhos de Inoue et al. [2], Inoue \& Fontoura [4], Lautenschläger [7] e Albuquerque [5].

Albuquerque [5] demonstra em detalhes a construção do modelo geomecânico de simulação de um campo a partir de um pacote de programas integrados chamado Olympus Suite. Este pacote opera em ambiente GOCAD ${ }^{\odot}$, onde o fluxo de trabalho de análise geomecânica é desenvolvido por meio de um plugin, denominado Gaia (Figura 2.11). Neste ambiente, é possível gerar uma malha de elementos finitos, tanto para o reservatório como também para as rochas adjacentes, com base em um grid de diferenças finitas do reservatório. Por meio do plugin Gaia, ainda há a possibilidade de atribuir propriedades geomecânicas e tratamentos geométricos (suavização de pequenos rejeitos de falha e remoção de pinchouts, que são geologicamente identificados por estratos de rochas mais jovens em forma de cunha que se estendem progressivamente através de uma superfície cortada por rochas mais antigas), finalizando a fase de pré-processamento.

Com o fim do pré-processamento, inicia-se a fase de análise através do programa Hermes. O Hermes consiste de um programa de acoplamento fluidomecânico parcial, que realiza automaticamente um intercâmbio de parâmetros geomecânicos entre os modelos de fluxo e tensões a cada passo de tempo. Como descrito anteriormente, o acoplamento parcial faz uso de dois simuladores: um de fluxo em reservatórios, e outro, de análise de tensões. Para a análise de reservatórios, podem ser utilizados os simuladores comerciais IMEX ou ECLIPSE. A análise de tensões utiliza um programa desenvolvido pelo próprio GTEP/PUCRio denominado CHRONOS, que permite o uso do artifício de processamento em GPU (Graphics Processing Unit) para resolver a análise de tensões em elementos finitos.

O pacote Olympus Suite permite que sejam feitas análises tanto de forma explícita, quanto de forma iterativa. No acoplamento explícito, apenas o simulador de reservatórios envia pressões de poros para o simulador geomecânico. Como nenhuma informação é repassada pelo simulador geomecânico para o simulador de fluxo, a modificação no estado de tensões no reservatório e rochas adjacentes não interfere no problema de fluxo. Por outro lado, o método de acoplamento parcial interativo, focalizado nessa dissertação, apresenta as equações de fluxo e tensões sendo resolvidas separadamente e sequencialmente para cada intervalo de tempo. 
Dessa forma, as informações são trocadas no mesmo intervalo de tempo entre os simuladores de reservatório e geomecânico até alcançar a convergência de uma variável escolhida, como por exemplo, a pressão de poros.

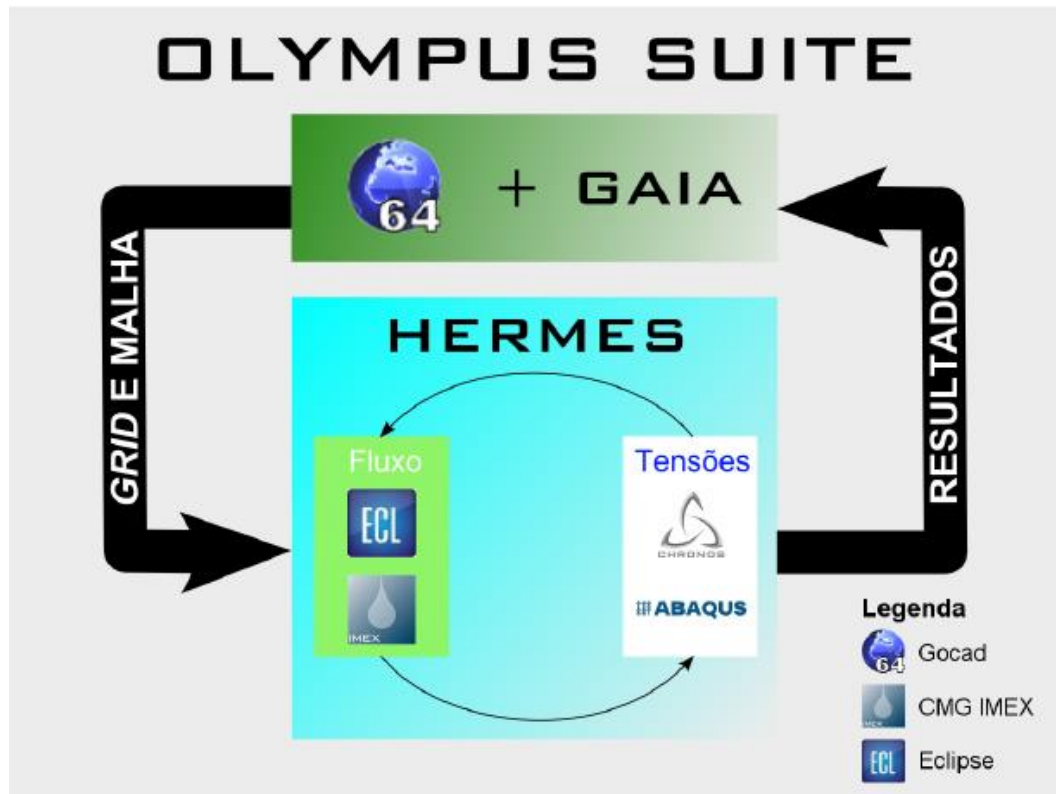

Figura 2. 11: Fluxo de processamento de dados no acoplamento parcial iterativo nos programas do pacote Olympus Suite (Adaptado de Albuquerque [5])

Inoue \& Fontoura [4] propõem um método de acoplamento iterativo que permite obter, a partir da simulação de fluxo convencional de reservatórios, uma resposta semelhante à equação de fluxo do acoplamento total.

Como pode ser visto na Figura 2. 10, comparando as equações de fluxo 2.80 e 2.88, lê-se que os termos $c_{f} \emptyset^{n} \partial p / \partial t$ e $k / \mu \nabla^{2} p$ são comuns em ambas as equações. Os autores propõem então a remoção do efeito da compressibilidade dos grãos da rocha $\left(c_{s}=0\right)$ da equação 2.88 , além da introdução do efeito da deformação volumétrica da rocha e dos poros, representado pelo termo $\partial \varepsilon_{v} / \partial t$ na equação de fluxo convencional.

Em função dos simuladores de fluxo e de tensões (exceto o CHRONOS) utilizados no acoplamento parcial iterativo serem originários de fontes comerciais, o acesso ao código-fonte não estava disponível. Tal fato gerou a necessidade de que a troca de informações entre os simuladores tivesse de ser realizada por um código externo. Dessa forma, a utilização de parâmetros de acoplamento adequados tornou-se uma necessidade com o objetivo de levar os efeitos da variação volumétrica à simulação de reservatórios. Ao mesmo tempo também buscava-se 
retornar ao simulador de tensões um resultado de pressões influenciado pelos efeitos geomecânicos.

Um dos parâmetros de acoplamento foi denominado pseudocompressibilidade $\left(c_{\text {pseudo }}\right)$, escrita em termos do diferencial de deformação volumétrica e pressão entre os intervalos de tempo e da porosidade inicial do sistema. Esse parâmetro, o qual é inserido no simulador de fluxo, substitui a compressibilidade de poros e é calculado a cada iteração através da equação 2.108. É preciso destacar, porém, que a pseudo-compressibilidade é apenas um parâmetro de acoplamento e não guarda relação física com o a compressibilidade de poros.

$$
c_{p}=\frac{\varepsilon_{v}^{n+1}-\varepsilon_{v}^{n}}{\emptyset^{n+1}\left(p_{i}^{n+1}-p_{i}^{n}\right)}
$$

A porosidade também é utilizada como parâmetro de acoplamento e reescrita a cada iteração, tomando por base também a análise do diferencial de deformação volumétrica.

$$
\emptyset^{n+1}=\emptyset^{n}+\alpha\left(\varepsilon_{v}^{n+1}-\varepsilon_{v}^{n}\right)+\frac{1}{Q}\left(p^{n+1}-p^{n}\right)
$$

Substituindo o parâmetro de Biot $Q$ pela equação 2.84 e lembrando a premissa de que os grãos da rocha são incompressíveis $\left(c_{s}=0\right)$, temos:

$$
\emptyset^{n+1}=\emptyset^{n}+\alpha\left(\varepsilon_{v}^{n+1}-\varepsilon_{v}^{n}\right)+c_{f} \emptyset^{n}\left(p^{n+1}-p^{n}\right)
$$

A Figura 2.12 ilustra o esquema de acoplamento parcial iterativo dentro de um intervalo de tempo usando a abordagem descrita acima. Ainda na Figura 2.12, $\bar{F}$ é o vetor de carregamentos nodais, [Q] é a matriz de acoplamento e $\bar{p}$ é o vetor de pressões de poros. 


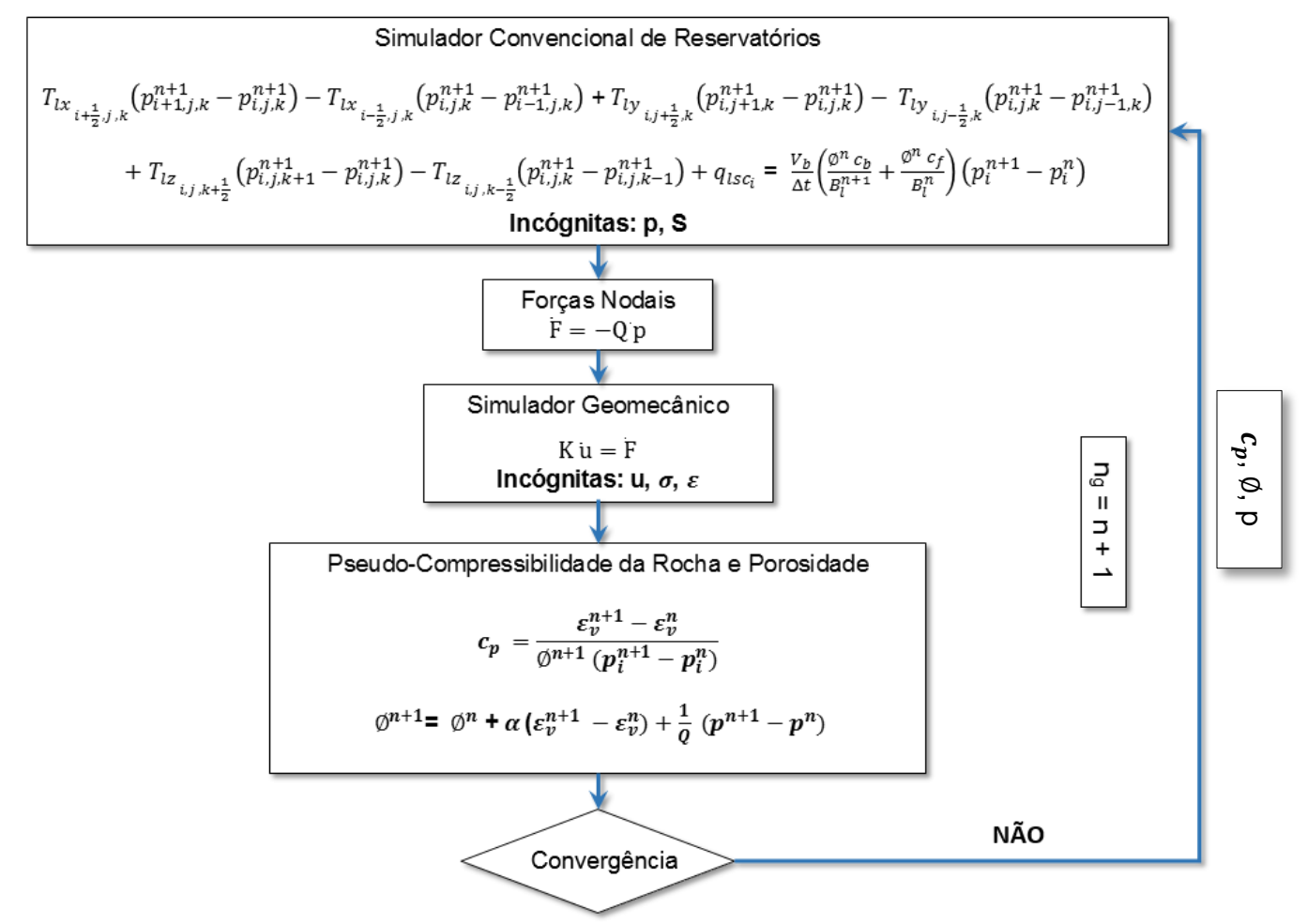

Figura 2. 12: Aproximação da equação de fluxo do simulador convencional de reservatórios através da pseudo-compressibilidade da rocha e da porosidade (adaptado de Inoue \& Fontoura [4]) para o caso isotérmico.

Segundo Lautenschläger [7], a pseudo-compressibilidade da rocha, a porosidade e a pressão de poros calculadas no final do intervalo de tempo devem ser reescritas no arquivo de entrada do simulador convencional de reservatórios. Ainda segundo o autor, se a análise é realizada utilizando o esquema de acoplamento parcial iterativo, a pressão de poros na equação da variação da porosidade deve ser a pressão de poros calculada no final do intervalo de tempo. No momento em que a análise convergir, ou seja, $p^{n+1}=p^{n}$ e $\emptyset^{n+1}=\emptyset^{n}$, é garantida uma solução única e consistente com o esquema de acoplamento total.

Segundo Lautenschläger [7], o critério de convergência adotado, mostrado na equação a seguir, mapeia as dez maiores diferenças de pressão de poros observadas no modelo e as compara individualmente com o valor obtido na iteração anterior, de acordo com o valor estabelecido para o critério.

$$
\frac{p_{i}^{n+1}-p_{i}^{n}}{p^{0}}<\text { convergência }
$$

Na equação, $p_{i}^{n+1}$ é a pressão de poros no passo de tempo $n+1$, $p_{i}^{n}$ é a pressão de poros no passo de tempo anterior $n$ e $p^{0}$ é a pressão de poros inicial. 
A fim de garantir a convergência, inicialmente é realizada uma simulação de reservatório para todo o tempo de análise, da qual os intervalos de tempo (definidos pelos critérios de convergência do simulador de fluxo e honrando o balanço de massa) serão armazenados para posterior utilização na análise parcialmente acoplada. Desta forma, evita-se que os intervalos de tempo sejam definidos pelo usuário, o que poderia causar incerteza quanto a convergência do problema de fluxo ou subdivisões indesejadas ao longo da simulação acoplada.

O Hermes, totalmente automatizado realiza a chamada dos programas de fluxo e análise de tensões, a leitura dos arquivos de saída e a escrita dos arquivos de entrada.

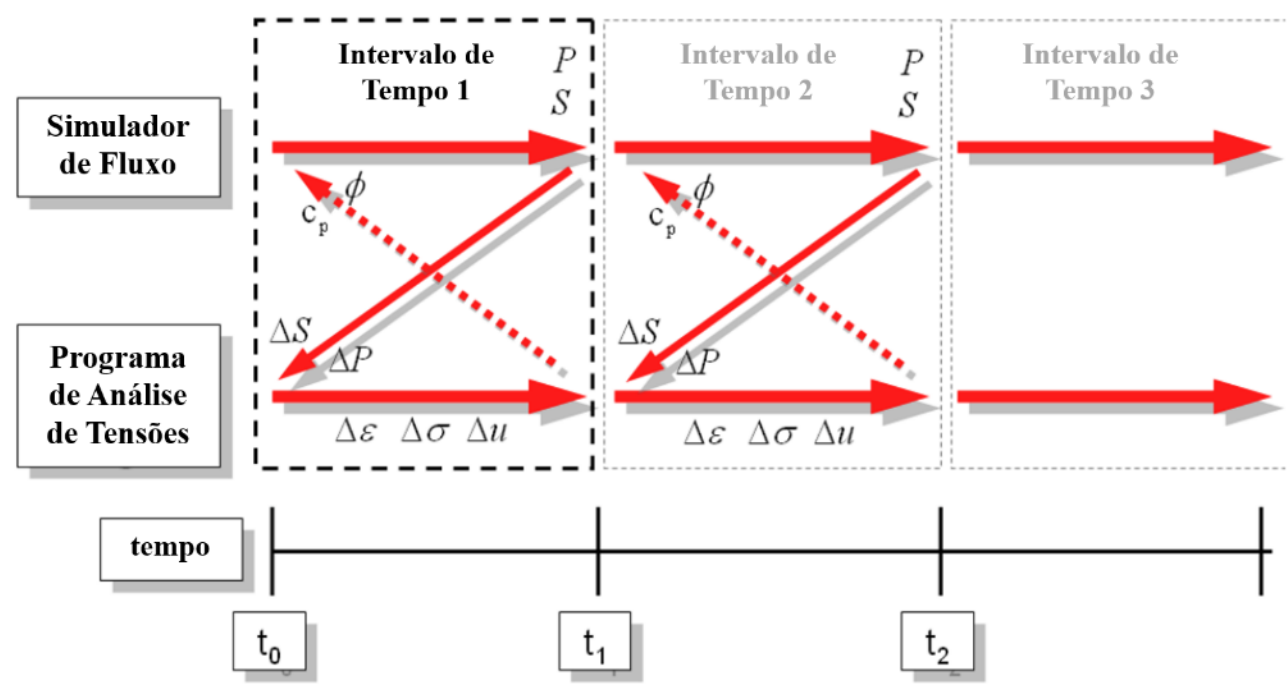

Figura 2. 13: Esquema de processos, realizados pelo Hermes, entre simulador de fluxo e programa de análise de tensões

Segundo Inoue \& Fontoura [4], a combinação de pseudo-compressibilidade e porosidade como parâmetros de acoplamento garante um procedimento muito robusto de acoplamento e que apresenta resultados bem próximos da solução totalmente acoplada. 


\section{3 \\ Medições diretas e indiretas dos módulos de elasticidade e compressibilidade}

Entende-se por medição um conjunto de operações que tem por objetivo determinar o valor de uma grandeza, ou seja, sua expressão quantitativa.

A medição direta é aquela cujo resultado é obtido diretamente dos dados experimentais. $\mathrm{O}$ valor da grandeza procurada é obtido comparando diretamente com padrões ou através de instrumentos de medida graduados segundo as unidades respectivas.

A medição indireta é aquela cujo resultado é obtido através de medições diretas de outras grandezas, ligadas por uma dependência conhecida com a grandeza procurada. São utilizadas quando é difícil medir diretamente a grandeza, ou quando a medição indireta produz resultados mais precisos.

A seguir, serão descritos superficialmente alguns métodos de medição direta de módulos elásticos. Já as medições indiretas serão mais detalhadas pelo fato de irem ao encontro dos objetivos propostos nesta dissertação.

\section{1}

Medição direta

O teste triaxial é um dos ensaios de laboratório mais utilizados para determinar propriedades de rocha para um grande intervalo de tensão e temperatura. A amostra deve apresentar preferencialmente o diâmetro de até 101,6 mm e não inferior a $47 \mathrm{~mm}$. Além disso, a relação entre o comprimento da amostra e o diâmetro pode variar de 2:1 a 2,5:1 (ASTM [28]).

O ensaio consiste na aplicação de um carregamento axial e de confinamento que é obtido por meio da aplicação de óleo sobre pressão na câmara triaxial, onde é colocada a amostra envolvida por uma membrana flexível e impermeável e selada no cap superior e inferior. Essa membrana permite que a rocha se deforme radialmente (Lobato [29]).

O conjunto, composto de amostra, membrana, caps, extensômetros radial e axial, é então colocado num pedestal. A tensão confinante é aplicada 
axissimetricamente e na vertical no cap superior. Posteriormente, uma força axial é aplicada na vertical no cap superior, pelo pistão, conforme Figura 3.1.

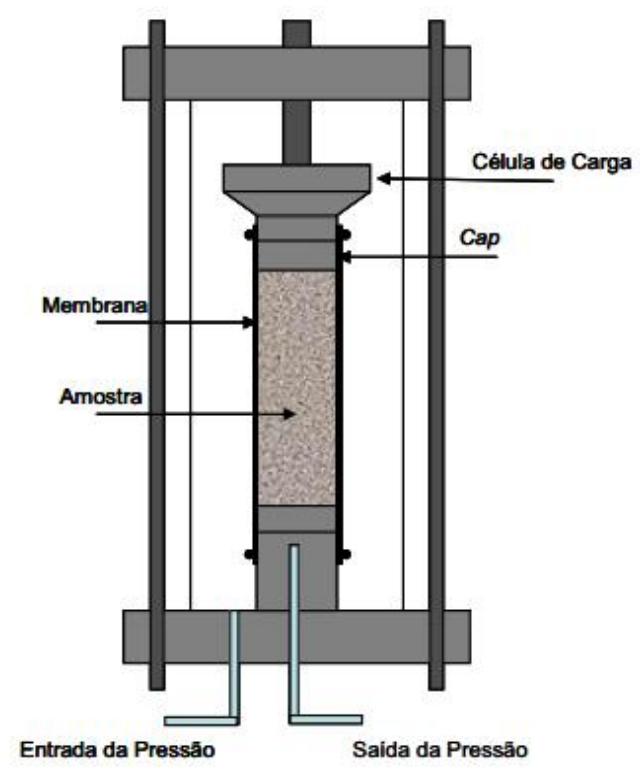

Figura 3. 1: Representação esquemática do ensaio triaxial. Adaptado de Lobato [29]

Durante o ensaio triaxial é realizada a aquisição dos seguintes dados ao longo do tempo: tensões desviadora e confinante, deformações axial e radial. A tensão desviadora é definida como a diferença entre a carga axial aplicada na amostra e a tensão confinante. Com estes dados calculam-se o coeficiente de Poisson e o módulo de Young para cada tensão confinante (Lobato [29]).

Para determinação de módulos de compressibilidade (bulk) da rocha, são realizadas principalmente medições hidrostáticas. Normalmente, a ruptura por cisalhamento não ocorre sob carga hidrostática, embora o esmagamento de grãos em arenitos possa induzir falhas em casos de altas tensões. Os testes hidrostáticos são realizados sob condições drenadas ou não-drenadas.

Em um experimento hidrostático drenado, o parâmetro mensurado é o módulo de compressibilidade da estrutura da amostra drenada $K_{D}$ por meio da inclinação da curva tensão-deformação volumétrica. Nesses testes, conhecidos como testes de compressibilidade com jaqueta, os canais através dos pistões ficam abertos para que a pressão de fluido dos poros seja mantida a qualquer valor desejado. Muitas vezes, as saídas são abertas à atmosfera, tornando a pressão (manométrica) de poros igual a zero. Nesse caso, as tensões efetivas serão semelhantes às tensões totais. Em testes com amostras de baixa permeabilidade, a condição drenada só é atingida se o 
experimento for realizado a uma velocidade suficientemente lenta que evite um acréscimo de pressão quando a amostra deforma.

Em um experimento hidrostático não-drenado, a pressão dos poros sofre mudanças durante o teste e a inclinação da curva de tensão-deformação será igual ao módulo de compressibilidade bulk saturado $\left(K_{\text {sat }}\right)$. Nos testes não-drenados os canais de saída estão fechados, de modo que os fluidos contidos nos poros não possam escapar. Em função disso, a variação na pressão confinante é repassada ao fluido.

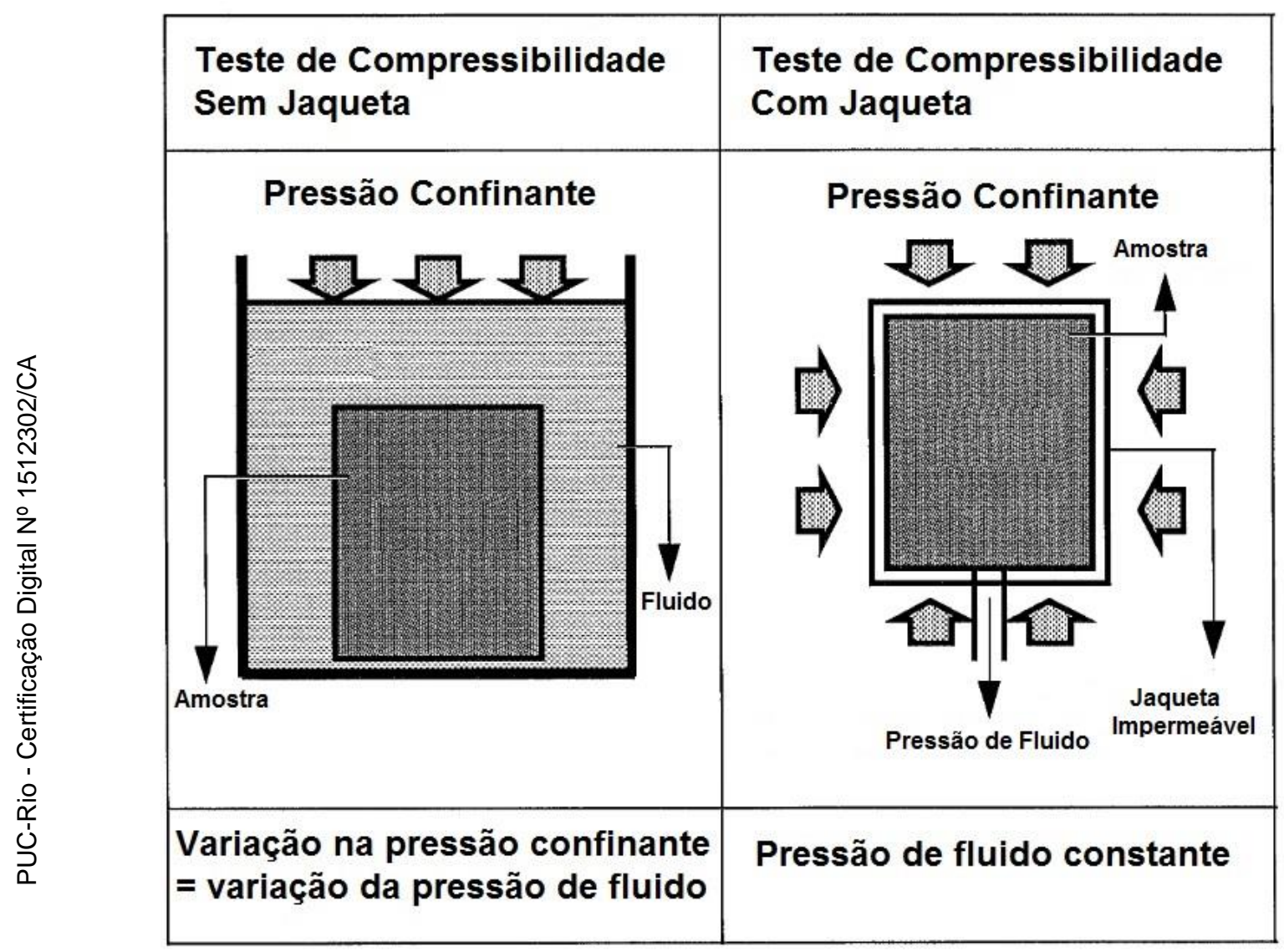

Figura 3. 2: Esquemas dos testes de compressibilidade com e sem jaqueta. Modificado de Chen et al. [30]

Segundo Detournay \& Cheng [14], as respostas drenadas e não drenadas também caracterizam os comportamentos instantâneos e de longo prazo do material poroelástico sob as condições particulares de um carregamento constante aplicado repentinamente. Considerando a resposta instantânea do material poroelástico como uma etapa do carregamento, logo após essa imposição de carga, o fluido do poro ainda não teve tempo hábil para se mover para elementos materiais vizinhos indicando que não houve mudança no conteúdo de fluido. Depois de um período 
de tempo maior, a pressão dos poros irá se equilibrar com a pressão de poros imposta na fronteira.

\section{2 \\ Medição indireta por meio de ondas compressionais e cisalhantes}

Ondas elásticas são perturbações mecânicas que se propagam através de um material. Tais ondas são capazes de viajar distâncias muito longas através da Terra e, portanto, podem trazer informações sobre formações que são inacessíveis em um primeiro momento. Logo, segundo Lacy [12], perfilagem sônica da formação e testes ultrasônicos de laboratório são baseados no mesmo princípio físico. Sua velocidade é dada pela rigidez elástica e pela densidade da formação. Tais parâmetros se relacionam também com a porosidade. Dessa forma, é proporcionado um método pelo qual dados podem ser estimados (Fjaer et al.[13]).

Neste sentido, a tarefa requer relacionar a resposta sísmica com a rocha, desde sua estrutura sólida e mineral, passando pelos fluidos nela presentes, além da capacidade de combiná-las. Um dos modelos mais amplamente usados para prever tal resultado é o modelo de Gassman. As equações a seguir fazem uso do módulo de compressibilidade bulk saturado, do módulo de cisalhamento e da densidade do meio em estudo para definir as velocidades compressional $\left(W_{p}\right)$ e de cisalhamento $\left(W_{S}\right)$.

$$
\begin{gathered}
W_{p}=\sqrt{\frac{K_{\text {sat }}+\frac{4}{3} G}{\rho}} \\
W_{S}=\sqrt{\frac{G}{\rho}}
\end{gathered}
$$

As equações acima são válidas apenas para um meio isotrópico a nível de célula do grid, homogêneo e totalmente saturado. Segundo Mavko et al.[31], as equações de Gassman são válidas apenas para frequências muito baixas nos quais a pressão de poros induzida está em equilíbrio em todo espaço poroso, permitindo que haja tempo suficiente para o fluido fluir e eliminar ondas induzidas por gradientes de poropressão. Essa é a justificativa do porquê dessas relações 
funcionarem melhor para dados sísmicos in situ $(<100 \mathrm{~Hz})$ e não reproduzirem tão bem perfilagens sônicas $\left(\approx 10^{4} \mathrm{~Hz}\right)$ e medições ultrasônicas de laboratório $\left(\approx 10^{6}\right.$ $\mathrm{Hz})$.

A análise conjunta das informações provenientes das ondas compressionais e das ondas cisalhantes é importante na fase de exploração do campo ao relacionar as características das rochas com os hidrocarbonetos e outros fluidos presentes. Dessa forma, por meio de testes ou simulações, correlações são obtidas e viabiliza-se uma melhor compreensão do comportamento dos dados em estudo. Duas relações entre as ondas compressionais e cisalhantes estão descritas a seguir:

$$
\begin{gathered}
\frac{W_{P}}{W_{S}}=\sqrt{\frac{K_{s a t}}{G}+\frac{4}{3}} \\
\frac{W_{P}}{W_{S}}=\sqrt{\frac{1-v}{\frac{1}{2}-v}}
\end{gathered}
$$

Segundo Fjaer et al. [13], as velocidades das ondas dependem explicitamente dos módulos elásticos, como visto nas equações acima. Tais relações implicam que, por exemplo, deveria-se obter o mesmo valor para o módulo de Young $(E)$ com a utilização das velocidades acústicas e da densidade por meio da equação mostrada abaixo, ou por meio da mensuração da tensão e deformação em um teste de compressão triaxial. A partir disso, seria possível obter o módulo de Young, mesmo se não houvesse a possibilidade de realizar ensaios mecânicos de rocha. Entretanto, não é o que acontece.

$$
E=\rho W_{S}^{2} \frac{3 W_{P}^{2}-4 W_{S}^{2}}{W_{P}^{2}-W_{S}^{2}}
$$

Ainda segundo o autor, há uma vasta gama de evidências experimentais mostrando que os módulos elásticos estáticos (obtidos a partir de medições de tensão e deformação em uma rocha por ensaio mecânico) diferem significativamente dos módulos elásticos dinâmicos (obtidos a partir de velocidades acústicas e densidade definidas por perfilagem, por exemplo). Geralmente, os módulos dinâmicos tendem a ser maiores do que os estáticos correspondentes. A diferença é mais significativa em rochas pouco rígidas. 
Segundo Lacy [12], as seguintes equações podem ser usadas para calcular módulos de Young e coeficiente de Poisson dinâmicos:

$$
\begin{gathered}
v_{D}=\frac{W_{P}^{2}-2 W_{S}^{2}}{2\left({W_{P}}^{2}-{W_{S}}^{2}\right)} \\
E_{D}=\rho W_{P}^{2} F(v) \\
F(v)=\left[\frac{(1-2 v)(1+v)}{1-v}\right]
\end{gathered}
$$

A equação 3.6 define que o coeficiente de Poisson dinâmico depende apenas das velocidades das ondas compressionais e cisalhantes. Já o módulo de elasticidade dinâmico é uma função do Poisson, da velocidade da onda compressional e da densidade do meio. Ainda segundo Lacy [12], apesar dessas equações serem baseadas na teoria da elasticidade linear, quando o coeficiente de Poisson se aproxima de seu limite teórico de 0,5, por exemplo, em arenitos inconsolidados ou poucos consolidados, $F(v) \rightarrow 0$. Tal fato leva o módulo de Young a valores baixos e caracteriza um material não-linear, compressível e inelástico. No outro sentido, à medida que o coeficiente de Poisson se aproxima de zero em rochas rígidas e de baixa porosidade, $F(v) \rightarrow 1$ e a rocha é linear e elástica.

$\mathrm{Na}$ modelagem geomecânica, recomenda-se a utilização de parâmetros elásticos estáticos. Como os dados elásticos obtidos por sísmica e perfilagem são considerados dinâmicos, torna-se necessário transformá-los em valores estáticos. Lacy [12] realizou testes dinâmicos, estáticos uniaxais e triaxiais para 600 amostras de 60 formações distintas. Por meio de seu trabalho, conseguiu comparar módulos de Young dinâmicos e estáticos para diferentes tipos de rochas e construiu correlações que permitem corrigir dados dinâmicos para seus respectivos valores estáticos.

A Figura 3. 3 traz a correlação obtida por Lacy [12] para arenitos e que pode ser resumida pela equação 3.9 com coeficiente de correlação aproximado de 0,74. Os módulos de Young estão na unidade Mpsi.

$$
E_{S}=0,0293 E_{D}^{2}+0,4533 E_{D}
$$




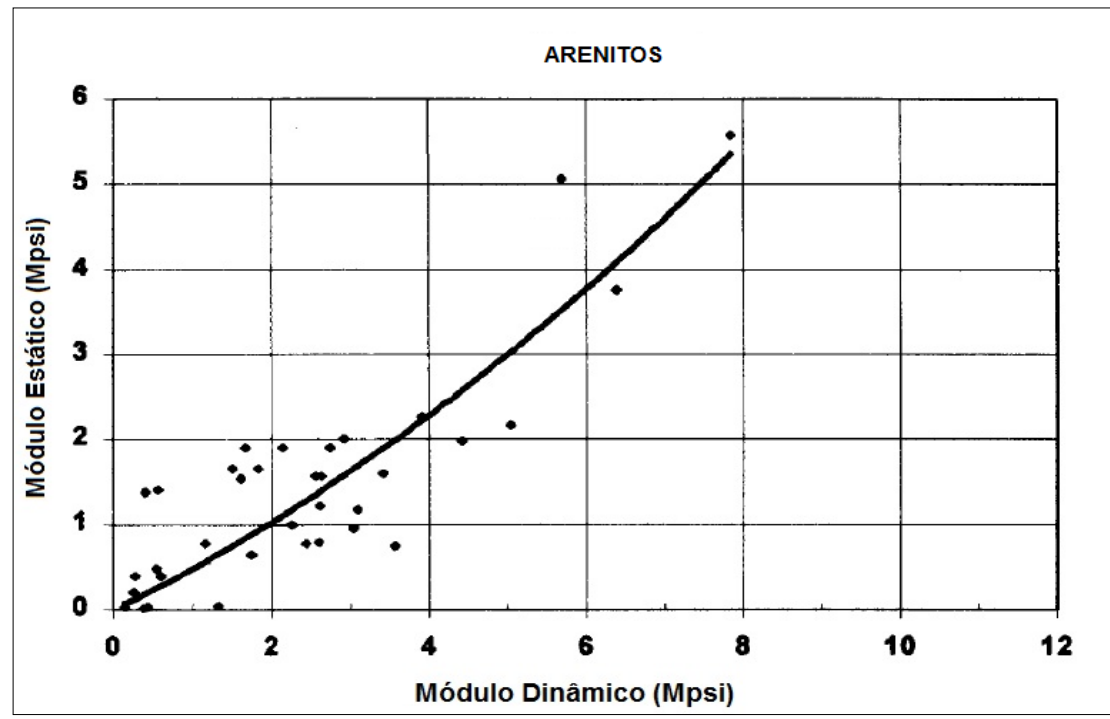

Figura 3. 3: Correlação entre módulos de Young estáticos e dinâmicos para arenitos.

Lacy [12] também obteve uma correlação para folhelhos, mostrada na Figura 3.4. O ajuste da equação em relação aos pontos experimentais para essa litologia é bem mais alto e é igual a 0,926 . A correlação é mostrada na equação a seguir:

$$
E_{S}=0,0428 E_{D}^{2}+0,2334 E_{D}
$$

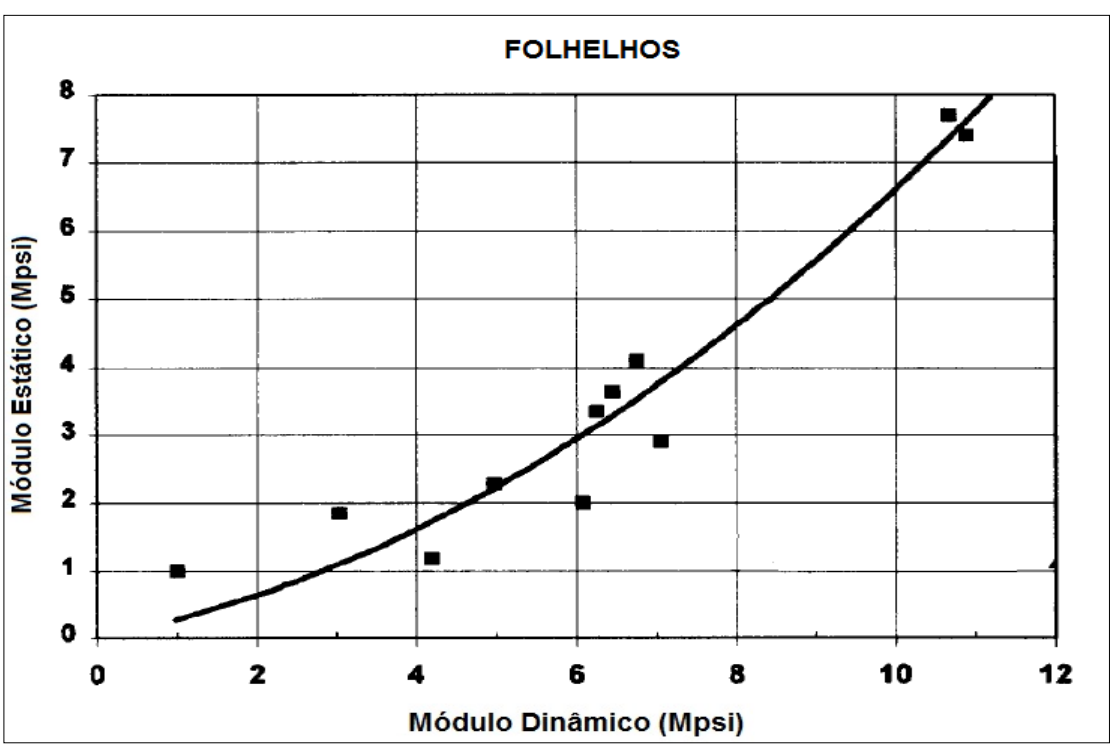

Figura 3. 4: Correlação entre módulos de Young estáticos e dinâmicos para folhelhos.

O autor não apresenta a correlação específica para carbonatos, mas apresenta uma equação mais geral que pode ser usada para todos os tipos de litologias e está apresentado a seguir:

$$
E_{S}=0,0180 E_{D}^{2}+0,422 E_{D}
$$




\section{3 \\ Medição indireta por meio de perfis}

De acordo com Nery [32], as rochas podem ser identificadas em função de suas propriedades elétricas (condutividade elétrica, polarização induzida, constante dielétrica), acústicas (velocidade de propagação ou tempo de trânsito de ondas elásticas compressionais ou cisalhantes), radioativas (radioatividade natural ou induzida), mecânicas, térmicas. Esses dados podem ser obtidos através dos sinais registrados pelos sensores do equipamento de perfilagem e possibilitam que outras propriedades petrofísicas sejam inferidas.

Como já discutido no Capítulo 1, não são encontrados em grande profusão trabalhos que tragam um workflow completo que permita calcular módulos elásticos a partir de perfis, principalmente para perfis não-sísmicos. Normalmente, trabalhos nas áreas de Geofísica e Geologia estão preocupados em obter correlações estratigráficas para compreensão da distribuição das litologias nos ciclos deposicionais, determinar eletrofácies através de perfis geofísicos, descrever os testemunhos obtidos e realizar a caracterização petrofísica. Dessa forma, a partir dos trabalhos de Nery [32], Côrte [33], Passarella [34], Rosa et al. [35], Borges [36] e Cruz [37] é possível obter informações como o volume de argila, porosidades total e efetiva, permeabilidade, identificação de litologias e fluidos com suas respectivas saturações.

Por outro lado, trabalhos que envolvem a modelagem petroelástica para cálculo de impedâncias acústicas, trabalhos de gerenciamento de produção em reservatórios ou ainda de acoplamento geomecânico utilizam dados de entrada já organizados na forma de modelos de fluxo. Significa dizer que há grande detalhamento de porosidade, permeabilidade absoluta e relativa, saturação e tabelas PVT dos fluidos. Entretanto, estão, na maior parte das vezes, ausentes dados de densidade da rocha, mineralogia e argilosidade que são dados cruciais na determinação dos módulos de Young e coeficientes de Poisson para a litologia local. Um workflow que exemplifica essa situação está disponível na Figura 3.5, adaptada do trabalho de Emerick et al. [38]. Significa dizer que o autor já obteve os dados tratados pelo setor de geofísica e petrofísica. Na prática, a dificuldade de obtenção de um workflow completo desde os perfis até os módulos elásticos é uma 
questão de setorização da indústria do petróleo. Os trabalhos acadêmicos acabam por refletir a questão de prioridade e ênfase a que cada área se ocupa.

Em função disso, a criação de um workflow que garantisse os objetivos desta dissertação, envolveu a pesquisa e apuração de equações e correlações de diversos trabalhos a fim de complementar as lacunas que, eventualmente, surgiram ao longo de sua elaboração. Entre os trabalhos envolvidos nesse processo, além dos autores citados anteriormente, estão: Gonzalez [39], Souza et al. [40], Rosa [41], Souza [42] e Castagna et al. [43].

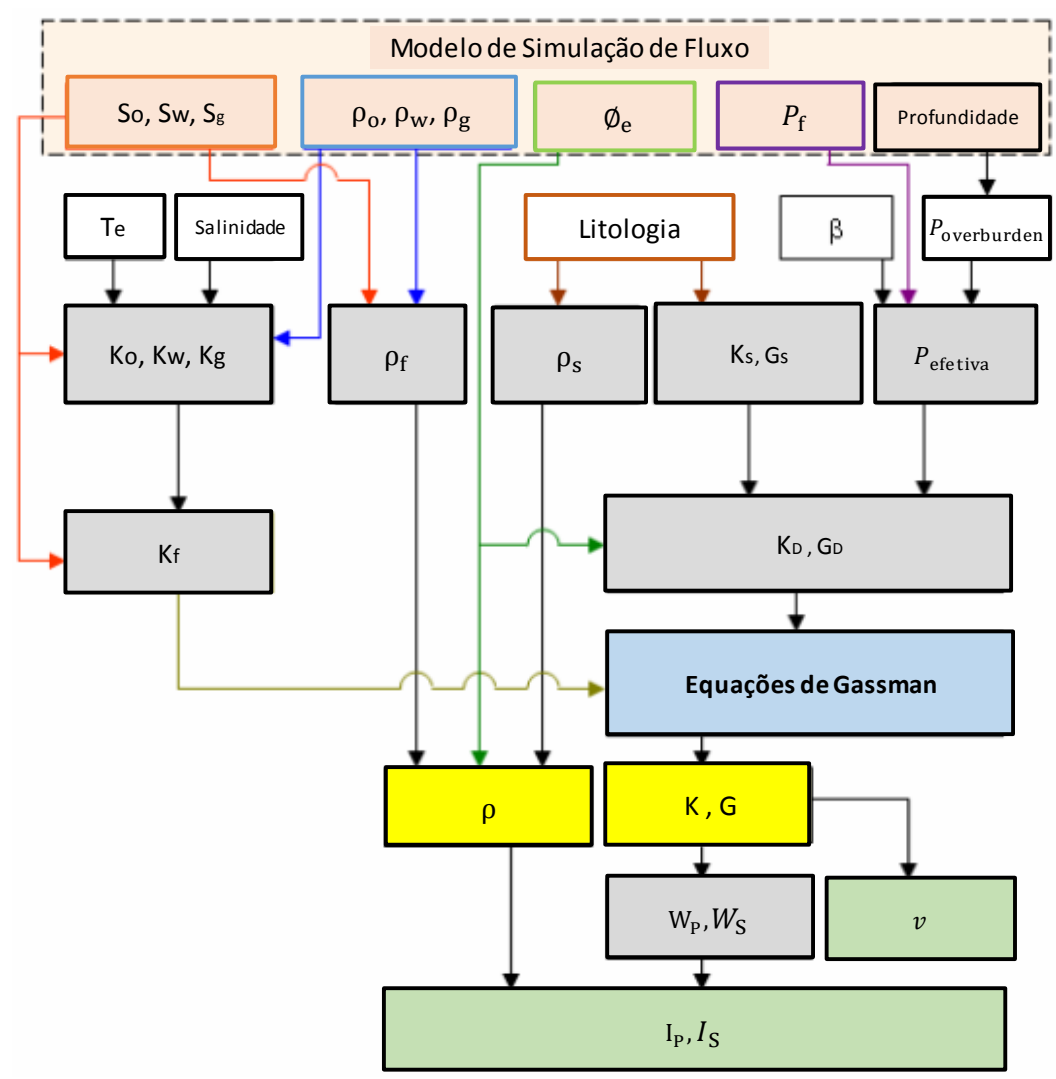

Figura 3.5: Workflow para modelo petroelástico Adaptado de Emerick et al. [38].

O resultado de toda a pesquisa é retratado em dois fuxogramas e apresentados no Apêndice A. A Figura A.1 elenca o fluxo de informações desde a obtenção dos dados gerados pelos perfis e dados proveninentes da bibliografia tais como frações volumétricas de cada mineral constituinte da litologia, com suas respectivas densidades e módulos de compressibilidade e cisalhamento. A partir desses dados de entrada, várias outras propriedades são calculadas até que se chegue a valores de módulos de compressibilidade e de cisalhamento saturados das fácies definidas ( $K_{S}$ e $G_{S}$, respectivamente), assim como dos fluidos $\left(K_{f}\right)$. 
NaFigura A.2, por meio dos dados de porosidade, $K_{S}, G_{S}, K_{f}, G_{f}$ e porosidade calculados no primeiro workflow são mostradas as relações para encontrar as compressibilidades, módulo de Young, coeficiente de Poisson e parâmetro de Lamè. As equações que sustentam a constituição desses fluxogramas estão apresentadas neste Capítulo e também no Capítulo 2. Os resultados gerados e que serão incorporados à simulação parcialmente acoplada serão detalhamente expostos no Capítulo 4.

\subsection{1}

\section{Determinação de $K_{S}$ e $G_{S}$}

$\mathrm{Na}$ ausência de amostras para a realização de ensaios mecânicos, há uma alternativa que permite definir os módulos elásticos de uma mistura de minerais por meio de uma abordagem de limites teóricos. Tais limites definem um range de valores que determina propriedade da mistura pode possuir e leva em conta as frações volumétricas de cada componente constituinte da rocha.

Para a determinação dos módulos elásticos de uma rocha constituída de diferentes minerais e/ou fluidos é preciso especificar:

- as frações volumétricas ocupadas por cada componente;

- os módulos elásticos de cada componente;

- os detalhes geométricos de como os componentes estão arranjados no sistema.

Para determinação das frações volumétricas ocupadas por cada componente é necessário o conhecimento da composição mineral da matriz sólida. De posse dessa informação é possível, por exemplo, determinar o módulo de incompressibilidade da fase sólida $\left(K_{S}\right)$ ao realizar também uma estimativa do volume de argila da rocha $\left(V_{s h}\right)$. Os valores de argilosidade são apresentados em percentual, sendo 0\% para uma rocha livre de argila (rocha limpa) e 100\% para um folhelho "puro". Esse dado pode ser adquirido via perfil de raios gama com o cálculo do índice de raios gama $\left(I_{G R}\right)$. O comportamento do perfil de gamma ray em função do tipo de rocha pode ser observado na Figura 3. 6.

$$
I_{G R}=\frac{G R_{\log }-G R_{\text {min }}}{G R_{\text {max }}-G R_{\text {min }}}
$$

Onde: 
$G R_{l o g}$ é o valor de raio gama lido na formação;

$G R_{\min }$ é o valor de raio gama mínimo lido num arenito "limpo" ou carbonato da formação;

$G R_{\max }$ é o valor de raio gama máximo lido numa seção de folhelho da formação.

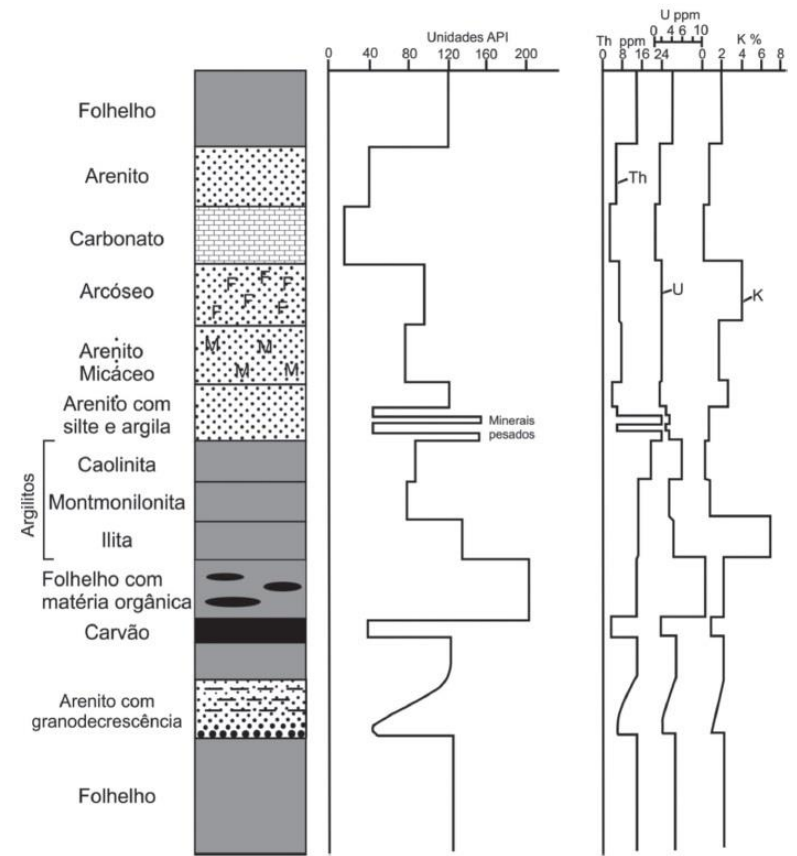

Figura 3. 6: Assinaturas gamaespectométricas típicas dos principais litotipos sedimentares (Adaptado de Rider, 1990)

Segundo a literatura, a determinação da argilosidade a partir do perfil de raios gama, depende de muitos fatores como, por exemplo, a idade dos sedimentos e sua consolidação. Modelos empíricos foram formulados por Larionov, em 1969, para tal estimativa em sedimentos com idades terciárias e mesozóicas. A equação a seguir, descreve a estimativa da argilosidade em arenitos não-consolidados de idade terciária.

$$
V_{s h}=0,083\left[2^{3,7 I_{G R}}-1,0\right]
$$

Para arenitos consolidados de idade mesozóica é aplicada a equação 3.14.

$$
V_{s h}=0,33\left[2^{2 I_{G R}}-1,0\right]
$$

Em 1977, outra relação foi proposta por Clavier et al.[44]:

$$
V_{s h}=1,70-\sqrt{3,38-\left(I_{G R}+0,70\right)^{2}}
$$


$\mathrm{Na}$ ausência de detalhes geométricos, não é possível determinar os valores exatos para os módulos elásticos da totalidade da rocha, porém é possível obter limites máximos e mínimos para estes valores (Mavko et al. [31]). A equação do limite mínimo de Reuss descreve exatamente o módulo elástico de uma suspensão de grãos não interconectados, ou seja, com a menor resistência possível a movimentos mecânicos.

$$
\frac{1}{M_{R}}=\sum_{i=1}^{n} \frac{f_{i}}{M_{i}}
$$

Onde $M$ representa qualquer módulo elástico que se deseja definir, $f$ é a fração volumétrica do mineral presente e $i$ é o índice da fração.

Excluindo os sistemas monofásicos, não existem sistemas físicos reais que sejam tão rígidos quanto o limite máximo de Voigt $\left(M_{V}\right)$ (Mavko et al. [31]) definido por:

$$
M_{V}=\sum_{i=1}^{n} f_{i} M_{i}
$$

Segundo Côrte [33], como os modelos de física de rochas usualmente assumem uma matriz homogênea, é apropriado assumir uma média geral para toda a rocha. Em virtude disso, é utilizada a média de Voigt-Reuss-Hill $\left(M_{V R H}\right)$, que se dá por uma média simples entre os valores obtidos pelos limites máximo e mínimo. Portanto, essa média é bastante útil quando se necessita de uma aproximação para os valores dos módulos e, não somente, os limites.

$$
M_{V R H}=\frac{1}{2}\left(M_{V}+M_{R}\right)
$$

Levando em consideração um sistema formado basicamente de quartzo e argila, podemos relacionar seus módulos de compressibilidade $\left(K_{S_{\text {quartzo }}}=38 \mathrm{GPa}\right.$ e $K_{S_{\text {argila }}}=20,9 \mathrm{GPa}$ ) com o limite mínimo de Reuss, máximo de Voigt e a média de Voigt-Reuss-Hill, como mostra a figura a seguir. Para cada fração de argila e quartzo, obtemos o range teórico do módulo de compressibilidade bulk $\operatorname{mineral}\left(K_{S}\right)$. 


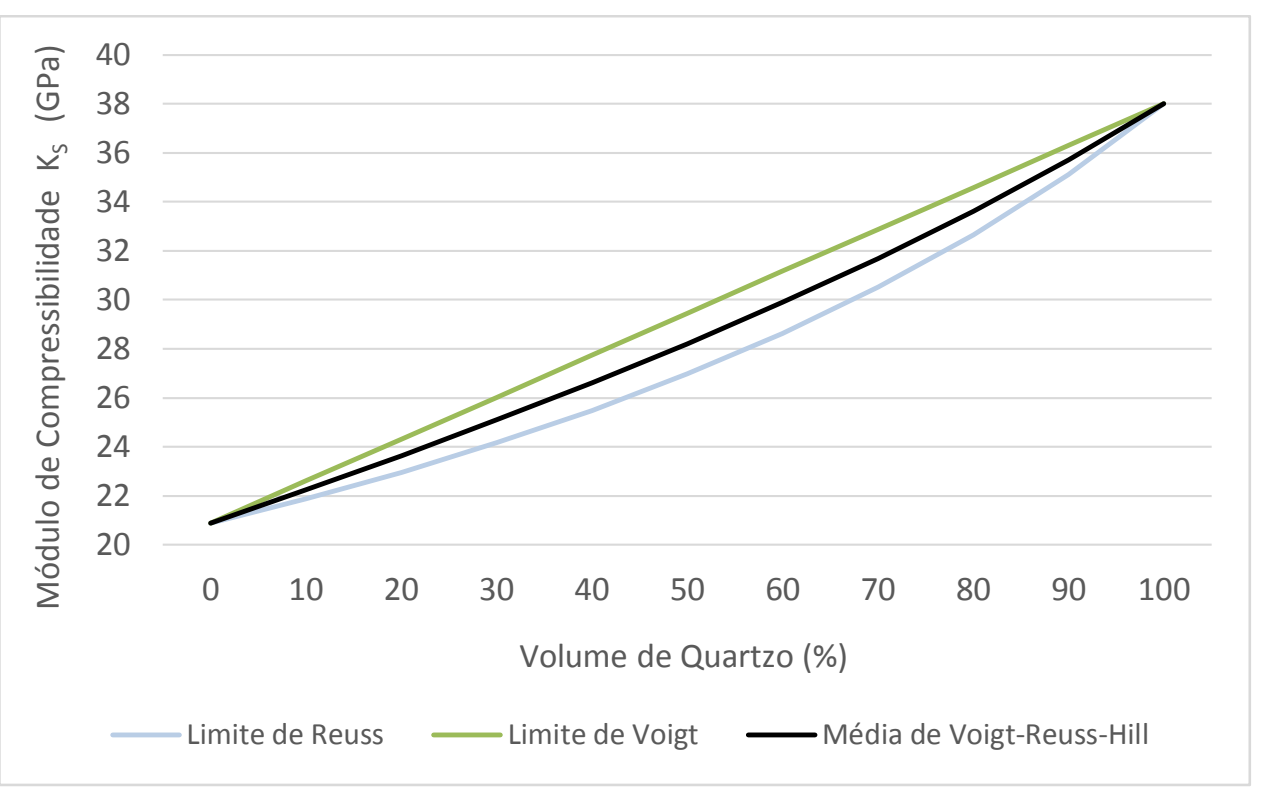

Figura 3. 7: Limites de Reuss, Voigt e média de Voigt-Reuss-Hill para módulo de compressibilidade em um sistema hipotético formado de argila e quartzo.

Hashin e Shtrikman [45] desenvolveram um estudo aplicando princípios variacionais à teoria de elasticidade de sólidos, para derivar os limites para uma janela de incerteza mais estreita. Os limites superior e inferior dos módulos de compressibilidade mineral e de cisalhamento são definidos como:

$$
\begin{gathered}
K^{H S \pm}=K_{1}+\frac{f_{2}}{\left(G_{2}-G_{1}\right)^{-1}+f_{1}\left(K_{1}+\frac{4}{3} G_{1}\right)^{-1}} \\
G^{H S \pm}=G_{1}+\frac{f_{2}}{\left(G_{2}-G_{1}\right)^{-1}+\frac{2 f_{1}\left(K_{1}+2 G_{1}\right)}{5 G_{1}\left(K_{1}+\frac{4}{3} G_{1}\right)}}
\end{gathered}
$$

O limite máximo (HS+) insere nos subscritos 1, a propriedade do material mais rígido, enquanto que o índice 2 refere-se ao material de menor rigidez. Para o limite mínimo (HS-) é necessário que se inverta os índices. As equações acima são utilizadas quando há somente dois minerais misturados e o mineral mais rígido possui tanto o módulo de compressibilidade como o de cisalhamento maiores que o segundo. $\mathrm{O}$ valor final do módulo pode ser calculado pela média aritmética dos limites superior e inferior, assim como a média de Voigt-Reuss-Hill.

A figura abaixo exemplifica os limites acima citados, para um sistema composto de calcita e argila. Qualquer mistura desses grãos cairá entre os limites 
gerados, porém sem informações de como ocorre a conexão dos grãos, não é possível determinar o exato valor dentro desses limites.

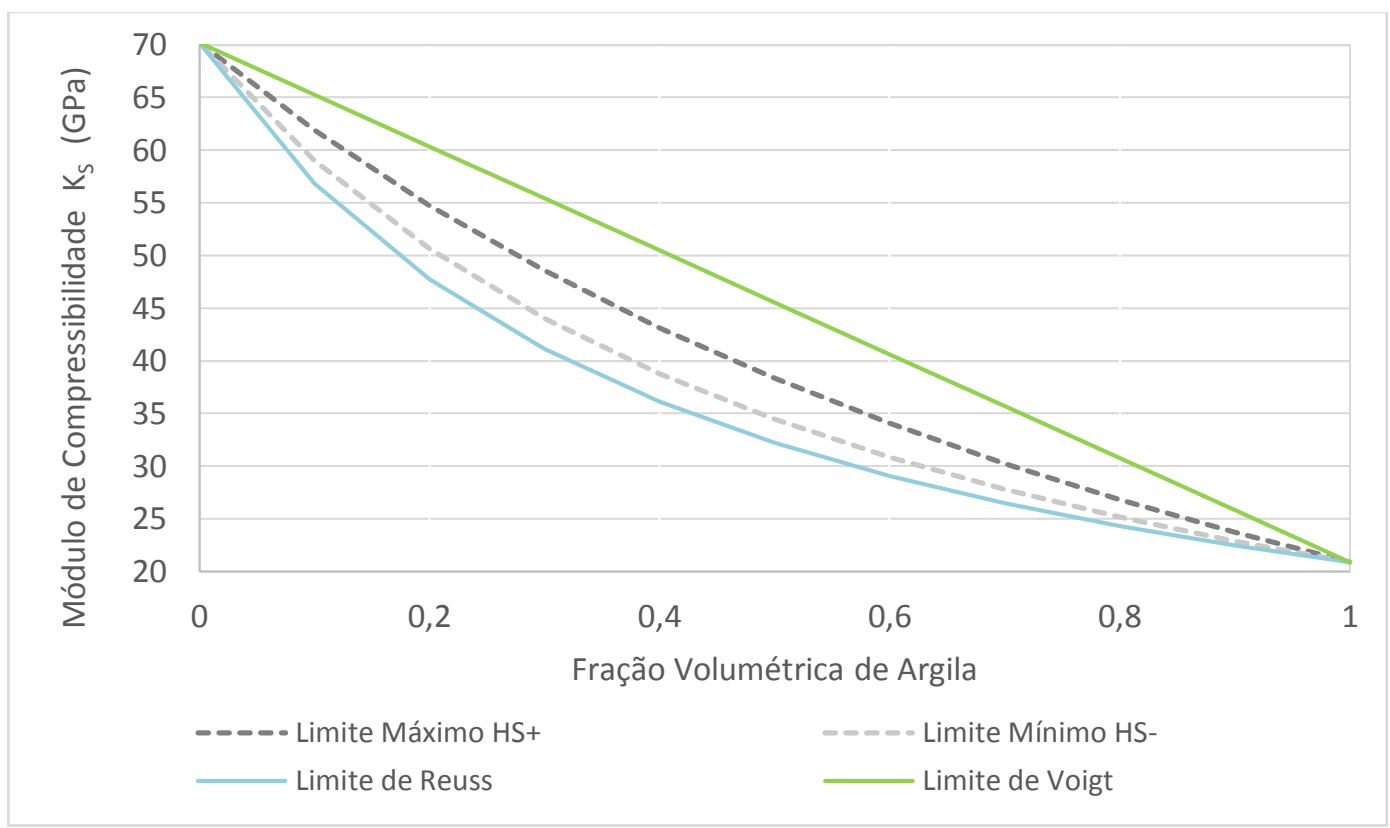

Figura 3. 8: Limites de módulo de compressibilidade de Reuss, Voigt e de Hashin-Shtrikman para um sistema hipotético formado de argila e calcita.

\subsection{2 \\ Determinação de $\boldsymbol{K}_{\boldsymbol{f}}$}

Da mesma forma que na determinação do $K_{S}$, o conhecimento da composição da rocha era necessário, para definir o valor do módulo de compressibilidade do fluido $\left(K_{f}\right)$ é também imprescindível determinar a fração de água e hidrocarbonetos presentes no ambiente rochoso. Para alcançar esse objetivo pode ser utilizado o perfil de resistividade.

Segundo Nery [32], o perfil de resistividade é um perfil elétrico que mede a resistividade da formação, ou seja, sua resistência à passagem do fluxo de uma corrente elétrica. A mensuração da resistividade da formação é um dos métodos introdutórios de identificação do fluido no reservatório e no cálculo de saturação de água $\left(S_{w}\right)$. Tal fato é possível porque os hidrocarbonetos são maus condutores e causam o aumento da resistividade medida da rocha. Se os poros são preenchidos por água, ao contrário, a resistividade é menor. Os valores de resistividade também dependem da litologia e da granulometria da formação.

A relevância da estimativa dos fluidos presentes em um reservatório fez com que diversos pesquisadores desenvolvessem ao longo dos anos modelos que 
pudessem estimar a saturação de água nas formações. Archie [46] foi um dos precursores elaborando equações que são utilizadas até hoje em muitos estudos. Tais equações fazem uma associação para formações limpas (sem presença de argila) entre a resistividade da formação, a resistividade da água de formação, a porosidade total da rocha e a saturação de água conata, como pode ser visto a seguir.

$$
S_{w}=\sqrt[n]{\frac{a R_{w}}{\emptyset_{e}^{m} R_{T}}}
$$

O coeficiente $m$, relativo à cimentação tem estimativa empírica e, através da análise de diferentes amostras, foram obtidos valores que variam entre 1,8 e 2,0 para arenitos consolidados e um valor de 1,3 para os inconsolidados. Por sua vez, Archie [46] estabeleceu que o valor do expoente $n$ é igual a 2 quando a rocha analisada é um arenito consolidado ou inconsolidado. A equação também é composta pelo coeficiente litológico $a, R_{w}$ é a resistividade da água e $R_{T}$ é a resistividade total da formação.

Todavia, tal formulação não pode ser aplicada no caso de formações argilosas porque geraria valores superestimados para a saturação de água. A argila também é responsável pela diminuição da porosidade e da permeabilidade de um reservatório. Portanto, equações adicionais foram desenvolvidas posteriormente considerando o volume de argila como fator de correção. Desta forma, a saturação de água para reservatórios argilosos é calculada pela equação 3.22, sugerida por Fertl \& Hammack em 1971.

$$
S_{w}=\sqrt[n]{\frac{a R_{w}}{\emptyset_{e}^{m} R_{T}}}-\frac{V_{s h} R_{w}}{0,4 R_{s h} \emptyset_{e, s h}}
$$

onde $R_{s h}$ é a resistividade de um folhelho adjacente com GR máximo e $\emptyset_{e, s h}$ é a porosidade efetiva corrigida pela presença de argila, descrita pela equação 3.29.

A saturação de água em arenitos argilosos também é mensurada pela equação Nigéria como foi proposto por Al-Waheed e Ruwaili em 2005.

$$
S_{w}=\sqrt[n]{\frac{1}{R_{T}\left[\sqrt{\frac{\emptyset_{e}{ }^{m}}{R_{w}}}+\sqrt{\frac{V_{s h}{ }^{2,8}}{R_{s h}}}\right]^{2}}}
$$


De posse da saturação de água e da saturação de hidrocarbonetos, é possível definir o módulo de compressibilidade $K_{f}$. A modelagem deste cenário geralmente é feita substituindo o conjunto de fases por um único fluido equivalente ou fluido efetivo. Tal modelo assume que as diferentes fases do fluido (óleo, gás e água) estão uniformemente misturadas para uma microescala dentro do espaço poroso. Isso permite calcular a incompressibilidade através de uma média harmônica, também conhecida como equação de Domênico:

$$
K_{f}=\left(\sum_{i=1}^{n} \frac{S_{i}}{K_{f_{i}}}\right)^{-1}
$$

onde $K_{f_{i}}$ é o módulo de incompressibilidade de cada fase fluida e $S_{i}$ é a saturação da respectiva fase.

Para um sistema simples, composto por duas fases (água e óleo), a equação se torna:

$$
K_{f}=\left[\frac{S_{w}}{K_{w}}+\frac{\left(1-S_{w}\right)}{K_{\text {óleo }}}\right]^{-1}
$$

\subsection{2 \\ Determinação do $K_{\text {sat }}$}

Como descrito no capítulo anterior, o módulo bulk saturado $\left(K_{\text {sat }}\right)$ pode ser definido pelos módulos de compressibilidade das fases sólida $K_{S}$ e fluida $K_{f}$ relacionando-as à porosidade. Observe que a equação a seguir é semelhante à equação que define o limite mínimo de Reuss (equação 3.16).

$$
\frac{1}{K_{s a t}}=\frac{1-\emptyset}{K_{S}}+\frac{\emptyset}{K_{f}}
$$

Neste trabalho também será usado o limite de Voigt para o cálculo da média de Voigt-Reuss-Hill do $K_{\text {sat }}$, chegando à seguinte equação:

$$
K_{\text {sat }}=\frac{\left((1-\emptyset) K_{S}+\emptyset K_{f}\right)+\left(\frac{\emptyset}{K_{f}}+\frac{1-\emptyset}{K_{S}}+\frac{\emptyset}{K_{f}}\right)^{-1}}{2}
$$


A porosidade pode ser obtida indiretamente por meio do perfil de densidade da formação (RHOB). A justificativa se encontra no fato de que nessa perfilagem é possível registrar continuamente as variações de densidade correspondentes não só aos minerais formadores das rochas e seus respectivos volumes, mas também aos fluidos presentes no poros e fraturas das mesmas. Com o conhecimento da densidade da matriz sólida $\left(\rho_{s}\right)$ e dos fluidos $\left(\rho_{f}\right)$, a porosidade é obtida como mostrado a seguir:

$$
\emptyset=\frac{\rho_{s}-\rho_{b}}{\rho_{s}-\rho_{f}}
$$

Para casos de arenitos argilosos, recorre-se a uma expressão que considera o volume de argila $\left(V_{s h}\right)$, calculado pela equação 3.15, como fator de correção. Desta forma, a porosidade efetiva para reservatórios argilosos calculada a partir do perfil densidade é dada por:

$$
\emptyset_{e, s h}=\left(\frac{\rho_{s}-\rho_{b}}{\rho_{s}-\rho_{f}}\right)-V_{s h}\left(\frac{\rho_{s}-\rho_{s h}}{\rho_{s}-\rho_{f}}\right)
$$

Onde $\rho_{s h}$ é a densidade do perfil RHOB medido num ponto de folhelho com GR máximo. 


\section{4. \\ Construção do Modelo Geomecânico}

Neste capítulo, encontra-se a apresentação detalhada do campo escolhido para estudo. A descrição encontrada nas próximas páginas também inclui as rochas adjacentes utilizadas no modelo geomecânico criado, com a definição das propriedades das litologias que compõem a simulação. Todos esses dados foram obtidos por meio de métodos indiretos, descritos no Capítulo 3, com o objetivo de trazer maior nível de acurácia e detalhamento à simulação acoplada. Além disso, é apresentado o workflow para preenchimento da malha de elementos finitos com propriedades mecânicas, proposto por Albuquerque [5] e que compõe a metodologia de acoplamento utilizada pelo GTEP/PUC-RIO introduzida no Capítulo 2.

Os resultados expostos aqui também serão a base das premissas utilizadas na composição dos novos cenários apresentados no Capítulo 5.

\section{1.}

\section{Campo de Namorado}

O Campo de Namorado localiza-se na Bacia de Campos, a $80 \mathrm{~km}$ da costa do Estado do Rio de Janeiro e foi perfurado pela primeira vez em 1975. Com uma área de $23 \mathrm{~km}^{2}$, é um dos campos de petróleo mais importantes desta bacia na área da plataforma continental brasileira. Está sob uma lâmina d'água que varia de 140 a $250 \mathrm{~m}$ (Morais [47]) e apresenta reservatórios formados por arenitos, encontrados em profundidades que variam entre $2.850 \mathrm{~m}$ e $3.400 \mathrm{~m}$.

Winter et al. [48] elaboraram a última versão da carta estratigráfica da Bacia de Campos (Figura 4.1), na qual há ênfase na análise cronológica. A rocha reservatório em estudo neste trabalho está inserida na Formação Namorado, porção superior do Grupo Macaé, constituída por arenitos arcosianos turbidíticos e informalmente conhecidos como Arenito Namorado. O sistema turbidítico da Formação Namorado é composto, basicamente, por brechas polimíticas, conglomerados, arenitos, argilas, margas e calcilutitos. 
As principais rochas geradoras da Bacia de Campos são os folhelhos do Grupo Lagoa Feia, depositados durante a fase rifte. Essas rochas, de acordo com dados geoquímicos e sedimentológicos, foram formadas em um ambiente lacustre, apresentando querogênio tipo I.

Segundo Bastos [49], o tipo de migração de hidrocarbonetos mais importante na bacia são as janelas de sal locais sem a presença de evaporitos da Formação Retiro, onde falhamentos lístricos levam o óleo da fase rifte até os diferentes reservatórios da fase drifte. A migração também pode ocorrer por contato direto, no caso de reservatórios intercalados ou em contato com a rocha geradora. Outra forma de migração consiste em contato lateral por falha.

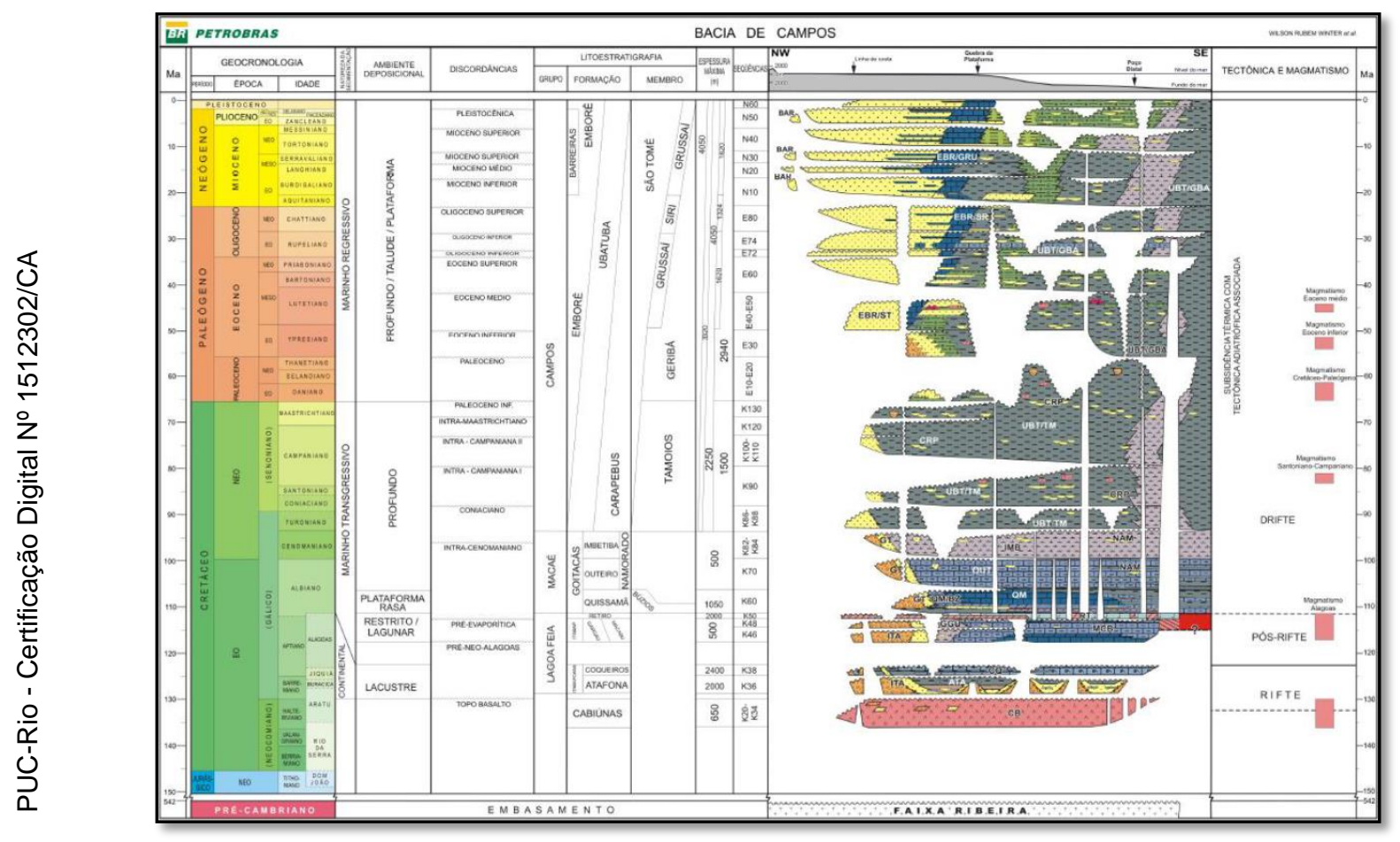

Figura 4.1: Carta estratigráfica da Bacia de Campos (adaptada de Winter et al.[48]).

O Campo de Namorado se apresenta sob a forma de uma estrutura dômica alongada de direção NW-SE sendo que a sua acumulação de óleo é controlada tanto pelo acunhamento estratigráfico (pinchout) do arenito turbidítico quanto pelas feições estruturais. A norte e sul, o reservatório é limitado por pinchouts e a sudeste, noroeste e sudoeste por falhas. Já as rochas selantes do Arenito Namorado são constituídas essencialmente por carbonatos de baixa energia das Formações Outeiro e Imbetiba.

A espessura do reservatório na área central do campo está entre 150 m e 200 m e aloja um volume de óleo $\left(31,9^{\circ} \mathrm{API}\right)$ in situ de $1,17 \times 10^{8} \mathrm{~m}^{3}$. 


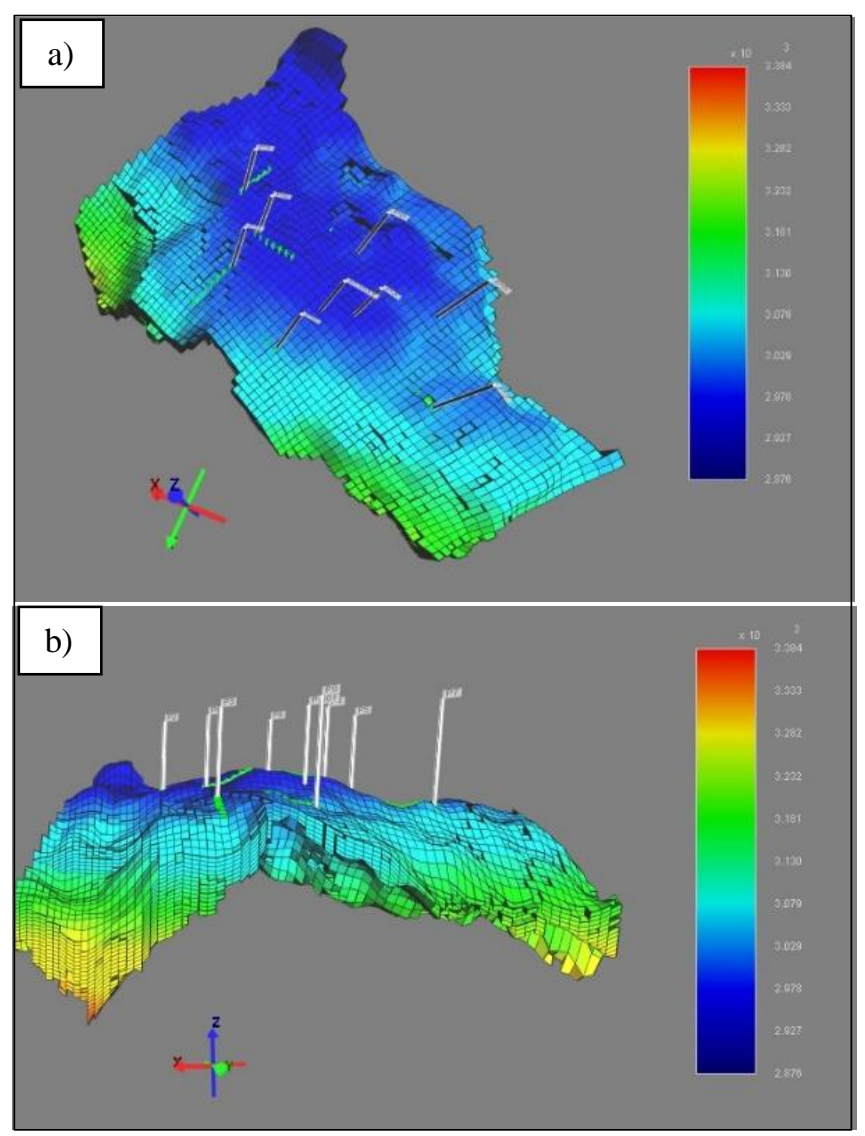

Figura 4. 2: Estrutura do Campo de Namorado com os 9 poços de produção e legenda em função da profundidade no programa Results da CMG. a) Visão superior do Campo de Namorado; b) Visão lateral do Campo de Namorado.

Em relação às rochas adjacentes, a base do reservatório faz fronteira com um underburden caracterizado por um substrato carbonático, composto de calcilutitos e margas, principalmente. Já o limite superior ao reservatório é constituído por um pacote radioativo argilo-siltoso, indicando rochas do tipo folhelho.

Nesta dissertação, um modelo fluxo do Campo de Namorado é utilizado como base para a simulação de produção. Entretanto, este modelo apresenta informações bloco a bloco bem detalhadas apenas a respeito de parâmetros como porosidade, permeabilidade, pressão de fluido, contato óleo-água e propriedades dos fluidos. Os dados mecânicos da rocha reservatório estão restritos à compressibilidade e, como já foi discutido, é considerado muito simplificado para a simulação geomecânica acoplada. Dessa forma, dados de módulo de Young, coeficiente de Poisson e outros módulos elásticos não estão presentes. O mesmo vale para as rochas adjacentes, visto que estão ausentes quando empregado o método de simulação convencional de reservatórios. 
O Campo de Namorado é caracterizado por possuir grande parte de sua área coberta por levantamento sísmico 3D e uma quantidade significativa de poços que apresentam dados de perfilagem. Em função disso, será utilizado o fluxograma do Apêndice $\mathrm{A}$ e as equações apresentadas nos Capítulos 2 e 3 para estimar as propriedades mecânicas das rochas que formam esse sistema petrolífero. Com as informações obtidas por meio dos perfis, será possível mensurar o impacto da consideração de um acoplamento geomecânico em uma simulação de fluxo de reservatório marítimo.

\section{2 \\ Definição de fácies}

O termo fácies, cunhado pelo geólogo suíço Amanz Gressly em 1838, é definido como o conjunto de rochas que apresentam características distintivas paleontológicas ou litológicas, considerando qualquer aspecto químico, mineralógico ou estrutural.

Com o intuito de representar as litofácies mais características do Campo de Namorado, critérios geológicos (granulometria, constituição mineralógica, feições sedimentares) e diagenéticos (cimentação) podem ser aplicados. Segundo Passarella [34], com o auxílio da Análise Sequencial de Testemunhos (ANASETE) para 14 poços testemunhados neste campo entre $2.850 \mathrm{~m}$ e $3.900 \mathrm{~m}$, é possível determinar 29 fácies distintas. A listagem das 29 fácies identificadas em seu trabalho e sua presença nos poços perfilados utilizados nesta dissertação pode ser observada no Apêndice B.

Passarella [34] também disserta a respeito da dificuldade de realizar uma análise detalhada de todas as fácies com base em dados de perfis de poços. Em função disso, propõe a definição de 5 agrupamentos de fácies, a saber: arenito, arenito argiloso, arenito cimentado, folhelho e carbonato. Tal resolução é também corroborada no trabalho de Rosa et al.[35].

A fácies Arenito corresponde a arenitos arcosianos e conglomerados polimíticos (com clastos de diversos tipos de rocha e minerais) que apresentam boa porosidade e indícios elevados de conter hidrocarbonetos. Já a fácies arenito Argiloso, corresponde à arenitos associados a rochas pelíticas que apresentam uma porosidade regular e indícios moderados de conter hidrocarbonetos. A fácies arenito 
cimentado corresponde à arenitos médios cujo espaço poroso encontra-se totalmente cimentado, não contendo, portanto, indícios de hidrocarbonetos.

Além dos arenitos, Passarella [34] descreve também a fácies carbonato correspondendo a calcilutitos e margas que apresentam porosidade desprezível e, por isso, não possuem indícios de conter hidrocarbonetos. Por fim, a fácies folhelho corresponde a rochas com predominância de sedimentos de granulação fina depositados em ambiente de baixa energia, apresentando também porosidade baixa e sem indícios de conter hidrocarbonetos.

A partir das descrições das cinco fácies apresentadas acima, verifica-se que as fácies arenito e arenito argiloso constituem as rochas reservatório. Por outro lado, as fácies arenito cimentado, carbonato e folhelho, constituem as rochas nãoreservatório ou rochas adjacentes.

Ainda assim, Passarella [34] verificou a dificuldade em associar os registros dos perfis para reconhecimento do arenito cimentado uma vez que apresentava características que possibilitavam que fosse atribuído tanto a fácies arenito quanto a fácies carbonato. Isso significa dizer que os registros não se mostraram consistentes na individualização da fácies arenito cimentado, visto que as rochas que a representavam são compostas por arenitos médios com poros preenchidos por cimento. Dessa forma, os registros geofísicos as classificavam como fácies carbonato em alguns intervalos.

Nesta dissertação, a opção de classificação contém as 3 seguintes fácies: arenito, folhelho e carbonato. A opção pela ausência de distinção entre as fácies arenito e arenito argiloso encontra-se no fato de que o teor de argila será calculado em todos os arenitos. Em função disso, as consequências de um maior ou menor teor de argila serão observados no perfil gamma ray, incorporados aos cálculos e expressos nas propriedades das rochas, como descrito no subcapítulo a seguir. Por fim, os dados coletados do perfil de resistividade serão responsáveis pela identificação se o arenito faz parte ou não de uma rocha reservatório.

\section{3 Definição mineralógica}

As rochas sedimentares são resultantes da consolidação de sedimentos provenientes da desagregação e do transporte de rochas preexistentes, da 
precipitação química, além da ação biogênica. A transformação dos sedimentos em rochas ocorre após a sua deposição por meio de um conjunto de processos químicos, como a dissolução, precipitação, oxidação, redução e recristalização. Processos diagenéticos também podem ocorrer e englobam fenômenos como: a cimentação, a compactação e a autigênese.

Os folhelhos são descritos como rochas sedimentares detríticas, que apresentam fissilidade e predominância de elementos de fração fina, como os siltes e argilas. Nos folhelhos que circundam o Campo de Namorado, a cimentação está bastante presente. Tal processo é caracterizado pela cristalização dos minerais carreados pela água que percola o espaço poroso, preenchendo os poros e dando coesão ao material. $\mathrm{O}$ cimento mais comum observado nesse sistema é a calcita. Com base nessas informações e no trabalho elaborado por Borges [36], a composição do folhelho utilizada nessa dissertação é apresentada na Tabela 4.1.

Os arenitos arcosianos ou arcósios são caracterizados na literatura pela presença de feldspato em uma taxa superior a $25 \%$. No caso do Campo de Namorado, esse mineral compõe pelo menos $35 \%$ da totalidade da constituição mineral. Para arenitos, como já dito anteriormente, a proporção de argilominerais será calculada a cada profundidade selecionada por meio de perfis. Nesta dissertação, será considerada uma constituição para os arcósios de $60 \%$ de quartzo e $40 \%$ de feldspato em relação ao volume mineral não argiloso, ou seja, do volume total mineral descontado do volume de argila.

As rochas carbonáticas do sistema são classificadas principalmente como calcilutitos. Trata-se de um carbonato argiloso consolidado, ou seja, com predominância de partículas de calcita com granulometria inferior a $0,1 \mathrm{~mm}$ segundo a classificação de Glabau em 1960.

Tabela 4. 1: Associação das fácies com suas respectivas composições mineralógicas.

\begin{tabular}{|c|c|c|c|c|}
\cline { 3 - 5 } \multicolumn{2}{c|}{} & \multicolumn{3}{c|}{ Fácies } \\
\cline { 2 - 5 } \multicolumn{2}{c|}{} & Arenito * & Folhelho & Carbonato \\
\hline \multirow{3}{*}{$\begin{array}{c}\text { Composição } \\
\text { Mineral (\%) }\end{array}$} & Feldspato & 40 & - & - \\
\cline { 2 - 5 } & Quartzo & 60 & 30 & 80 \\
\cline { 2 - 5 } & Calcita & - & 25 & 20 \\
\cline { 2 - 5 } & Argila & Variável & 45 & - \\
\hline
\end{tabular}

* Os percentuais de quartzo e feldspato no arenito são referentes ao volume mineral subtraído do volume de argila calculado em cada profundidade. 


\section{4 \\ Dados de Perfilagem}

Após a definição das fácies que irão constituir o o modelo geomecânico de simulação, é preciso definir as suas propriedades. Idealmente, tal objetivo deveria ser alcançado por meio de ensaios laboratoriais, alguns deles apresentados de forma resumida no Capítulo 3. Em função da ausência de amostras para a realização desses ensaios, foram utilizados nessa dissertação dados indiretos advindos de 5 poços de perfilagem: RJS19, NA02, NA04, NA07 e NA12 (Apêndice C). O posicionamento de cada um desses poços perfilados pode ser observado na figura a seguir.

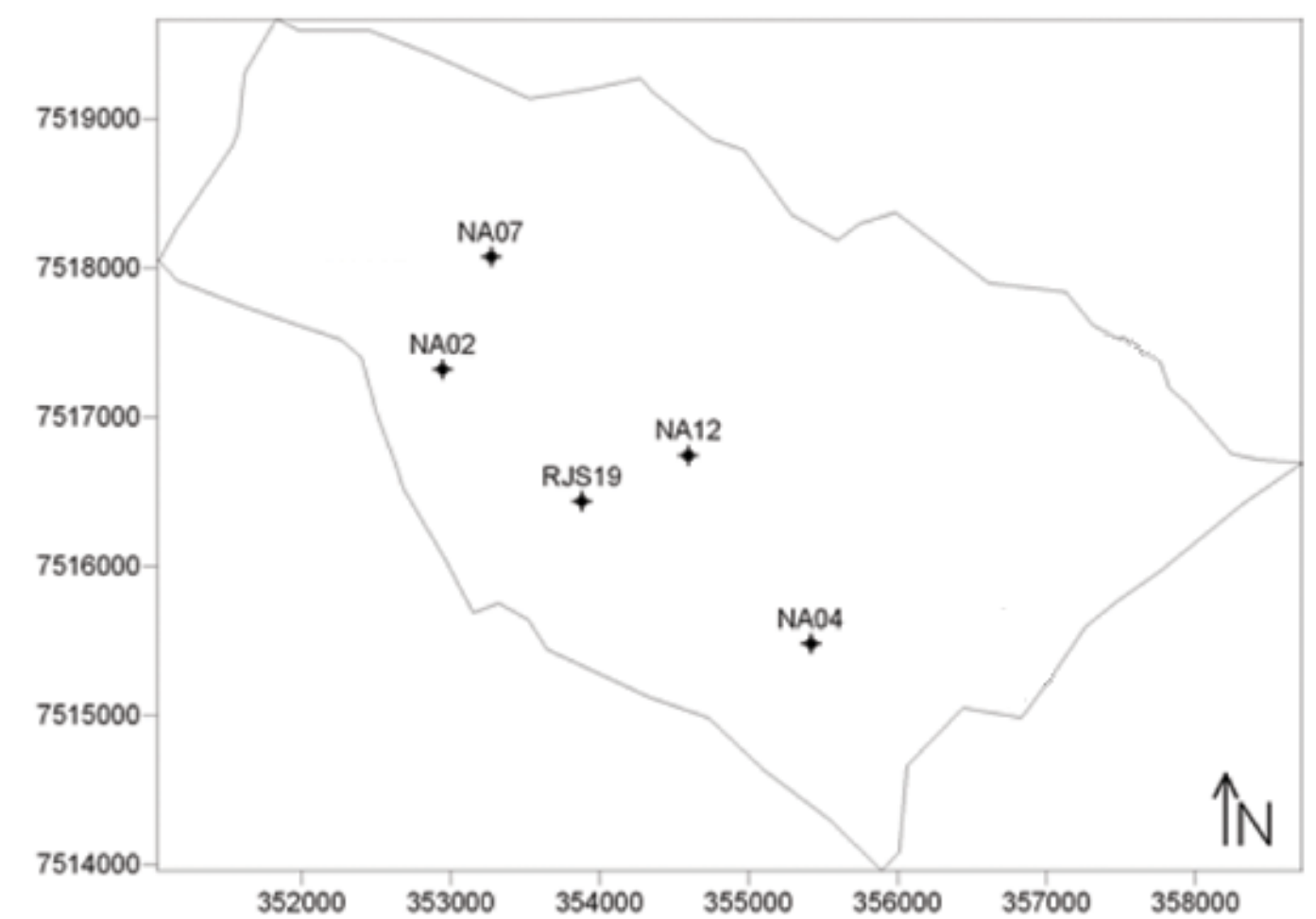

Figura 4. 3: Mapa do Campo de Namorado com a localização dos poços de perfilagem utilizados neste trabalho.

Como justificado na seção anterior, a opção feita neste trabalho foi a de considerar 3 litologias principais como descrito na Tabela 4. 1. A primeira parte dessa análise dos perfis foi a classificação da litologia presente no sistema por meio de critérios resumidos na Tabela 4.2. Para alcançar esse objetivo, perfis de radioatividade (GR), densidade (RHOB) e resistividade (ILD) foram utilizados. 
Tabela 4. 2: Critérios para classificação das fácies em função dos dados de perfilagem.

\begin{tabular}{|c|c|c|}
\hline \multicolumn{2}{|c|}{ FÁCIES } & CRITÉRIO \\
\hline \multicolumn{2}{|c|}{ Folhelho } & SE GR $\geq 65^{\circ}$ \\
\hline \multicolumn{2}{|c|}{ Carbonato } & SE GR $<65^{\circ}$ e RHOB $>2,5 \mathrm{~g} / \mathrm{cm}^{3}$ \\
\hline \multirow{2}{*}{ Arenito } & Reservatório & SE GR $<65^{\circ}$ e RHOB $\leq 2,5 \mathrm{~g} / \mathrm{cm}^{3}$ e $R_{T}>10$ \\
\cline { 2 - 3 } & Não Reservatório & SE GR $<65^{\circ}$ e RHOB $\leq 2,5 \mathrm{~g} / \mathrm{cm}^{3}$ e $R_{T} \leq 10$ \\
\hline
\end{tabular}

A justificativa para o critério de radioatividade está no fato de que o Campo de Namorado ser caracterizado por arenitos arcosianos que, em função da presença de feldspato e argila, tendem a apresentar valores mais altos nessa medição quando comparados a arenitos limpos. Valores entre $10^{\circ}$ e $30^{\circ}$ API seria o resultado esperado para arenitos livres de argila. Já as rochas carbonáticas, que normalmente apresentam também baixos valores no perfil GR, sofrem as consequências de associações com rochas pelíticas que, por sua vez, são rochas naturalmente radioativas. Em função disso, como no intervalo entre $60-65^{\circ}$ API havia amostras com densidade superior a $2,5 \mathrm{~g} / \mathrm{cm}^{3}$ e que, em função disso, não se ajustavam à classificação de arenito e folhelho, optou-se pelo valor de corte de $65^{\circ}$ API. Por fim, trechos com GR acima de $65^{\circ}$ API foram tomados como folhelhos.

O critério de densidade é baseado no peso específico dos minerais. A calcita é o mineral mais denso dentre os apresentados na Tabela $4.1 \mathrm{com} 2,71 \mathrm{~g} / \mathrm{cm}^{3}$. Como já visto anteriormente, os carbonatos dessa área apresentam porosidade muito baixa, garantindo assim que os valores medidos no perfil de densidade ficarão acima da linha de $2,5 \mathrm{~g} / \mathrm{cm}^{3}$. As outras duas fácies, em função da presença de argila em suas constituições e porosidade não tão baixa estão garantidas abaixo do critério de classificação.

Com base nos critérios da Tabela 4.2 aplicados aos cinco poços perfilados foi possível determinar a litologia entre 2.945 e 3.175 metros de profundidade, onde localiza-se trechos de rocha reservatório (Figura 4.4). É possível observar que acima do arenito há predominância de folhelhos, enquanto abaixo dos reservatórios tendem a aparecer carbonatos, coincidindo com os dados da carta estratigráfica apresentada na Figura 4.1. 


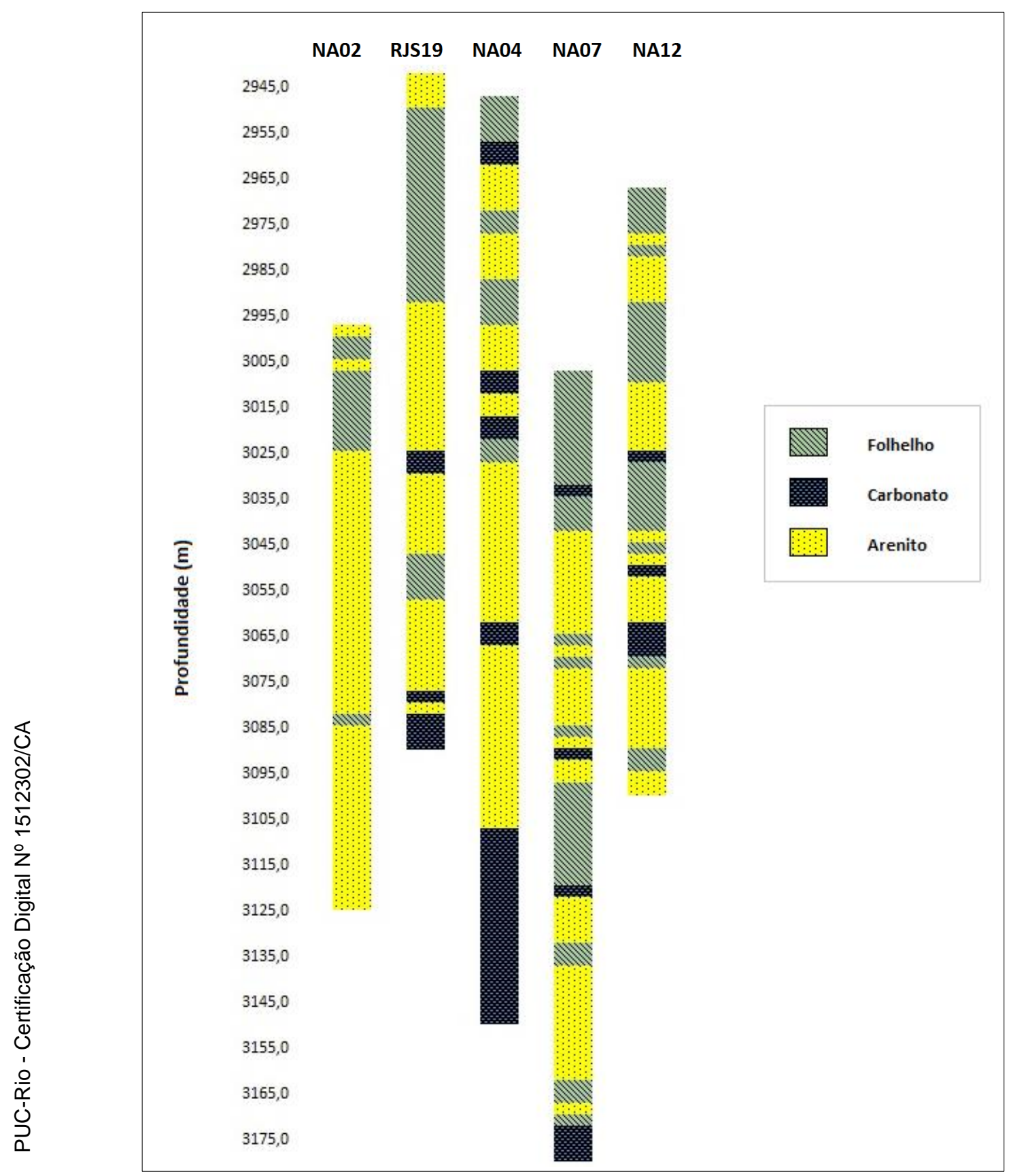

Figura 4.4: Fácies classificadas a partir dos critérios da Tabela 4.2 para cinco poços de perfilagem.

A definição das fácies atende ao objetivo de correlacionar as rochas à sua estrutura mineralógica. De posse desses dados e outros obtidos também por perfis, como argilosidade, porosidade, saturação de água e óleo, torna-se viável mensurar os módulos elásticos.

\section{5 \\ Cálculo dos Módulos Elásticos}

Uma das utilidades do perfil gamma ray foi estipular o volume de argila presente nos arenitos com o uso das equações 3.12 e 3.15. Essa determinação é 
importante visto que a argila possui compressibilidade superior quando comparada a outros componentes minerais do arenito. Os resultados obtidos para cada poço perfilado são apresentados na figura a seguir.

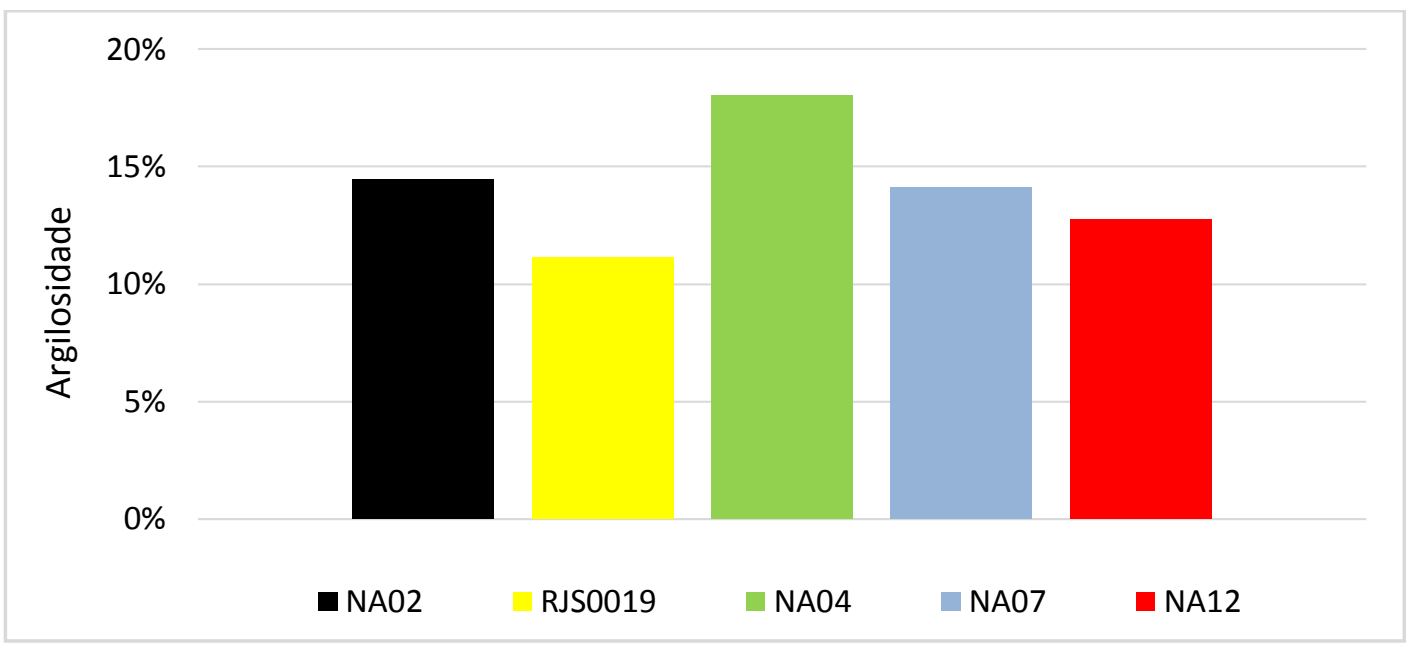

Figura 4. 5: Percentual médio de argila nas litologias identificadas como arenito em cada poço perfilado.

Tabela 4. 3: Quadro de módulo de compressibilidade, módulo de cisalhamento e densidade para cada mineral que compõe as fácies definidas.

\begin{tabular}{|c|c|c|}
\hline \multirow{4}{*}{ Módulo de Compressibilidade do Mineral } & Quartzo & $38,0 \mathrm{GPa}$ \\
\cline { 2 - 3 } & Feldspato & $37,5 \mathrm{GPa}$ \\
\cline { 2 - 3 } & Calcita & $70,2 \mathrm{GPa}$ \\
\cline { 2 - 3 } Módulo de Cisalhamento do Mineral & Argila & $20,9 \mathrm{GPa}$ \\
\hline & Quartzo & $44,0 \mathrm{GPa}$ \\
\cline { 2 - 3 } & Feldspato & $15,0 \mathrm{GPa}$ \\
\cline { 2 - 3 } & Calcita & $29,0 \mathrm{GPa}$ \\
\hline \multirow{3}{*}{ Densidade do Mineral } & Argila & $6,9 \mathrm{GPa}$ \\
\hline & Quartzo & $2,65 \mathrm{~g} / \mathrm{cm}^{3}$ \\
\cline { 2 - 3 } & Feldspato & $2,62 \mathrm{~g} / \mathrm{cm}^{3}$ \\
\cline { 2 - 3 } & Calcita & $2,71 \mathrm{~g} / \mathrm{cm}^{3}$ \\
\cline { 2 - 3 } & Argila & $2,58 \mathrm{~g} / \mathrm{cm}^{3}$ \\
\hline
\end{tabular}

A partir da composição mineral definida na Tabela 4.1, dos módulos de compressibilidade e cisalhamento de cada mineral na Tabela 4.3 e da argilosidade calculada acima, foi possível gerar os módulos de compressibilidade da matriz sólida $\left(K_{S}\right)$ dos arenitos por meio das equações $3.16,3.17$ e 3.18 , referentes aos limites de Reuss, Voigt e média de Voigt-Reuss-Hill. A ausência de argila estabeleceria um valor de $K_{S}$ de 37,8 GPa que representa exatamente uma mistura de $60 \%$ de quarto de $40 \mathrm{GPa}$ e $40 \%$ de feldspato de $37,5 \mathrm{GPa}$, como pode ser visto 
na figura a seguir. Como esperado, os valores encontram-se dentro dos limites estabelecidos

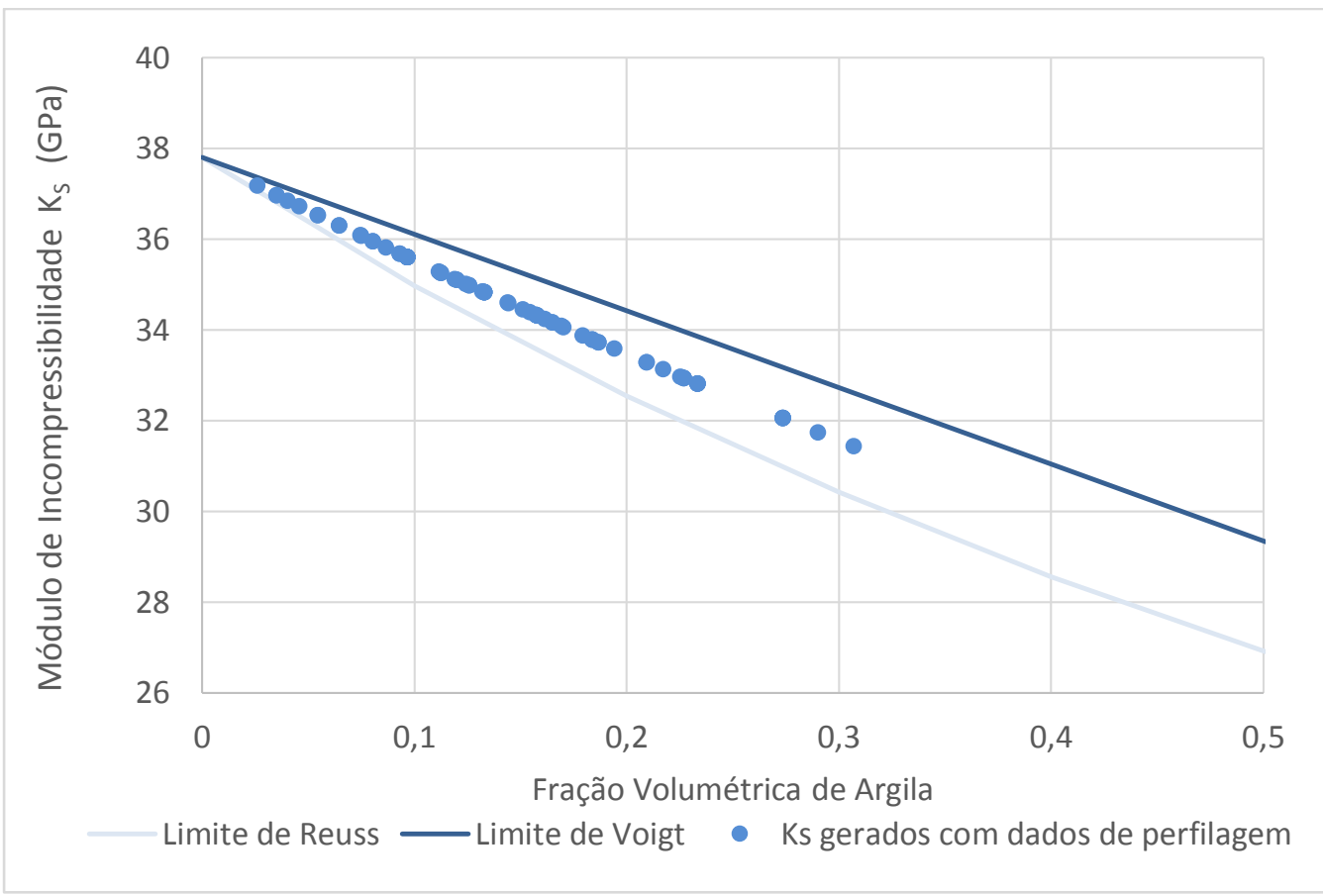

Figura 4. 6: Módulo de compressibilidade da estrutura mineral dos pontos identificados como arenito.

A figura a seguir revela os modelos de contorno de Reuss-Voigt para os módulos de compressibilidade e cisalhamento das três fácies definidas neste trabalho. Dessa forma, a Figura 4.6 representa um zoom do modelo de contorno para os arenitos desse campo. Pela observação da Figura 4.7 é possível perceber que para uma mesma fração volumétrica de argila, em função da mineralogia definida para cada fácies, os carbonatos tendem a apresentar maiores valores de $K_{S}$, enquanto que os arenitos tendem a retornar valores mais baixos.

Por sua vez, os modelos de contorno para módulo de cisalhamento de arenitos e carbonatos são muito próximos para qualquer fração volumétrica de argila em função do quartzo e feldspato, presentes no arenito, terem módulos cisalhamento bem distintos, mas cujo valor ponderado pela fração de cada mineral na composição desta litologia praticamente igualar o módulo de cisalhamento da calcita, que é dominante na composição do carbonato.

Importante salientar que a fração de argila que gera o gráfico anterior tem aplicação real para arenitos e carbonatos apenas quando a argilosidade não é predominante na composição, ou seja, um carbonato ou arenito com $95 \%$ de fração volumétrica de argila, por exemplo, jamais seria classificado como carbonato ou 
arenito na prática. Isso permite dizer, hipoteticamente, que as zonas de interseção dos modelos de contorno para altos valores de argila indicariam a possibilidade de mudança de litologia, tornando a classificação mais apropriada sendo a de folhelho. Como nenhum dado de arenito e carbonato ultrapassa o ponto de $35 \%$ de argila, não é uma preocupação neste trabalho.

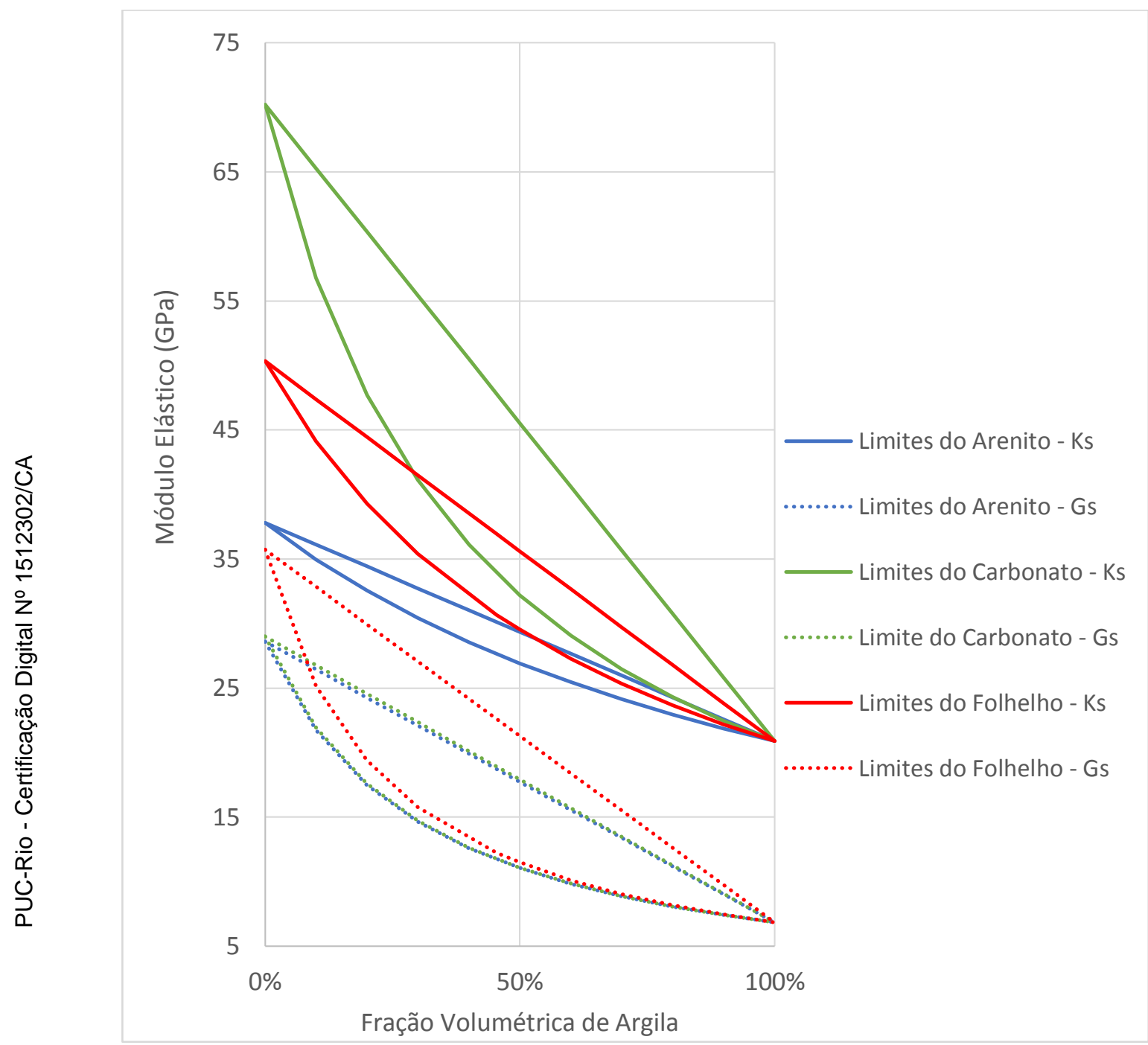

Figura 4.7: Modelo de contorno de Reuss-Voigt dos módulos de compressibilidade mineral e cisalhamento para as 3 litologias.

De posse dos dados de $K_{S}$, há a possibilidade de calcular os módulos de compressibilidade bulk saturado $\left(K_{\text {sat }}\right)$ e de cisalhamento $\left(G_{s a t}\right)$ das três rochas mencionadas. Para chegar a esse objetivo é necessário obter a porosidade e saturação de fluidos.

Como já introduzido anteriormente, o perfil de densidade RHOB é o responsável pela distinção entre arenitos e carbonatos. Regiões com densidades superiores a 2,5 $\mathrm{g} / \mathrm{cm}^{3}$ eram classificadas como rochas carbonáticas. Outra 
importante função desse perfil foi também no cálculo de porosidade (equações 3.28 e 3.29) para as três litologias, cujos resultados estão expressos a seguir.

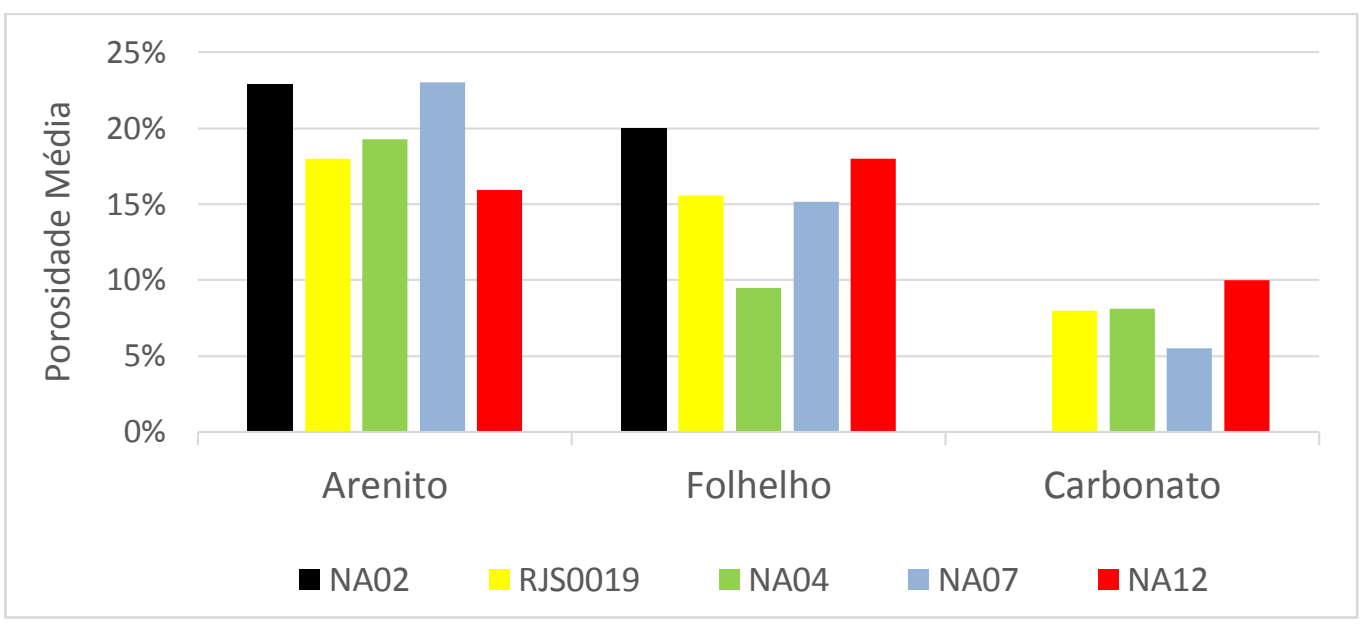

Figura 4. 8: Porosidade média obtida por meio de dos do perfil de densidade para as 3 fácies dos cinco poços perfilados.

Os arenitos apresentaram a maior porosidade absoluta média entre as três fácies identificadas com valor de vazios correspondendo a 20\%. Quando levada em consideração a argilosidade, por meio do emprego da equação 3.29 a porosidade efetiva se reduz a 18\%. Para os folhelhos, a porosidade absoluta média é de 18\%, enquanto que os carbonatos possuem volume poroso correspondente a $8 \%$ de seu volume total.

O perfil de resistividade ILD foi o responsável pela distinção dos arenitos que apresentavam alta saturação de hidrocarbonetos. Valores de resistividade $\left(R_{T}\right)$ acima de 10 ohm.m eram considerados indicadores de presença de óleo em maior escala. O cálculo da saturação de água nos arenitos foi realizado por meio da equação 3.21 e reproduzida novamente abaixo. Foram considerados valores $0,81,2$ e 2 para o coeficiente litológico, o coeficiente de cimentação e o expoente de saturação, respectivamente (Gonzalez [39]). A resistividade da água salina foi considerada igual a $0,012 \mathrm{ohm} . \mathrm{m}$.

$$
S_{w}=\sqrt[n]{\frac{a R_{w}}{\emptyset_{e}^{m} R_{T}}}
$$

Como os arenitos apresentam argilosidade, também foi calculada a saturação de água corrigida por meio da equação Nigéria (equação 3.23). A partir dessa saturação corrigida era calculada a saturação de óleo no reservatório. Importante 
frisar que o Campo de Namorado não apresenta gás livre no tempo inicial de simulação. Em função disso, considerou-se nos cálculos de saturação apenas água e óleo.

$$
S_{w}=\sqrt[n]{\frac{1}{R_{T}\left[\sqrt{\frac{\emptyset_{e}{ }^{m}}{R_{w}}}+\sqrt{\frac{V_{s h}^{2,8}}{R_{s h}}}\right]^{2}}}
$$

Quando a litologia era identificada como folhelho ou carbonato, assumiu-se que a saturação de água era igual a $100 \%$.

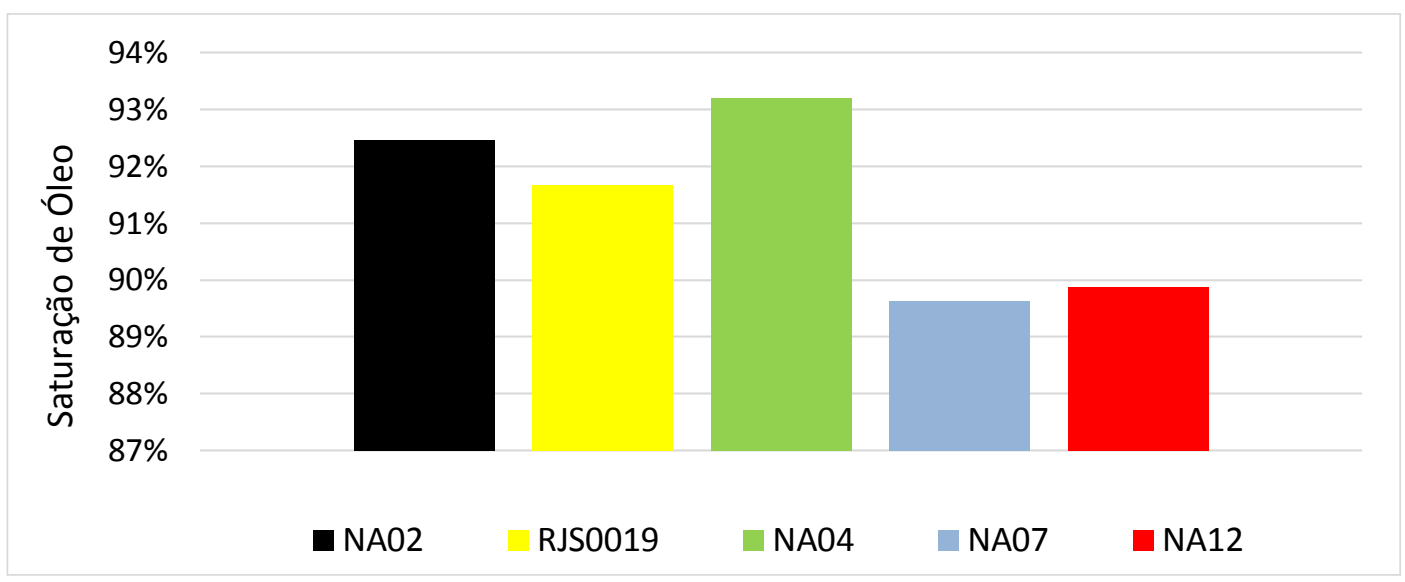

Figura 4.9: Saturação média de óleo nos arenitos classificados como reservatórios.

O óleo presente no Campo de Namorado apresenta uma densidade média em condições standard de $866 \mathrm{~kg} / \mathrm{m}^{3}$, representando assim um óleo de 31,9 $9^{\circ}$ API. O reservatório se encontra inicialmente com uma pressão de poros em torno de 322 $\mathrm{kgf} / \mathrm{cm}^{2}(31,57 \mathrm{MPa})$ e compressibilidade igual a $1,27 \times 10^{-4}\left(\mathrm{kgf} / \mathrm{cm}^{2}\right)^{-1}$. A água, por sua vez, apresenta compressibilidade inferior à do óleo e em torno de $4,9 \times 10^{-5}$ $\left(\mathrm{kgf} / \mathrm{cm}^{2}\right)^{-1}$, caracterizando assim um módulo de compressibilidade maior do que o do hidrocarboneto.

Tabela 4.4: Quadro de módulo de compressibilidade e módulo de compressibilidade para cada fluido presente na formação.

\begin{tabular}{|c|c|c|}
\hline \multirow{2}{*}{ Compressibilidade do Fluido } & Água & $4,9 \times 10^{-5}\left(\mathrm{kgf} / \mathrm{cm}^{2}\right)^{-1}$ \\
\cline { 2 - 3 } & Óleo & $1,27 \times 10^{-4}\left(\mathrm{kgf} / \mathrm{cm}^{2}\right)^{-1}$ \\
\hline \multirow{3}{*}{$\begin{array}{c}\text { Módulo de Compressibilidade } \\
\text { do Fluido }\end{array}$} & Água & $20.408,2 \mathrm{kgf} / \mathrm{cm}^{2}$ \\
\cline { 2 - 3 } & & $2,00 \mathrm{GPa}$ \\
\cline { 2 - 3 } & Óleo & $7.849,3 \mathrm{kgf} / \mathrm{cm}^{2}$ \\
\cline { 3 - 3 } & & $0,77 \mathrm{GPa}$ \\
\hline
\end{tabular}


Com a obtenção dos dados de $K_{S}$, porosidade e dos fluidos presentes na formação, novamente é utilizada a média dos limites de Reuss e Voigt para definição dos módulos de compressibilidade bulk saturado das fácies. Os modelos de contorno agora são traçados relacionando $K_{S}$ e porosidade.

$$
\begin{gathered}
\frac{1}{K_{\text {sat }}}=\frac{1-\emptyset}{K_{S}}+\frac{\emptyset}{\left(\sum_{i=1}^{n} \frac{S_{i}}{K_{f_{i}}}\right)^{-1}} \\
K_{\text {sat }}=(1-\emptyset) K_{S}+\emptyset\left(\sum_{i=1}^{n} \frac{S_{i}}{K_{f_{i}}}\right)^{-1}
\end{gathered}
$$

Por meio da média obtida entre as duas equações acima, como era esperado, o carbonato apresentou os maiores $K_{\text {sat }}$ em função da predominância de calcita em sua composição (Figura 4.10). Por sua vez, arenitos e folhelhos apresentaram resultados bem próximos para uma mesma faixa de porosidade em função das premissas de composição definidas na seção 4.3. Essas premissas se referem à presença de $45 \%$ de argila na composição dos folhelhos e também devido à fração de calcita nos folhelhos, que veio a contribuir no aumento do valor do módulo de compressibilidade saturado dessa rocha a patamares próximos a do quartzo e o feldspato que eram predominantes no arenito.

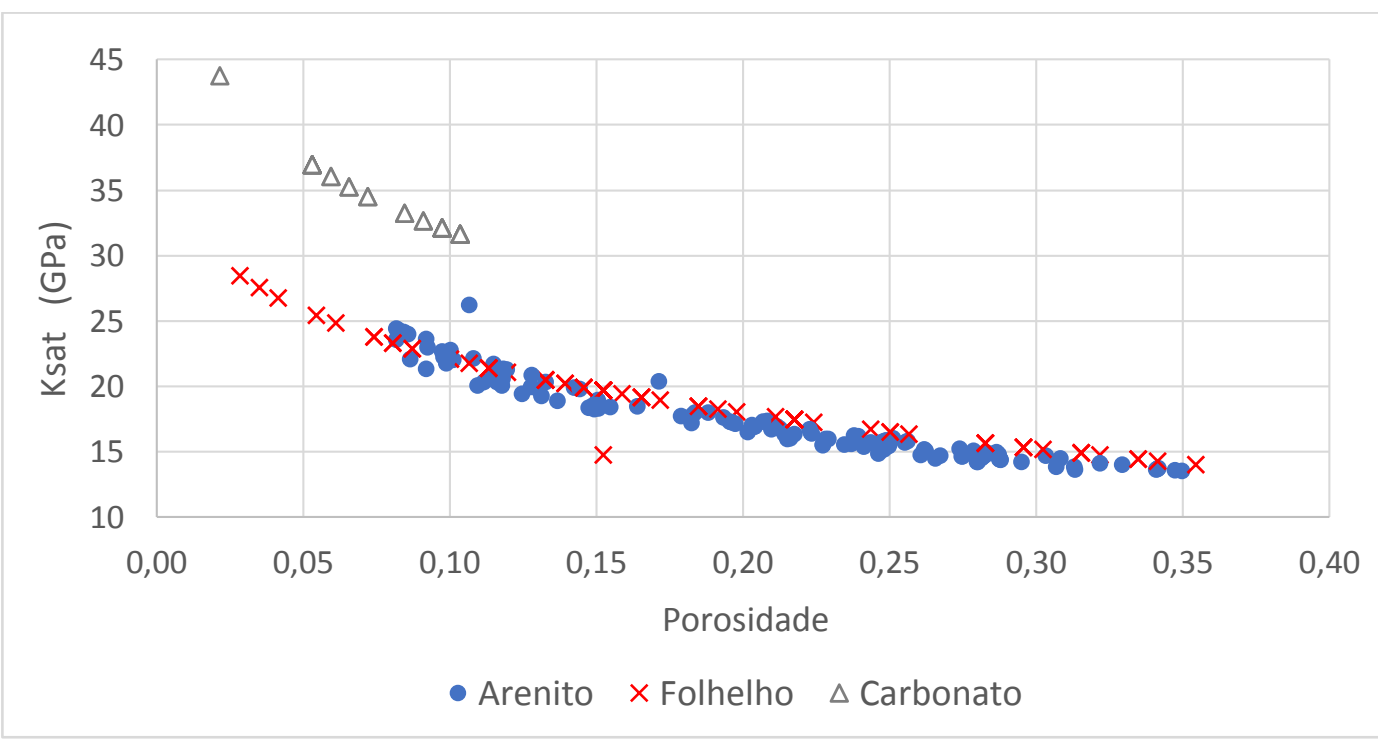

Figura 4.10: Módulo de compressibilidade bulk saturado em função da porosidade para arenitos, folhelhos e carbonatos. 
O cálculo do módulo de compressibilidade bulk drenado $\left(K_{D}\right)$ foi feito a partir da equação 2.49. A comparação entre os módulos drenado e saturado no arenito pode ser observada no gráfico a seguir. É possível perceber que a diferença entre $K_{\text {sat }}$ e $K_{D}$ é sempre inferior a $2 \mathrm{GPa}$ para esse campo em específico. Quando se tratou de um folhelho essa diferença oscilou entre 2,5 e 3,7 GPa. Por fim, para os carbonatos, esse valor oscilou entre 4 e 5,1 GPa.

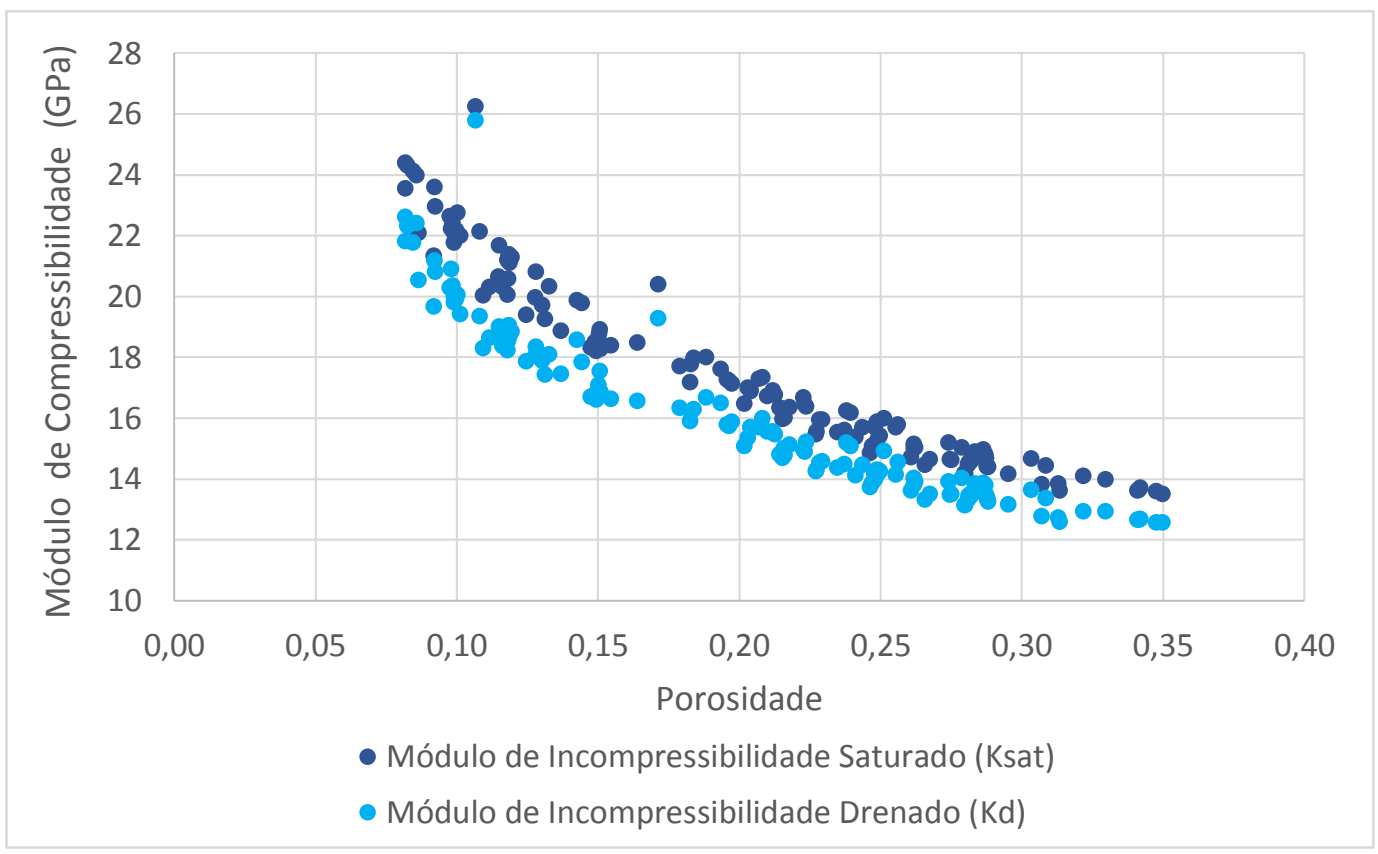

Figura 4. 11: Módulo de compressibilidade bulk saturado e drenado em relação à porosidade para os pontos classificados como arenito.

A fim de obter os módulos de cisalhamento bulk saturado $\left(G_{\text {sat }}\right)$, foi feita a opção neste trabalho de utilizar uma correlação própria para arenitos apresentada por Lee [50] em seu trabalho e outra elaborada por Nur et al. [51] para obter os resultados das outras duas litologias.

Especificamente para arenitos, Lee [50] faz uso de um parâmetro de consolidação $\beta$ e de um parâmetro $\xi$ que é calculado a partir de $\beta$, como mostrado a seguir:

$$
\xi=\frac{1+2 \beta}{1+\beta}
$$

O parâmetro de consolidação pode ser obtido a partir dos módulos de bulk saturado, drenado e da porosidade dos arenitos, como mostrado a seguir. 


$$
\beta=\frac{K_{s}(1-\emptyset)-K_{D}}{K_{D} \emptyset}
$$

A partir desses dois parâmetros, o autor gera o gráfico a seguir e também relaciona uma curva da razão de velocidades $W_{p} / W_{S}$. Essas curvas foram geradas pelo autor para arenitos com porosidade de $25 \%$.

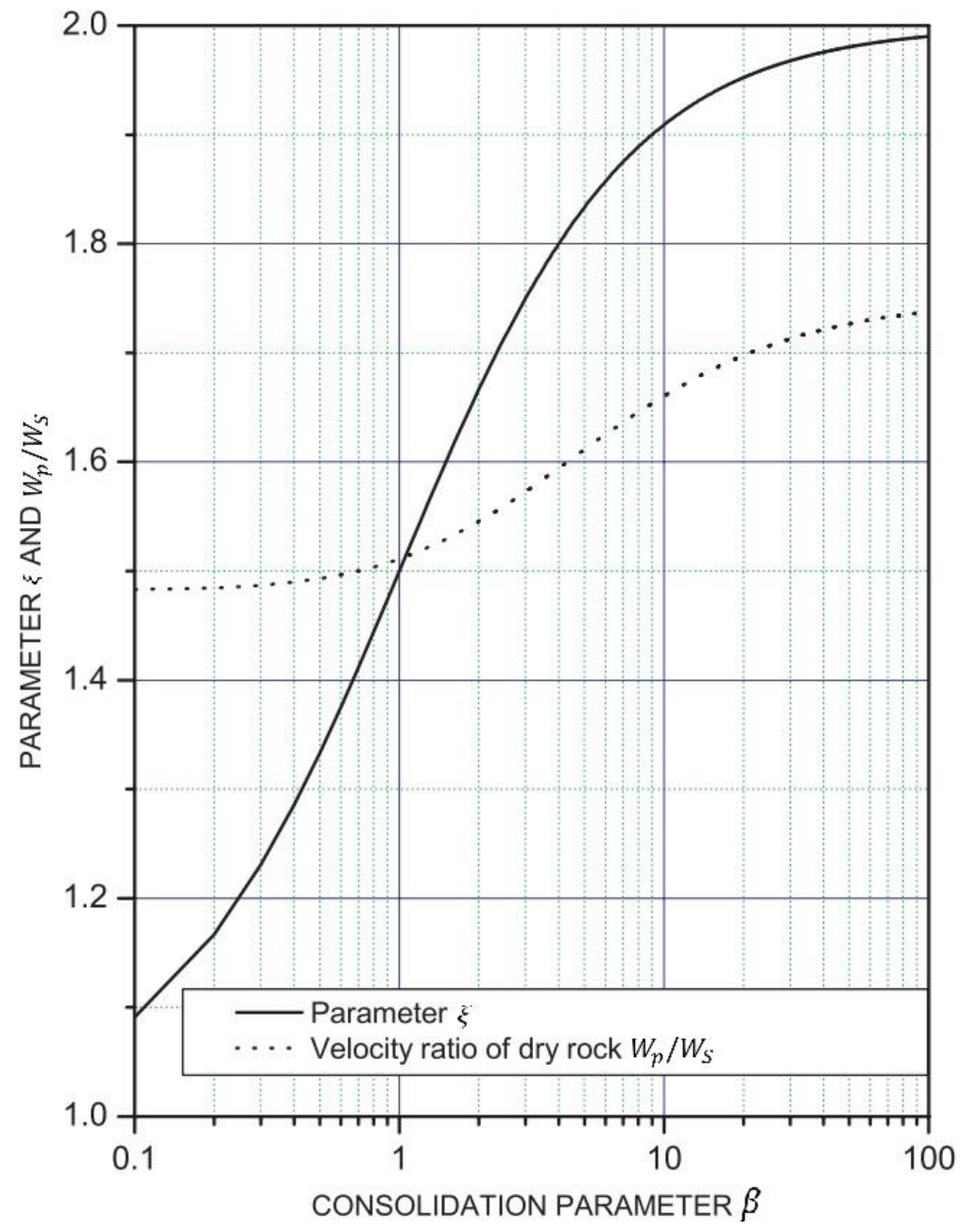

Figura 4. 12: Relação entre parâmetro de consolidação e razão de velocidade (linha sólida) e relação entre parâmetro de consolidação e parâmetro $\xi$ (linha pontilhada). (Adaptado de Lee [50])

De posse dos dois parâmetros mencionados anteriormente, é possível calcular o módulo de cisalhamento bulk drenado que é igual ao módulo de cisalhamento bulk saturado, em função dos fluidos presentes nos poros não apresentarem forças cisalhantes associadas $\left(G_{f}=0\right)$.

$$
G_{D}=G_{s a t}=\frac{G_{s}(1-\emptyset)}{1+\xi \beta \varnothing}
$$

A comparação de magnitude entre os módulos de cisalhamento e os de compressibilidade podem ser observados na figura a seguir. Como esperado, os 
módulos de cisalhamento são iguais entre si e apresentam valores inferiores aos de $K_{D}$ e $K_{\text {sat }}$.

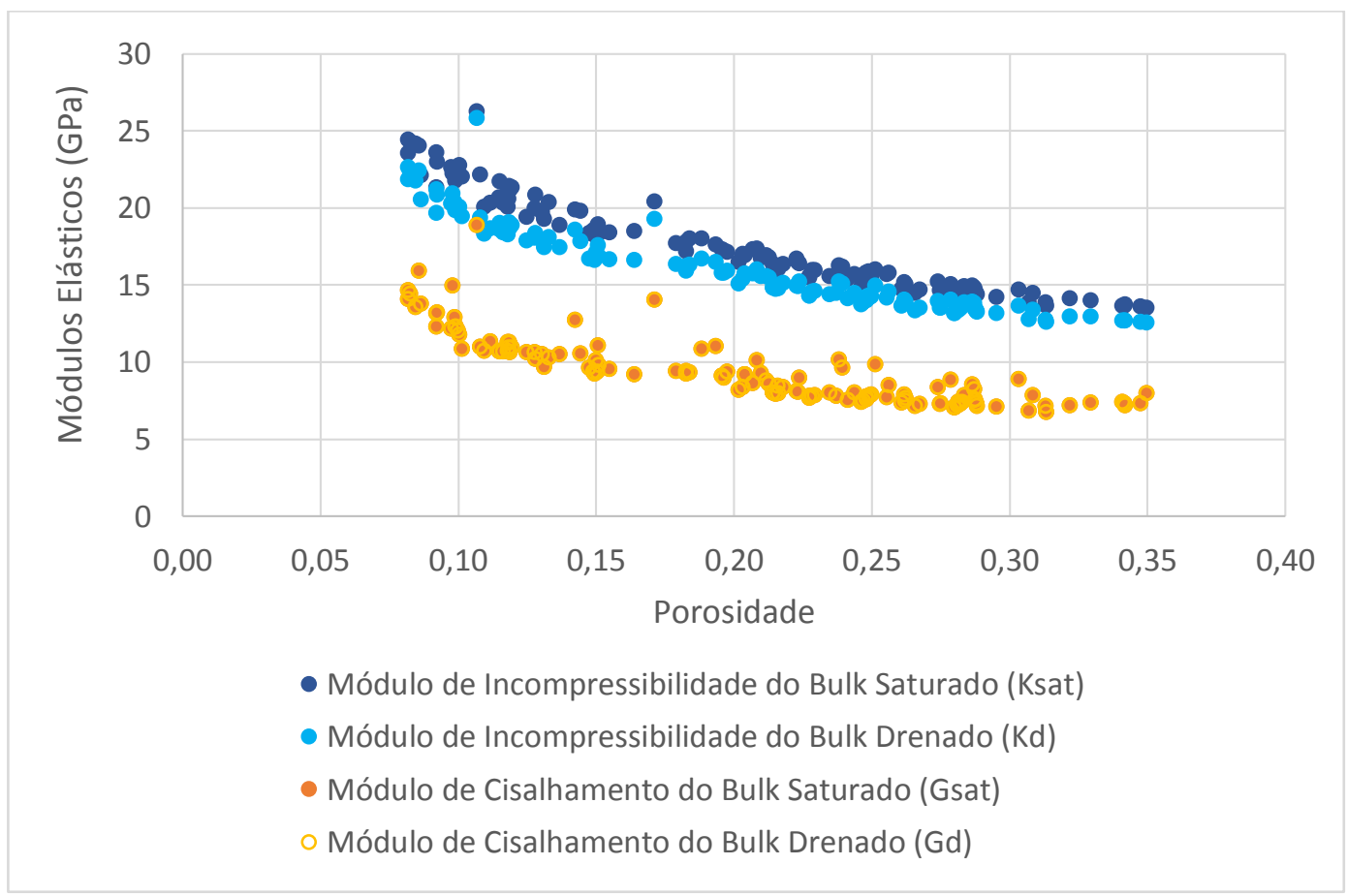

Figura 4. 13: Módulos de compressibilidade e cisalhamento bulk saturado e drenado em relação à porosidade para os pontos classificados como arenito.

Como forma de confrontar os dados obtidos neste trabalho com outros presentes na literatura, os resultados demonstrados na figura acima foram comparados com os obtidos no trabalho de Emerick et al. [38]. Os módulos de compressibilidade e cisalhamento bulk drenado obtidos por Emerick et al. [38] são representados na Figura 4.14 por meio das linhas de tendência geradas em seu trabalho, com as respectivas equações também representadas.

Os autores tomaram por base um campo real na Bacia de Campos, onde também está localizado o Campo de Namorado. Trata-se de um arenito do Oligoceno, onde foi adquirida uma sísmica de alta resolução em 2005. A densidade do óleo varia de 18 a $25^{\circ} \mathrm{API}$. Além disso, o reservatório, utilizado por Emerick et al. [38], não tem qualquer mecanismo de suporte de pressão e a pressão do ponto de bolha está próxima da pressão inicial.

Os autores consideraram uma composição mineral de quartzo e argila para o arenito, porém não há informações da fração volumétrica de cada componente mineral. Os módulos de compressibilidade e cisalhamento da argila utilizados eram iguais a 24,5 GPa e 8,8 GPa, respectivamente. A presença de calcita na composição 
do arenito apresentado nesta dissertação, pode ser um dos fatores que tornaram os resultados obtidos mais altos quando comparados aos de Emerick et al. [38].

Em função do Campo de Namorado ter um processo de sedimentação mais antigo e, por isso, provavelmente estar a uma maior profundidade do que o campo descrito por Emerick et al. [38], tal fator poderia também explicar os resultados mais altos desta dissertação.

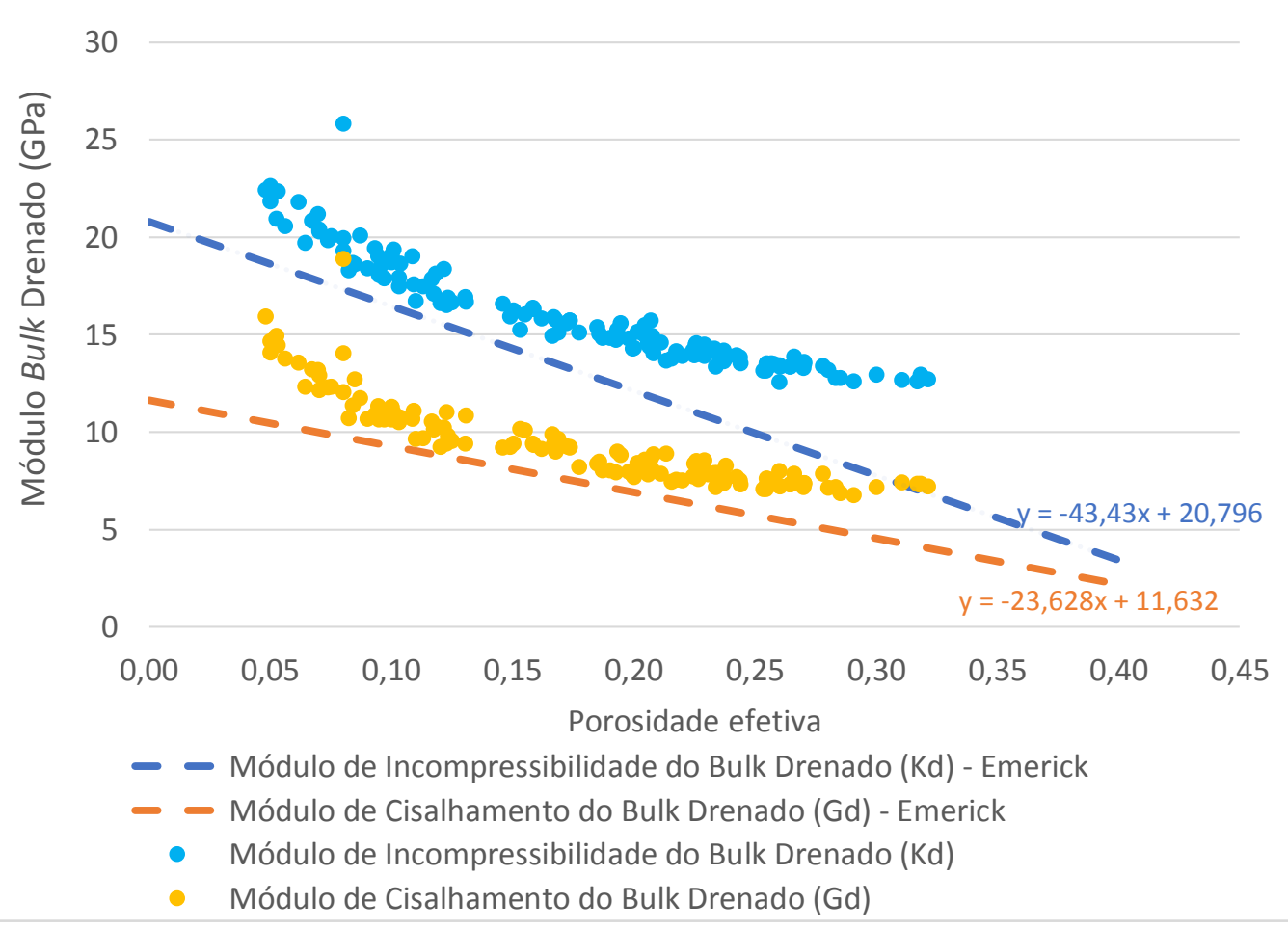

Figura 4.14: Módulos de compressibilidade e cisalhamento bulk drenado em relação à porosidade obtidos nesta dissertação e no trabalho de Emerick et al. [38].

É importante salientar também que para valores de porosidade entre $10 \%$ e $20 \%$, onde a maior parte dos resultados está concentrada, o comportamento dos dados obtidos nesta dissertação e das equações obtidas por Emerick et al. [38] apresentam semelhança.

$\mathrm{Na}$ ausência de uma correlação específica para folhelhos e carbonatos, como a apresentada anteriormente por Lee [50] voltada para arenitos, será usada a equação apresentada por Nur et al. [51]. Essa equação insere a porosidade crítica no cálculo do módulo de compressibilidade bulk drenado $\left(K_{D}\right)$, junto à porosidade absoluta e ao módulo bulk mineral, como pode ser visto na equação a seguir.

$$
K_{D}=K_{S}\left(1-\frac{\emptyset}{\emptyset_{c}}\right)
$$


Para os folhelhos, a porosidade crítica foi considerada igual a $65 \%$ e para os carbonatos, 60\% (Mavko et al. [31]). O módulo de cisalhamento bulk drenado também pode ser calculado com a inserção da porosidade crítica. Os resultados encontram-se na Figura 4.15.

$$
G_{D}=G_{s}\left(1-\frac{\emptyset}{\emptyset_{c}}\right)
$$

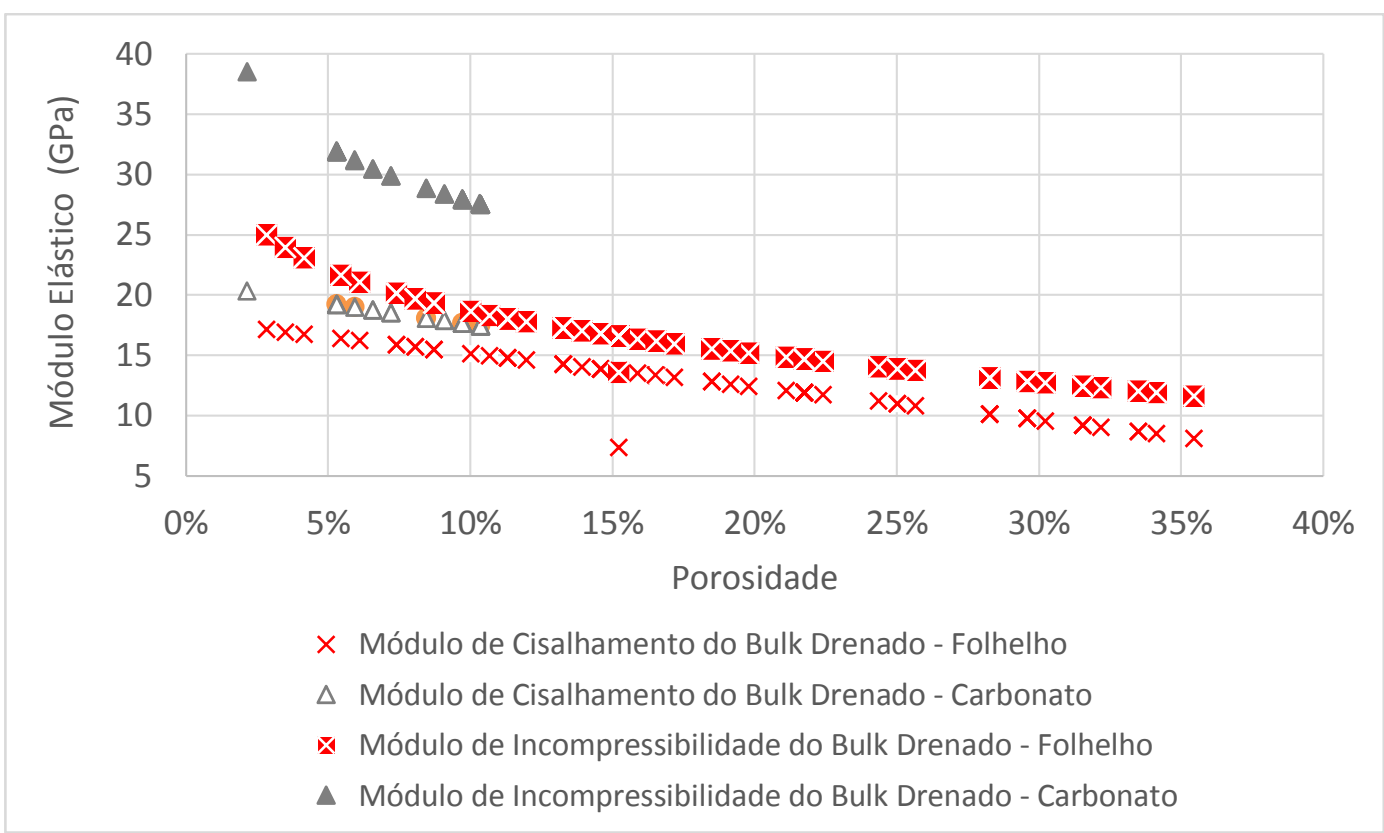

Figura 4.15: Módulos de compressibilidade e cisalhamento bulk saturado e drenado em relação à porosidade para os pontos classificados como folhelho e carbonato.

Com todos os módulos de compressibilidade e cisalhamento detalhados, é possível calcular os dois módulos elásticos que serão utilizados na construção do modelo geomecânico para posterior utilização na simulação parcialmente acoplada. O coeficiente de Poisson dinâmico será calculado por meio da equação 4.10, enquanto o módulo de Young dinâmico está detalhado na equação 4.11. Dessa forma, será possível determinar deformações e deslocamentos ao longo do período de depleção do campo estudado, além de seus efeitos na explotação de fluidos.

$$
\begin{gathered}
v=\frac{3 K_{\text {sat }}-2 G_{\text {sat }}}{2\left(3 K_{\text {sat }}+G_{\text {sat }}\right)} \\
E_{D}=2 G_{\text {sat }}(1+v)
\end{gathered}
$$

Na Figura 4.16 está exposta a relação entre porosidade e módulo de Young dinâmico para as 3 fácies estudadas nesta dissertação. Para uma mesma faixa de porosidade, o arenito apresenta o menor módulo de elasticidade e que tende a 
crescer à medida que a porosidade diminui. Comportamento semelhante é visto nas curvas referentes a folhelhos e carbonatos.

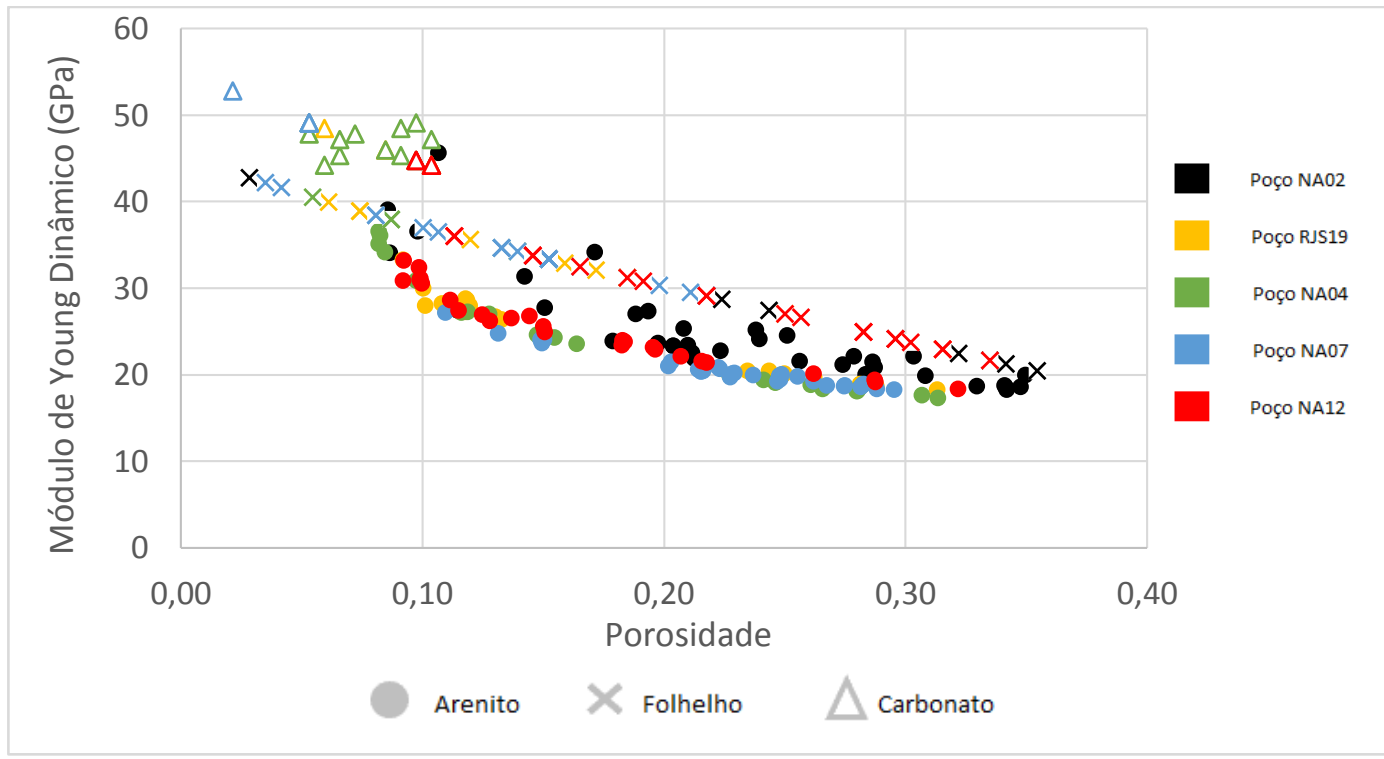

Figura 4.16: Módulo de Young em relação à porosidade para as três fácies nos cincos poços perfilados.

Na Figura 4.17 estão expostos os coeficientes de Poisson obtidos em função da porosidade. É possível observar que todos os dados do Poisson estão entre 0.21 e 0,3. Para os arenitos, o poço NA02 é que apresenta dados mais esparsos, visto que os outros poços se concentram em valores entre 0,25 e 0,29 . Os folhelhos, apresentam aumento do coeficiente do Poisson à medida que a porosidade aumenta pelo menos na faixa de porosidade entre $10 \%$ e $26 \%$. Para baixas porosidades, o comportamento se inverte.

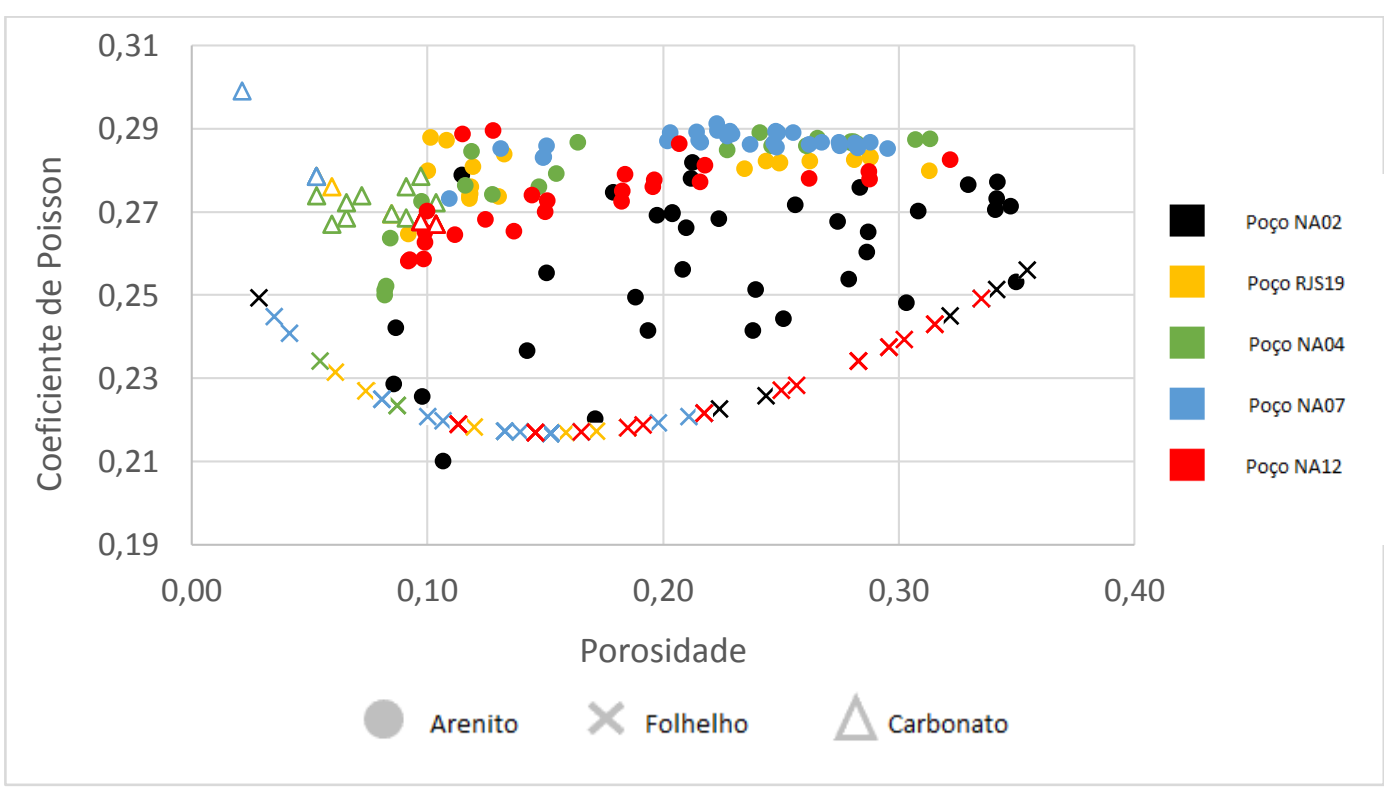

Figura 4. 17: Coeficiente de Poisson em relação à porosidade para as três fácies nos cincos poços perfilados. 
Todos os parâmetros calculados por meio dos perfis e das premissas definidas nas seções anteriores estão resumidos na tabela a seguir. A compressibilidade do volume poroso obtido pelo workflow do Apêndice A foi de $1,5 \times 10^{-5}\left(\mathrm{kgf} / \mathrm{cm}^{2}\right)^{-1}$. Por sua vez, a compressibilidade do volume poroso no modelo de fluxo cedido pela Petrobras era de $5 \times 10^{-5}\left(\mathrm{kgf} / \mathrm{cm}^{2}\right)^{-1}$.

Tabela 4.5: Resultados médios obtidos a partir dos perfis e premissas utilizados ao longo desse capítulo.

\begin{tabular}{|c|c|c|c|}
\hline & Arenito & Folhelho & Carbonato \\
\hline GR $\left({ }^{\circ} \mathrm{API}\right)$ & 55,53 & 81,95 & 44,38 \\
\hline IGR & 0,27 & 0,54 & 0,17 \\
\hline Volume de argila & 0,14 & 0,45 & 0,20 \\
\hline Volume de quartzo & 0,52 & 0,30 & - \\
\hline Volume de feldspato & 0,34 & - & - \\
\hline Volume de calcita & - & 0,25 & 0,80 \\
\hline Densidade bulk $\left(\mathrm{g} / \mathrm{cm}^{3}\right)$ & 2,32 & 2,35 & 2,56 \\
\hline Porosidade & 0,20 & 0,18 & 0,08 \\
\hline Porosidade efetiva & 0,18 & 0,18 & 0,08 \\
\hline Saturação de água & 0,25 & 1,00 & 1,00 \\
\hline Saturação de água corrigida & 0,27 & 1,00 & 1,00 \\
\hline Saturação de óleo & 0,73 & - & - \\
\hline $\begin{array}{l}\text { Módulo de compressibilidade da matriz sólida - Ks } \\
\text { (GPa) }\end{array}$ & 34,74 & 34,33 & 54,02 \\
\hline Módulo de compressibilidade do fluido - Kf (GPa) & 1,03 & 2,00 & 2,00 \\
\hline Módulo de compressibilidade bulk saturado - Ksat (GPa) & 17,51 & 19,15 & 34,23 \\
\hline Módulo de compressibilidade bulk drenado - KD (GPa) & 16,03 & 16,17 & 29,70 \\
\hline Módulo de Cisalhamento da matriz sólida - Gs (GPa) & 23,62 & 17,93 & 21,09 \\
\hline Módulo de Cisalhamento do fluido - Gf (GPa) & - & - & - \\
\hline Módulo de Cisalhamento bulk saturado - Gsat (GPa) & 9,37 & 12,89 & 18,32 \\
\hline Módulo de Cisalhamento bulk drenado - GD (GPa) & 9,37 & 12,89 & 18,32 \\
\hline$\alpha$ Biot & 0,54 & 0,53 & 0,45 \\
\hline Q Biot & 6,30 & 14,44 & 28,44 \\
\hline Compressibilidade bulk drenado - $\mathrm{CD}\left(\mathrm{kgf} / \mathrm{cm}^{2}\right)^{-1}$ & $6,28 \mathrm{E}-06$ & $6,24 \mathrm{E}-06$ & $3,32 \mathrm{E}-06$ \\
\hline Compressibilidade pseudo-bulk - Cbp $\left(\mathrm{kgf} / \mathrm{cm}^{2}\right)^{-1}$ & $3,45 \mathrm{E}-06$ & $3,38 \mathrm{E}-06$ & $1,51 \mathrm{E}-06$ \\
\hline $\begin{array}{l}\text { Compressibilidade do volume poroso em relação à } \\
\text { pressão confinante - } \mathrm{Cpc}\left(\mathrm{kgf} / \mathrm{cm}^{2}\right)^{-1}\end{array}$ & $1,76 \mathrm{E}-05$ & $2,03 \mathrm{E}-05$ & $2,01 \mathrm{E}-05$ \\
\hline $\begin{array}{l}\text { Compressibilidade do volume poroso em relação à } \\
\text { pressão de poros - CØ }\left(\mathrm{kgf} / \mathrm{cm}^{2}\right)^{-1}\end{array}$ & $1,50 \mathrm{E}-05$ & $1,75 \mathrm{E}-05$ & $1,83 \mathrm{E}-05$ \\
\hline$\lambda$ & 11,26 & 10,56 & 22,01 \\
\hline Coeficiente de Poisson & 0,27 & 0,22 & 0,27 \\
\hline Módulo de Elasticidade Dinâmico (GPa) & 23,84 & 31,58 & 46,64 \\
\hline Módulo de Elasticidade Dinâmico $\left(\mathrm{kgf} / \mathrm{cm}^{2}\right)$ & $2,4 \mathrm{E}+05$ & $3,2 \mathrm{E}+05$ & $4,8 \mathrm{E}+05$ \\
\hline Módulo de Elasticidade Dinâmico (psi) & $3,46 \mathrm{E}+06$ & $4,58 \mathrm{E}+06$ & $6,76 \mathrm{E}+06$ \\
\hline
\end{tabular}




\section{6 \\ Construção da Malha de Elementos Finitos}

Por meio do workflow denominado Gaia, Albuquerque [5] apresenta os passos para a construção de uma malha de elementos finitos que representa o reservatório em conexão às rochas adjacentes. Esse processo de criação da malha e regiões será detalhado a seguir para o Campo Namorado, foco desta dissertação.

A)

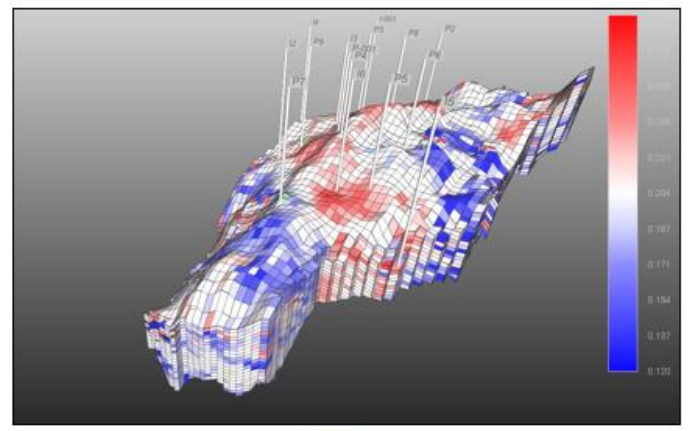

B)

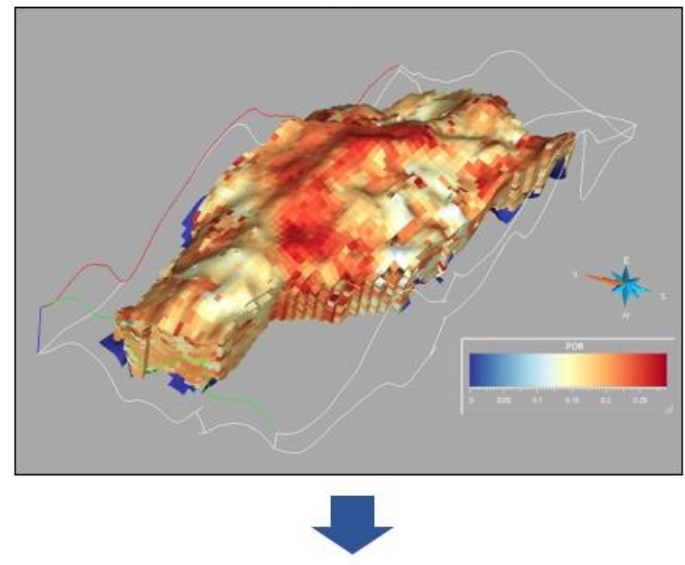

C)

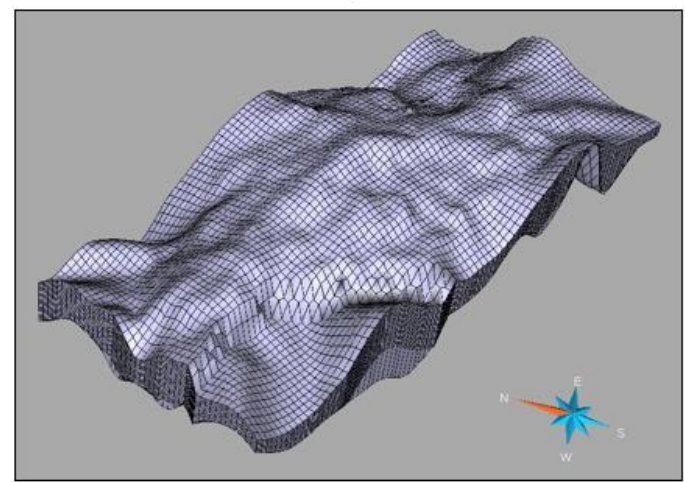

Figura 4. 18: (A) Distribuição da porosidade nas regiões ativas do grid em diferenças finitas do Campo de Namorado no Results3D da CMG; (B) Distribuição da porosidade nas regiões ativas na malha de elementos finitos gerados no GOCAD; (C) Malha de elementos finitos com as regiões inativas inseridas. 
Antes de começar o processo, é necessário que se tenha o grid do reservatório em diferenças finitas (Figura 4. 18A). A partir do arquivo .irf gerado pelo IMEX (do pacote de simulação da CMG), o modelador geológico GOCAD por meio do plugin Gaia consegue realizar a construção do respectivo grid em uma malha de elementos finitos (Figura 4. 18). O reservatório em estudo, apresenta dimensões de $8,5 \mathrm{~km}$ de comprimento por $4 \mathrm{~km}$ de largura.

O próximo passo leva à inserção do sideburden. Foram adicionados $12 \mathrm{~km}$ para cada lateral na direção de maior comprimento do reservatório, enquanto que na direção de menor comprimento, foram adicionados $6 \mathrm{~km}$. O objetivo era manter uma proporção de 1,5x de sideburden em relação à dimensão de reservatório. Dessa forma, o bloco abaixo apresenta uma visão superior com dimensões de 32,5 km X $16 \mathrm{~km}$.

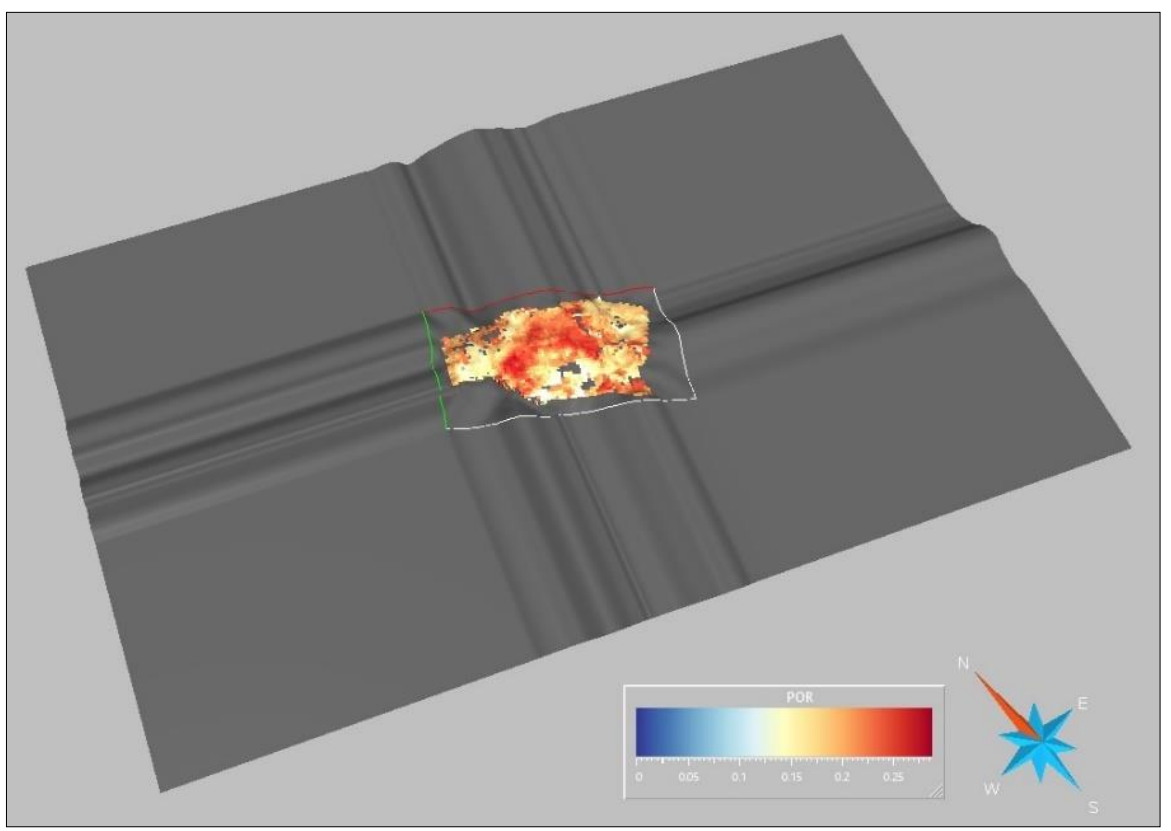

Figura 4. 19: Visão do reservatório anexado ao sideburden. A legenda de cores da porosidade refere-se apenas ao reservatório.

Após anexar o sideburden, foi a vez de inserir o underburden desde a base do reservatório até 4.000 metros de profundidade (Figura 4. 20) em 40 layers, cujas dimensões foram definidas de forma crescente, a partir do reservatório.

Por fim, um overburden de 2.830 metros de material litológico sob 170 metros de lâmina d'água também é acoplado ao sistema. Foram utilizados 40 layers com espessuras crescentes a partir do reservatório e também a partir do leito marinho. Tal aplicação foi possível porque o overburden foi separado em 3 grandes horizontes de propriedades distintas, com a região central apresentando espessuras 
constantes. Na figura a seguir, é possível visualizar todo o modelo. Essa imagem revela o overburden representado apenas pela malha de elementos finitos, de forma a permitir identificar o reservatório, que se encontra localizado na área nuclear do modelo (3.000 metros de profundidade), com 9 poços produtores verticais perfurados que estão representados na cor vermelha. Por sua vez, o underburden é representado pela área cinza sólida.

Dessa forma, o modelo final de simulação com o reservatório e todas as rochas adjacentes inseridas apresenta 2,2 milhões de nós.

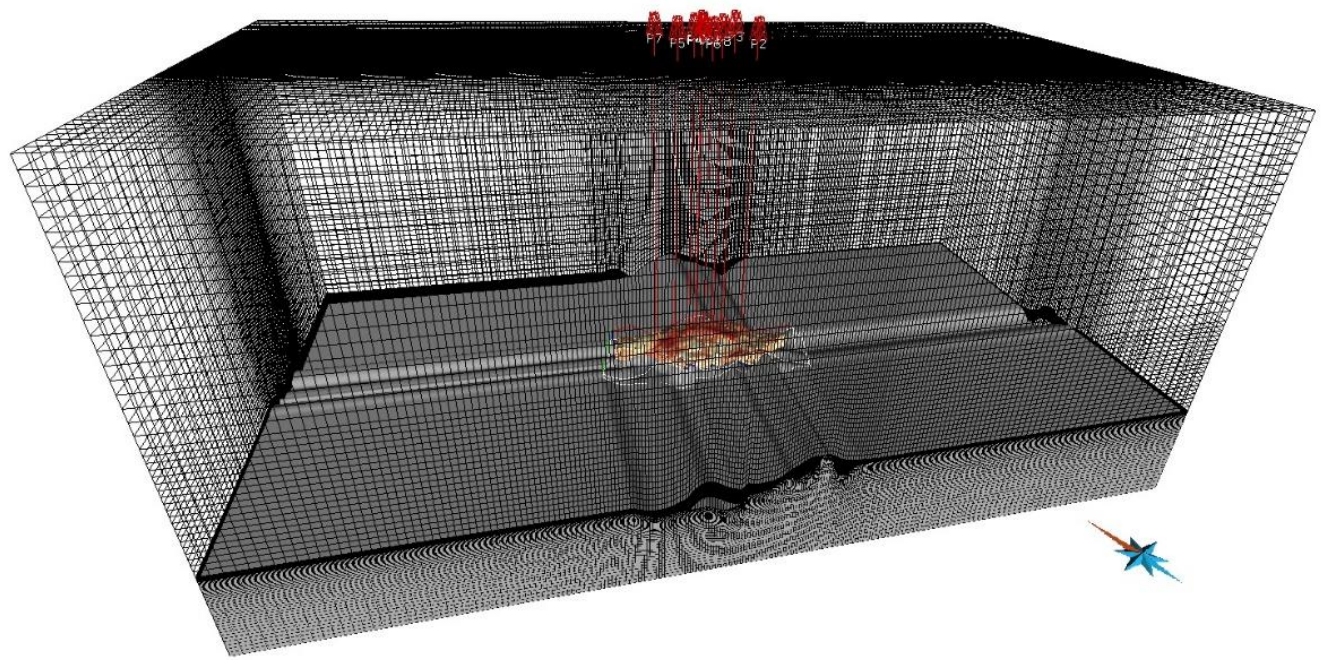

Figura 4. 20: Visão lateral do modelo com a presença do overburden, sideburden e underburden com o reservatório apresentado ao centro.

\section{7.}

Distribuição das Propriedades Mecânicas no Modelo em Estudo

Para que os efeitos do acoplamento geomecânico sejam mensurados, é necessário preencher a malha de elementos finitos com as propriedades mecânicas das rochas adjacentes e do próprio reservatório. Em função da metodologia GTEP/PUC-Rio só realizar análises baseadas na teoria da elasticidade linear, os elementos de malha são preenchidos apenas com propriedades elásticas, não sendo necessário considerar parâmetros de resistência das rochas. Significa dizer que não são feitos cálculos envolvendo plasticidade nessa simulação. Com base na proposta de Albuquerque [5], apenas dois parâmetros elásticos são utilizados para definir a matriz constitutiva do material: o módulo de Young e o coeficiente de Poisson. 
Os estudos, descritos nos capítulos 2 e 3 e realizados ao longo deste capítulo 4, objetivaram definir módulos de Young e o coeficientes de Poisson que estivessem em maior conformidade com a realidade encontrada no ambiente onde se encontra o Campo de Namorado. Como já dito anteriormente, a ausência de dados oriundos de testes com corpos de prova levou à busca pela obtenção desses dados por meio da perfilagem. As figuras 4.16 e 4.17 mostram as relações entre módulos de Young e Poisson com as respectivas porosidades medidas através de perfis ao longo dos poços exploratórios perfurados. Por meio desses resultados gerados, foram criados critérios para distribuição das propriedades mecânicas, tanto do reservatório como das rochas adjacentes.

$\mathrm{Na}$ figura a seguir é apresentado o histograma da porosidade do reservatório, obtido por meio do arquivo de propriedades do reservatório para simulações de fluxo .dat do campo em estudo, e que apresenta um valor médio igual a $22 \%$. Segundo este histograma, a maior porosidade encontrada no Campo de Namorado é de $29 \%$.

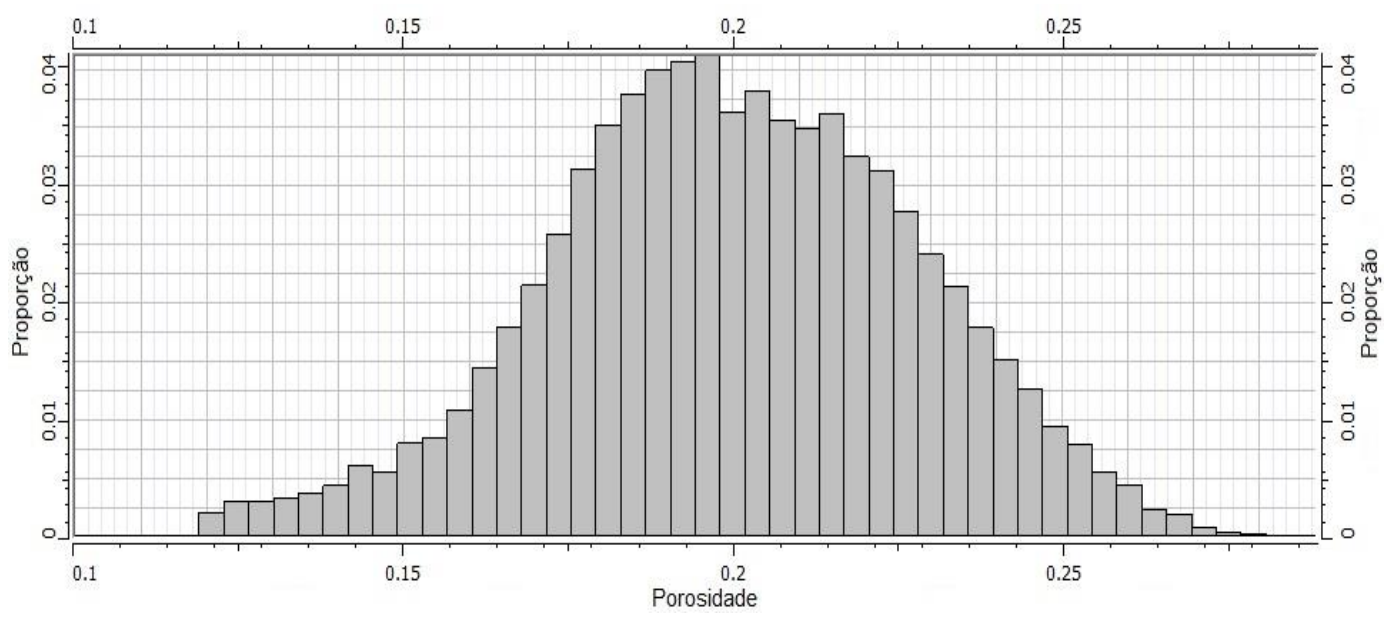

Figura 4. 21: Histograma de porosidade do arenito que compõe o reservatório.

A tabela a seguir apresenta mais informações a respeito do reservatório.

Tabela 4. 6: Dados obtidos a partir do arquivo de simulação de fluxo do IMEX do Campo de Namorado.

\begin{tabular}{|l|r|l|}
\hline \multicolumn{3}{|c|}{ Dados do grid do Campo de Namorado } \\
\hline Número de blocos do grid & 85.905 & \\
\hline Número de blocos ativos & 34.790 & \\
\hline Compressibilidade da rocha & $5 \times 10^{-5}$ & $\left(\mathrm{kgf} / \mathrm{cm}^{2}\right)^{-1}$ \\
\hline Profundidade de referência & 3.000 & $\mathrm{~m}$ \\
\hline Pressão de referência & 322 & $\mathrm{kgf} / \mathrm{cm}^{2}$ \\
\hline Temperatura do reservatório & 90 & ${ }^{\circ} \mathrm{C}$ \\
\hline
\end{tabular}




\begin{tabular}{|l|r|l|}
\hline Volume poroso do reservatório & $2,63 \times 10^{8}$ & $\mathrm{~m}^{3}$ \\
\hline${ }^{\circ}$ API do óleo & 31,9 & \\
\hline Densidade do óleo & 866 & $\mathrm{~kg} / \mathrm{m}^{3}$ \\
\hline Densidade do gás & 0,911 & $\mathrm{~kg} / \mathrm{m}^{3}$ \\
\hline Densidade da água & 1010 & $\mathrm{~kg} / \mathrm{m}^{3}$ \\
\hline Pressão de bolha & 248,03 & $\mathrm{kgf} / \mathrm{cm}^{2}$ \\
\hline Fator volume de formação da água & 1,043 & $\mathrm{~m}^{3} / \mathrm{m}^{3}$ \\
\hline Viscosidade da água & 0,6 & $\mathrm{cP}$ \\
\hline Volume total de óleo in place & $1,17 \times 10^{8}$ & $\mathrm{~m}^{3}$ \\
\hline Volume total de água in place & $9,29 \times 10^{7}$ & $\mathrm{~m}^{3}$ \\
\hline Volume de gás em solução in place & $1,49 \times 10^{10}$ & $\mathrm{~m}^{3}$ \\
\hline Volume de gás livre in place & 0 & $\mathrm{~m}^{3}$ \\
\hline
\end{tabular}

Para garantir uma melhor distribuição das propriedades mecânicas no reservatório, foram criadas quatro regiões no GOCAD utilizando a porosidade como critério. Essas regiões podem ser vistas em detalhes na figura a seguir.

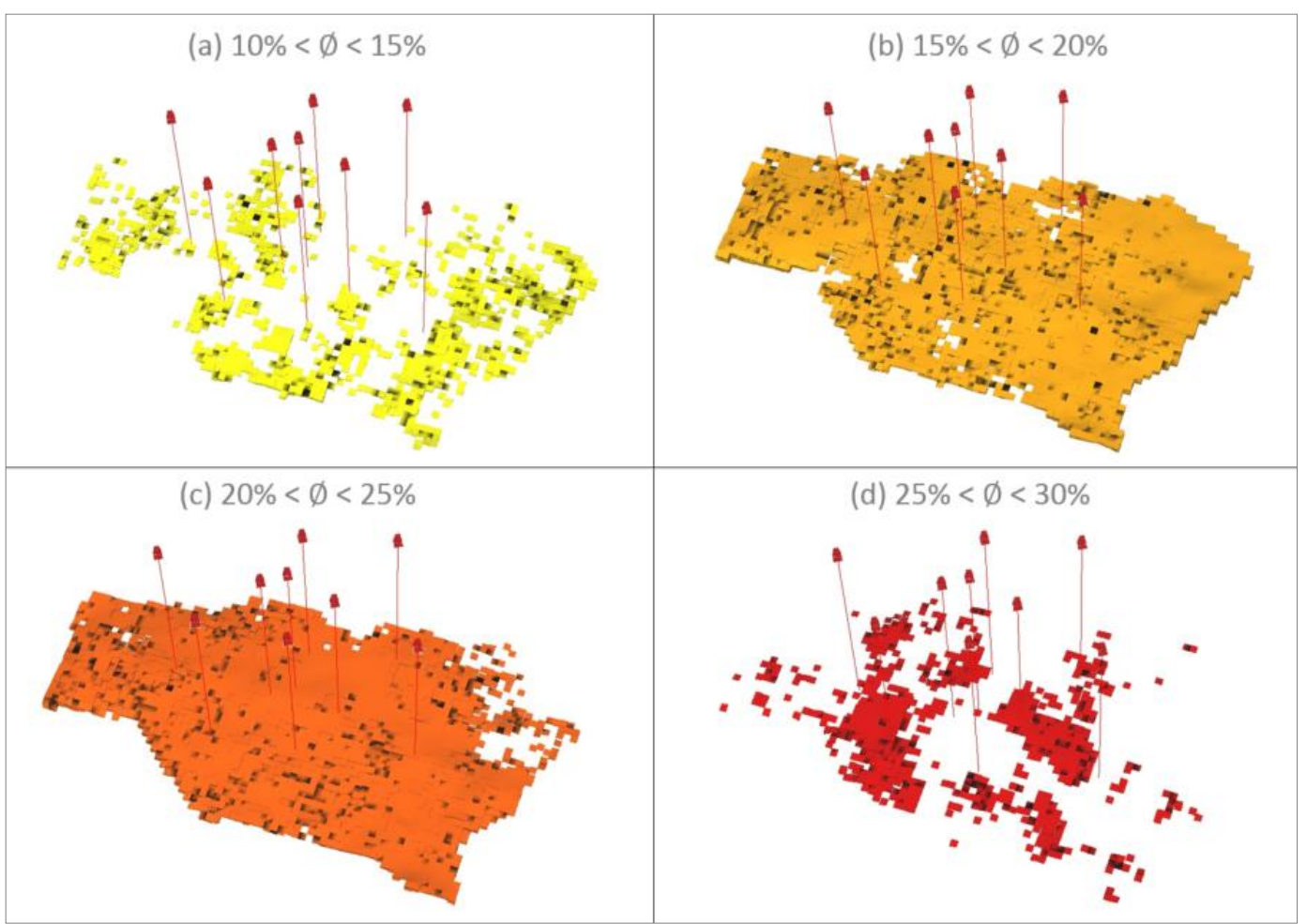

Figura 4. 22: Visualização do reservatório dividido em 4 regiões de porosidade com os 9 poços produtores.

A definição dos valores de módulos de Young e coeficientes de Poisson para as regiões do reservatório, obedeceram a divisão mostrada na figura acima, ou seja, foram associados valores, baseados nas curvas de tendência apresentadas na Figura 4. 23 em função da porosidade apresentada em cada bloco do reservatório. Mais 
uma vez, convém recordar que na modelagem geomecânica, recomenda-se a utilização de parâmetros elásticos estáticos. A partir das equações de Lacy [12] expostas na seção 3.2, os módulos de Young serão convertidos para dados estáticos. Em função da ausência de correlações confiáveis para conversão de dados de coeficiente de Poisson dinâmicos para estáticos, estes não serão modificados e acompanharão a Figura 4.17. A tabela a seguir resume esses dados ao apresentar os valores para os pontos médios de porosidade referentes a cada faixa selecionada.

Tabela 4. 7: Módulo de Young estático e coeficiente de Poisson em função da faixa de porosidade utilizados para distribuição de propriedades mecânicas na malha de elementos finitos.

\begin{tabular}{c|cc}
$\begin{array}{c}\text { Faixas de } \\
\text { Porosidade }\end{array}$ & $\begin{array}{c}\text { Módulo de Young Estático } \\
\text { (GPa) }\end{array}$ & $\begin{array}{c}\text { Coeficiente de } \\
\text { Poisson }\end{array}$ \\
\hline $10 \%<\emptyset<15 \%$ & 16,6 & 0,27 \\
$15 \%<\varnothing<20 \%$ & 13,6 & 0,27 \\
$20 \%<\varnothing<25 \%$ & 11,5 & 0,28 \\
$25 \%<\varnothing<30 \%$ & 10,4 & 0,28
\end{tabular}

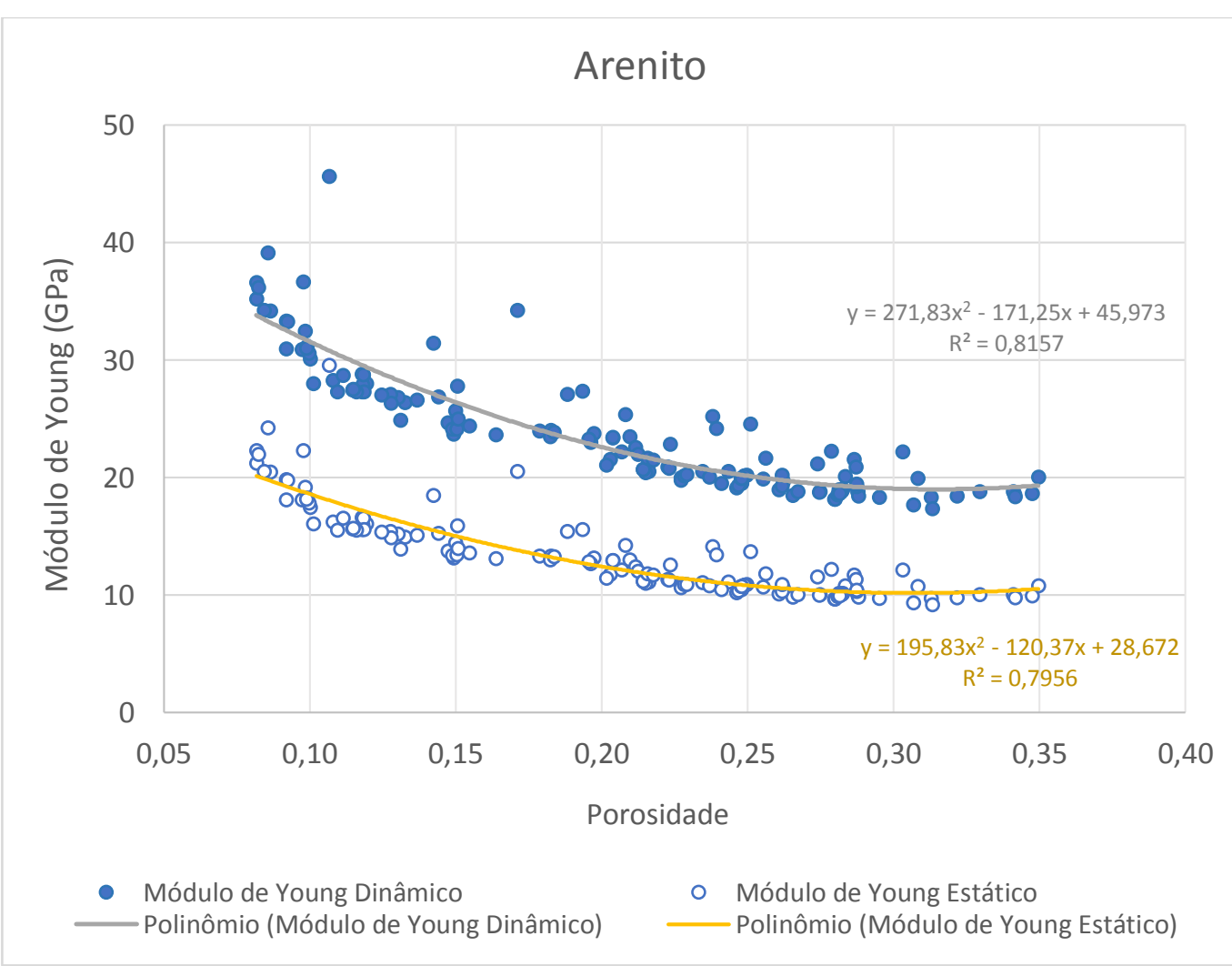

Figura 4. 23: Curvas de módulo de Young estático e dinâmico geradas pelos dados de arenitos obtidos dos cincos poços perfilados.

Em função da menor incidência de carbonatos nos resultados obtidos na janela de profundidade avaliada nos perfis e da deposição complexa que caracteriza o overburden e descrita na seção 4.2, optou-se por considerar as rochas adjacentes 
pertencentes a fácies folhelho. A fim de garantir uma maior proximidade com a realidade, o overburden foi dividido em 3 regiões, também tomando a porosidade como critério diferenciador.

A primeira região se estende do topo do reservatório (aproximadamente 3.000 metros) até profundidade de 2.000 metros e apresenta as mesmas propriedades do sideburden. Tanto o módulo de Young como o coeficiente de Poisson do sideburden foram considerados iguais a média dessas propriedades obtidas na perfilagem e apresentadas na Tabela 4.5.

Dessa forma, após a aplicação da correlação de Lacy [12], o sideburden apresenta módulo de elasticidade estático de 13,7 GPa e coeficiente de Poisson igual a 0,22 . A porosidade média do folhelho em ambas regiões é de $18 \%$.

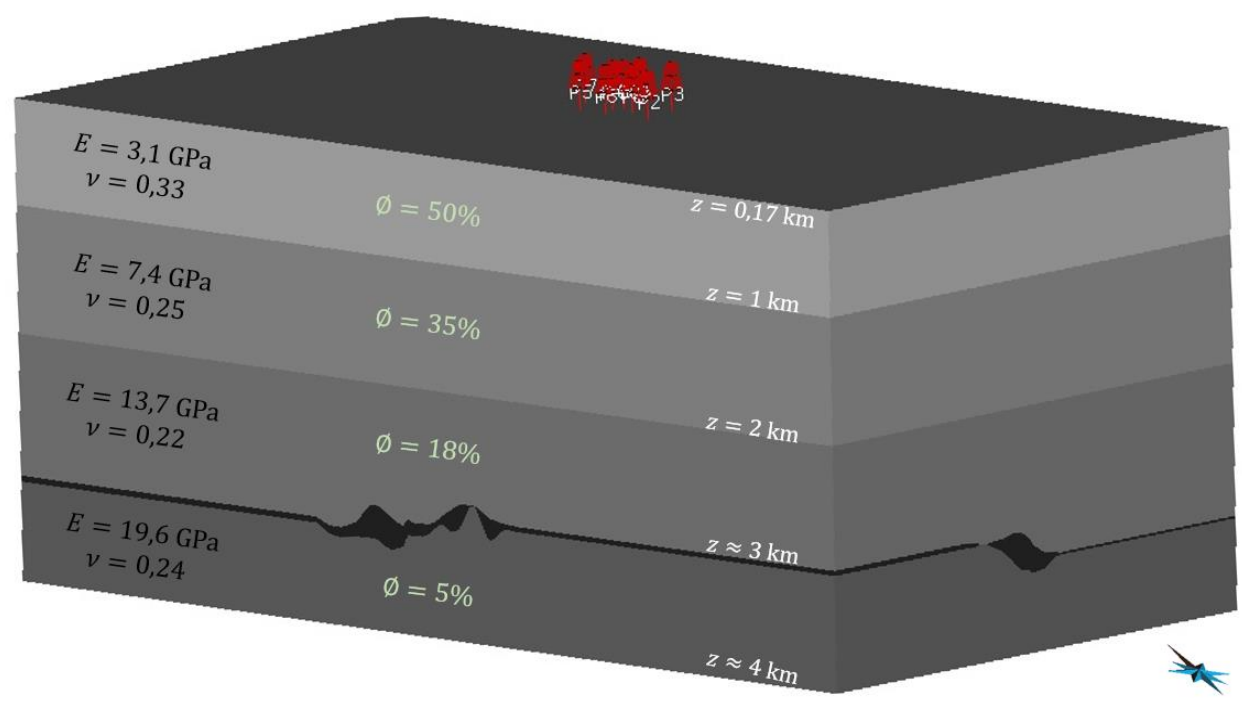

Figura 4. 24: Representação das rochas adjacentes com seus respectivos módulos de elasticidade estáticos, coeficientes de Poisson e porosidades.

Uma segunda zona se estende de 1.000 a 2.000 metros e apresenta porosidade média de $35 \%$. Por se tratar de uma profundidade não atingida pelos perfis utilizados nesta dissertação, foi a partir da Figura 4.26 que se obteve a estimativa de porosidade que serviu de base para obtenção dos módulo de Young estático $(E=7,4 \mathrm{GPa})$ e do coeficiente de Poisson $(v=0,25)$ com o uso da correlação obtida na Figura 4.25 e dados expostos na Figura 4.17, respectivamente. 


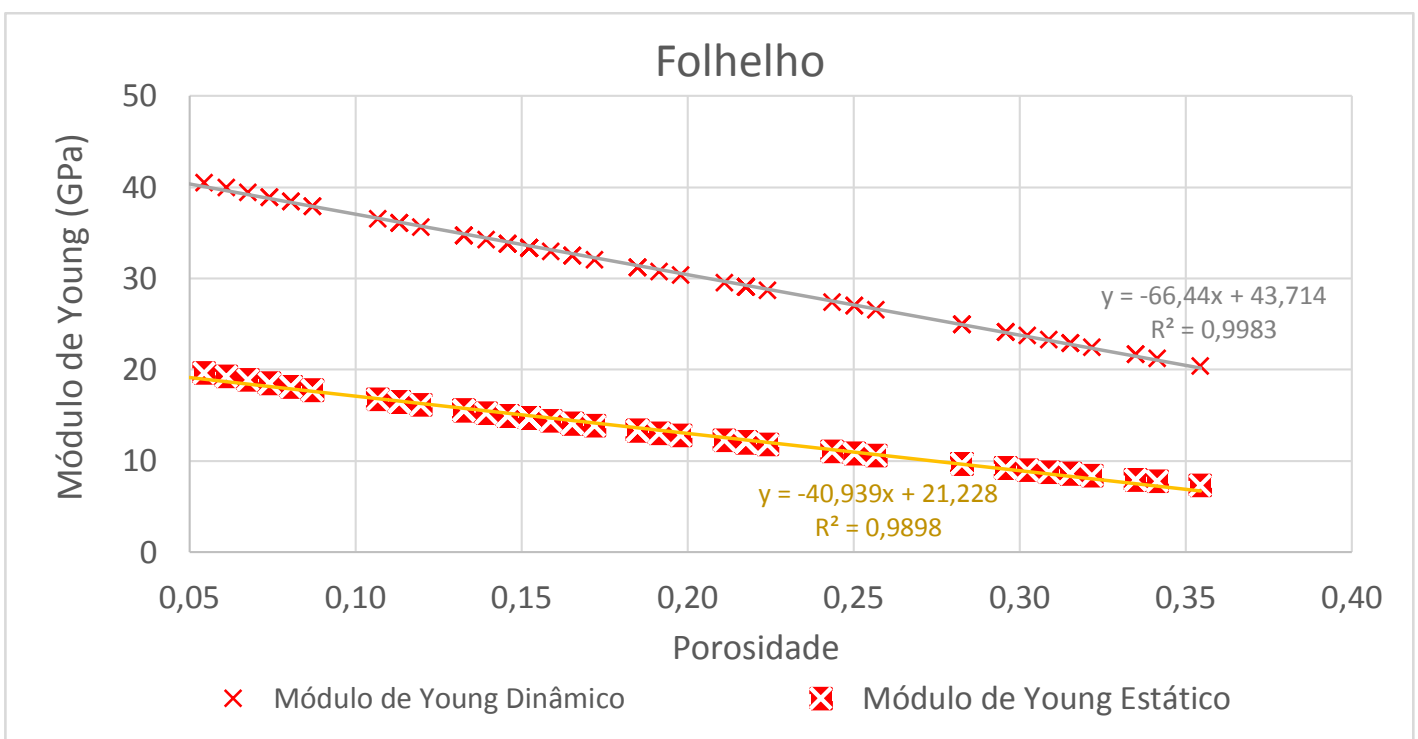

Figura 4.25: Curvas de módulo de Young estático e dinâmico geradas pelos dados de folhelhos obtidos dos cincos poços perfilados.

Uma última região no overburden está localizada entre as profundidades de

170 metros e 1.000 metros e, atribuiu-se a esta zona, também ao tomar por base a figura a seguir, uma porosidade média igual $50 \%$.

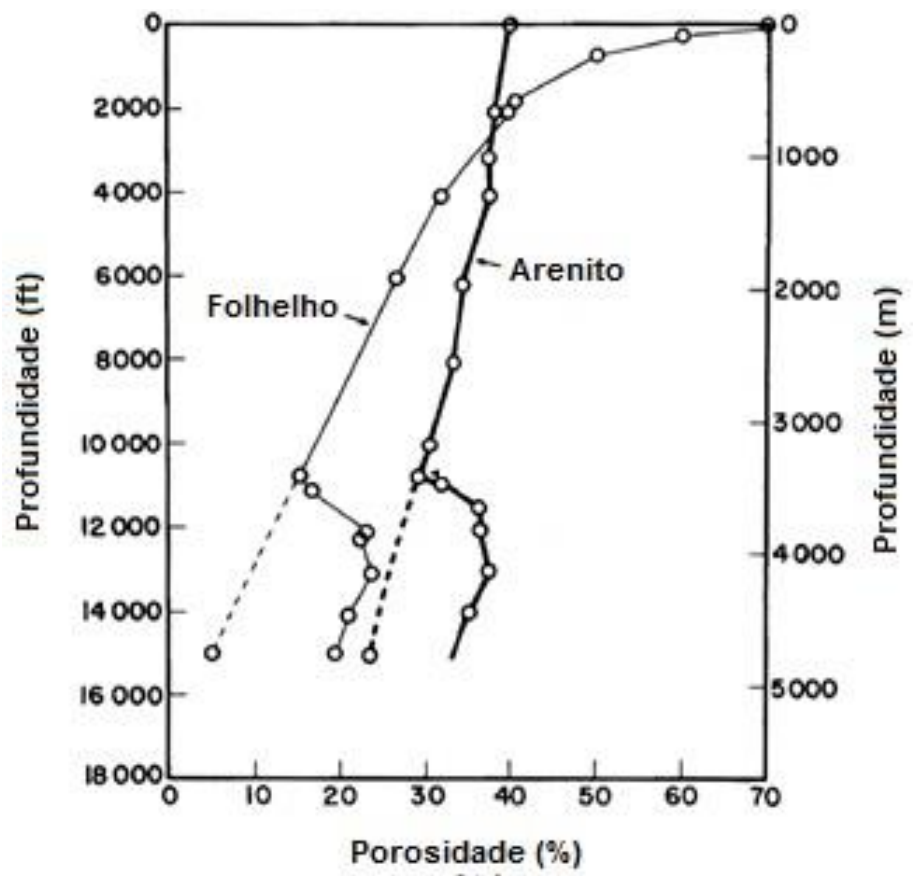

Figura 4. 26: Relação entre porosidade e profundidade para regiões formadas por arenito e folhelho (modificado de Stuart [52])

Um último dado que pode ser dimensionado é a tensão in situ. Entretanto, é importante ressaltar que as análises realizadas na metodologia apresentada são lineares e elásticas. Significa dizer que o estado inicial de tensões in situ não gera 
efeitos nos resultados buscados neste trabalho (deslocamentos, vazão de fluidos, RGO, pressão de poros) como em uma análise que envolve plasticidade.

Na tabela a seguir é mostrado o gradiente de tensão para cada camada do overburden. $\mathrm{O}$ valor médio do gradiente da tensão vertical para as três camadas do overburden é de $20,8 \mathrm{KPa} / \mathrm{m}$ (obtido por meio dos dados da tabela a seguir gerada com base na composição mineralógica das fácies), sendo os valores das tensões horizontais iguais à metade do vertical.

Tabela 4. 8: Gradiente de tensão em função da camada do overburden.

\begin{tabular}{|l|c|c|c|c|}
\cline { 2 - 3 } \multicolumn{1}{c|}{} & Espessura & Porosidade & $\begin{array}{c}\text { Composição } \\
\text { mineralógica (\%) }\end{array}$ & $\begin{array}{c}\text { Gradiente de Tensão } \\
\text { Vertical (KPa/m) }\end{array}$ \\
\hline & $170 \mathrm{~m}$ & \multicolumn{2}{|c|}{ Água do mar } & 10 \\
\hline Camada 1 & $830 \mathrm{~m}$ & $50 \%$ & \multirow{2}{*}{$\begin{array}{c}\text { Quartzo }=30 \% \\
\text { Calcita }=25 \%\end{array}$} & 18,3 \\
\cline { 1 - 3 } Camada 2 & $1.000 \mathrm{~m}$ & $35 \%$ & Argila $=45 \%$ & 20,6 \\
\cline { 1 - 3 } Camada 3 & $1.000 \mathrm{~m}$ & $18 \%$ & 23,1 \\
\hline
\end{tabular}




\section{5. \\ Estudo de Casos}

Esse capítulo tem como objetivo comparar os resultados gerados pelas simulações de fluxo e geomecânica no Campo de Namorado para um período de produção de hidrocarbonetos de 15 anos, divididos em 110 intervalos de tempo que são crescentes a partir do passo inicial. Em média, uma simulação desse porte com a metodologia GTEP/PUC-Rio em GPU e com a presença de 2,2 milhões de nós na malha de elementos finitos apresentou uma duração de 8,5 horas. Significa dizer, que para cada passo de tempo simulado foram gastos 5 minutos, aproximadamente.

No subcapítulo 5.1, são comparados parâmetros de fluxo resultantes da simulação sem acoplamento geomecânico com a simulação parcialmente acoplada de duas vias desenvolvida pelo GTEP/PUC-Rio. O cenário parcialmente acoplado faz uso dos dados mecânicos (módulo de Young e coeficiente de Poisson) obtidos ao longo da dissertação, compondo assim, o cenário original ou cenário $\mathrm{R} \mathrm{A}$, onde "R" se refere a "reservatório" e "A" se refere a "adjacente". O porquê dessa nomenclatura será entendido a seguir. Já no subcapítulo 5.2, o enfoque é dado aos resultados geomecânicos obtidos pela análise acoplada.

A nomenclatura $\mathrm{R}$ e $\mathrm{A}$ é bastante útil nesse capítulo para facilitar o entendimento de qual cenário está sendo analisado. Por exemplo, no subcapítulo 5.3, o objetivo é verificar as mudanças no comportamento mecânico e de fluxo para cenários com rochas adjacentes mais ou menos rígidas. Dessa forma, o cenário $\mathrm{R}$ A+ apresentará overburden, sideburden e underburden mais rígidos do que os presentes no cenário R A. Essa é a justificativa para o uso do “+” após o "A”. Nesse subcapítulo também é analisado o caso com rochas adjacentes menos rígidas, ou seja, o cenário R A-.

No subcapítulo 5.4, o foco será dado à mudança de rigidez do arenito que compõe o reservatório. Dessa forma, são inseridos os cenários R-A e R+A como fonte de análise.

No subcapítulo 5.5, é deixado de lado o foco nas mudanças de propriedades mecânicas das rochas e a visão estará direcionada à variação do grau API do óleo. São analisados cenários R A com óleo médio e pesado, juntamente ao cenário R A composto de óleo leve previamente avaliado nos subcapítulos 5.1 e 5.2. 


\section{1 \\ Comparação de resultados de fluxo gerados entre método de acoplamento GTEP/PUC-Rio e simulação sem acoplamento para o cenário $\mathbf{R} \mathbf{A}$}

Como descrito no capítulo anterior, o cenário $\mathrm{R}$ A é composto por rochas adjacentes formadas por folhelhos, enquanto que o reservatório é arenítico. A distribuição dos módulos de Young e coeficiente de Poisson, com o detalhamento do método de obtenção dessas propriedades mecânicas para este cenário, podem ser revisados nos capítulos 3 e 4 e se encontram resumidos na figura a seguir.

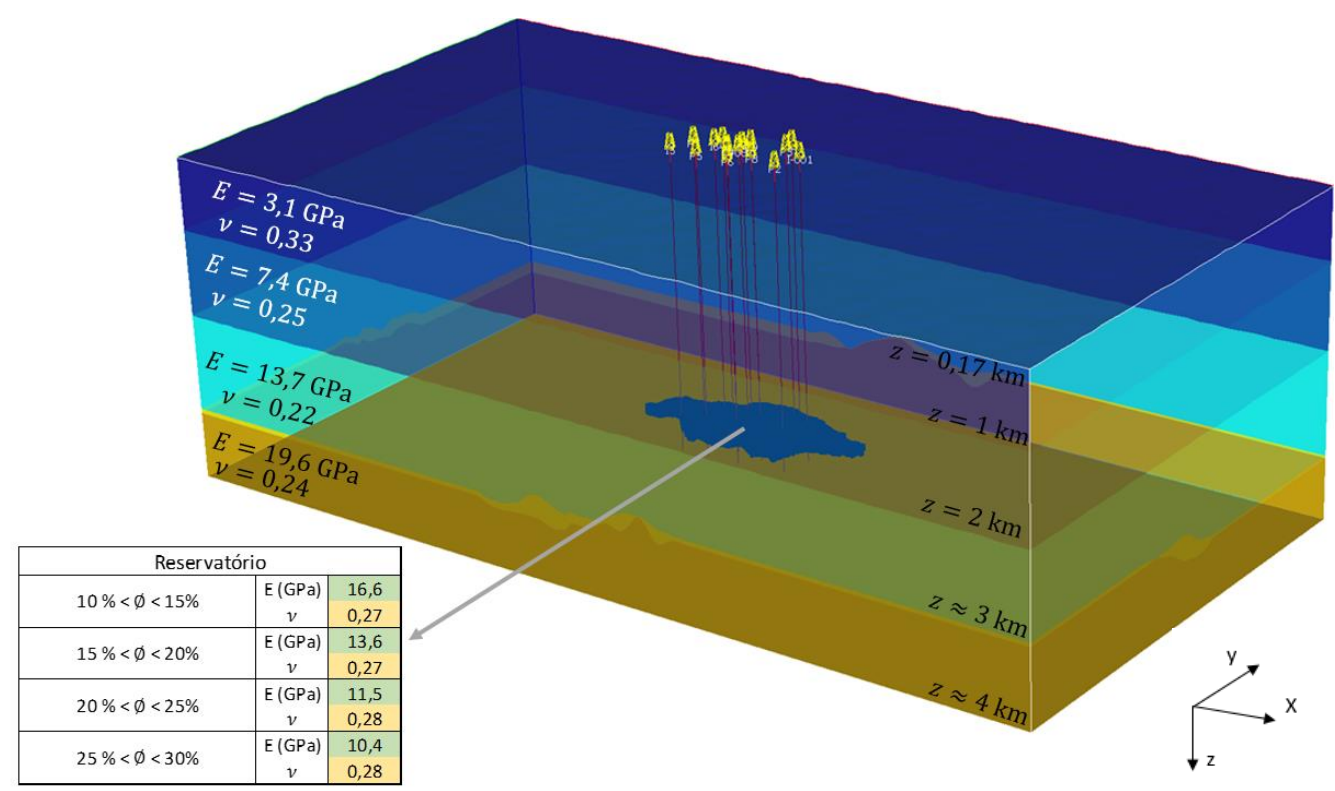

Figura 5. 1: Representação do reservatório e rochas adjacentes com seus respectivos módulos de Young e coeficientes de Poisson para o cenário R A.

A Figura 5. 2 mostra o histórico de volume acumulado de óleo do cenário sem acoplamento (identificado pela letra $S$ ) de compressibilidade do volume poroso $1,5 \times 10^{-5}\left(\mathrm{kgf} / \mathrm{cm}^{2}\right)^{-1}$ obtido nesta dissertação. Ao fim dos 15 anos de simulação, o volume de óleo produzido atingiu a soma de 20,3 milhões de $\mathrm{m}^{3}$. O fator de recuperação desse campo sem injeção de fluido atingiu a ordem de $17 \%$.

Ao fim do primeiro ano, houve a explotação de $15,1 \%$ de todo óleo produzido no histórico de uma década e meia. Por se tratar de uma simulação sem injeção de fluido, a vazão de óleo apresentou um comportamento de queda durante todo o período em função da redução da pressão média de poros no reservatório. Dessa forma, a vazão de óleo caiu de $9.000 \mathrm{~m}^{3} /$ dia para $8.150 \mathrm{~m}^{3} /$ dia ao fim dos primeiros 365 dias. 


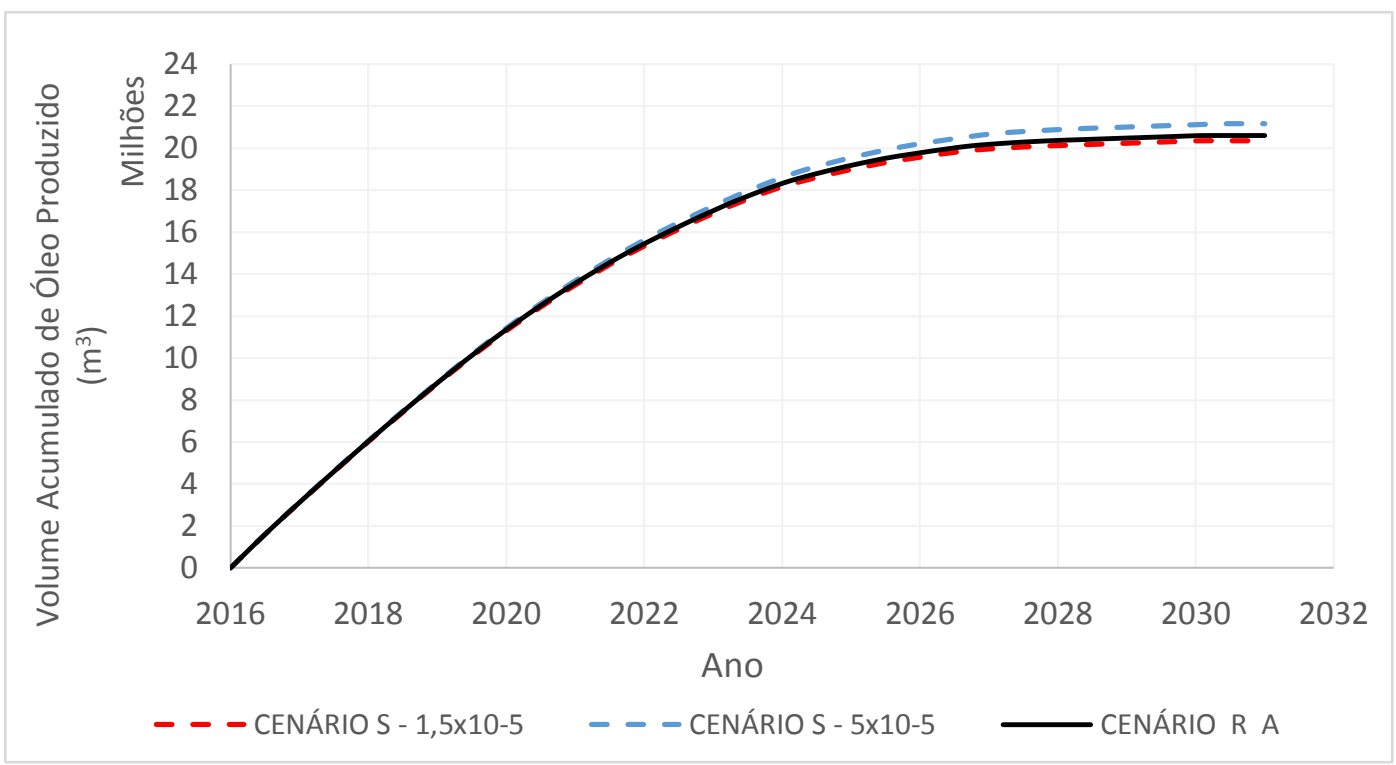

Figura 5. 2: Curvas de volume acumulado de óleo explotado do Campo de Namorado com e sem acoplamento geomecânico.

Ao completar 3 anos de produção, os poços já haviam produzido 42,8\% do volume total de óleo que viria a ser produzido. A vazão, por sua vez, continuou sua queda e atingiu o patamar de $7.350 \mathrm{~m}^{3} /$ dia. Com 9 anos de simulação, 93,3\% do total de óleo que seria extraído das rochas já havia sido produzido e a vazão alcançou valor de $2.000 \mathrm{~m}^{3} /$ dia.

Ainda pela Figura 5.2, observa-se que o comportamento do cenário R A com acoplamento geomecânico foi bem próximo à simulação desacoplada de $1,5 \times 10^{-5}$ $\left(\mathrm{kgf} / \mathrm{cm}^{2}\right)^{-1}$. A consequência da presença das rochas adjacentes atuando no sistema permitiu a produção de mais $300 \mathrm{mil} \mathrm{m}^{3}$ de óleo, representando um ganho de 1,2\%.

Já a linha pontilhada em azul representa a simulação sem acoplamento com compressibilidade igual a $5 \times 10^{-5}\left(\mathrm{kgf} / \mathrm{cm}^{2}\right)^{-1}$ e que estava presente na descrição do modelo de simulação desse campo (.dat) para IMEX e cedido pela Petrobras para estudos acadêmicos. Por se tratar de um cenário mais compressível, o resultado se reflete na maior produção de óleo, mais precisamente $4 \%$ superior ao cenário sem acoplamento de compressibilidade $1,5 \times 10^{-5}\left(\mathrm{kgf} / \mathrm{cm}^{2}\right)^{-1}$, obtida ao longo dessa dissertação.

Como não há injeção de fluidos nas simulações deste trabalho (em função dos muitos outros cenários que traria a necessidade de análise e que fogem ao escopo dessa dissertação), a queda de pressão de poros ao longo do tempo se dá pela redução do volume total de óleo antes presente no reservatório. O Campo de Namorado não apresentava gás livre na fase anterior à simulação. Significa dizer 
que a vazão de gás nos primeiros dias é resultado apenas da liberação, ao longo dos poços, da fase gasosa que se encontrava dissolvida no óleo, como pode ser visto na Figura 5.3.

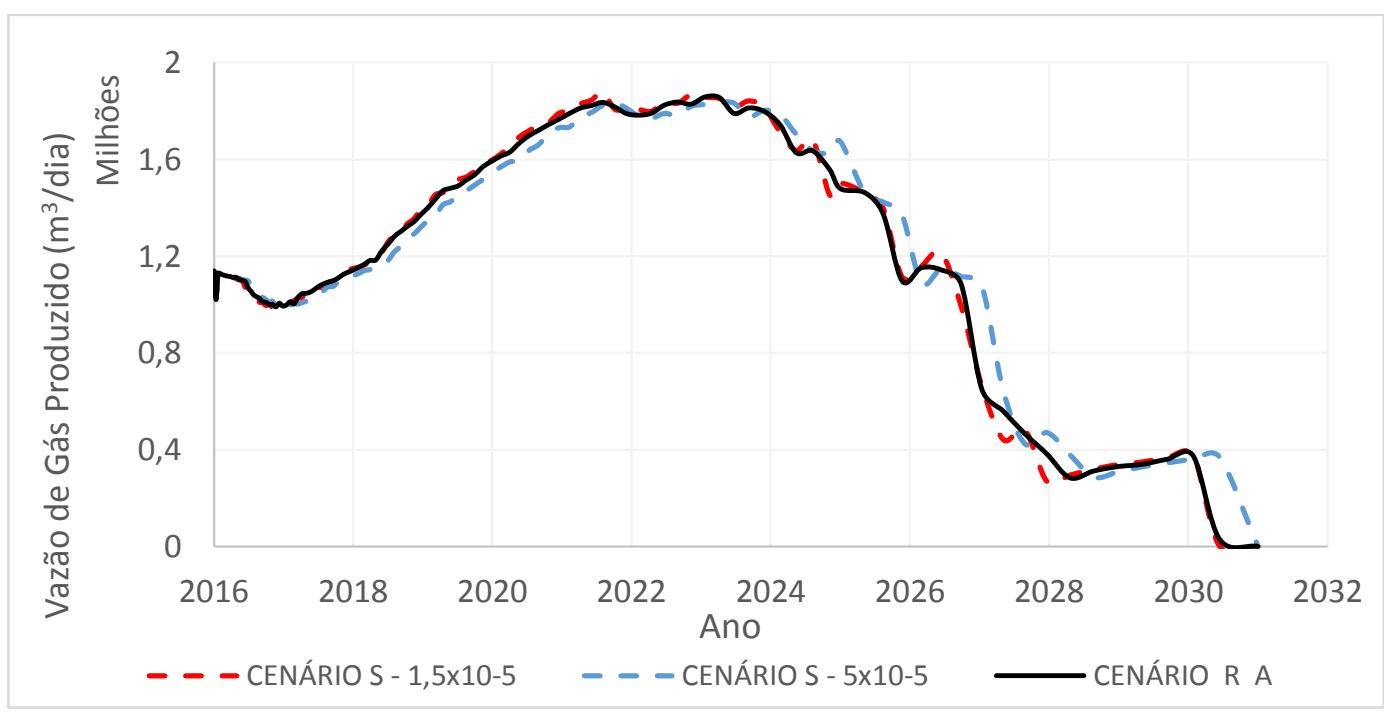

Figura 5. 3: Curva de vazão de gás em condições standard para cenários com e sem acoplamento geomecânico.

Como o objetivo desse trabalho também é investigar os efeitos do acoplamento dentro do reservatório, é preciso verificar como a liberação de gás ocorre dentro dessa região nas condições ali encontradas. A partir disso, pode-se traçar a curva de liberação de gás (Figura 5.4) dentro do arenito que compõe o reservatório.

A ausência de liberação de gás nos primeiros meses dentro do reservatório (Figura 5.4) e a ausência de aquíferos alimentando o sistema indicam que a produção de óleo, nesse período, é realizada por meio do seguinte ciclo. À medida que o óleo é produzido, a pressão de poros cai e permite a expansão dos fluidos ali presentes, em sua maioria, óleo e água conata. $\mathrm{O}$ volume de poros também sofre uma redução nesse processo de queda de pressão em função da compressibilidade do volume poroso e gera a expulsão desse fluido expandido. Por sua vez, mais fluido produzido gera maior queda de pressão. Dessa forma, a produção de óleo, principalmente nos 6 meses iniciais, é resultado da combinação desses processos de expansão de fluido e contração do meio poroso.

A partir do sexto mês de produção de fluidos, a liberação de gás sofre uma repentina aceleração, ou seja, a taxa dispara de um tímido valor (quando comparado com a vazão de óleo no mesmo período) de $100 \mathrm{~m}^{3} /$ dia para um ápice de 20.000 $\mathrm{m}^{3} /$ dia em um espaço de tempo de apenas 4 meses. 


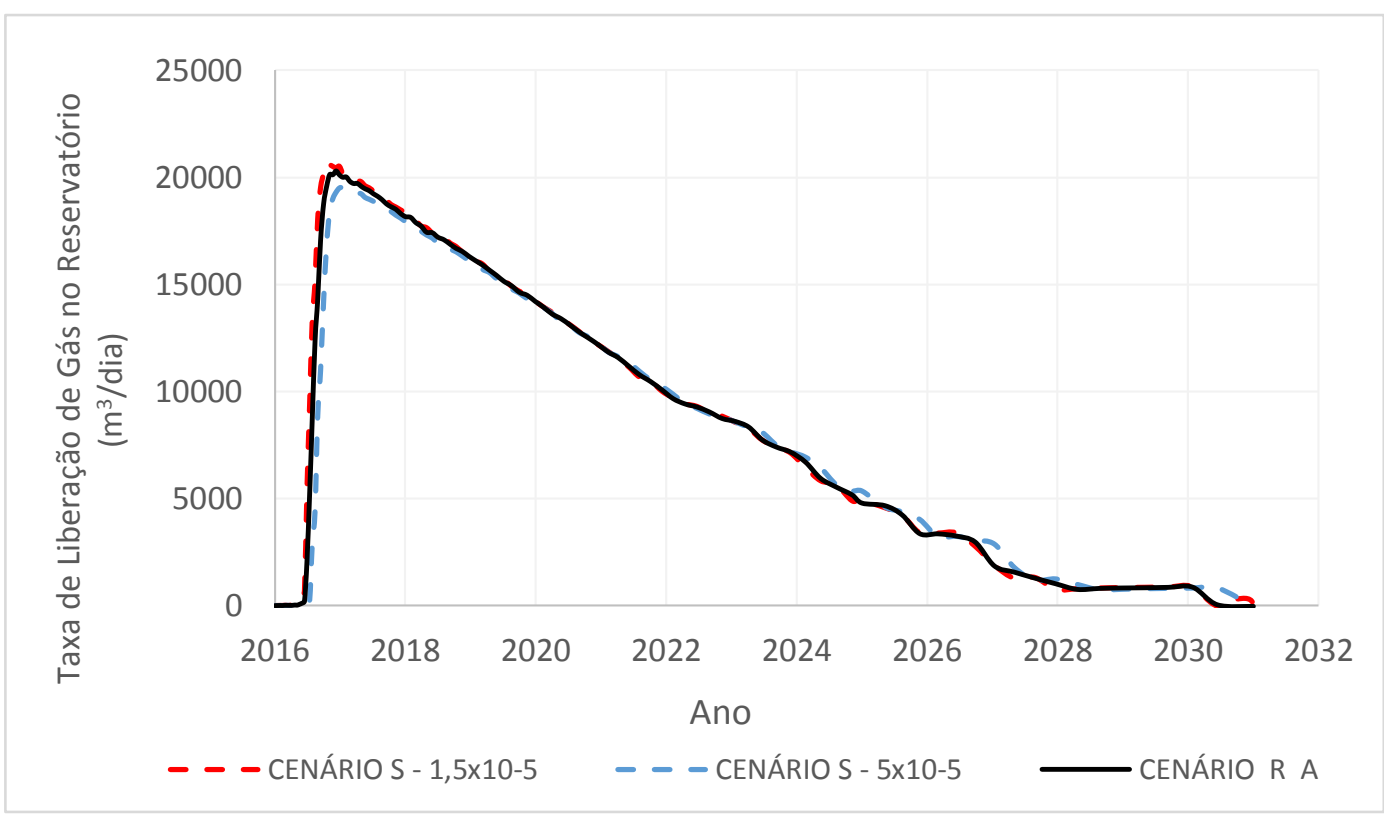

Figura 5. 4: Curva de liberação de gás dentro do reservatório para cenários com e sem acoplamento geomecânico.

Apesar disso, os fluidos e a formação rochosa apresentam baixas compressibilidades e permitem que a pressão sofra uma queda acentuada. Tal comportamento tem como consequência o alcance do ponto de pressão de bolha do óleo com liberação de gás. A partir daí as reduções de pressão promovem maior desprendimento de gás, permitindo que o mecanismo de gás em solução atue efetivamente. O gás passa a ser o principal responsável pelo deslocamento da fase líquida para fora da formação a partir desse ponto. Como a fase gasosa é muito mais expansível que o óleo, é a partir dessa expansão que há maior manutenção de pressão de poros no reservatório, como pode ser visto na figura a seguir.

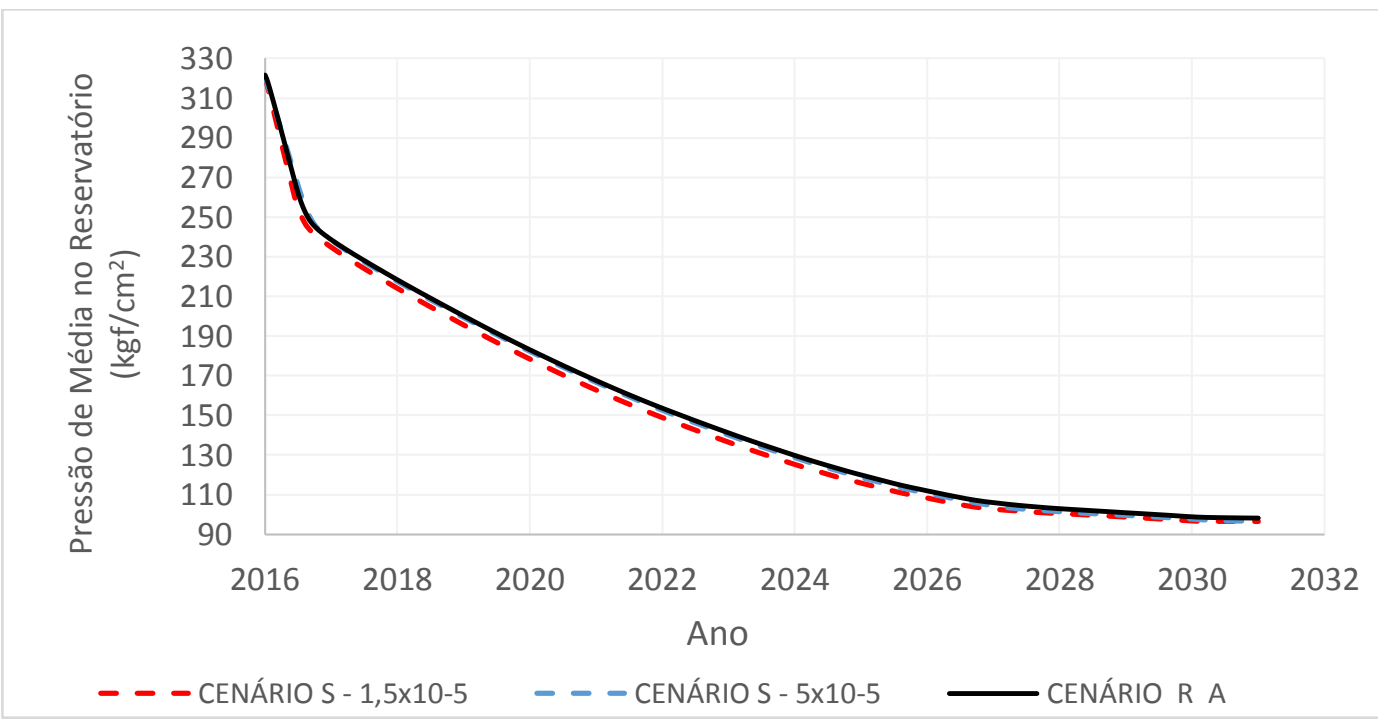

Figura 5. 5: Queda da pressão média do reservatório para cenários com e sem acoplamento geomecânico. 
A partir do nono mês de simulação, ou seja, no ponto central do período compreendido entre a liberação mais efetiva de gás em junho e o ápice em novembro, a derivada da curva de pressão sofre uma mudança mais brusca, indicando uma redução no perfil de queda de pressão no tempo por efeito do gás liberado (ver Figuras 5.4 e 5.5).

Após 2024, observa-se na Figura 5.5 que a queda de pressão volta a desacelerar em função da diminuição mais brusca nas vazões de óleo e gás produzidos. Outra informação importante que o gráfico de pressão de poros fornece é a pressão mínima em que o sistema consegue produzir fluidos respeitando um limite de RGO imposto na simulação de $1.300 \mathrm{~m}^{3} / \mathrm{m}^{3}$. Ao atingir esse patamar, os poços são fechados. Inclusive nos cenários que serão ainda analisados neste capítulo, ficará claro que praticamente todas as simulações tem seu fim com a pressão poros atingindo um valor em torno de 99 a $100 \mathrm{kgf} / \mathrm{cm}^{2}$ no momento que o critério de fechamento de todos os poços é concretizado. Alguns cenários terão grandes diferenças de pressão ao longo de sua vida produtiva, mas terão a pressão final, em fim de 2031, praticamente idênticas. Isso indica a importância de avaliar os cenários durante um longo período.

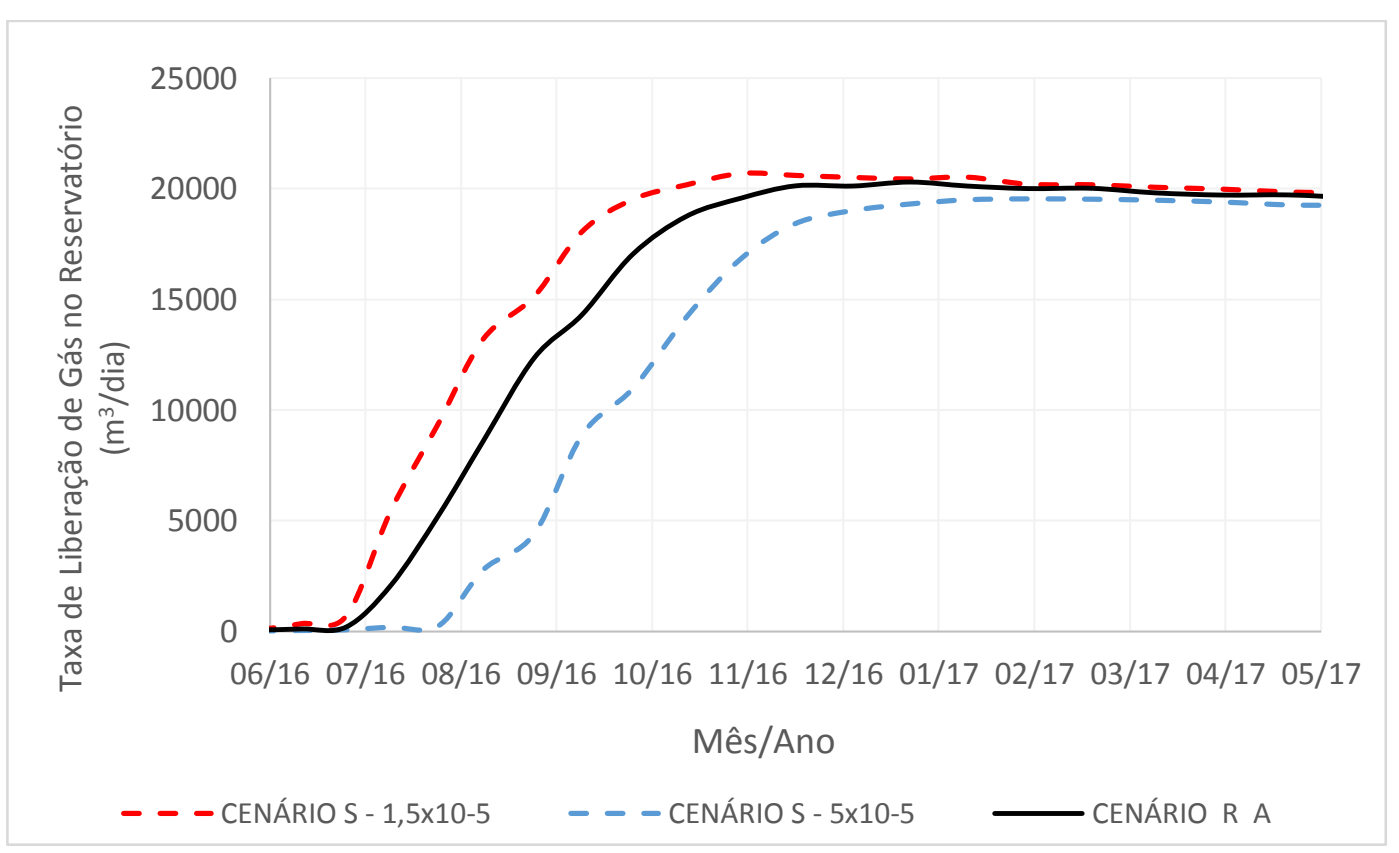

Figura 5. 6: Curva de liberação de gás dentro do reservatório para cenários com e sem acoplamento geomecânico para o período de junho de 2016 a maio de 2017.

Como visto na Figura 5.2, o cenário acoplado apresentou maior recuperação de óleo quando comparado ao cenário sem acoplamento de compressibilidade $1,5 \times 10^{-5}\left(\mathrm{kgf} / \mathrm{cm}^{2}\right)^{-1}$. A utilização de módulos elásticos com a consequente 
mensuração da deformação do reservatório no método GTEP/PUC-Rio ao invés de uma compressibilidade que considera o volume bulk constante como na simulação convencional de reservatórios foi a responsável pela diferença observada. O efeito de compressão do reservatório acoplado às rochas adjacentes não só produziu maior recuperação de óleo, como também manteve a pressão mais elevada ao longo de toda a simulação e retardou a liberação de gás, como está claro na figura a seguir que representa um zoom da Figura 5.4. Também é nítido que mesmo sem acoplamento às rochas que envolvem o reservatório, o cenário $\mathrm{S}$ de compressibilidade $5 \times 10^{-5}\left(\mathrm{kgf} / \mathrm{cm}^{2}\right)^{-1}$, em função da compressibilidade maior, apresentou o maior retardo na liberação da fase gasosa. Essa mesma compressibilidade foi a responsável pela maior produção de óleo, também identificado na Figura 5.2.

É importante mencionar que a ausência de uma equação de conversão do coeficiente de Poisson dinâmico para estático pode ser o responsável pelo comportamento da curva acoplada $\mathrm{R}$ A não ter se distanciado mais das curvas geradas pelo cenário sem acoplamento de compressibilidade $1,5 \times 10^{-5}\left(\mathrm{kgf} / \mathrm{cm}^{2}\right)^{-1}$.

\section{2}

Análise de resultados geomecânicos gerados pelo método de acoplamento GTEP/PUC-Rio para o cenário RA

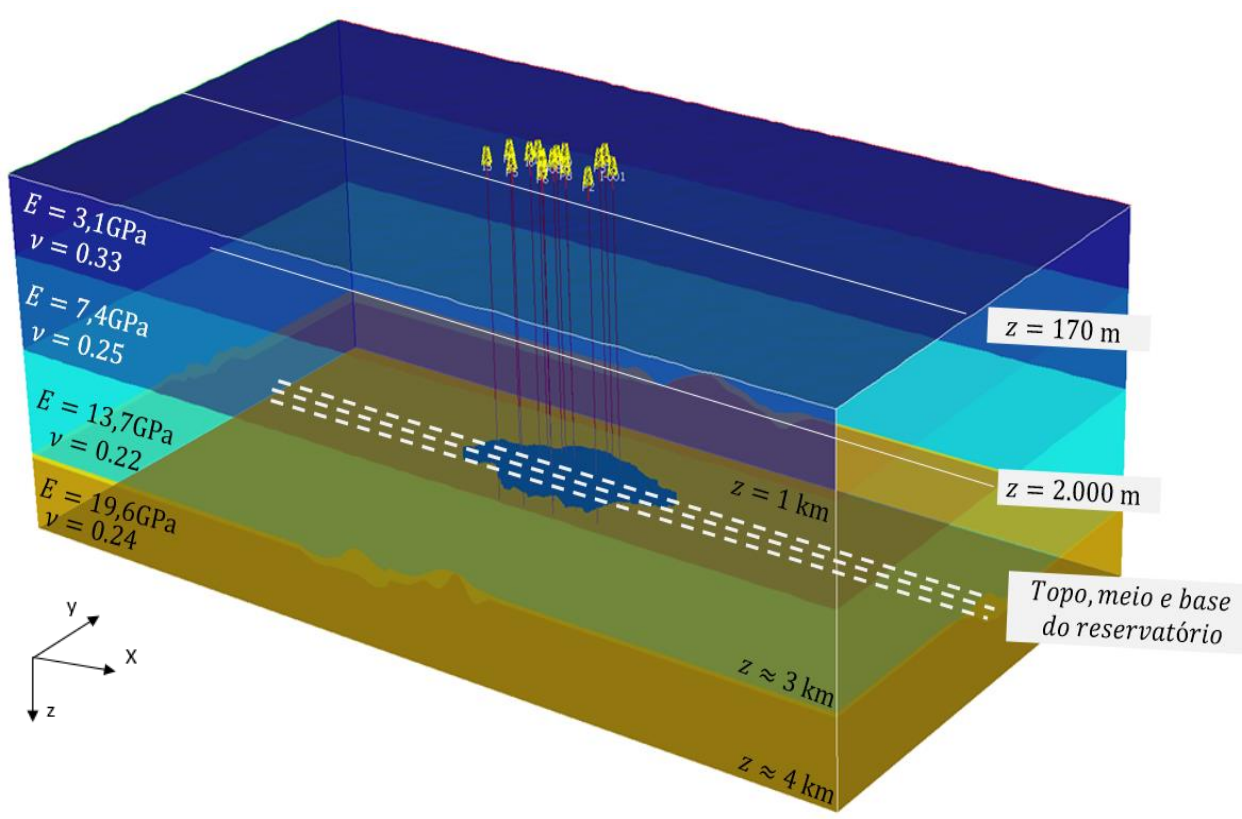

Figura 5. 7: Localização dos cincos horizontes selecionados para análise. 
Para análise dos deslocamentos, optou-se pela seleção de 5 horizontes de observação, como pode ser visto na figura acima. O primeiro se encontra na profundidade de 170 metros, onde está leito marinho e será identificado a partir daqui nos gráficos pela legenda " $Z=170 \mathrm{~m}$ ". O segundo horizonte estará numa região intermediária do overburden, mais especificamente na profundidade de 2.000 metros e será identificado por " $Z=2.000 \mathrm{~m}$ ”. Ambos são identificados por linhas cheias nas Figuras 5.7 e 5.8. Por fim, haverá 3 horizontes no reservatório (identificados por linhas tracejadas) que não obedecerão à critérios de profundidades, mas ao contorno do topo, meio e base do reservatório.

A partir da figura a seguir, pode-se tirar algumas conclusões a respeito do deslocamento dos horizontes selecionados. Foram plotados os dados para os anos 1,3 e 15 . O primeiro ponto a destacar é o pequeno deslocamento sofrido por todas as camadas, visto que em nenhum momento foi atingido um patamar superior a $18 \mathrm{~cm}$, principalmente se for levado em consideração o longo período analisado. Dessa forma, o deslocamento médio anual para o ponto da camada que sofreu maior alteração (topo do reservatório) foi igual a 1,2 cm/ano. Por meio da análise da figura, observamos, entretanto, que a taxa de deslocamento não foi constante no tempo. Por exemplo, para o primeiro ano, o topo do reservatório já apresentava pontos com deslocamento acima de $6 \mathrm{~cm}$, equivalentes a mais de $30 \%$ de todo o deslocamento nesta região ao fim da simulação.

Ao fim de 15 anos, deslocamentos acima de $1 \mathrm{~cm}$ são sentidos em todos os cinco horizontes e ao longo de todo comprimento de $8,5 \mathrm{~km}$ do reservatório, inclusive nas regiões próximas a fronteiras com rochas adjacentes laterais, onde o reservatório é menos espesso. Obviamente, alguns horizontes se deformam mais que outros em função da proximidade com a região que sofreu maior processo de perda de volume material e também em função do módulo de Young e coeficiente de Poisson que constituem cada camada. As maiores deformações são sentidas no topo do reservatório, principalmente até 3,2 3,8 km do centro do bloco de simulação. Para pontos mais distantes, os maiores deslocamentos são dos horizontes presentes no overburden, que possuem rochas menos rígidas. Inclusive, o horizonte do leito marinho é o mais deformável na região de 4,0 a 6,0 km do centro do modelo, em função de seu módulo de Young baixo e Poisson mais elevado. 


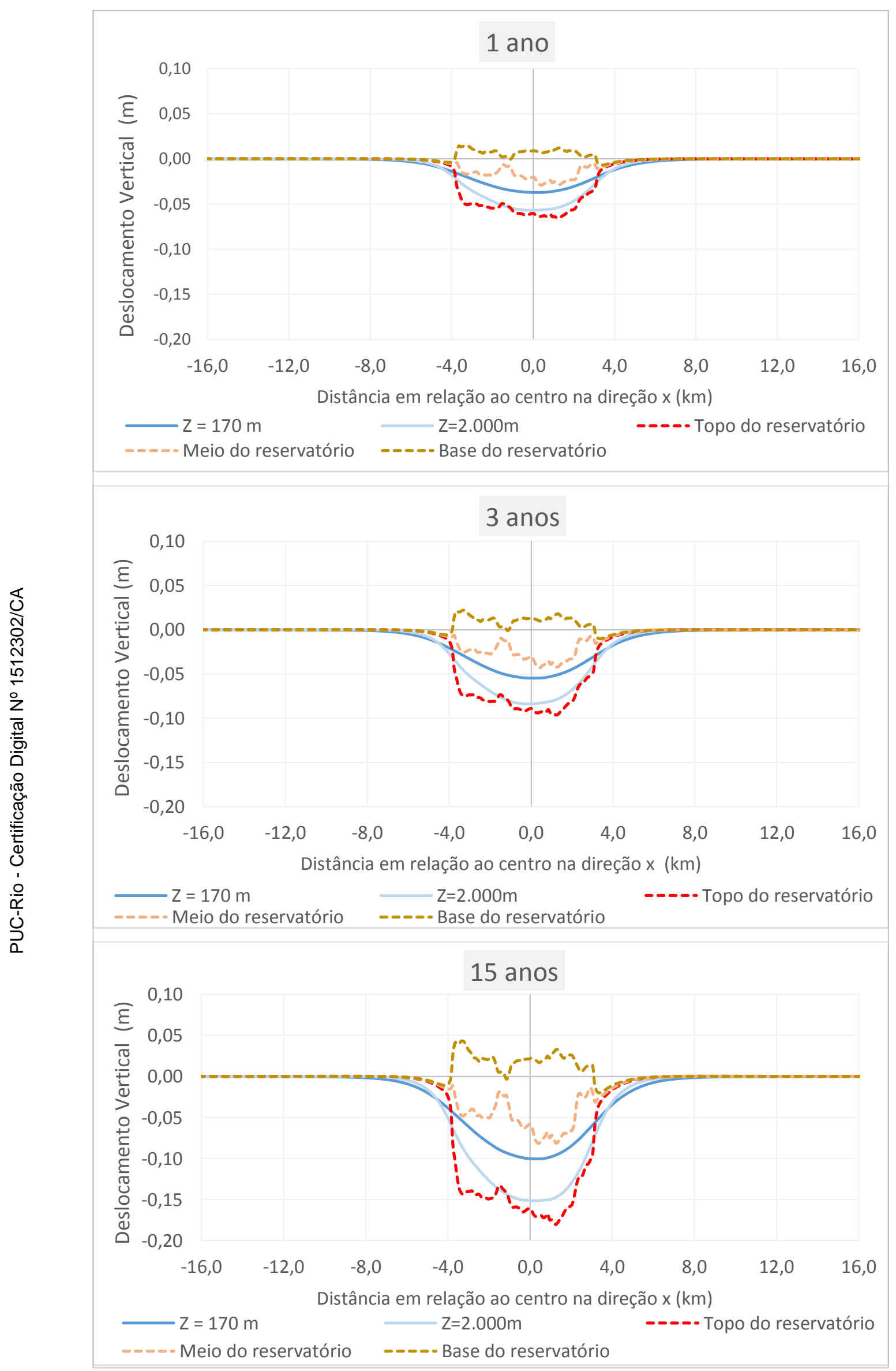

Figura 5. 8: Evolução dos deslocamentos dos cinco horizontes selecionados ao fim de 1, 3 e 15 anos de simulação. 
Outro ponto a destacar é o deslocamento do overburden. Para os dois horizontes analisados nessa área, observa-se que os pontos de maior deslocamento se encontram na região central do modelo de simulação, ponto onde se encontra o reservatório em profundidades maiores. O leito marinho, ao longo de todo processo, sempre se deslocou menos que os horizontes a 2.000 metros e o topo do reservatório. Umas das justificativas se encontra no fato de que o reservatório se deforma primeiro, visto que é a região que sofre depleção e, além disso, somente parte das consequências dessa deformação mecânica são sentidas no leito marinho. O topo do reservatório sofreu compactação de $2 \mathrm{~cm}$ com 4 meses de produção do campo. Já o leito marinho, só atingiu tal ponto após 6 meses. É preciso ressaltar também que esse dado é referente a um período de simulação no qual a liberação de gás era praticamente nula. Quando o reservatório já se encontra repleto de gás, esse processo se intensifica. $O$ deslocamento no topo do reservatório vai de $6,5 \mathrm{~cm}$ a 7,5 cm em apenas 8 meses. Por sua vez, no topo do overburden, esse mesmo efeito de deslocamento (de $6,5 \mathrm{~cm}$ para $7,5 \mathrm{~cm}$ ) dura 20 meses. Tal fato leva à necessidade de avaliar as velocidades com que esses horizontes se deslocam. Como podemos ver na figura a seguir, do sexto ao décimo mês, a velocidade de deslocamento do topo do reservatório é reduzida drasticamente. O ponto que sofre maior deslocamento nesse horizonte tem sua velocidade diminuída de $0,24 \mathrm{~mm} /$ dia para $0,06 \mathrm{~mm} /$ dia (queda de 75\%). Já no horizonte do leito marinho, a diminuição da velocidade do ponto de maior deslocamento ocorre de forma mais evidente entre o oitavo e décimo terceiro mês. Neste intervalo de tempo, sua velocidade vai de 0,15 $\mathrm{mm} /$ dia para $0,3 \mathrm{~mm} /$ dia, indicando uma redução de $80 \%$.

Quando as curvas de taxas de deslocamento mencionadas acima são postas num mesmo gráfico com a taxa de liberação de gás, vemos com nitidez a relação entre os fatos. Ao atingir o pico de desprendimento de gás no $10^{\circ}$ mês, as velocidades de deslocamento dos horizontes passam a cair de maneira menos drástica. Nos seis meses iniciais da simulação, desprovidos de grandes quantidades de gás livre no sistema, os deslocamentos apresentavam uma desaceleração mais controlada pela expansão do óleo. Nesse período, a queda da taxa diária de deslocamento do topo do reservatório foi de $16,5 \%$. Para o horizonte de leito marinho, a redução foi de $6 \%$.

Outro ponto importante na análise da Figura 5. 8 é a base do reservatório que sofre um processo de soerguimento. O ponto de deslocamento máximo ao fim 
dos 15 anos de simulação representa $23,8 \%$ do deslocamento máximo do topo do reservatório.

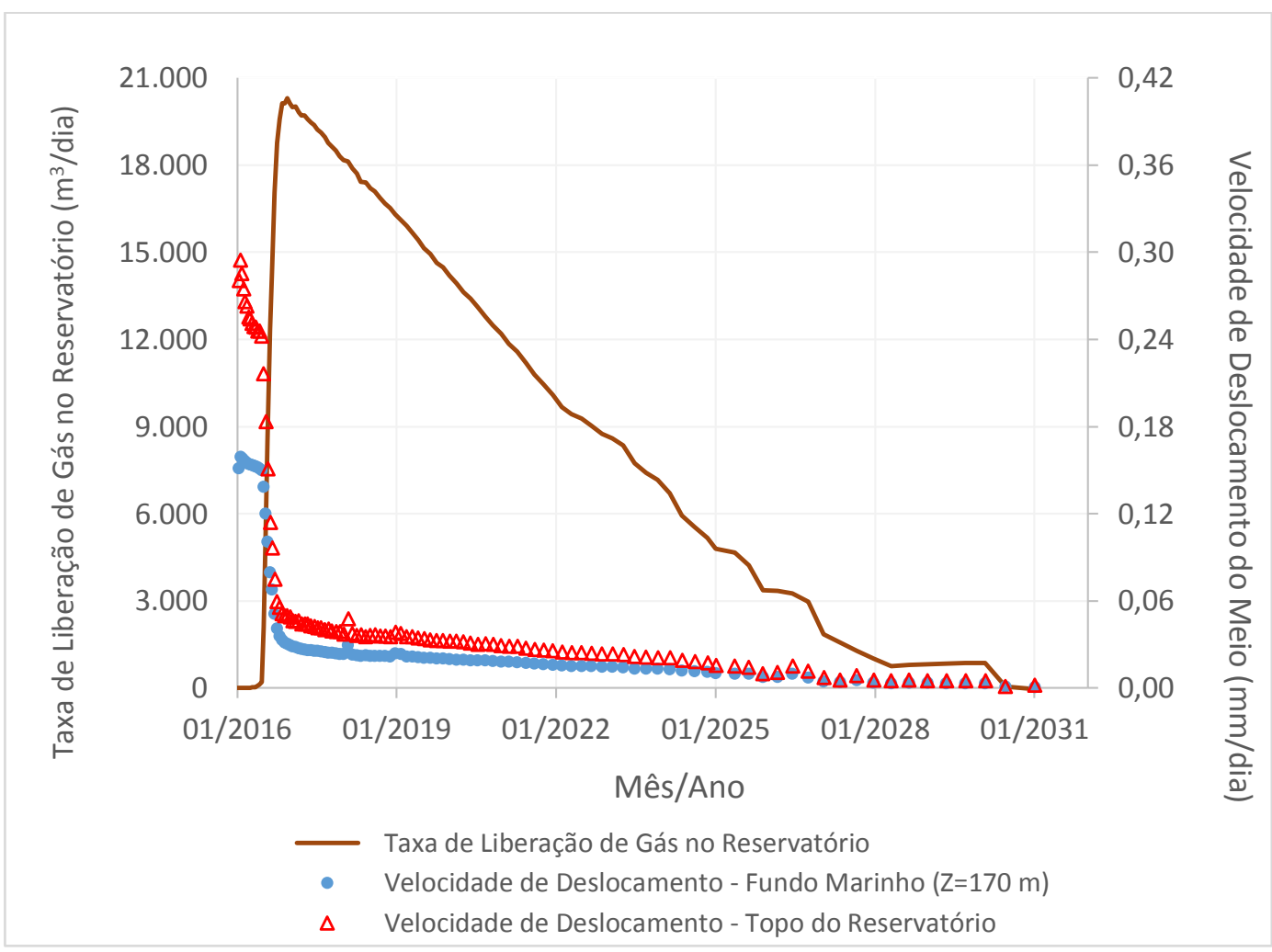

Figura 5. 9: Taxa de liberação de gás no reservatório e velocidades de deslocamento do leito marinho e topo do reservatório para o período de 15 anos de simulação.

Uma questão pertinente é avaliar até que ponto o refinamento na distribuição das propriedades mecânicas do overburden impacta no deslocamento dos horizontes quando comparado a um overburden homogêneo ao longo dos 3.000 metros, ou seja, como são simulados em alguns trabalhos relacionados ao tema de acoplamento geomecânico. Para responder a essa questão foi feita uma simulação utilizando como dados as médias utilizadas no cenário R A. Dessa forma, todas as 3 camadas acima do topo do reservatório apresentam $E=8,4 \mathrm{GPa}$ e $v=0,26$. Os deslocamentos obtidos para três horizontes se encontram na figura a seguir, ao fim do $15^{\circ}$ ano.

O gráfico indica que considerar o refinamento do overburden em camadas com propriedades distintas para o Campo de Namorado também significa obter resultados de deslocamentos menores na superfície do leito marinho $(-3,3 \%$ no ponto de maior deslocamento) e no topo do reservatório (-5,8\%). Para a profundidade de 2.000 metros, o deslocamento observado foi maior $(+5,5 \%)$ no cenário de maior refinamento. 


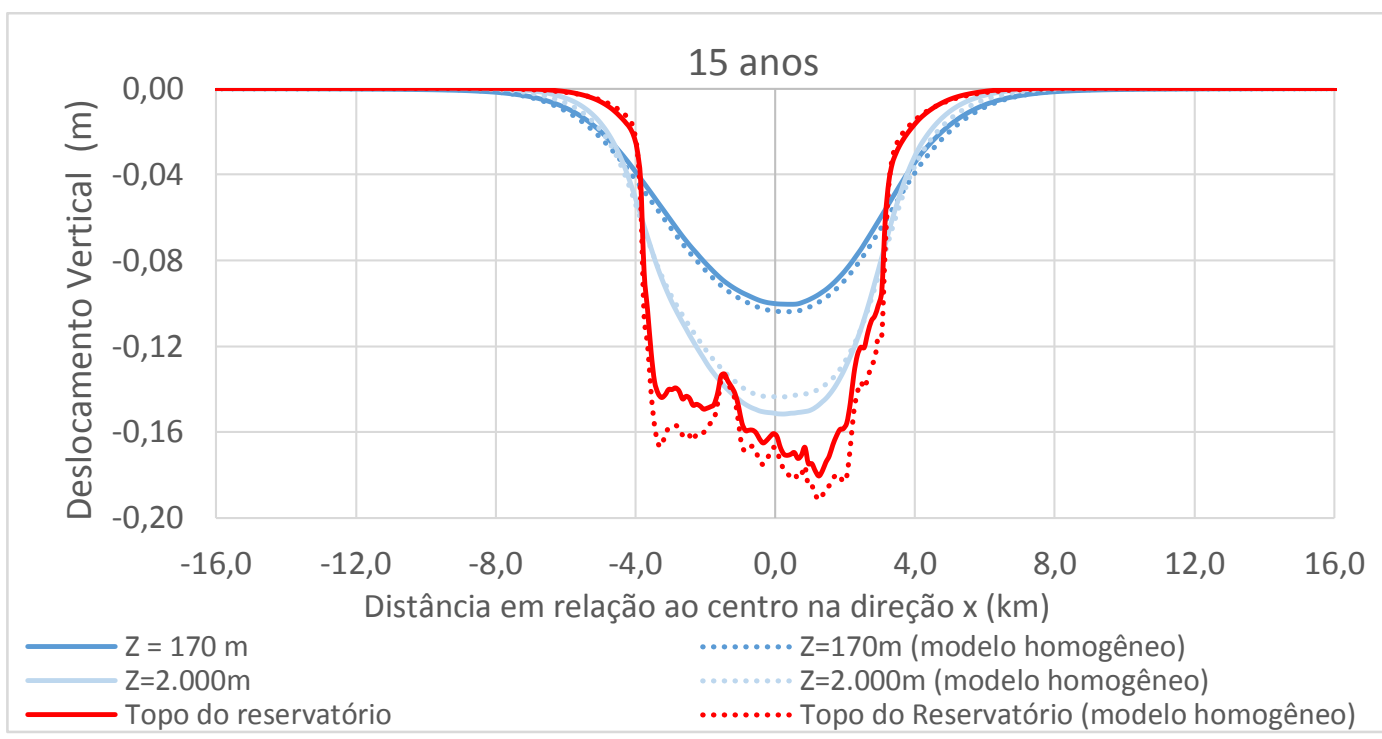

Figura 5.10: Comparação entre deslocamentos para 3 horizontes no cenário R A refinado no overburden e no cenário com overburden totalmente homogêneo.

\section{3 \\ Comparação de resultados entre o cenário $\mathbf{R} \mathbf{A}$ e outros cenários com diferentes propriedades mecânicas nas rochas adjacentes}

\subsection{1 \\ Definição dos cenários analisados}

O objetivo desse subcapítulo é comparar os resultados de fluxo e mecânicos entre o cenário R A, detalhado nos dois subcapítulos anteriores, com cenários com mudanças nos módulos de Young e coeficiente de Poisson de forma a tornar as rochas adjacentes mais ou menos rígidas. O reservatório não sofrerá alterações em suas propriedades. Para atender a esses objetivos, foram gerados dois cenários:

- $\mathrm{R} A+$ : cenário com rochas adjacentes mais rígidas do que as do cenário R A, tomando como base mudança na composição mineralógica para cálculo de novos módulos de elasticidade e coeficientes de Poisson. A partir disso, as rochas que não compõem o reservatório arenítico serão constituídas por $20 \%$ de argila, $40 \%$ de quartzo e $40 \%$ de calcita. O volume de poros para cada camada segue critério mostrado na Figura 4. 24. As novas propriedades mecânicas das rochas adjacentes estão representadas na figura abaixo. Para os módulos de elasticidade, os novos valores são de 53\% a 58\% superiores aos respectivos módulos do cenário $\mathrm{R}$ A para a mesma camada. 


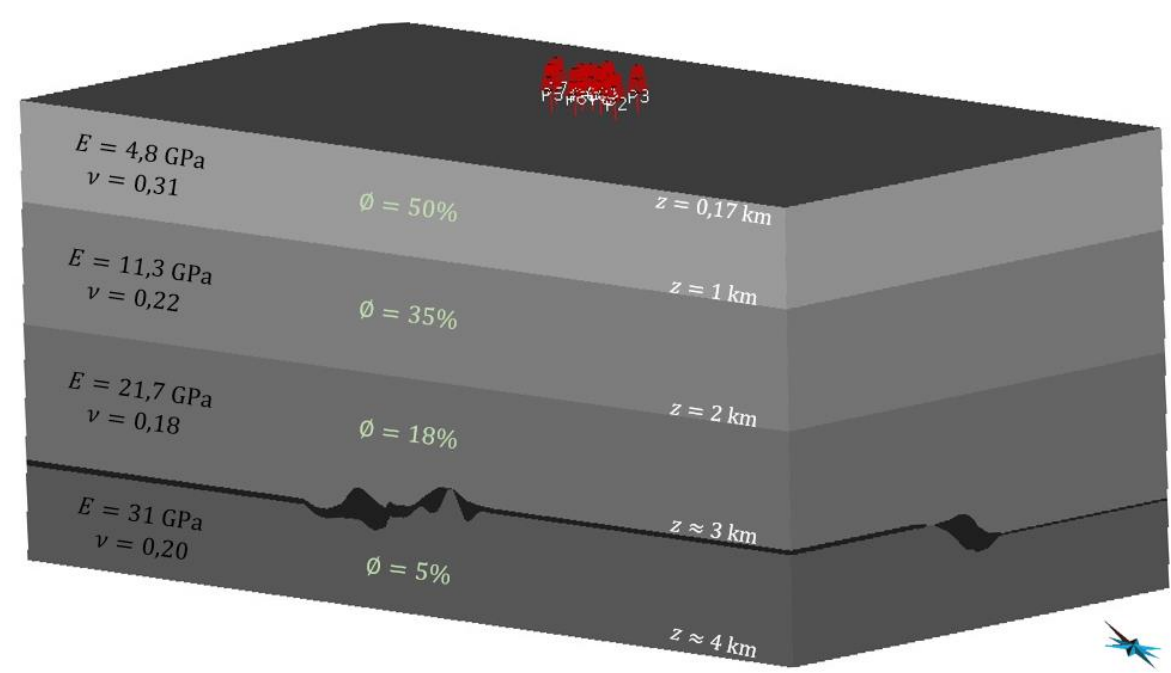

Figura 5.11: Representação das rochas adjacentes com seus respectivos módulos de Young, coeficientes de Poisson e porosidades para o cenário R A+.

- R A- : cenário com rochas adjacentes menos rígidas do que as do cenário R A, também tomando como base mudança na composição mineralógica Para esse cenário, as rochas que não compõem o reservatório serão constituídas por $90 \%$ de argila e $10 \%$ de quartzo. Mais uma vez, o volume de poros para cada camada segue critério mostrado na Figura 4. 24. As novas propriedades mecânicas das rochas adjacentes no cenário R A- estão representadas na Figura 5.12. Para os módulos de elasticidade, os novos valores são de $55 \%$ a $59 \%$ inferiores aos respectivos módulos do cenário $\mathrm{R}$ A para a mesma camada.

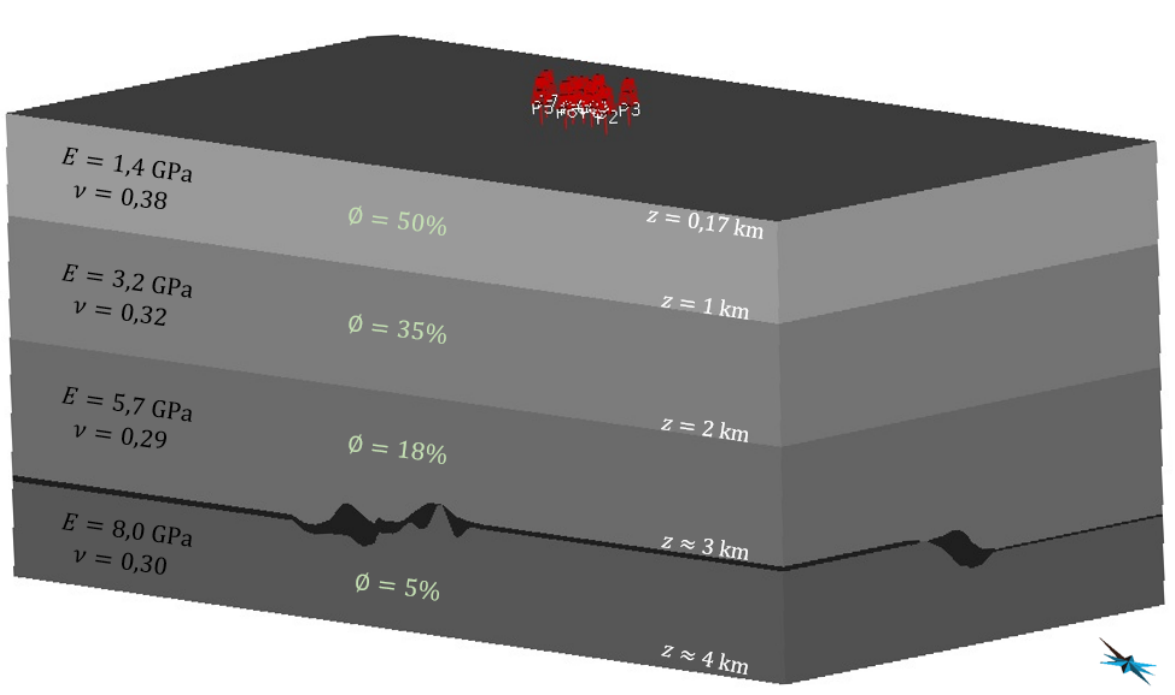

Figura 5.12: Representação das rochas adjacentes com seus respectivos módulos de elasticidade, coeficientes de Poisson e porosidades para o cenário R A-. 


\subsection{2}

\section{Análise de resultados de fluxo}

O aumento ou diminuição da rigidez das rochas adjacentes não provocou mudanças substanciais no volume de óleo produzido. Como pode ser visto na Figura 5.13, as curvas estão praticamente sobrepostas. Para o cenário R A-, o reservatório é mais rígido que qualquer camada que está em seu entorno, inclusive o underburden. Nessa configuração, o aumento do volume total de óleo explotado ao fim da simulação foi $0,6 \%$ superior ao do caso R A. Por sua vez, o cenário R A+ que apresenta underburden, sideburden e a primeira camada do overburden acima do arenito mais rígidos que o reservatório, obteve um volume total produzido de óleo $0,15 \%$ menor. Ainda assim, a alta rigidez do reservatório impediu que as rochas adjacentes exercessem uma influência maior sobre o fluxo.

Quando analisados os resultados de volume de gás produzido, os resultados são igualmente pouco perceptíveis. O cenário R A- permitiu a produção de mais $0,4 \%$ de volume gasoso que o caso $\mathrm{R} A$, enquanto que o caso $\mathrm{R} A+$ produziu $0,15 \%$ a menos.

Apesar da diferença em volume produzido ser tímida, é observável que um ambiente externo ao reservatório menos rígido tende a favorecer a retirada de fluidos. O contrário ocorre para um ambiente circundante mais rígido.

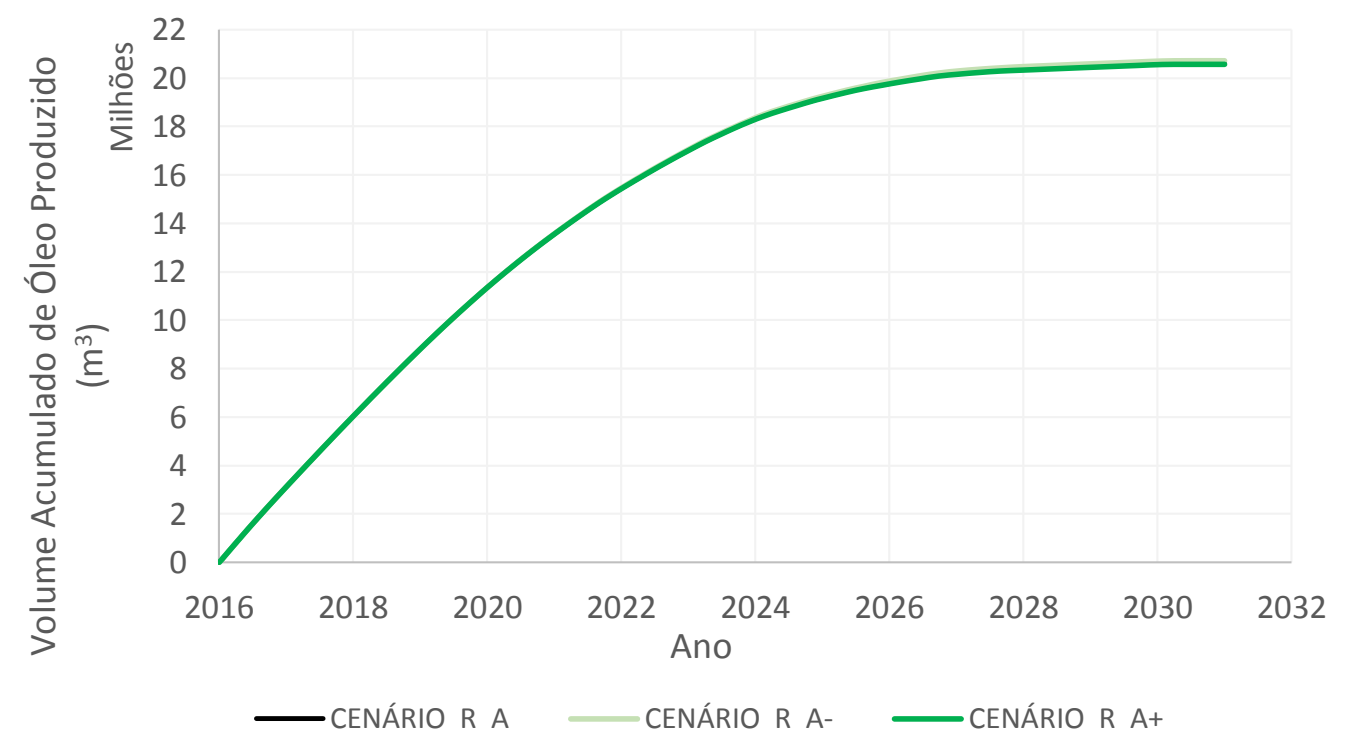

Figura 5. 13: Curva de volume acumulado de óleo produzido para cenários com mudanças de propriedades nas rochas adjacentes. 
A liberação de gás no reservatório também apresenta relação com o estado de rigidez das rochas vizinhas ao reservatório. Como pode ser observado na Figura 5.14, o comportamento da curva de liberação de gás é antecipado em alguns dias quando as rochas adjacentes são mais rígidas. A justificativa está na maior dificuldade de manutenção de pressão dentro do reservatório (ver Figura 5.15), já que teoricamente o reservatório deve sofrer menor deformação (será melhor detalhado na seção 5.3.3.). Como a pressão tem sua manutenção prejudicada, o ponto de bolha é atingido mais cedo com a consequente liberação de grande volume de gás.

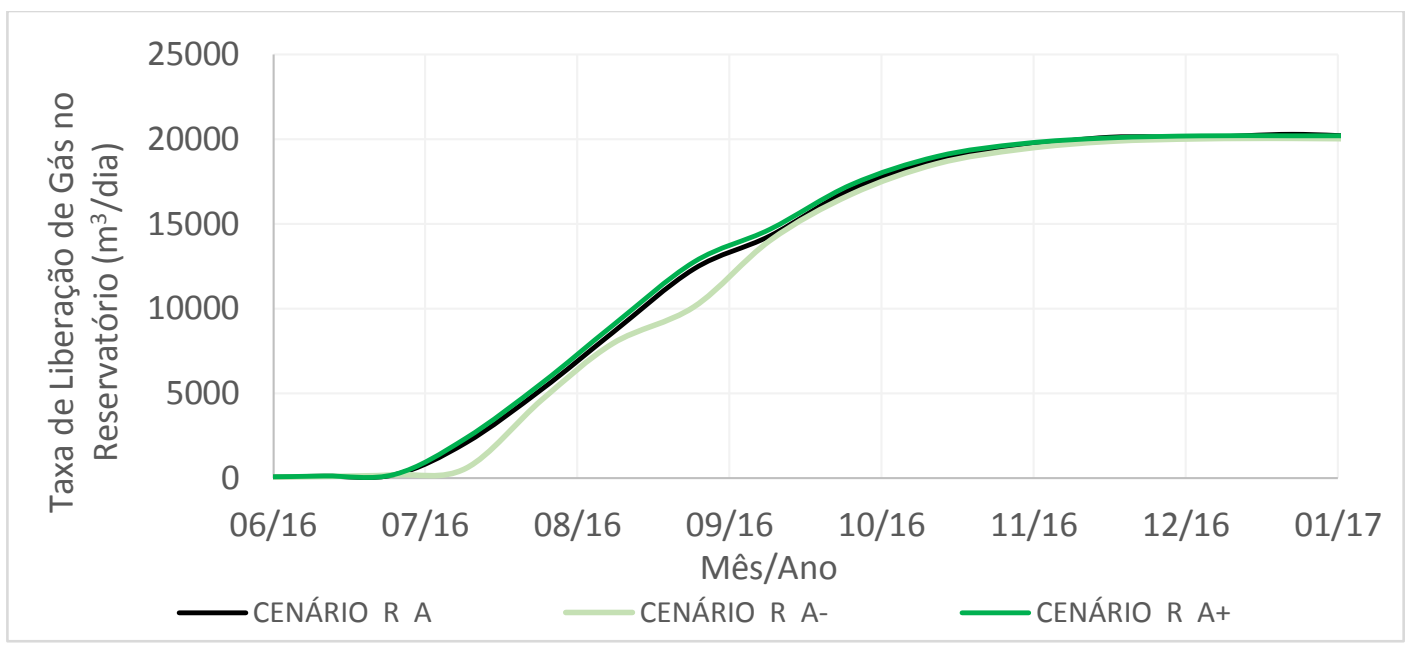

Figura 5. 14: Curva de liberação de gás dentro do reservatório para cenários R A, R A+ e R A- no período de junho de 2016 a janeiro de 2017.

Por sua vez, quando o ambiente adjacente é menos rígido, a pressão de poros se manteve sempre mais alta para os primeiros 10 anos simulados, o que gerou o retardamento da liberação de gás em, aproximadamente, 20 dias.

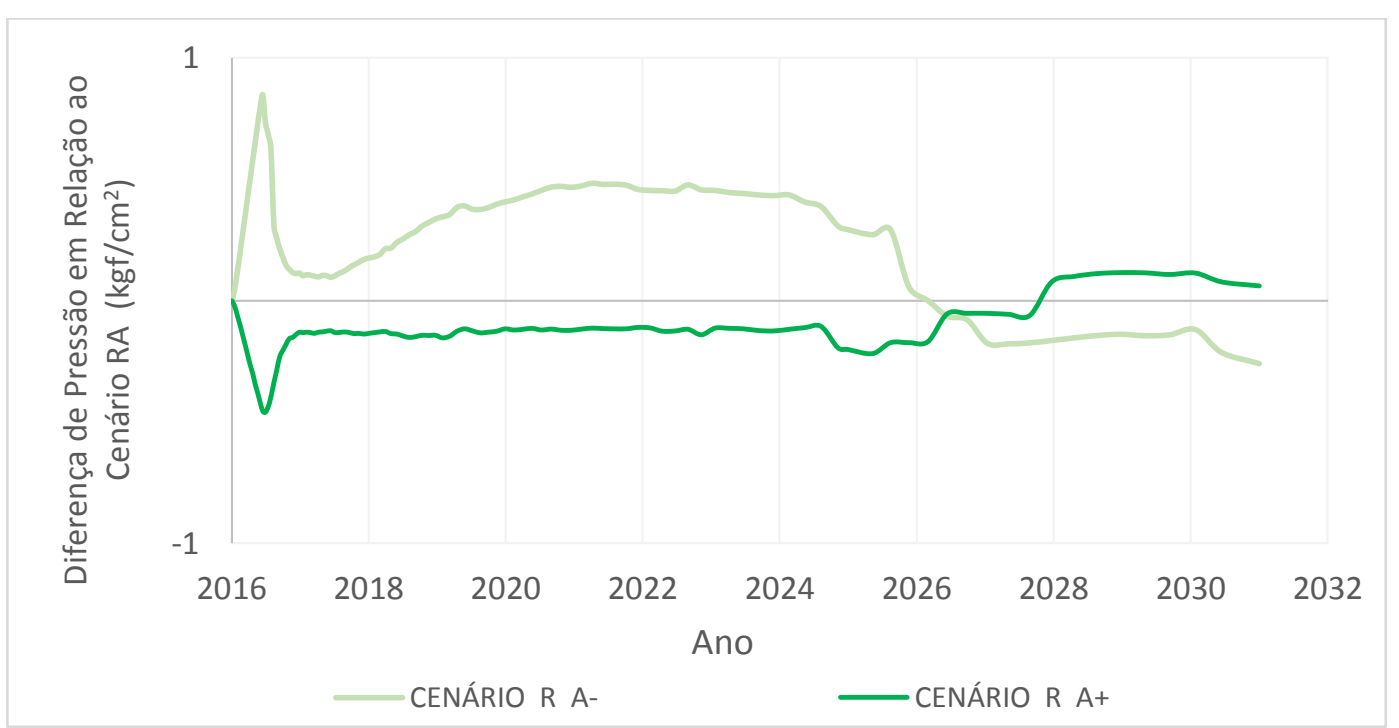

Figura 5.15: Diferença de pressão média no reservatório dos cenários R A- e R A+ em relação ao cenário R A ao longo dos 15 anos simulados. 
Dois pontos devem ser destacados na figura anterior. O primeiro deles é referente aos picos da diferença de pressão que ocorrem ainda em 2016 e próximos às datas de liberação de gás. Eles estão associados ao momento de mudança de declividade na curva de queda de pressão, que passa a ser menos acelerado como visto na Figura 5.5. Optou-se então por gerar o gráfico acima para melhor visualização porque as curvas de histórico de pressão dos cenários R A- e R A+ estariam praticamente sobrepostas ao cenário R A.

O segundo ponto a destacar é a mudança de tendência das curvas da Figura 5.15 após o ano de 2025 para o caso R A-, e no fim de 2027 para o R A+. O gráfico a seguir ajuda a elucidar essa questão. Inicialmente deve-se observar que até a metade de 2016, o cenário R A- produz mais óleo que o caso original (R A) em função do efeito geomecânico de maior compactação desse caso com rochas no entorno menos rígidas, como será melhor detalhado na seção 5.3.3. A partir daí há mudança na trajetória da curva e durante os anos de 2017, 2018 e 2019, o caso R A- produz menos óleo do que o cenário original. A justificativa está na liberação antecipada de gás no cenário R A causada pela menor manutenção de pressão. Com mais fase gasosa disponível no ambiente de reservatório, o gás passa a atuar na expulsão de fluido na fase líquida antes do cenário R A-, resultando assim num menor volume total de óleo produzido comparado ao cenário original. O efeito positivo dessa liberação mais tardia de hidrocarboneto gasoso só é sentido 4 anos depois, quando esse diferencial de óleo explotado volta a ser superior ao caso R A. Situação semelhante ocorre com o cenário R A+, porém em menor escala. A antecipação do desprendimento de gás trouxe a curva, em processo de crescimento no sentido negativo nos primeiros meses, para um valor quase igual a zero e semelhante ao total produzido pelo caso original. Porém, no início de 2020, a menor produção de óleo comparada ao cenário R A volta a ficar mais evidente. 


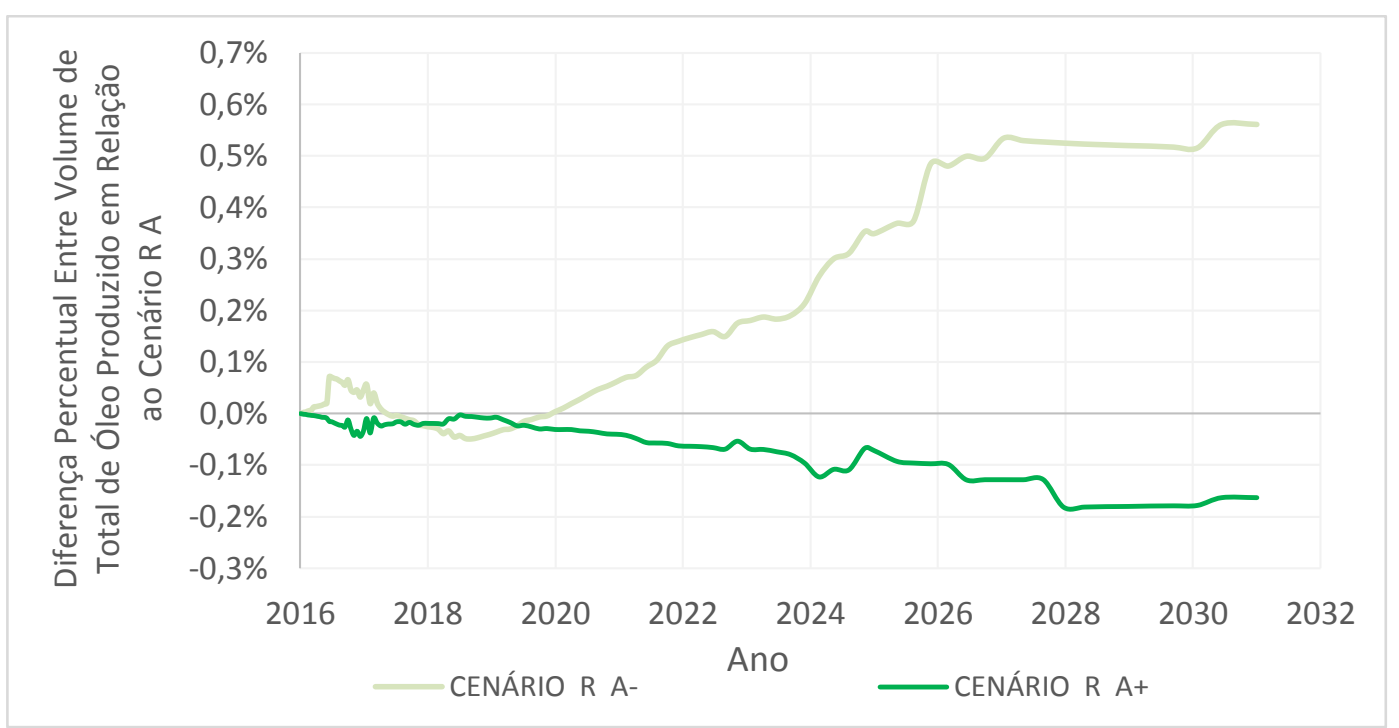

Figura 5. 16: Diferença percentual de entre volume total de óleo produzido nos cenários R A- e R A+ em relação ao cenário $\mathrm{R} A$.

\subsection{3}

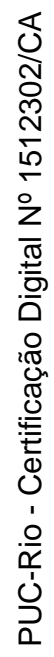

\section{Análise de resultados geomecânicos}

Assim como no subcapítulo 5.2, nesta seção optou-se pela seleção dos mesmos 5 horizontes de observação identificados na Figura 5.7. O deslocamento vertical de cada horizonte após 15 anos de simulação de produção de óleo, para o cenário R A-, pode ser visto a seguir.

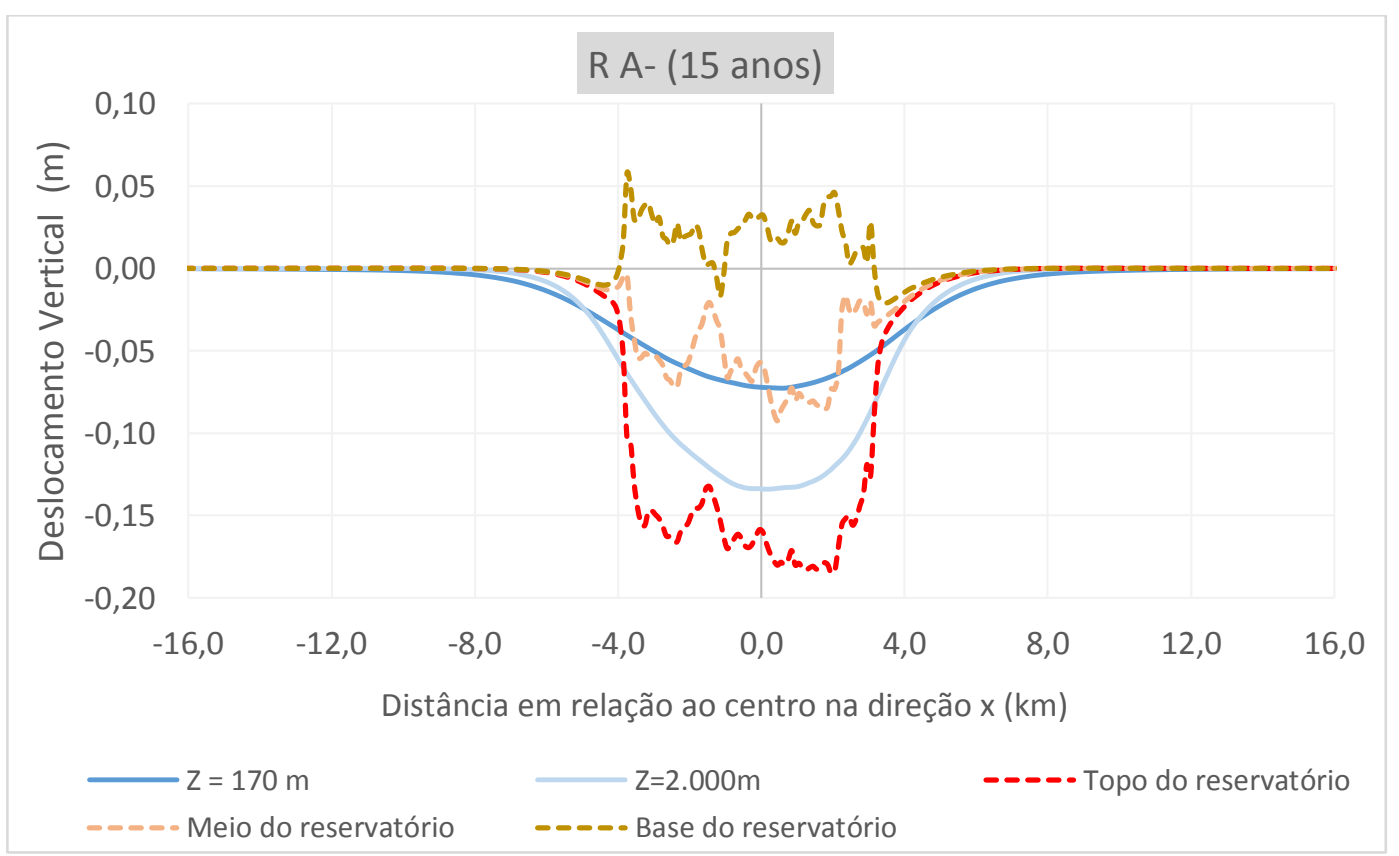

Figura 5. 17: Deslocamentos dos cinco horizontes selecionados após 15 anos de simulação para o caso R A-. 
Assim como no cenário R A, o deslocamento do leito marinho é menor do que o do horizonte a 2.000 metros de profundidade até distâncias horizontais de aproximadamente $4 \mathrm{~km}$ em relação ao centro do modelo acoplado. Além disso, a base do reservatório continua a sofrer soerguimento, enquanto o topo do reservatório, para regiões próximas ao centro do modelo acoplado, é o horizonte que apresenta os maiores deslocamentos. Os mesmos comentários inseridos nesse parágrafo se estendem para o cenário R A+ com seus deslocamentos representados na Figura 5.18.

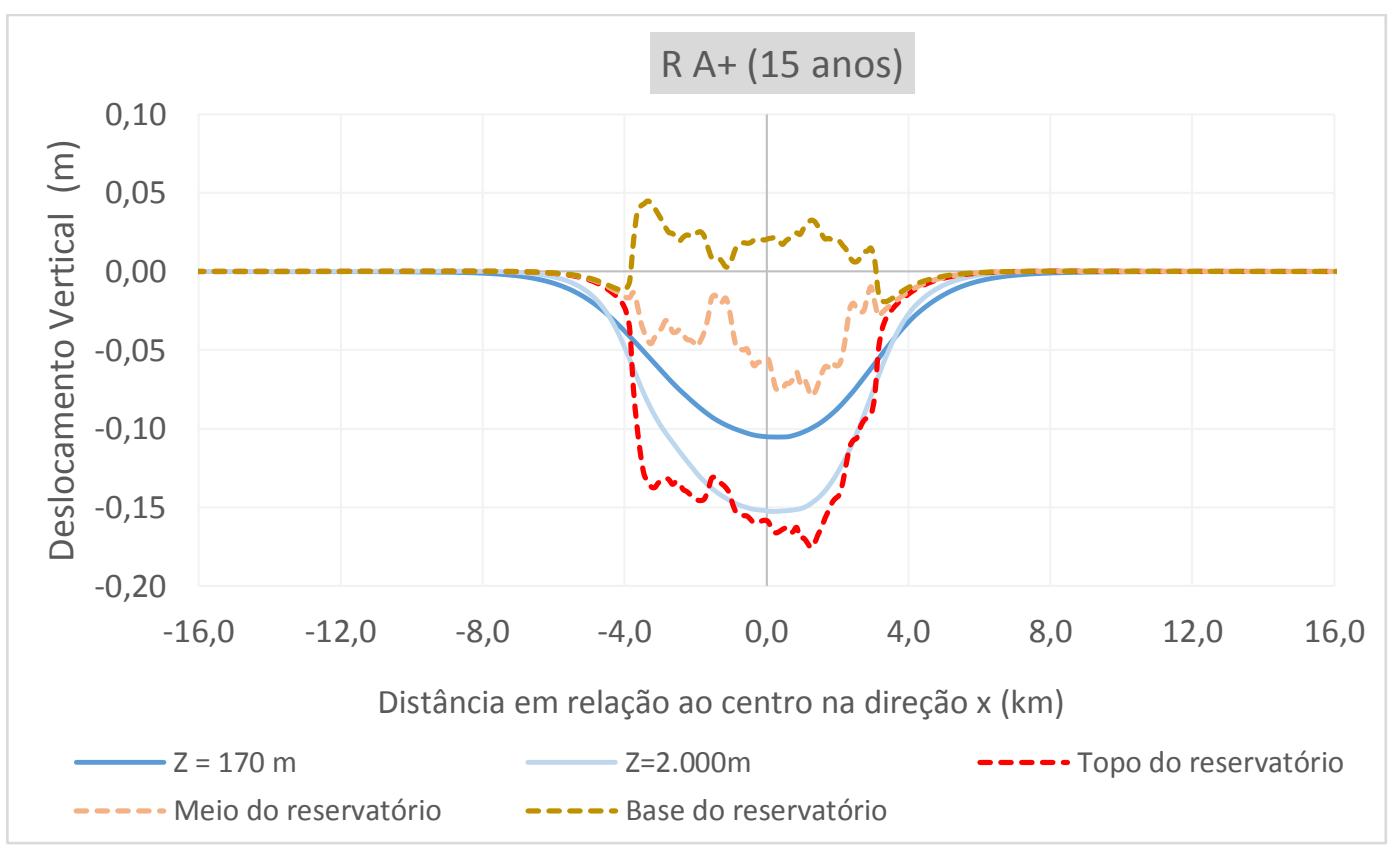

Figura 5.18: Deslocamentos dos cinco horizontes selecionados após 15 anos de simulação para o caso R A+.

Tão importante como saber se o comportamento vertical entre os cenários é semelhante, é também entender como esse comportamento se verifica à medida que se afasta lateralmente do centro do reservatório. Na figura a seguir, os deslocamentos verticais obtidos para o cenário R A- são subtraídos dos valores obtidos para o caso original ao longo dos $16 \mathrm{~km}$ de extensão do modelo de acoplado ao longo da direção x. É perceptível que o leito marinho, para um cenário menos rígido, tende a se deslocar verticalmente menos nas regiões centrais (até $4 \mathrm{~km}$ do centro do modelo acoplado) em relação ao cenário R A. Para distâncias entre 8 a 12 $\mathrm{km}$, passa a haver um processo de subsidência mais acentuado. A explicação para tal comportamento pode se encontrar no maior valor de Poisson quando comparado ao cenário R A. Quanto menor esse coeficiente, a subsidência seria sentida até distâncias menores, como pode ser visto na Figura 5.18 quando comparada à Figura 5. 17 na região entre 7 e $8 \mathrm{~km}$. 


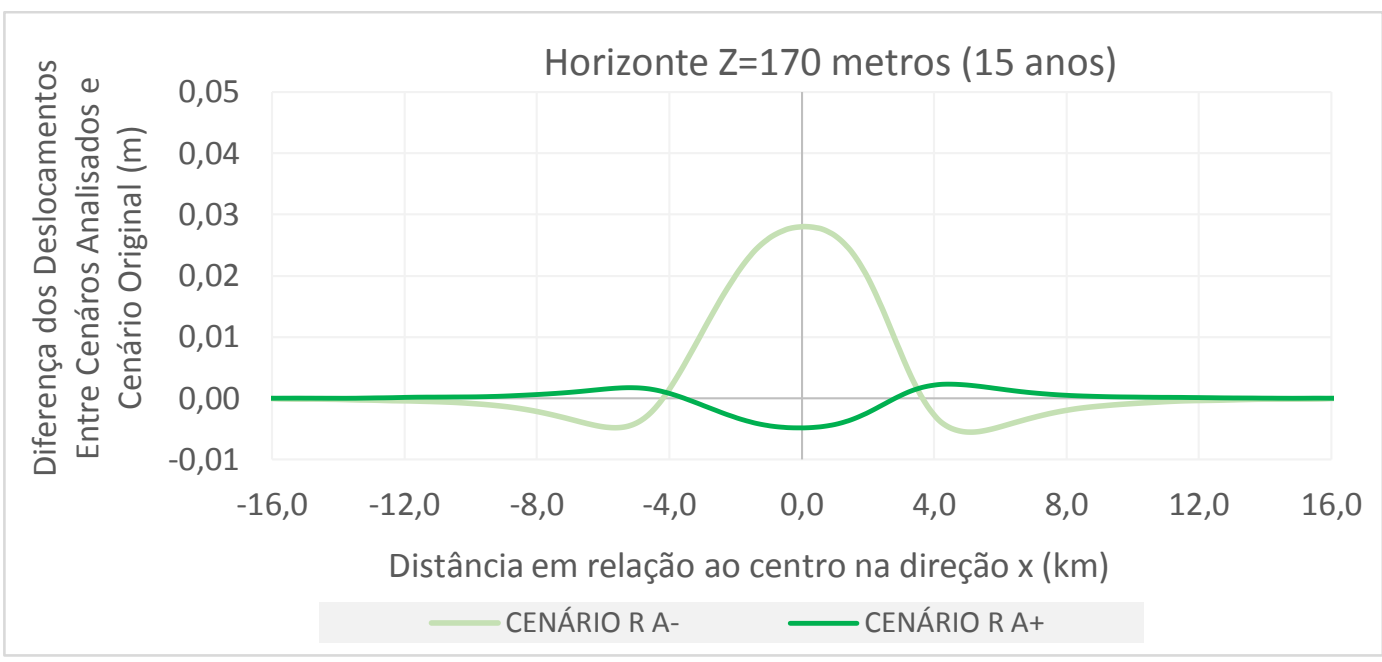

Figura 5.19: Diferença de deslocamentos entre os cenários R A- e R A+ para o cenário R A no horizonte de leito marinho ao fim de 15 anos.

Para o topo do reservatório, como as propriedades mecânicas não foram modificadas nos cenários desta seção e trata-se de um reservatório bastante rígido, não há mudanças significativas para distâncias muito além da extensão do arenito que armazena óleo. Os deslocamentos mostrados na figura a seguir foram em grande parte responsáveis por uma maior ou menor recuperação de hidrocarbonetos e na liberação de gás quando comparados ao cenário R A. Como pode ser observado na Figura 5.20, o cenário $\mathrm{R}$ A- permite que o topo do reservatório sofra deslocamentos até 3,8 cm maiores quando comparados ao cenário original. Já o cenário com rochas adjacentes mais rígidas, chega a apresentar um deslocamento até $1,5 \mathrm{~cm}$ menor do que o $\mathrm{R} \mathrm{A}$.

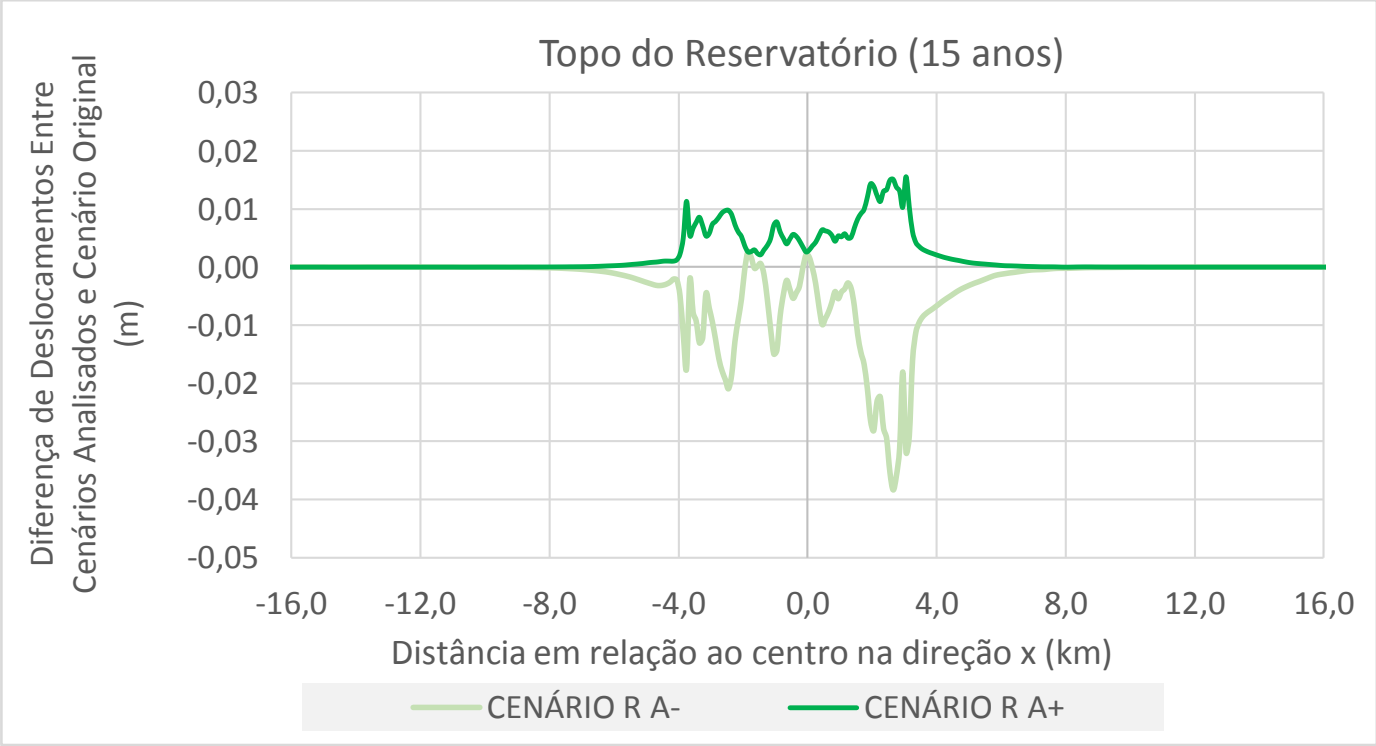

Figura 5. 20: Diferença de deslocamentos entre os cenários R A- e R A+ para o cenário R A no horizonte de topo do reservatório ao fim de 15 anos. 
Para facilitar uma análise que envolve tantos horizontes e pontos ao longo do tempo, tomou-se a opção de fazer uma análise comparativa apenas dos pontos que sofreram maior deslocamento dentro de cada horizonte e em 4 períodos de tempo (mês de janeiro dos anos 1, 3, 9 e 15). Os resultados dessa análise estão expostos nas Figura 5. 21 e Figura 5. 22. Comparativamente ao caso original, dois horizontes tiveram seus processos de compactação atenuados no cenário R A- e ambos pertencem ao overburden (Figura 5. 21). O ponto de maior deslocamento situado no horizonte $Z=170 \mathrm{~m}$ apresentou deslocamento vertical, em média, $28 \%$ menor que o caso R A ao longo de todo processo. Já o ponto pertencente ao horizonte situado a 2.000 metros, sofreu um deslocamento $12 \%$ menor ao longo dos anos.

Por sua vez, o reservatório teve seu processo de compactação mais estimulado. O topo de reservatório se deslocou mais $0,4 \mathrm{~cm}$ para baixo em relação ao cenário original, enquanto que a base soergueu mais $1,5 \mathrm{~cm}$. O soerguimento da base do reservatório foi, inclusive, o deslocamento que apresentou maior expansão atingindo uma média de $34,6 \%$ em relação ao caso original.

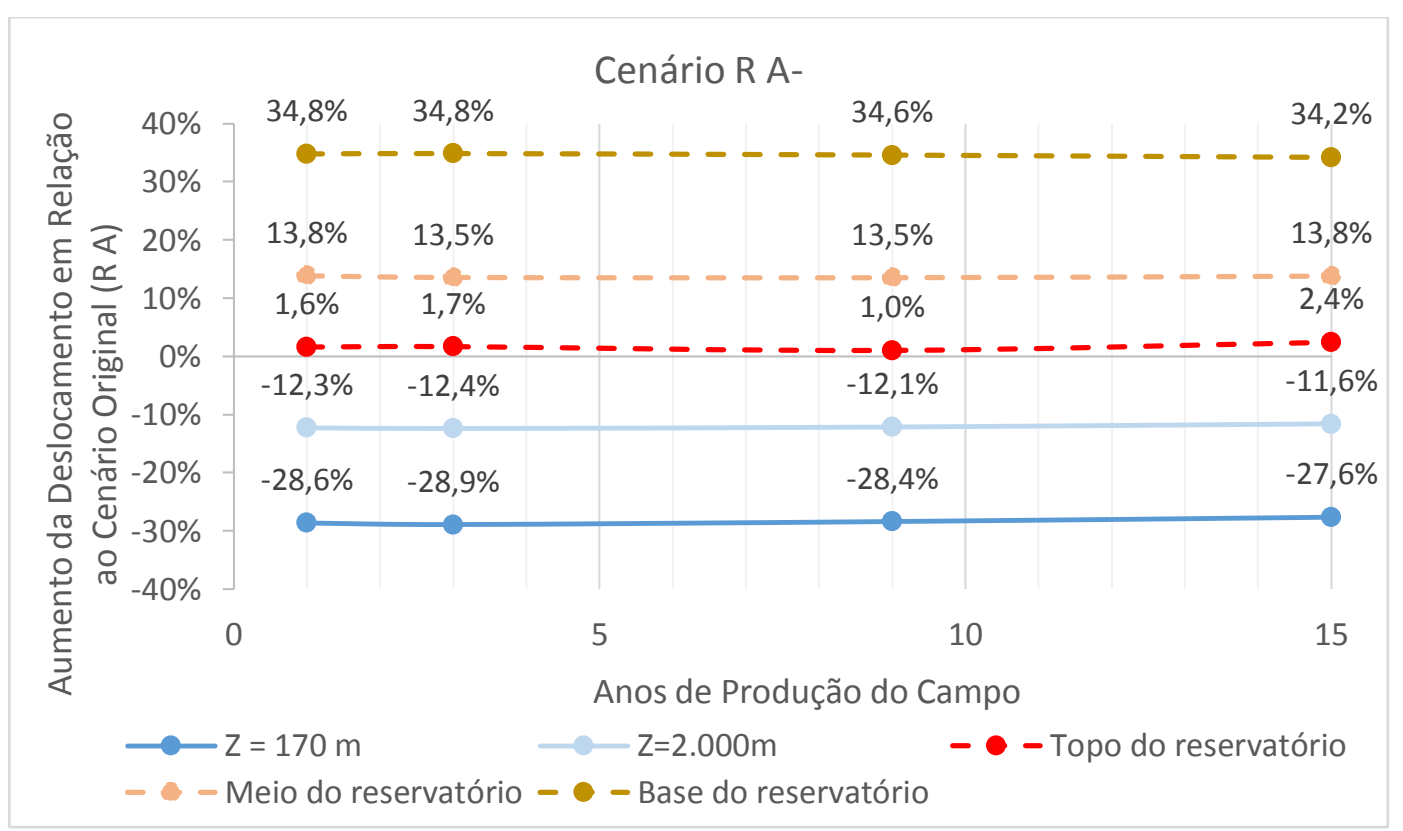

Figura 5. 21: Comparação entre deslocamentos dos horizontes no cenário R A- em relação ao cenário R A.

O cenário R A+ desenvolveu maiores deslocamentos que o caso $\mathrm{R} A$ nos horizontes de overburden e na base do reservatório. Já o topo e meio do reservatório cederam menos verticalmente. Independentemente do maior ou menor deslocamento, as variações em relação ao caso original ficaram restritas a uma janela percentual mais estreita (Figura 5. 22) do que a vista na Figura 5. 21. 


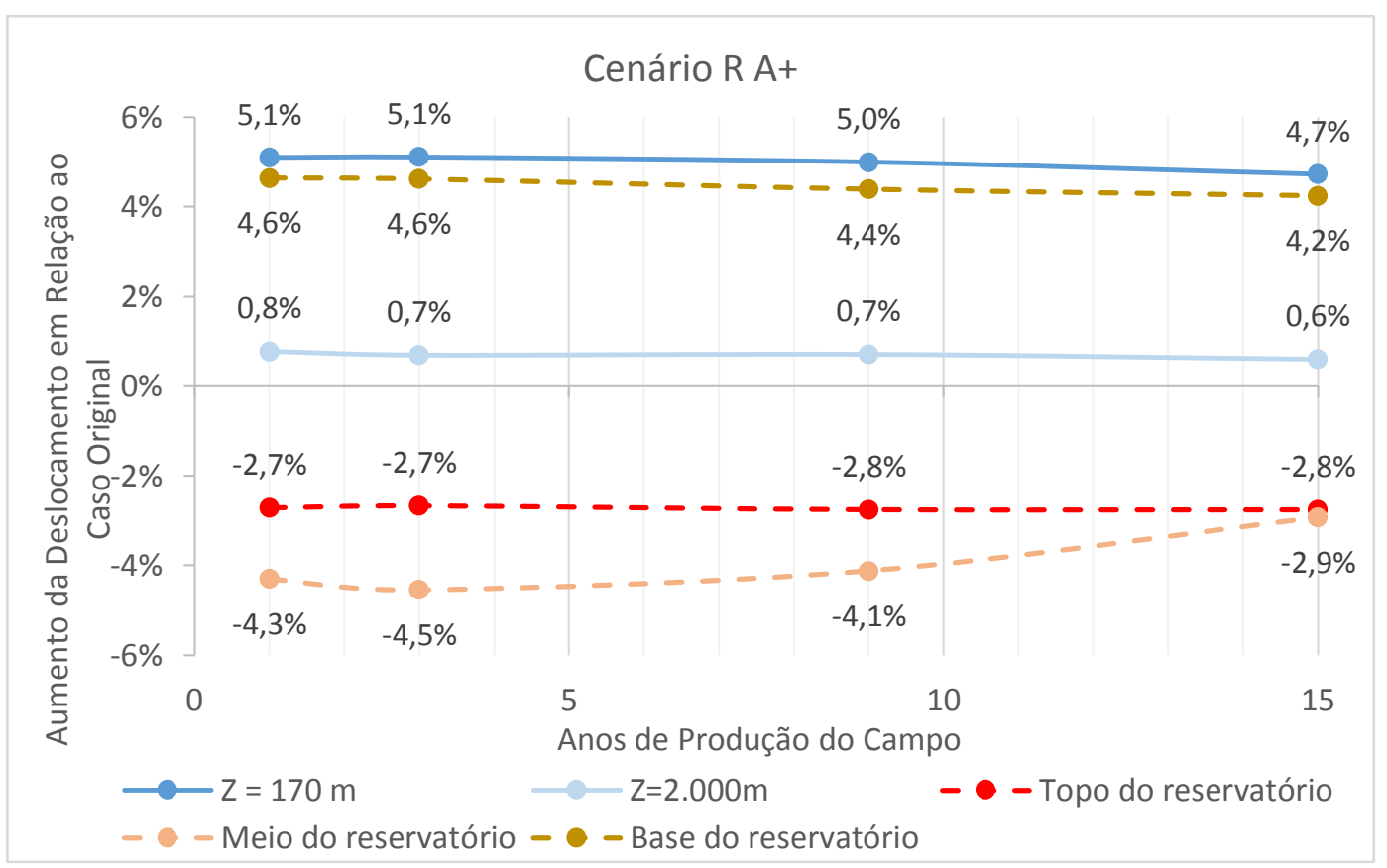

Figura 5. 22: Comparação entre deslocamentos dos horizontes no cenário R A+ em relação ao cenário R A.

\section{4 \\ Comparação de resultados entre o cenário acoplado original e outros cenários com diferentes propriedades mecânicas na rocha reservatório}

\section{4 .1 \\ Definição dos cenários analisados}

O objetivo desse subcapítulo é comparar os resultados de fluxo e mecânicos entre o cenário R A, detalhado nos subcapítulos 5.1 e 5.2, com cenários com mudanças nos módulos de Young e coeficiente de Poisson de forma a tornar a rocha reservatório mais ou menos rígida. As rochas adjacentes não sofrerão mudanças em suas propriedades, permanecendo iguais às presentes no cenário R A. Para atender a esse objetivo, foram gerados dois cenários:

- $\mathrm{R}+\mathrm{A}$ : cenário com reservatório mais rígido do que o cenário RA. Uma nova simulação em relação aos parâmetros mecânicos que definem a rocha reservatório foi feita com mudança de mineralogia e percentual de argila de forma a alcançar um módulo de Young próximo a $20 \mathrm{GPa}$, como encontrado em dados de bibliografia (ver Tabela 5.1). Dessa forma, houve aumento do módulo de Young em $82,4 \%$ e os coeficientes de Poisson respeitaram os dados gerados nessa nova 
simulação. Não houve modificações na porosidade do reservatório em relação ao cenário original porque isso modificaria inclusive o volume de óleo in place.

Tabela 5. 1: Módulo de Young estático e coeficiente de Poisson para as fácies definidas neste trabalho. Modificado de Read \& Stacey [53] (com base em dados de Jaeger \& Cook (1979), Goodman (1989), Bell (2000) e Gonzalez de Vallejo (2002)).

\begin{tabular}{|c|c|c|}
\multicolumn{1}{c|}{ Rocha } & Módulo de Young (GPa) & Coeficiente de Poisson \\
\hline Arenito & $10-60$ & $0,10-0,45$ \\
\hline Carbonato & $30-65$ & $0,25-0,35$ \\
\hline Folhelho & $5-65$ & $0,20-0,30$ \\
\hline
\end{tabular}

- R-A: cenário com reservatório menos rígido do que o cenário RA. Para gerar um cenário simétrico ao $\mathrm{R}+\mathrm{A}$, os módulos de Young respeitaram o percentual de variação criado no cenário $R+A$ entre as faixas de porosidade. Dessa forma, foi criado um cenário com diminuição do módulo de Young no reservatório de $82,4 \%$ em todas as faixas de porosidade. Os coeficientes de Poisson respeitaram o mesmo critério. Não houve modificações na porosidade do reservatório em relação ao cenário original.

Tabela 5. 2: Módulo de Young e coeficiente de Poisson para as faixas de porosidade dos cenários R+A e R-A

\begin{tabular}{|c|c|c|c|c|c|c|c|c|}
\hline $\begin{array}{l}\text { Faixa de } \\
\text { Porosidade }\end{array}$ & \multicolumn{4}{|c|}{ Cenário $R+A$} & \multicolumn{4}{|c|}{ Cenário R-A } \\
\hline \multirow{2}{*}{$10 \%<\emptyset<15 \%$} & $\mathrm{E}(\mathrm{GPa})$ & 30,3 & \multirow{8}{*}{$\begin{array}{c}\text { Variação } \\
\text { percentual } \\
\text { em relação } \\
\text { ao dado na } \\
\text { faixa de } \\
\text { porosidade } \\
\text { entre } 20 \% \\
\text { e 25\% }\end{array}$} & $44 \%$ & $\mathrm{E}(\mathrm{GPa})$ & 2,9 & \multirow{8}{*}{$\begin{array}{c}\text { Variação } \\
\text { percentual } \\
\text { em relação } \\
\text { ao dado na } \\
\text { faixa de } \\
\text { porosidade } \\
\text { entre } 20 \% \\
\text { e } 25 \%\end{array}$} & $45 \%$ \\
\hline & $v$ & 0,20 & & $-5 \%$ & $v$ & 0,36 & & $-5 \%$ \\
\hline \multirow{2}{*}{$15 \%<\emptyset<20 \%$} & $\mathrm{E}(\mathrm{GPa})$ & 24,8 & & $18 \%$ & $\mathrm{E}(\mathrm{GPa})$ & 2,4 & & $20 \%$ \\
\hline & $v$ & 0,20 & & $-5 \%$ & $v$ & 0,37 & & $-3 \%$ \\
\hline \multirow{2}{*}{$20 \%<\varnothing<25 \%$} & $\mathrm{E}(\mathrm{GPa})$ & 21,0 & & $0 \%$ & $\mathrm{E}(\mathrm{GPa})$ & 2,0 & & $0 \%$ \\
\hline & $v$ & 0,21 & & $0 \%$ & $v$ & 0,38 & & $0 \%$ \\
\hline \multirow{2}{*}{$25 \%<\emptyset<30 \%$} & $\mathrm{E}(\mathrm{GPa})$ & 18,9 & & $-10 \%$ & $\mathrm{E}(\mathrm{GPa})$ & 1,8 & & $-10 \%$ \\
\hline & $v$ & 0,21 & & $0 \%$ & $v$ & 0,38 & & $0 \%$ \\
\hline
\end{tabular}

\section{4 .2}

\section{Análise de resultados de fluxo}

$\mathrm{O}$ aumento e, principalmente, a diminuição da rigidez do reservatório provocaram mudanças significativas no volume de óleo produzido, como pode ser visto na Figura 5.23. Para o cenário $\mathrm{R}+\mathrm{A}$, o reservatório (exceto região com porosidade entre $25 \%$ e $30 \%$ ) é mais rígido que qualquer camada que está em seu entorno. Nessa configuração, o cenário R+A produziu menor volume total de óleo 
ao fim da simulação $(-1,5 \%)$ quando comparado ao caso R A. Por sua vez, o cenário $\mathrm{R}-\mathrm{A}$ que apresentava todas as camadas em torno do reservatório mais rígidas do que a rocha reservatório, obteve um volume total produzido de óleo 10,8\% maior.

Em relação aos resultados de volume de gás, o cenário R-A permitiu a produção de mais $5,3 \%$ de volume gasoso do que o caso R A, enquanto que o caso $\mathrm{R}+\mathrm{A}$ produziu $0,5 \%$ a menos.

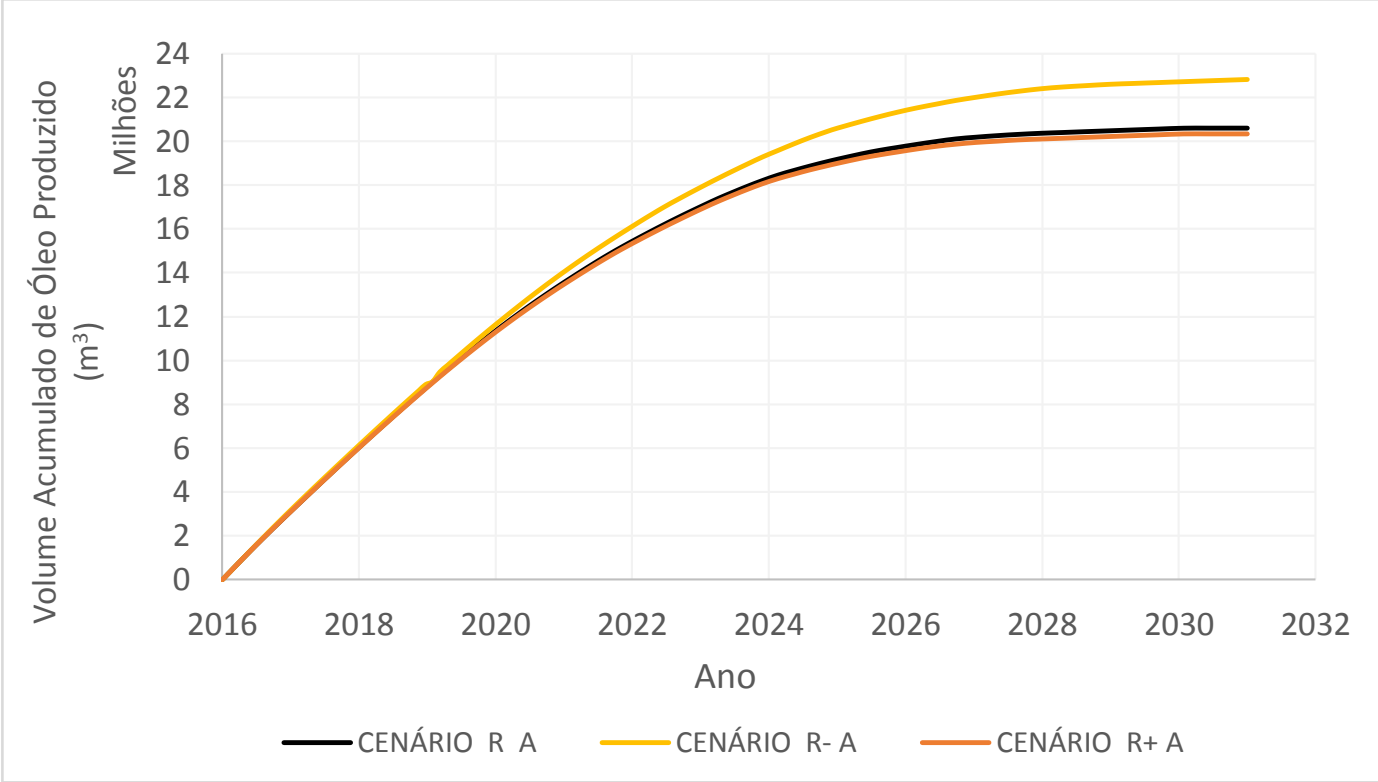

Figura 5.23: Curva de volume acumulado de óleo produzido para cenários com mudanças de propriedades no reservatório.

Era de se esperar que a produção de fluidos fosse impactada mais pela mudança de propriedades no reservatório do que nas rochas adjacentes. Primeiro porque é no reservatório que se encontra o fluido e mudanças no local de armazenamento são normalmente mais sensíveis para esse tipo de ambiente rochoso. Além disso, a alta rigidez do reservatório nos cenários $\mathrm{R} A+\mathrm{e} R \mathrm{~A}$ impediram que se observasse maiores efeitos da geomecânica. $\mathrm{O}$ cenário $\mathrm{R}+\mathrm{A}$ apresentou uma queda relativamente pequena de produção para o alto aumento de rigidez $(+82,4 \%)$ comparado ao cenário $\mathrm{R}$ A. Tal situação indica que realmente o cenário RA já se encontrava numa configuração de baixa compressibilidade, perto do limiar de compressão nula.

Uma outra questão que surge é se um cenário extra R- A- (menos rígido tanto no reservatório como nas adjacências) produziria um excedente de óleo em relação ao cenário R-A superior ao excedente gerado pelo caso R A- em relação ao R A. A resposta encontra-se na Tabela 5.3 e indica que um reservatório mais compressível 
aliado a rochas adjacentes menos rígidas tende a produzir um excedente de óleo maior. Na comparação realizada, o volume excedente de óleo produzido em $\mathrm{m}^{3}$ dobrou.

Tabela 5. 3: Excedente de óleo explotado para cenários com rochas adjacentes mais compressíveis. A nomenclatura EXT se refere a cenário extra, inserido apenas para análises pontuais,

\begin{tabular}{|c|c|c|c|}
\hline $\begin{array}{c}\text { Volume total de óleo } \\
\text { produzido }\left(\mathrm{m}^{3}\right)\end{array}$ & $\begin{array}{c}\text { Volume total de óleo } \\
\text { produzido }\left(\mathrm{m}^{3}\right)\end{array}$ & $\begin{array}{c}\text { Volume excedente de } \\
\text { óleo produzido }\left(\mathrm{m}^{3}\right)\end{array}$ & Ganho (\%) \\
\hline Cenário R A- & Cenário R A & $1,16 \mathrm{E}+05$ & $0,56 \%$ \\
\hline $2,07 \mathrm{E}+07$ & $2,06 \mathrm{E}+07$ & Ganho $(\%)$ \\
\hline $\begin{array}{c}\text { Volume total de óleo } \\
\text { produzido }\left(\mathrm{m}^{3}\right)\end{array}$ & $\begin{array}{c}\text { Volume total de óleo } \\
\text { produzido }\left(\mathrm{m}^{3}\right)\end{array}$ & $\begin{array}{c}\text { Volume excedente de } \\
\text { óleo }\left(\mathrm{m}^{3}\right)\end{array}$ & $1,02 \%$ \\
\hline Cenário EXT R- A- & Cenário R-A & $2,32 \mathrm{E}+05$ & 105 \\
\hline $2,31 \mathrm{E}+07$ & $2,28 \mathrm{E}+07$ & &
\end{tabular}

Voltando à análise dos cenários $\mathrm{R}+\mathrm{A}$ e R-A, pode-se verificar na figura seguinte que o cenário R-A foi muito mais eficiente na manutenção de pressão ao longo dos 12 anos iniciais. A partir de 2028, a curva de pressão se aproxima da curva do cenário original como em todos os outros cenários. Esses fatos indicam que para haver uma produção 10,7\% superior de óleo com pressão final em 2031 tão próxima a do caso $\mathrm{R}$ A, deve ter havido também um processo de compressão do reservatório mais acentuado do que o cenário original. Na seção 5.4.3. será vista a confirmação dessa afirmativa.

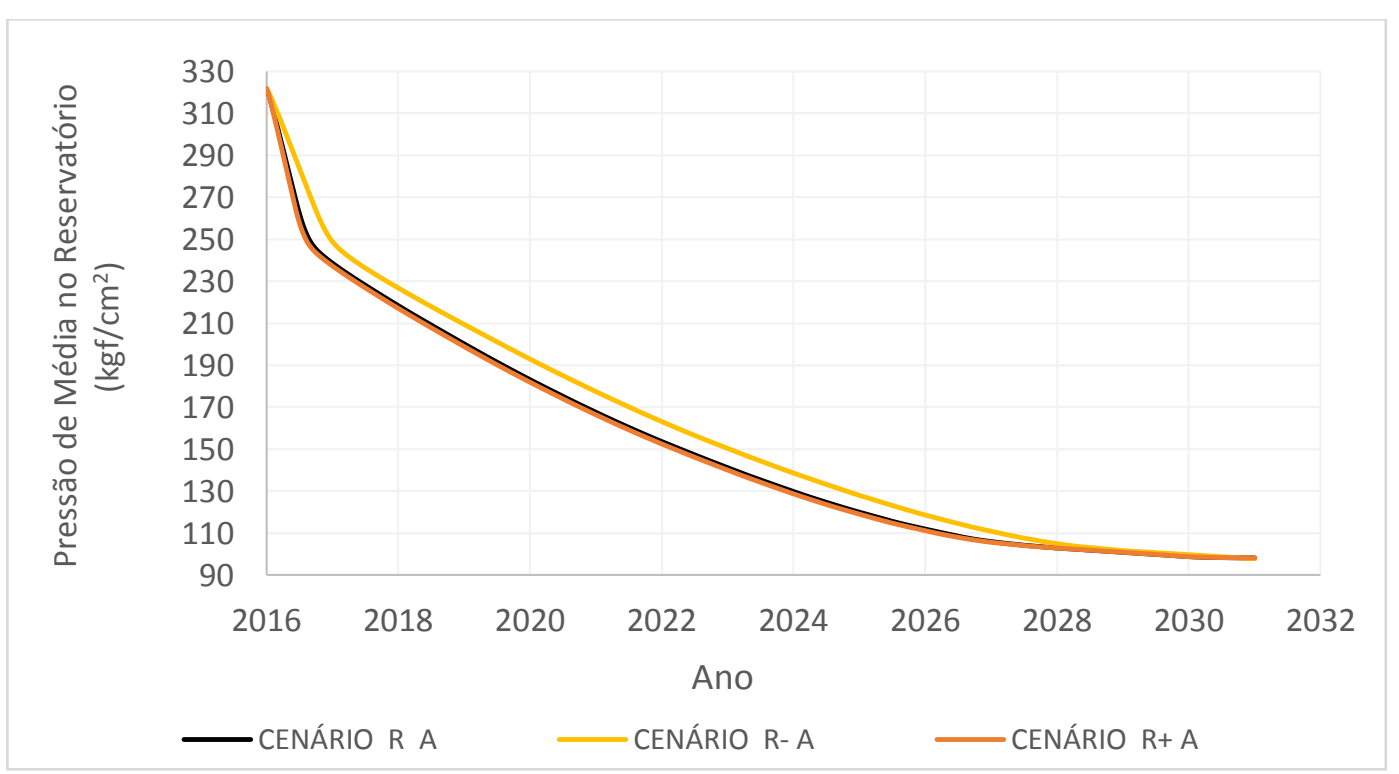

Figura 5.24: Queda da pressão média do reservatório para cenários R A, R+A e R-A.

Pela análise da figura a seguir, que apresenta a diferença de pressão de cada cenário para o caso R A em cada um dos 110 períodos de tempo simulados, é perceptível mais uma vez a presença de um pico na diferença de pressão. E mais 
uma vez, está associado ao início de grande liberação de gás pelo reservatório no cenário original.

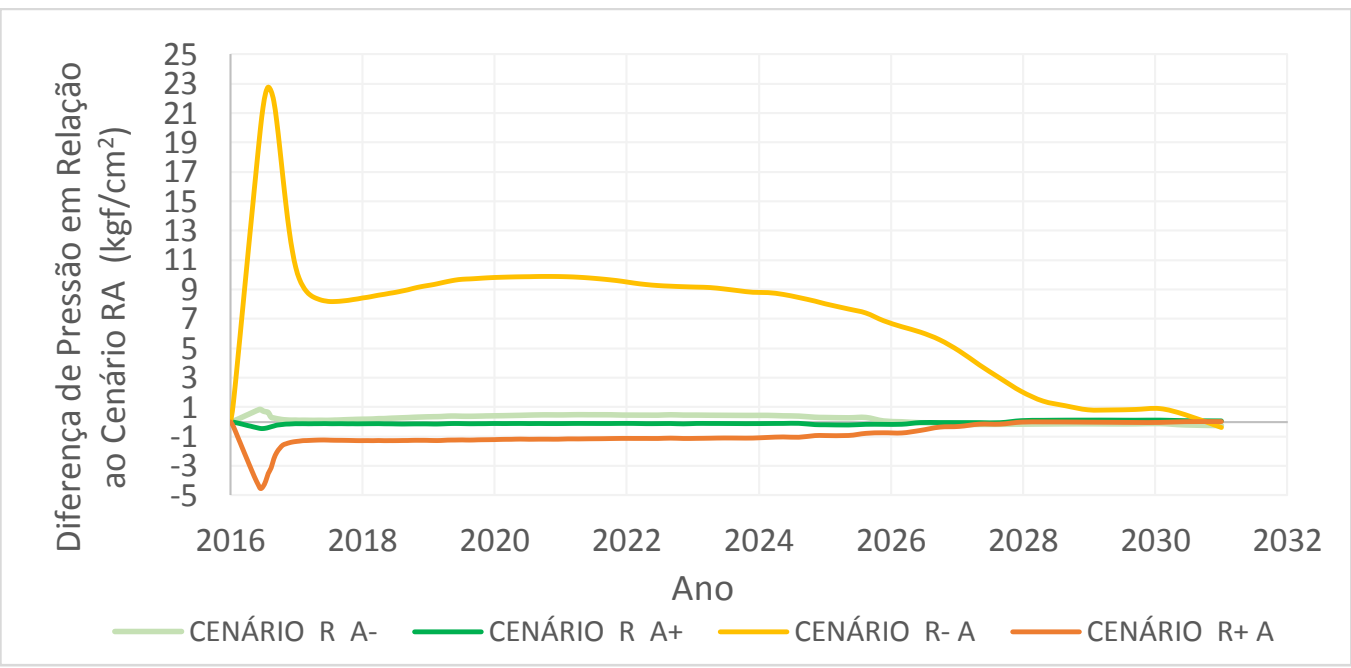

Figura 5. 25: Diferença de pressão média no reservatório dos cenários R A- e RA+ em relação ao cenário R A ao longo dos 15 anos simulados.

O pico é mais acentuado no cenário R-A do que no cenário R A-, não só porque exerce melhor manutenção da pressão de poros, como também reflete o maior retardamento do momento de liberação de gás dentro do reservatório. $\mathrm{Na}$ figura a seguir, temos a confirmação de que o cenário R-A é o último a desprender volume gasoso em altas vazões, ou seja, há um retardamento de 105 dias em relação ao caso original. Quando essa liberação de gás começa a ocorrer em outubro de 2016, o pico de diferença de pressão de poros começa a se desfazer. A partir daí, tem início uma fase de duração de 9 anos no qual a diferença de pressão sempre está acima de $6 \mathrm{kgf} / \mathrm{cm}^{2}$ (ver figura acima).

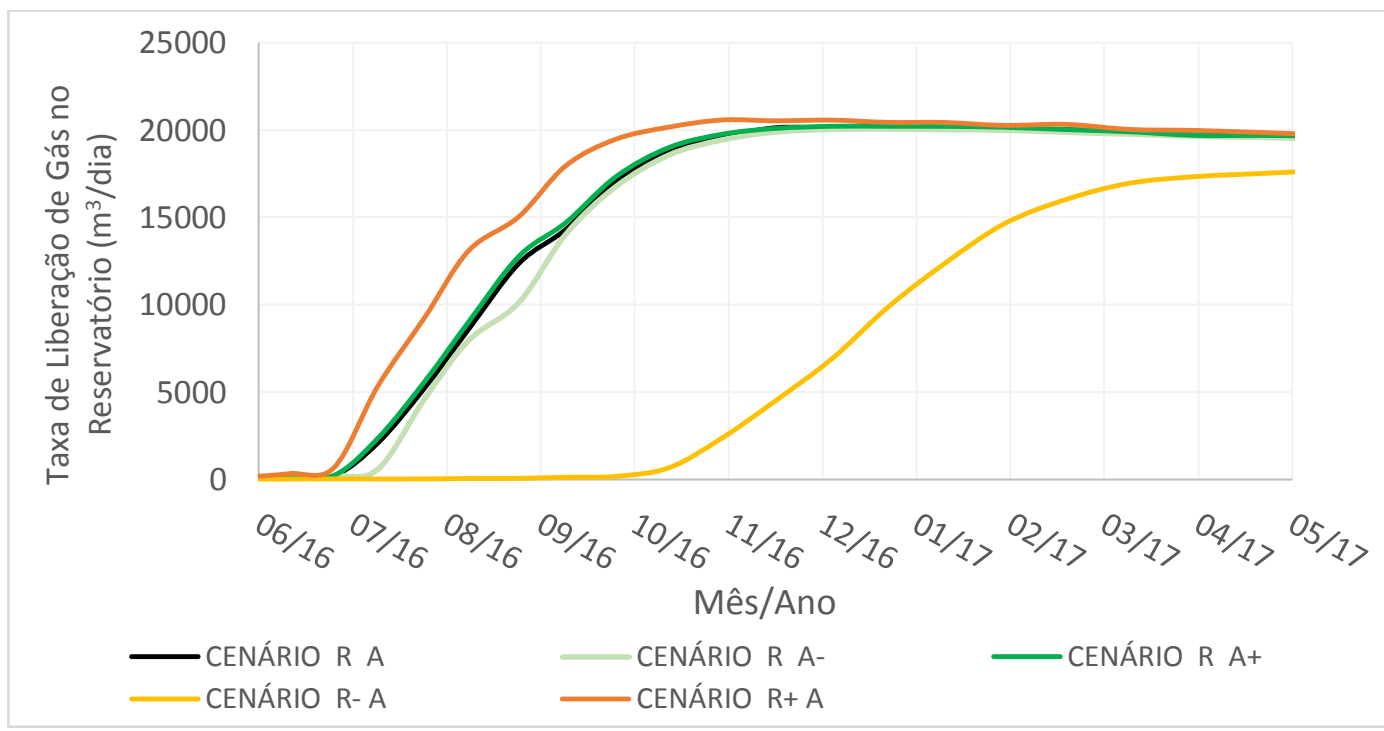

Figura 5.26: Curva de liberação de gás dentro do reservatório para cenários simulados no período de junho de 2016 a maio de 2017. 


\section{4 .3}

\section{Análise de resultados geomecânicos}

Diferentemente da seção 5.3.3., onde os deslocamentos entre os cenários diferiram pouco, quando são analisadas variações no módulos de Young estáticos e coeficiente de Poisson na rocha que compõe o reservatório, as mudanças são mais expressivas. Abaixo é possível observar os deslocamentos dos 5 horizontes que têm sido analisados nessa dissertação após 15 anos de produção do campo para o cenário com arenito mais rígido. Assim como em todos os cenários antes descritos, o topo do reservatório é o que sofre maior deslocamento no tempo para a região central do bloco e alcança um valor de 17,5 cm. Para distâncias além dos 3,5 4 km em relação ao ponto central, os deslocamentos de pontos do overburden são superiores.

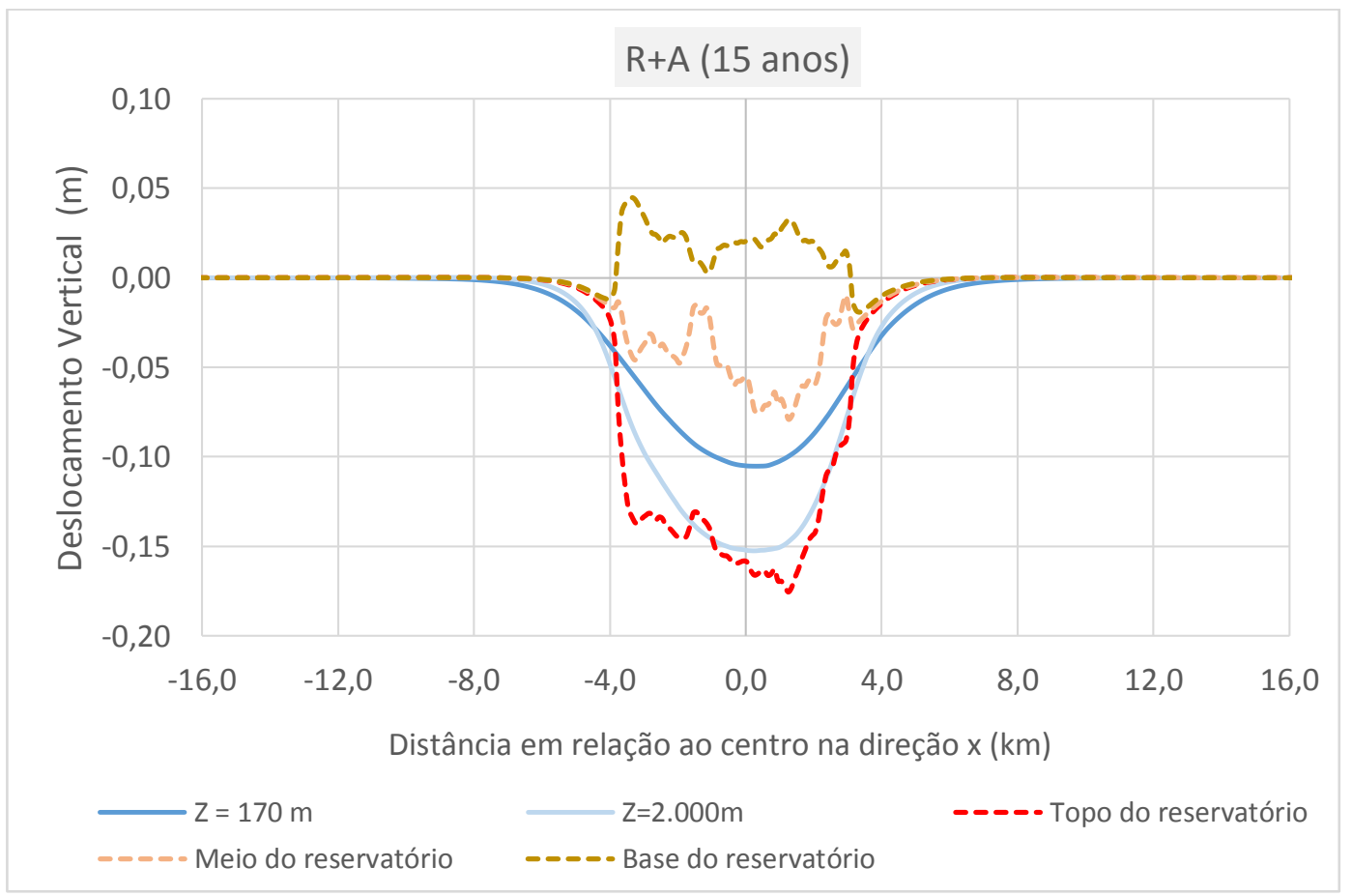

Figura 5. 27: Deslocamentos dos cinco horizontes selecionados após 15 anos de simulação para o caso R+A.

A base do reservatório também continua a sofrer soerguimento $(4,5 \mathrm{~cm}$ em seu ponto máximo), porém é um deslocamento máximo inferior aos cenários analisados até aqui, fato também observado em todos os outros horizontes quando comparados aos casos já vistos. A comparação percentual com o cenário R A pode ser vista na figura a seguir. Aos 15 anos, todos os horizontes se deslocam entre 30\% a $43 \%$ menos que os seus respectivos resultados no caso original. 


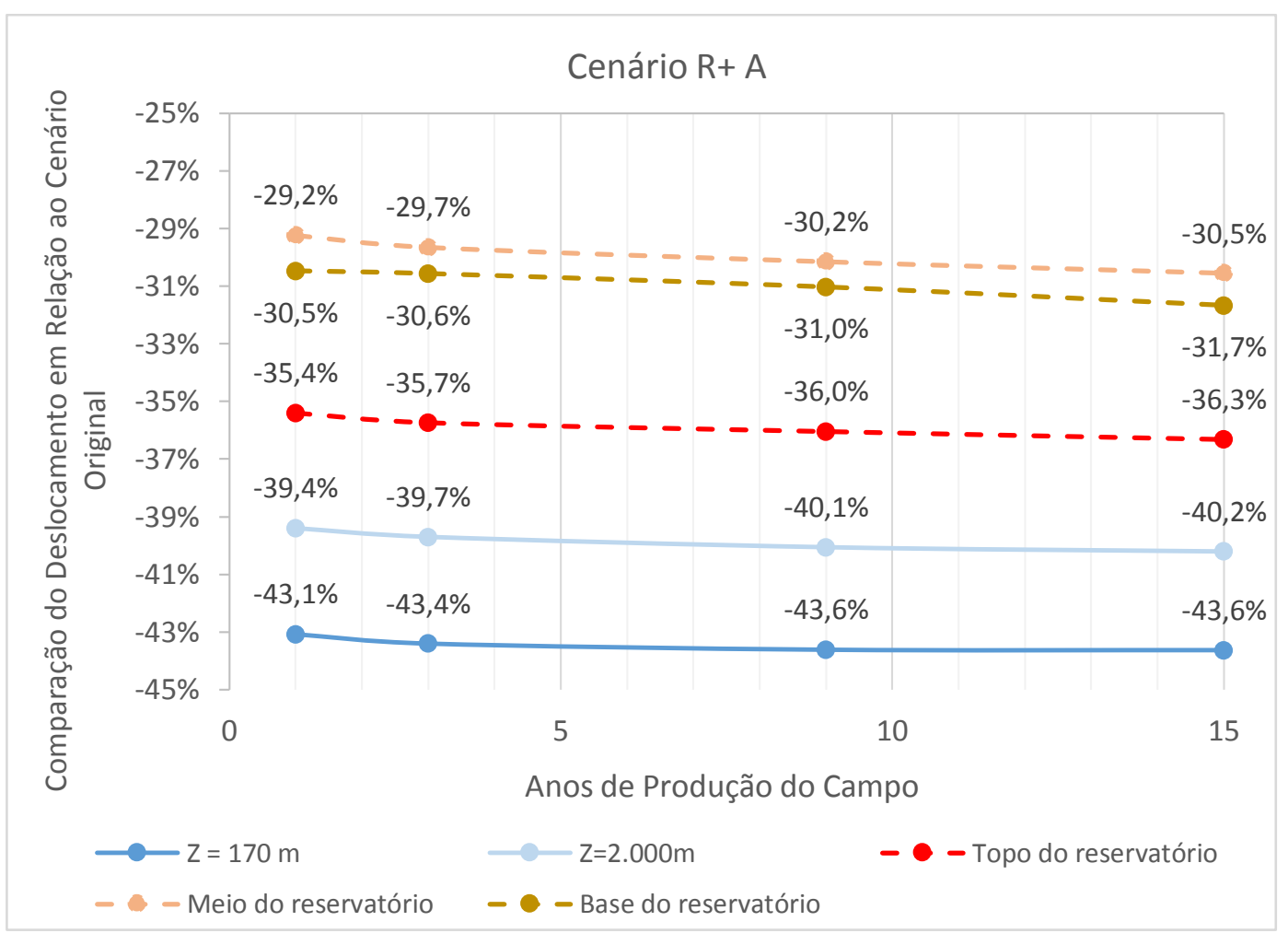

Figura 5. 28: Comparação entre deslocamentos dos horizontes no cenário R+A em relação ao cenário R A.

O cenário R-A foi o cenário que apresentou os deslocamentos verticais mais expressivos para todos os horizontes analisados. O deslocamento do topo do reservatório atingiu um máximo de $64,2 \mathrm{~cm}$. Já o soerguimento do underburden atingiu uma marca de $15,8 \mathrm{~cm}$.

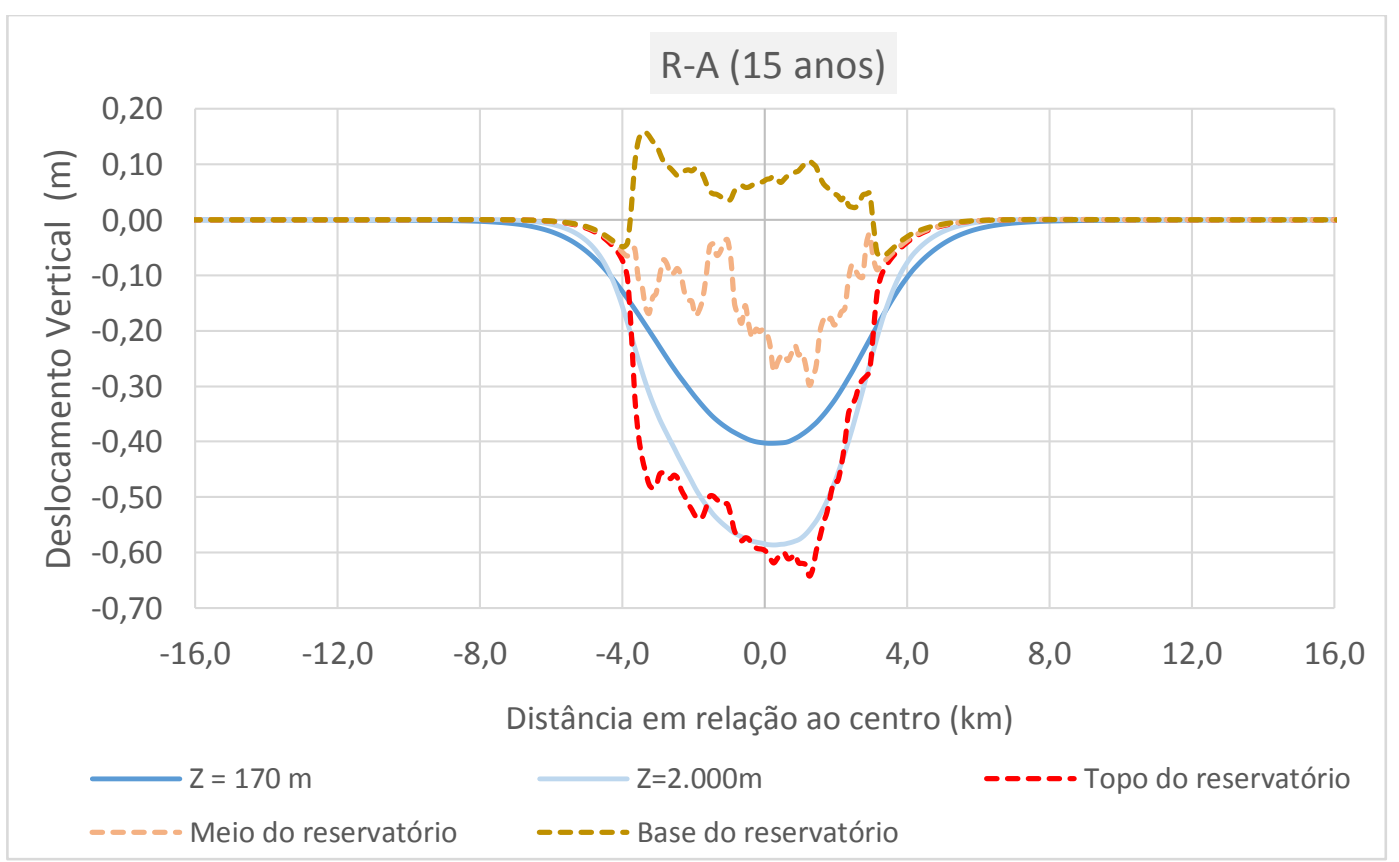

Figura 5. 29: Deslocamentos dos cinco horizontes selecionados após 15 anos de simulação para o caso R-A. 
A comparação percentual com o cenário $R$ A revela que, ao fim dos 15 anos, todos os horizontes se deformam de 2,5 a 3 vezes mais que os seus respectivos resultados no caso original. Além disso, a liberação de gás, por ter retardo tão expressivo, promove mudanças de vazões e pressão ao longo de todo o histórico que se refletem no crescimento do diferencial de deslocamento entre R-A e R A com o passar dos anos.

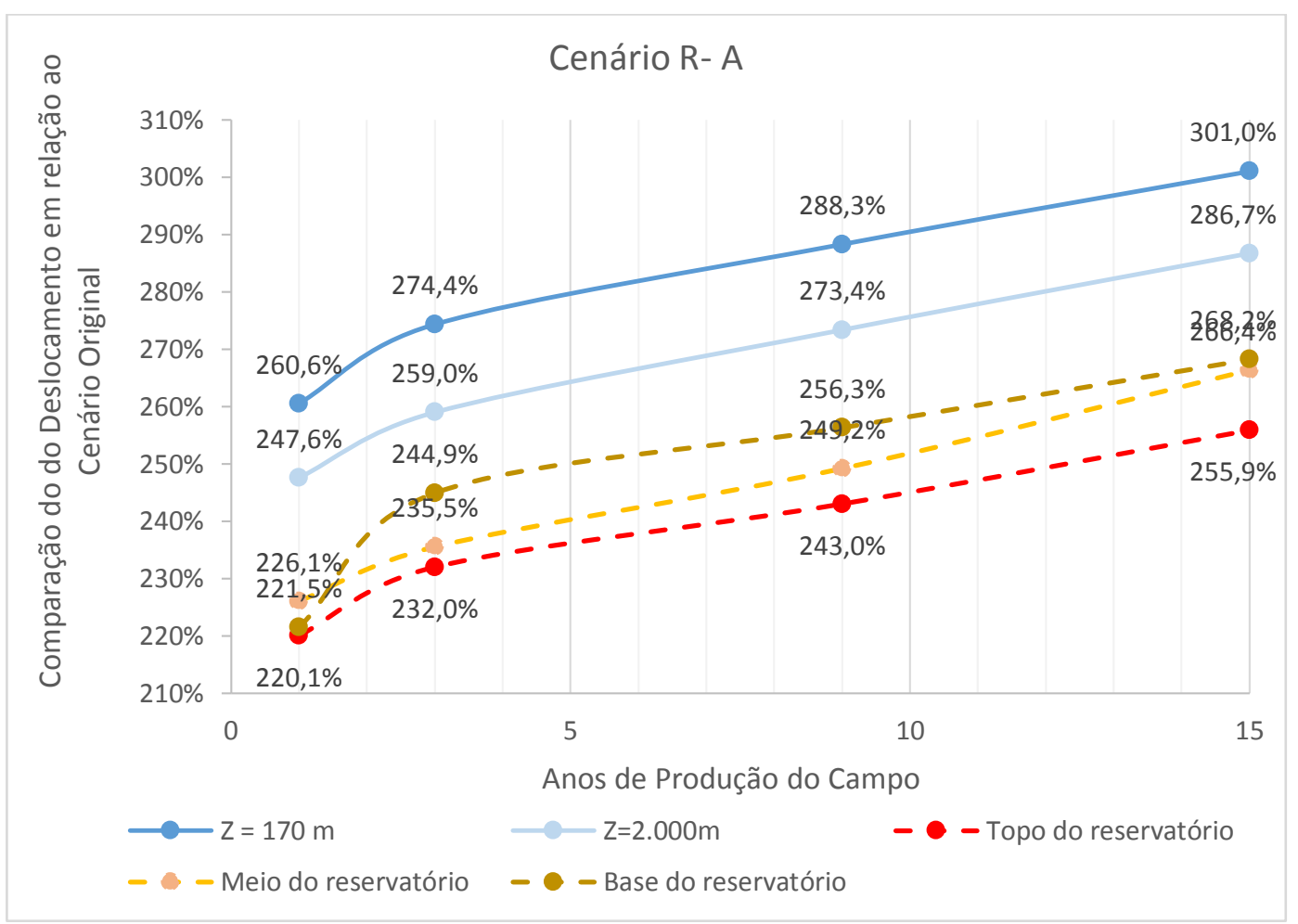

Figura 5. 30: Comparação entre deslocamentos dos horizontes no cenário R-A em relação ao cenário R A.

A figura a seguir traz os perfis de deslocamentos verticais para os cenários $\mathrm{R}-\mathrm{A}, \mathrm{R}+\mathrm{A}$ e $\mathrm{R}$ A ao longo de uma linha imaginária traçada no centro do modelo acoplado e que acompanha a profundidade do ambiente rochoso. Mais uma vez, nota-se a grande diferença que o caso com reservatório menos rígido impõe aos deslocamentos. Ao longo dos 2.975 metros de overburden, por onde a linha traçada toca, pode-se ver o crescimento do deslocamento até atingir $67 \mathrm{~cm}$. Ao atingir a região do reservatório, o comportamento do deslocamento passa de subsidência para soerguimento. $\mathrm{O}$ ponto máximo de ascensão $(7 \mathrm{~cm})$ ocorre na base do reservatório. 


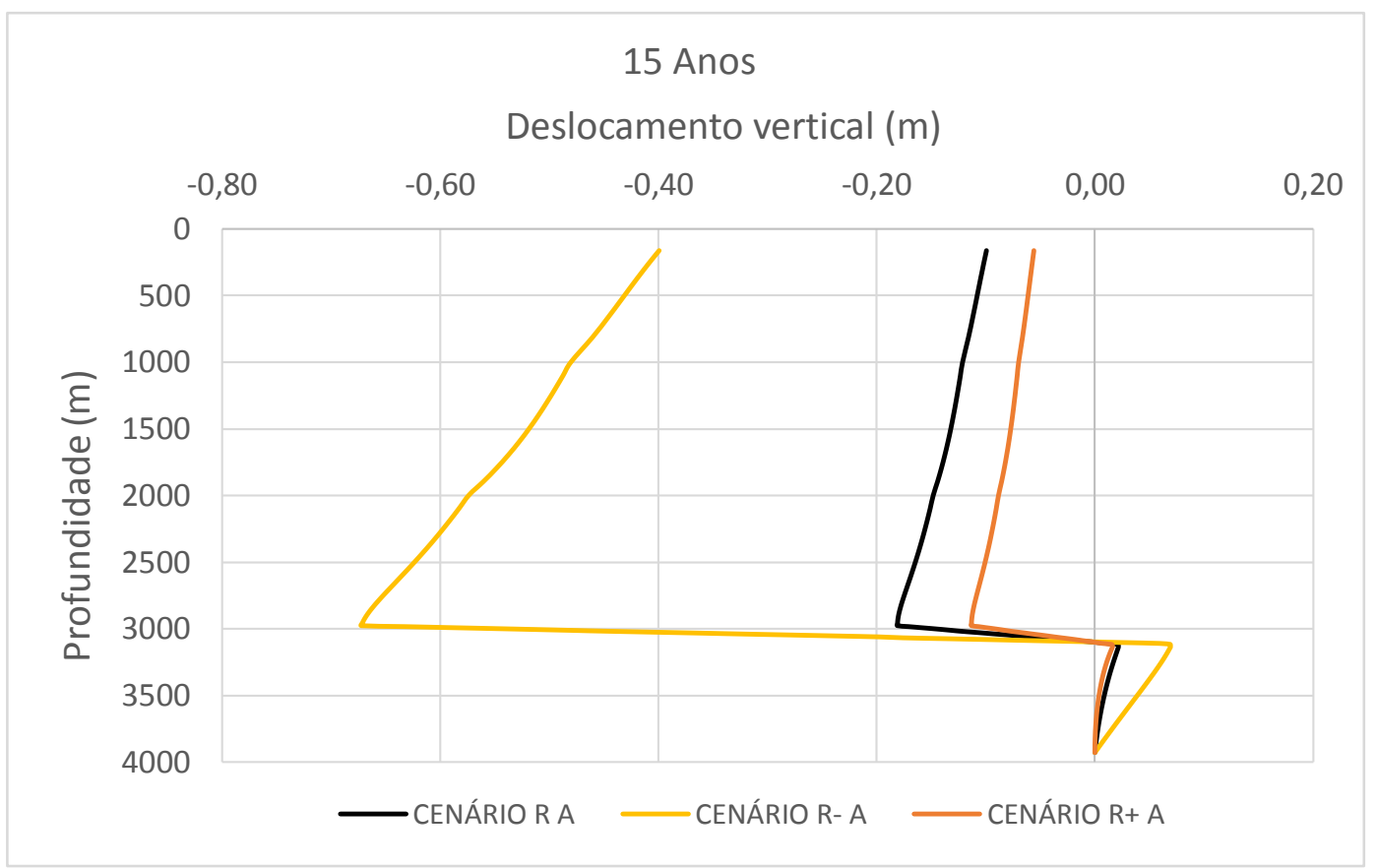

Figura 5.31: Deslocamento vertical ao longo da profundidade do ambiente rochoso para os cenários $\mathrm{R}+\mathrm{A}$, R-A e R A.

\section{5 \\ Comparação de resultados entre o cenário acoplado original e outros cenários com hidrocarbonetos de graus API distintos}

\section{5 .1}

Definição dos cenários analisados

O objetivo desse subcapítulo é comparar os resultados de fluxo e geomecânicos priorizando a mudança das propriedades dos fluidos que preenchem a rocha reservatório. Em função disso, três fluidos foram selecionados a partir do manual do simulador de fluxo IMEX da empresa CMG, com o objetivo de garantir acurácia nas tabelas de permeabilidade relativa óleo-água, gás-óleo e PVT.

- Óleo Leve ( $\left.32^{\circ} \mathrm{API}\right)$ : Na prática é o óleo que foi utilizado em todas as simulações feitas até este ponto da dissertação e originalmente encontrado no Campo de Namorado. Apresenta viscosidade de $1,25 \mathrm{cP}$ e compressibilidade $1,3 \times 10^{-4}\left(\mathrm{kgf} / \mathrm{cm}^{2}\right)^{-1}$ para a pressão de poros inicial da simulação. É um óleo de massa específica $866 \mathrm{~kg} / \mathrm{m}^{3}$ e pressão de bolha de $248 \mathrm{kgf} / \mathrm{cm}^{2}$.

- Óleo Médio (24,6 $6^{\circ}$ API): Óleo de massa específica $906 \mathrm{~kg} / \mathrm{m}^{3}$ e pressão de bolha de $182 \mathrm{kgf} / \mathrm{cm}^{2}$. Apresenta viscosidade de 1,61 cP e compressibilidade $1,12 \times 10^{-4}\left(\mathrm{kgf} / \mathrm{cm}^{2}\right)^{-1}$ para a pressão de poros inicial da 
simulação. No Brasil, um campo que apresenta algumas características semelhantes a este cenário é o de Espadarte, localizado sob lâmina d'água de 1.100 metros e constituído por reservatórios de arenitos turbidíticos que se encontravam originalmente subsaturados, tendo a produção associada ao mecanismo de gás em solução. O óleo desse campo é mediano, com $26^{\circ}$ API em média.

- Óleo Pesado (16,6 API): Óleo de massa específica $955 \mathrm{~kg} / \mathrm{m}^{3}$ e pressão de bolha de $82 \mathrm{kgf} / \mathrm{cm}^{2}$. Apresenta uma média de viscosidade de $23 \mathrm{cP}$ e compressibilidade $0,66 \times 10^{-4}\left(\mathrm{kgf} / \mathrm{cm}^{2}\right)^{-1}$ para a pressão de poros inicial da simulação. No Brasil, óleos pesados entre $13^{\circ}$ e $16^{\circ}$ API são encontrados, por exemplo, nos Campos de Peregrino e Pitangola.

As análises serão feitas para duas configurações de rochas reservatório e adjacências. A primeira terá as propriedades mecânicas das rochas definidas no cenário original RA. A partir dos dados gerados nos subcapítulos 5.3 e 5.4, a segunda análise fará uso de um cenário com reservatório e rochas adjacentes menos rígidas (R- A-), por apresentar a configuração de distribuição de propriedades que mais afetou a deformação do reservatório. Na seção 5.5.2 serão mostrados os resultados de fluxo. Os resultados geomecânicos estão no item 5.5.3.

Importante mencionar que as alterações nas propriedades do óleo por interferirem na densidade afetaram, principalmente, o volume dos fluidos presentes dentro do reservatório no momento inicial da simulação. É uma consequência advinda da premissa de não alterar o volume poroso. Além disso, um objetivo secundário era não alterar a pressão inicial do reservatório e que foi conquistado com êxito (ver Figura 5.33).

Tabela 5. 4: Volume de fluido no momento que antecede a simulação para os 3 cenários com óleos de diferentes graus API.

Volume de fluido in place (condições standard)

Óleo $\left(\times 10^{6} \mathrm{~m}^{3}\right) \quad$ Gás $\left(\times 10^{6} \mathrm{~m}^{3}\right) \quad$ Água $\left(\times 10^{6} \mathrm{~m}^{3}\right)$

\begin{tabular}{|l|c|c|c|}
\hline Cenário com óleo leve & 119,3 & 15.051 & 89,6 \\
\hline Cenário com óleo médio & 110,9 & 9.295 & 126,3 \\
\hline Cenário com óleo pesado & 146,7 & 75 & 110,6 \\
\hline
\end{tabular}

Como pode ser visto na tabela acima, o volume de óleo sofreu maior variação para o caso de óleo mais denso. O volume de gás tinha sua grande variação esperada em função das características de cada óleo. Quanto menor o grau API, menor é o volume de gás associado. 


\section{5 .2}

Análise de resultados de fluxo

Como era esperado, a produção de óleo varia muito em função dos fluidos que preenchem o reservatório. Como exemplo desta afirmação, é possível ver na Figura 5. 32 que o volume explotado de hidrocarboneto líquido pesado, ao fim de 15 anos, representou apenas $11 \%$ do volume obtido no cenário RA LEVE. A produção do cenário de óleo médio foi de $23 \%$ do volume explotado pelo cenário de fluido mais leve. Tais resultados são consequência das diferentes viscosidades e pesos específicos dos óleos, além das permeabilidades relativas entre fluidos. Outro dado importante é que o cenário com óleo leve sempre produziu mais que os outros dois cenários.

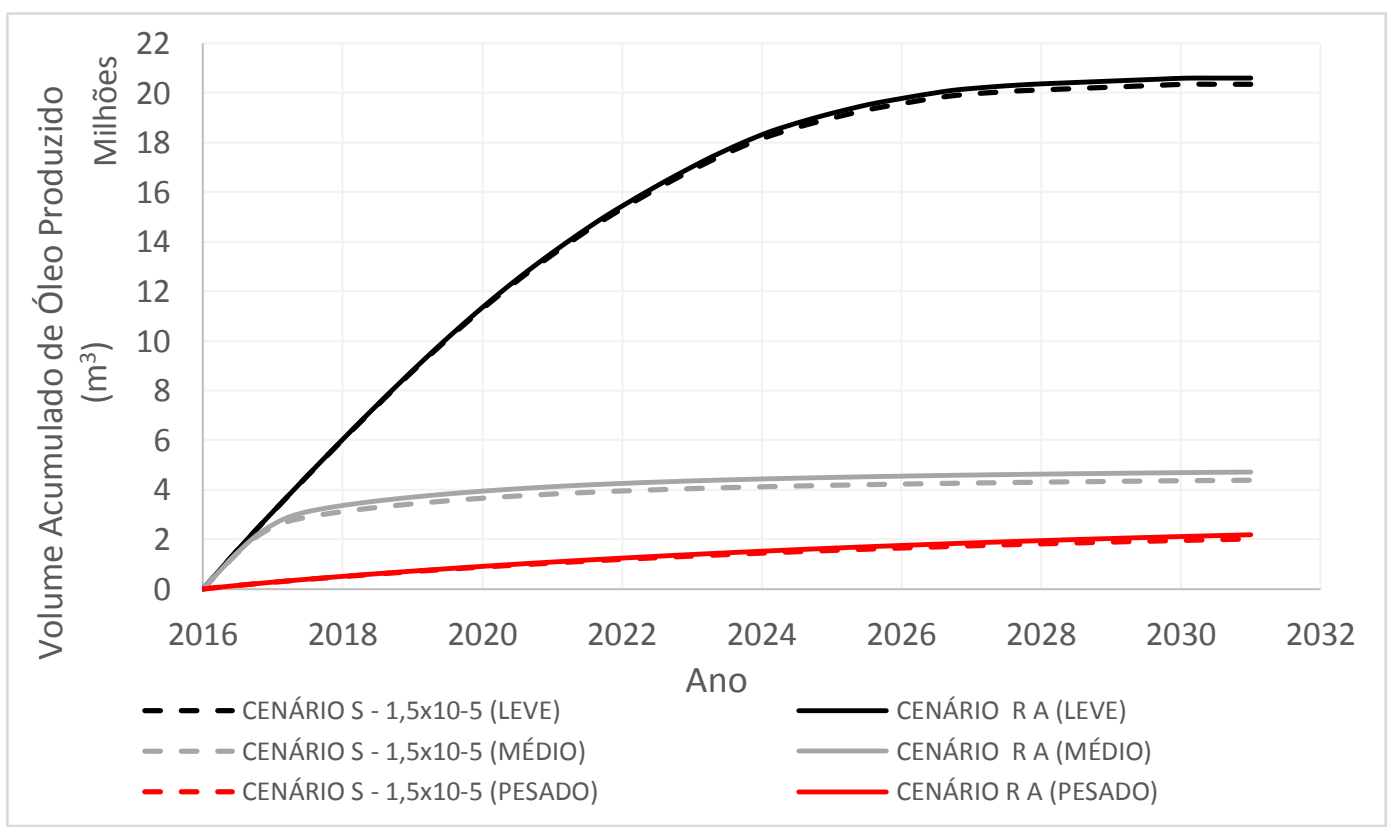

Figura 5. 32: Curvas de volume acumulado de óleo do Campo de Namorado para cenários de óleo leve, médio e pesado com e sem acoplamento geomecânico.

Antes de começar a análise comparativa entre os cenários RA e R-A-, é analisado o efeito geomecânico na produção acumulada de óleo ao fim de uma década e meia de explotação. Para todos os pesos de óleo, a produção do cenário parcialmente acoplado foi superior aos respectivos casos sem acoplamento (Tabela 5.5). Apesar de percentualmente o maior ganho ter sido do cenário com óleo pesado $(8,4 \%)$, é o caso com óleo médio que apresenta o maior ganho em volume de hidrocarboneto líquido excedente. São $327.000 \mathrm{~m}^{3}$ a mais de óleo. 
Tabela 5. 5: Análise de volume de óleo produzido para os cenários R A com óleo leve, médio e pesado com e sem acoplamento.

\begin{tabular}{|c|c|c|c|}
\hline \multicolumn{4}{|c|}{ Óleo Leve (15 anos) } \\
\hline $\begin{array}{l}\text { Volume total de } \\
\text { óleo }\left(\mathrm{m}^{3}\right)\end{array}$ & $\begin{array}{l}\text { Volume total de } \\
\text { óleo }\left(\mathrm{m}^{3}\right)\end{array}$ & $\begin{array}{l}\text { Volume excedente } \\
\text { de óleo }\left(\mathrm{m}^{3}\right)\end{array}$ & $\begin{array}{c}\text { Ganho na } \\
\text { Produção (\%) }\end{array}$ \\
\hline Sem Acoplamento & Com Acoplamento & \multirow{2}{*}{$2,49 E+05$} & \multirow{2}{*}{$1,23 \%$} \\
\hline $2,04 \mathrm{E}+07$ & $2,06 \mathrm{E}+07$ & & \\
\hline \multicolumn{4}{|c|}{ Óleo Médio (15 anos) } \\
\hline $\begin{array}{l}\text { Volume total de } \\
\text { óleo }\left(\mathrm{m}^{3}\right)\end{array}$ & $\begin{array}{l}\text { Volume total de } \\
\text { óleo }\left(\mathrm{m}^{3}\right)\end{array}$ & $\begin{array}{l}\text { Volume excedente } \\
\text { de óleo }\left(\mathrm{m}^{3}\right)\end{array}$ & $\begin{array}{l}\text { Ganho na } \\
\text { Produção (\%) }\end{array}$ \\
\hline Sem Acoplamento & Com Acoplamento & \multirow{2}{*}{$3,27 E+05$} & \multirow{2}{*}{$7,46 \%$} \\
\hline $4,39 \mathrm{E}+06$ & $4,72 \mathrm{E}+06$ & & \\
\hline \multicolumn{4}{|c|}{ Óleo Pesado (15 anos) } \\
\hline $\begin{array}{l}\text { Volume total de } \\
\text { óleo }\left(\mathrm{m}^{3}\right)\end{array}$ & $\begin{array}{l}\text { Volume total de } \\
\text { óleo }\left(\mathrm{m}^{3}\right)\end{array}$ & $\begin{array}{l}\text { Volume excedente } \\
\text { de óleo }\left(\mathrm{m}^{3}\right)\end{array}$ & $\begin{array}{l}\text { Ganho na } \\
\text { Produção (\%) }\end{array}$ \\
\hline Sem Acoplamento & Com Acoplamento & \multirow{2}{*}{$1,70 \mathrm{E}+05$} & \multirow{2}{*}{$8,41 \%$} \\
\hline $2,02 \mathrm{E}+06$ & $2,19 \mathrm{E}+06$ & & \\
\hline
\end{tabular}

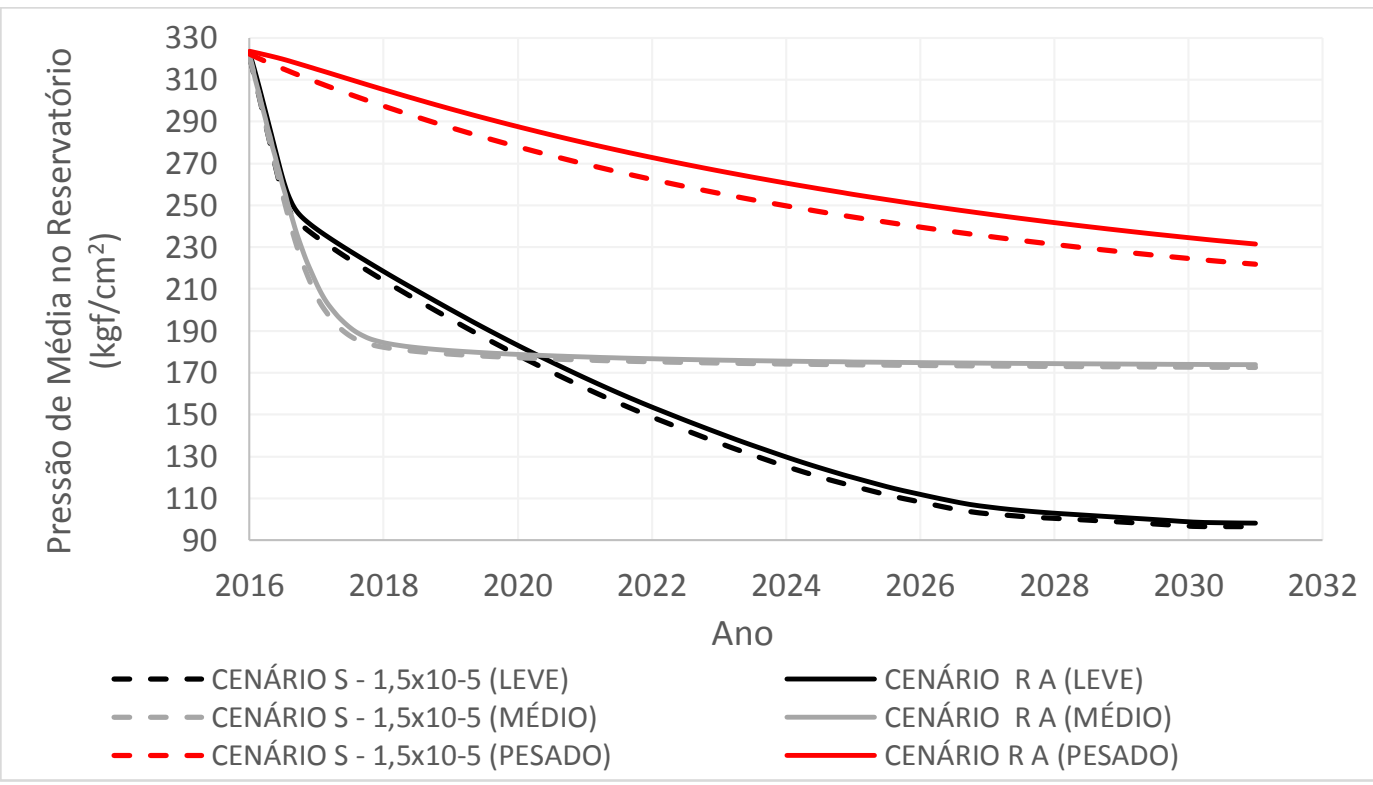

Figura 5.33: Curvas de queda pressão de poros para cenários de óleo leve, médio e pesado com e sem acoplamento geomecânico.

A queda da pressão de poros também apresentou características distintas em relação a cada cenário. Como já visto anteriormente, o caso com óleo leve libera gás com 6 meses e gera uma desaceleração da taxa de queda de pressão de poros no reservatório. Por sua vez, o cenário de óleo médio só inicia o processo de desprendimento de grandes volumes de gás com 20 meses de poços abertos. É a razão pela qual a taxa de queda de pressão se conserva acentuada por mais tempo. Já o caso com óleo pesado, não libera gás e apresenta ao fim dos 15 anos um maior 
diferencial de pressão entre o cenário acoplado e o sem acoplamento geomecânico. A explicação é a vazão ainda existente, no fim do décimo quinto ano, nos cenários de óleo pesado ( $360 \mathrm{~m}^{3} /$ dia no cenário acoplado), ou seja, as pressões tenderiam a se encontrar se tivessem sido simulados mais alguns anos de produção.

O objetivo da figura a seguir é comparar os ganhos de produtividade para o cenário original e o cenário que gera maior deformação ao reservatório (R-A-) para os três tipos de óleo definidos. Um cenário mais compressível a nível de reservatório e aliado ao efeito geomecânico de um overburden também mais elástico tem a capacidade de produzir mais $54,8 \%$ de óleo quando esse fluido possui 24,6 API. É neste mesmo caso que também se verifica o maior ganho em volume de óleo, chegando a 2,58 milhões de $\mathrm{m}^{3}$.

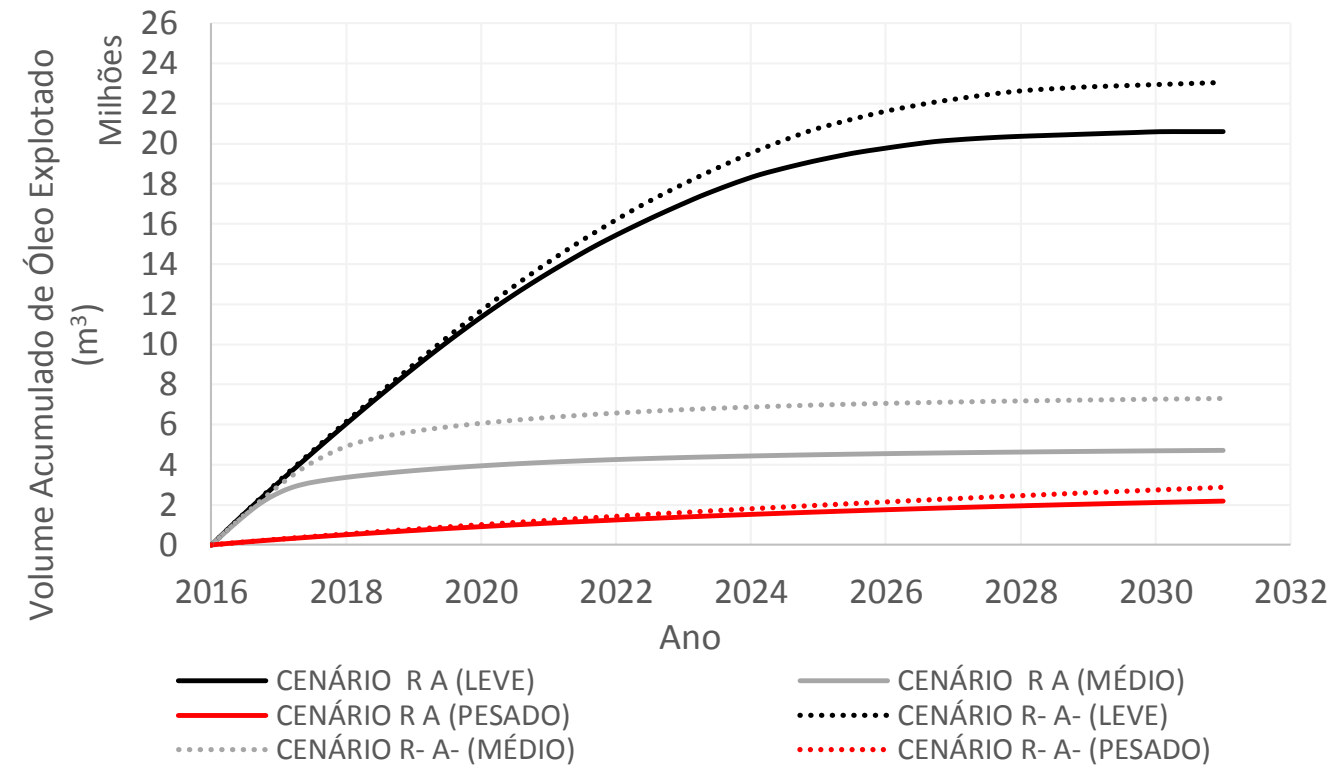

\begin{tabular}{|c|c|c|c|}
\hline \multicolumn{4}{|c|}{ Óleo Leve (15 anos) } \\
\hline Volume total de óleo $\left(\mathrm{m}^{3}\right)$ & Volume total de óleo $\left(\mathrm{m}^{3}\right)$ & Volume excedente de óleo $\left(\mathrm{m}^{3}\right)$ & Diferença (\%) \\
\hline Cenário R A & Cenário R-A- & \multirow{2}{*}{$2,45 \mathrm{E}+06$} & \multirow{2}{*}{$11,90 \%$} \\
\hline $2,06 \mathrm{E}+07$ & $2,31 \mathrm{E}+07$ & & \\
\hline \multicolumn{4}{|c|}{ Óleo Médio (15 anos) } \\
\hline Volume total de óleo $\left(\mathrm{m}^{3}\right)$ & Volume total de óleo $\left(\mathrm{m}^{3}\right)$ & Volume excedente de óleo $\left(\mathrm{m}^{3}\right)$ & Diferença (\%) \\
\hline Cenário R A & Cenário R- A- & \multirow{2}{*}{$2,58 \mathrm{E}+06$} & \multirow{2}{*}{$54,81 \%$} \\
\hline $4,72 E+06$ & $7,30 \mathrm{E}+06$ & & \\
\hline \multicolumn{4}{|c|}{ Óleo Pesado (15 anos) } \\
\hline Volume total de óleo $\left(\mathrm{m}^{3}\right)$ & Volume total de óleo $\left(\mathrm{m}^{3}\right)$ & Volume excedente de óleo $\left(\mathrm{m}^{3}\right)$ & Diferença (\%) \\
\hline Cenário R A & Cenário R- A- & \multirow{2}{*}{$8,57 E+05$} & \multirow{2}{*}{$42,45 \%$} \\
\hline $2,02 E+06$ & $2,87 E+06$ & & \\
\hline
\end{tabular}

Figura 5. 34: Análise de volume de óleo produzido para os cenários com óleo leve, médio e pesado relativos aos casos R A e R-A- ao fim de 15 anos de simulação. 
Grande parte da explicação pelos aumentos detectados acima tem relação em primeiro lugar com um reservatório com maior potencial de deformação em função de apresentar módulos de Young menores e maiores coeficientes de Poisson. Esse maior potencial à compactação modifica as vazões, como fica claro na figura a seguir. Para o cenário R A de óleo médio, apesar de haver uma vazão inicial próxima aos casos de óleo leve, ocorre uma acentuada queda verificada do quinto ao vigésimo primeiro mês em função da maior dificuldade do fluido se deslocar dentro do reservatório. A mudança para um cenário menos rígido, gera maior deformação do reservatório em menor espaço de tempo e permite que a vazão sofra queda semelhante com 6 meses de atraso, tempo suficiente para que o volume total de óleo produzido sofra um impacto muito grande antes que o desprendimento de gás aconteça. Importante frisar que a liberação de gás nos casos de óleo médio não apresenta o mesmo desempenho na explotação de fluidos como nos casos de óleo leve em função do menor volume liberado e da maior dificuldade em deslocar um óleo mais denso e viscoso.

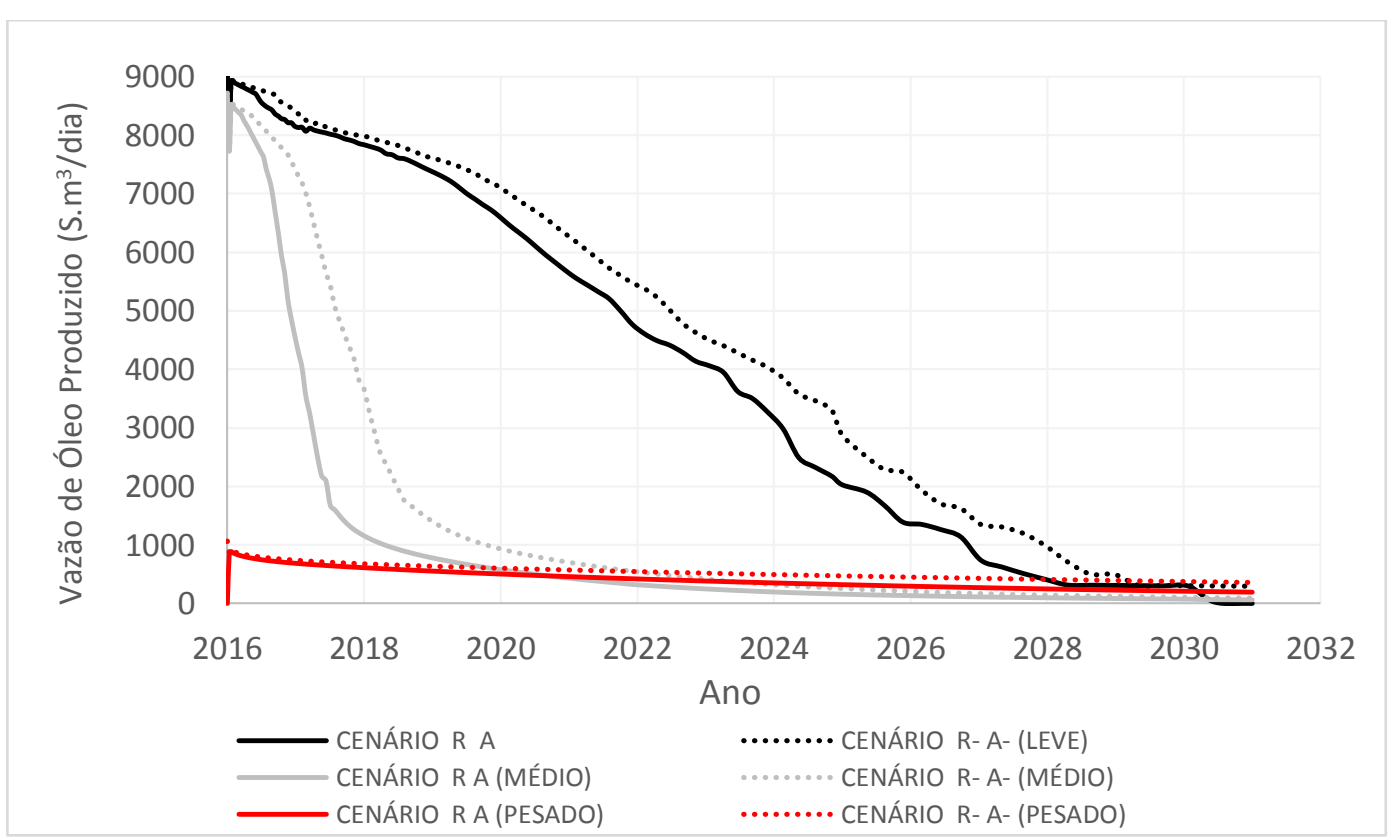

Figura 5. 35: Histórico de vazão de óleo dos cenários R A e R-A- de óleo leve, médio e pesado. 


\section{5 .3}

\section{Análise de resultados geomecânicos}

Como a análise geomecânica envolve 2 cenários (R A e R- A-) e 3 casos de óleos distintos, totalizando 6 cenários, a opção a partir daqui é analisar apenas 2 horizontes e seus deslocamentos. Dessa forma, serão analisados os horizontes de topo do reservatório e leito marinho $(\mathrm{Z}=170 \mathrm{~m})$.

A Figura 5. 36 apresenta o histórico de deslocamento do topo do reservatório para todos os casos propostos para esta seção do capítulo. Inicialmente será feita a análise dos três cenários $\mathrm{R}$ A.

Após 1 ano de produção de óleo, o deslocamento de topo de reservatório do cenário com fluido de $24,6^{\circ}$ API é maior do que o caso de óleo leve. O cenário de óleo pesado, por sua vez, tem máximo deslocamento de apenas 1,6 cm nesse período. Após 5 anos, o cenário de óleo leve ultrapassa o deslocamento apresentado pelo caso de óleo médio e mantém a dianteira até o fim dos 15 anos simulados.

Quando a análise passa a ser focalizada nos três cenários R-A-, percebe- se que ao fim do primeiro ano, o cenário de óleo leve teve maior deslocamento que o cenário de óleo médio. Porém, até o final do terceiro ano, as posições se invertem. Novamente, na visualização de 15 anos, é observada nova inversão e o cenário de óleo $32^{\circ}$ API assume o posto de maior deslocamento. Essa dinâmica de troca de posições entre o caso de óleo leve e médio tem sua justificativa baseada principalmente na liberação de gás no reservatório e nas vazões de fluidos como fica provado na Figura 5.37. É possível observar que o cenário de óleo médio começa a se distanciar em termos de deslocamento do cenário de óleo leve quando o desprendimento de gás deste último começa a se tornar muito acentuado. Nesse ponto, o deslocamento do topo do reservatório tem uma desaceleração também acentuada. Uma nova inversão só se realiza em 2021. Nesse meio tempo, a liberação de gás pelo cenário de óleo médio também ocorre, porém mais importante que isso, é a queda acentuada da vazão de óleo produzido, como visto na Figura 5.35. 


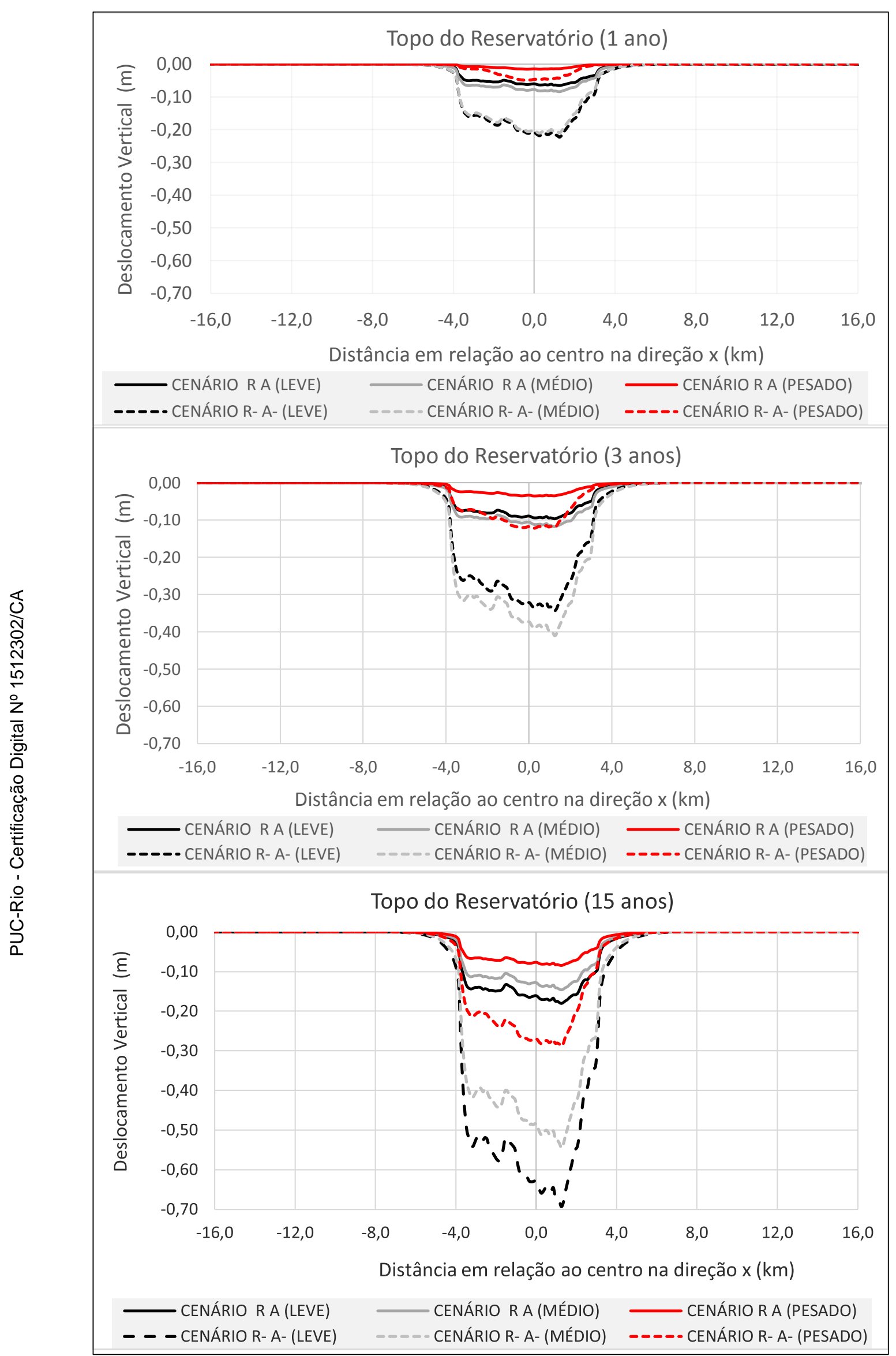

Figura 5. 36: Evolução dos deslocamentos do horizonte do topo do reservatório para cenários R A e R-A- com óleo leve, médio e pesado ao fim de 1, 3 e 15 anos de simulação. 


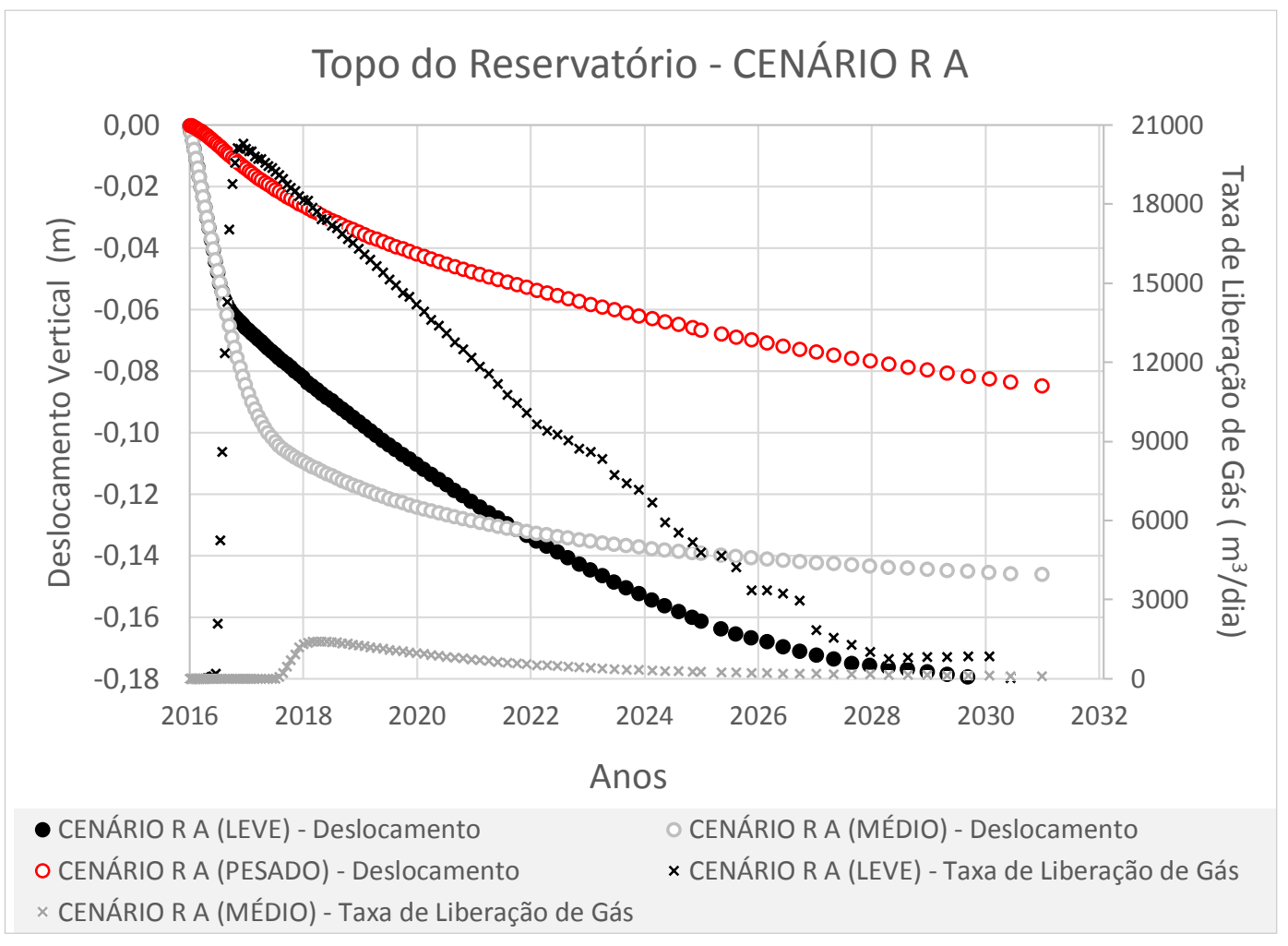

Figura 5. 37: Histórico do deslocamento vertical e taxa de liberação de gás para o cenário R A com óleo leve, médio e pesado.

Outra conclusão obtida pela Figura 5.36 é a de que todos os cenários menos rígidos, independente do óleo presente nos poros, superam os deslocamentos de seus respectivos cenários R A. O cenário R-A- de óleo pesado supera, inclusive, o cenário R A de óleo leve. A partir da análise da Tabela 5.6, fica comprovado como cenários $55 \%$ menos rígidos nas rochas adjacentes e $82,4 \%$ menos rígidos na rocha reservatório permitem um deslocamento do topo do reservatório de 2,4 a 2,7 vezes superior ao fim de 15 anos de simulação. Os dados do primeiro ano destoam, principalmente, para o cenário de óleo médio em função da questão do retardo da queda de vazão mencionado acima.

Tabela 5. 6: Comparação entre deslocamentos do cenário R-A- e cenário R A para o horizonte de topo do reservatório.

\begin{tabular}{|c|c|c|c|c|c|}
\cline { 3 - 5 } & & 1 ano & 3 anos & 9 anos & 15 anos \\
\cline { 2 - 6 } Topo do & CENÁRIO R- A- (LEVE) & $239,3 \%$ & $255,9 \%$ & $269,8 \%$ & $284,2 \%$ \\
\cline { 2 - 6 } Reservatório & CENÁRIO R- A- (MÉDIO) & $149,5 \%$ & $248,4 \%$ & $267,1 \%$ & $272,4 \%$ \\
\cline { 2 - 6 } & CENÁRIO R- A- (PESADO) & $212,9 \%$ & $245,9 \%$ & $244,1 \%$ & $239,9 \%$ \\
\hline
\end{tabular}

Outro ponto de destaque da Figura 5.36 é o baixo deslocamento da região mais à direita do gráfico e localizado entre 2 a $4 \mathrm{~km}$ do centro do bloco de simulação. A presença de um hidrocarboneto líquido mais viscoso impede que esse 


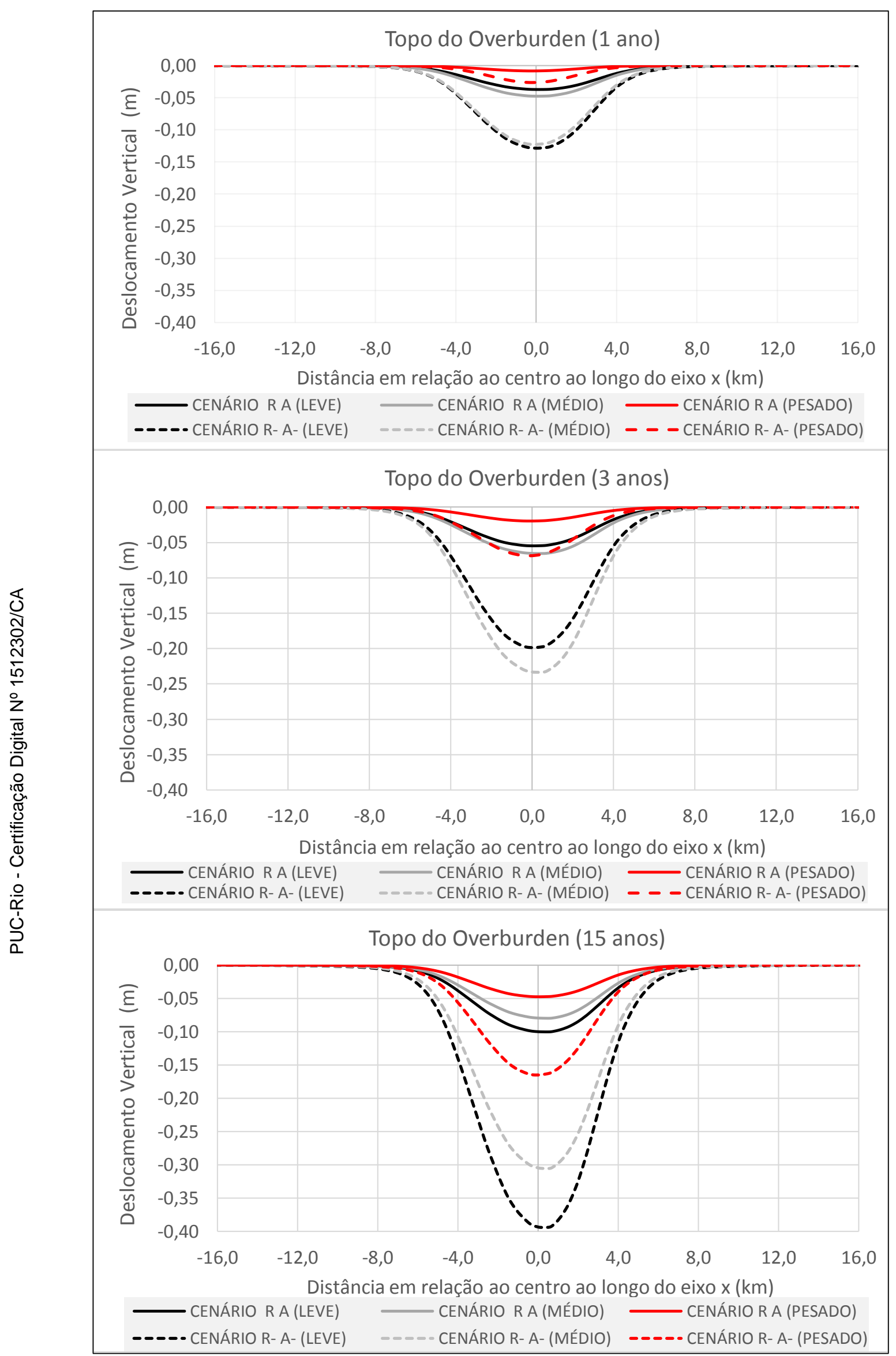

Figura 5. 38: Evolução dos deslocamentos do horizonte do leito marinho para cenários R A e R-A- com óleo leve, médio e pesado ao fim de 1, 3 e 15 anos de simulação. 
fluido se desloque até os poços mais centrais do campo e onde residem as maiores vazões.

Ainda é importante salientar que o mesmo comportamento de alternância de maior deslocamento entre os cenários de óleo leve e médio é verificado na subsidência do leito marinho (Figura 5.38). Como já visto anteriormente, esses deslocamentos são menores do que os observados no topo do reservatório. O caso R-A- com óleo leve é o que sofre maior subsidência, alcançando o valor de $40 \mathrm{~cm}$. Já o cenário com óleo $16^{\circ} \mathrm{API}$, não alcança subsidência acima de $17 \mathrm{~cm}$ nem no caso menos rígido. 


\section{6. \\ Considerações Finais}

\section{1 Conclusões}

Após a análise de 15 cenários ao longo do Capítulo 5, é possível concluir que: - A análise de pressão em reservatórios para diferentes cenários, principalmente na consideração dos efeitos geomecânicos de longo prazo, deve abranger uma observação mais detalhada que vá além da comparação entre o último ponto simulado e o início da simulação. Em inúmeros cenários descritos no Capítulo 5, fica claro que sob efeito da geomecânica, a pressão tende a convergir a longo prazo para valores muito próximos a de outros casos, mesmo que as propriedades mecânicas das rochas adjacentes e, até mesmo as do reservatório, tenham contribuído para a produção de maior volume de fluidos;

- Como visto no Capítulo 5, os efeitos geomecânicos promovem mudanças no comportamento do campo especialmente no curto prazo, que podem repercutir anos depois. Em função disso, trata-se de uma ferramenta interessante no ajuste de histórico de campos em produção, principalmente em questões que tangenciam uma melhor previsibilidade da liberação de gás dentro do reservatório e queda mais acentuada de vazão de hidrocarbonetos.

- A presença de um overburden menos rígido promove uma maior deformação do reservatório, uma vez que seus componentes não sofrem tanta resistência originada pela rigidez de seu próprio meio. Já os deslocamentos dentro da própria região do overburden são menos sentidos em qualquer profundidade em relação a áreas próximas ao topo do reservatório porque o material consegue se deslocar em sua região basal (próximo ao topo do reservatório), expandir e gerar assim um menor deslocamento no leito marinho. Prova disso é a figura anterior que traz o percentual de deslocamento do topo do overburden em relação ao topo do reservatório para os casos simulados, comprovando que a transmissão dos deslocamentos para o leito marinho é menor na medida que o overburden torna-se menos rígido; 


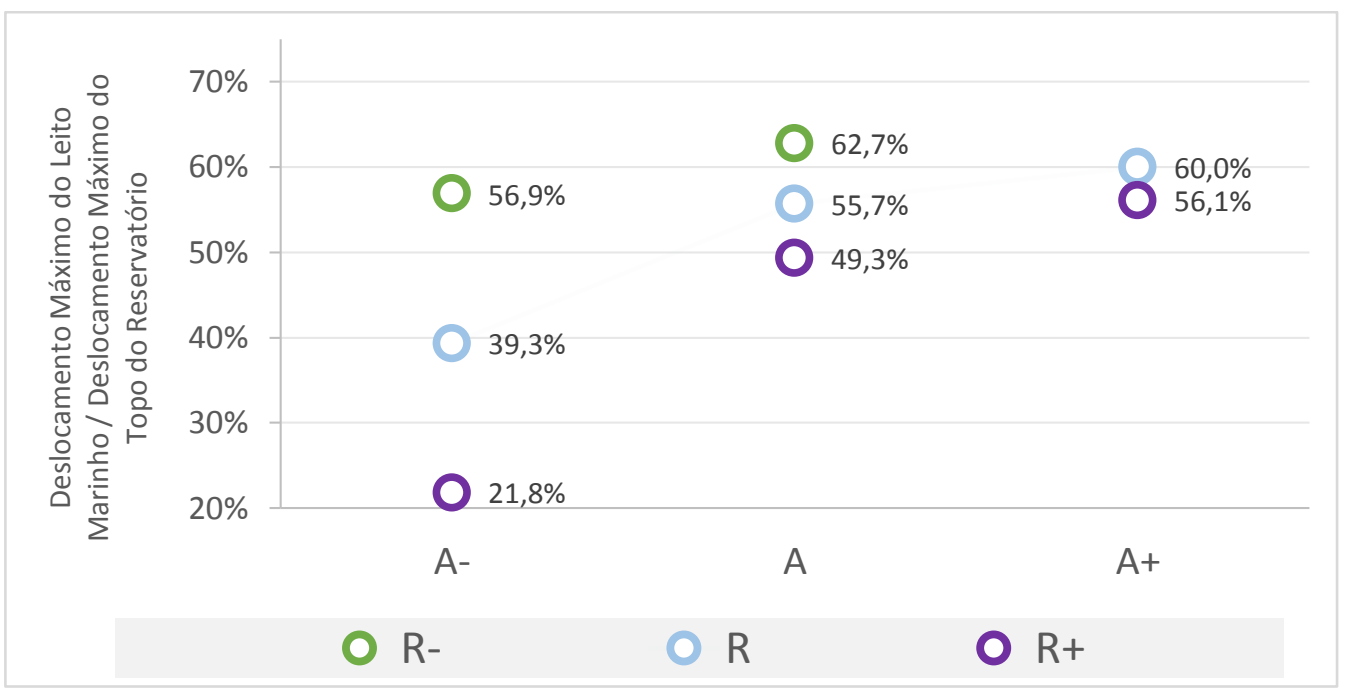

Figura 6.1: Percentual de deslocamento do topo do overburden em relação ao topo do reservatório para 8 cenários simulados ao fim de 15 anos.

- A figura a seguir permite concluir que à medida que o reservatório se torna mais rígido, menor é o deslocamento do overburden. O mesmo vale no sentido de tornar as rochas adjacentes do overburden menos rígidas;

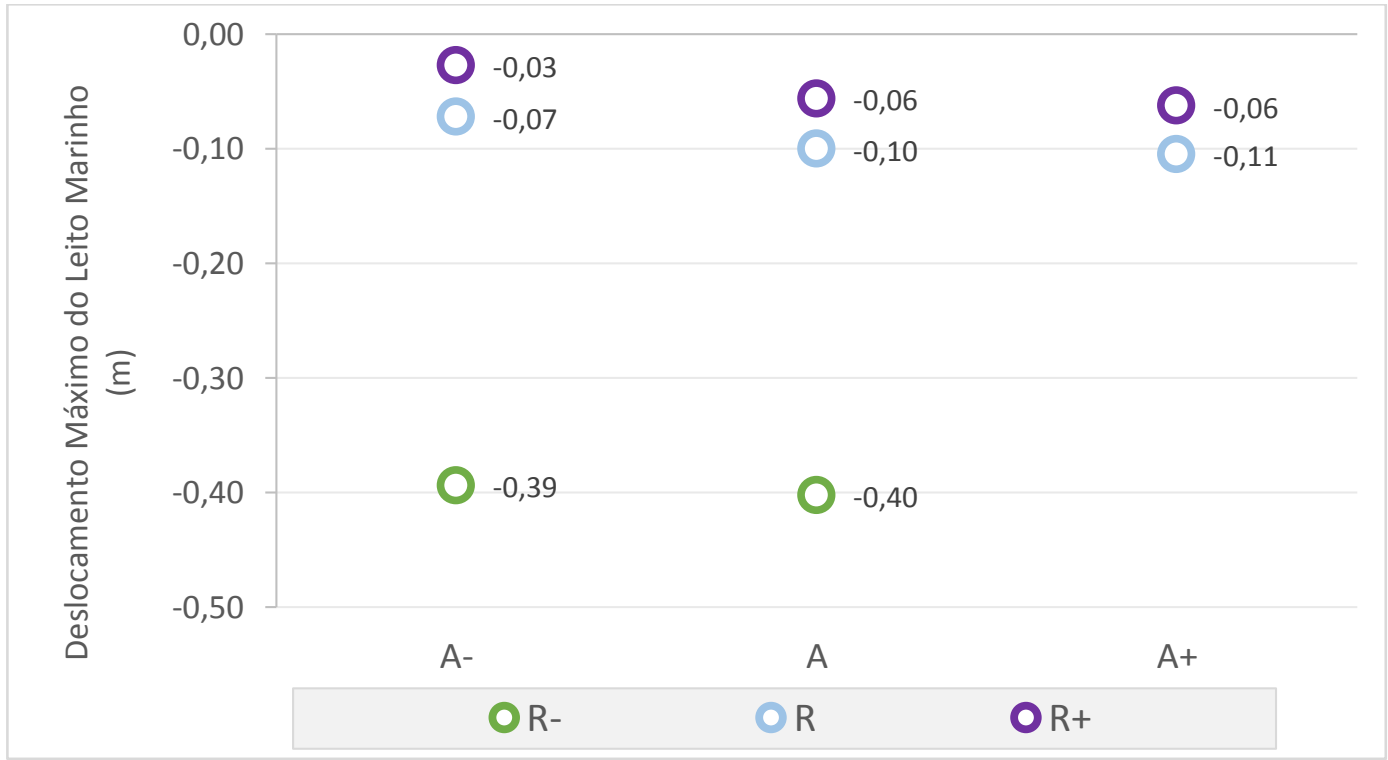

Figura 6.2: Deslocamento do topo do overburden para 8 cenários simulados ao fim de 15 anos.

- O cenário mais susceptível aos efeitos geomecânicos a nível de reservatório é o R-A- para óleo leve com uma compactação que chegou a $81 \mathrm{~cm}$. Trata-se de um cenário análogo à realidade de um campo de petróleo relativamente jovem, no qual processos de diagênese não estão em processo avançado. Em função da rigidez ser menor tanto no reservatório quanto nas rochas adjacentes, tal fato pode indicar um campo situado a profundidades menores. O único ponto 
discordante entre essa realidade e o cenário R-A- seria a profundidade deste último, visto que o Campo de Namorado está a 3.000 metros abaixo da superfície do mar. - O cenário mais susceptível aos efeitos geomecânicos a nível de subsidência do leito marinho é o R-A com um deslocamento vertical de $40 \mathrm{~cm}$;

- Para cenários de óleo leve no Campo de Namorado, a desaceleração da compactação do reservatório para períodos de até 2 anos de produção está muito mais associada à liberação do gás em solução do que à queda de vazão de fluido produzido;

- Para cenários de óleo médio no Campo de Namorado, a desaceleração da compactação do reservatório para períodos de até 2 anos de produção está mais associada à queda repentina e brusca de vazão. Tal comportamento está relacionado, inclusive, à maior viscosidade do óleo quando comparado ao cenário de óleo leve. Apesar da liberação de gás, o volume é muito menor e tem essa viscosidade do óleo como complicador na eficácia do mecanismo de gás em solução como método de produção;

- Para cenários de óleo pesado no Campo de Namorado, a desaceleração da compactação do reservatório é associada prioritariamente á viscosidade alta do óleo, visto que não há liberação de gás em nenhum momento. 


\section{2}

\section{Sugestões para próximos trabalhos}

O primeiro ponto que necessita de maior investigação na busca de maior realismo à simulação parcialmente acoplada é a inserção da permeabilidade como parâmetro de acoplamento. Como definido pelo Princípio de Terzaghi, a compactação do reservatório tende a estreitar as conexões entre poros, prejudicando o fluxo de material. No trabalho de Seabra [54], esse efeito pode ser observado para um reservatório carbonático. Entretanto, ainda há carência de resultados de simulações com cenários hipotéticos distintos, como os apresentados nesta dissertação, de forma a mensurar, por exemplo, como o retardamento da liberação de gás pode alterar o histórico de produção do campo sob a influência de uma correção da permeabilidade do campo.

Um segundo ponto que pode ser melhor explorado é como os deslocamentos são impactados pela injeção de fluidos como forma de recuperação secundária de hidrocarbonetos. Os impactos podem inclusive determinar critérios não só de arranjos de conjuntos de poços injetores, como também na previsão de melhores períodos para injeção, tomando por base a rigidez das rochas que formam o sistema petrolífero.

Com a pesquisa de acoplamento geomecânico com a injeção de fluidos mais desenvolvida também seria possível analisar se as curvas simuladas estariam mais próximas das curvas de histórico de produção do campo. Seria mais um passo na busca por um ajuste de histórico mais fidedigno, visto que os maiores efeitos geomecânicos ocorrem no curto prazo, principalmente em reservatórios de óleo leve.

Outra linha que pode ser mais explorada em trabalhos futuros é a previsão de módulos elásticos por meio de dados indiretos via poços de perfilagem. Foi observado neste trabalho, durante as simulações, uma certa dificuldade em chegar a valores de módulo de Young muito baixos, indicando que talvez não seja a melhor metodologia para obtenção desses módulos em campos poucos rígidos e mais deformáveis.

Outro ponto que vale ser analisado é a comparação entre os dados de módulo de Young e coeficiente de Poisson obtidos nesta dissertação, tanto para arenitos, folhelhos e carbonatos, com os mensurados em ensaios laboratoriais com amostras locais do Campo de Namorado. 


\section{7. \\ Referências bibliográficas}

[1] ROSA A.; CARVALHO R.; XAVIER, D. - Engenharia de Reservatórios de Petróleo. Editora Interciência Ltda., Rio de Janeiro, 2011. 808 p.

[2] INOUE, N.; FONTOURA, S. A. B. - Explicit Coupling Between Flow and Geomechanical Simulators. International Conference on Computational Methods for Coupled Problems in Science and Engineering. Ischia Island, Italy: [s.n.], 2009

[3] DOSTER, F., NORDBOTTEN, J. M. - Full Pressure Coupling for Geomechanical Multi-phase Multi-component Flow Simulations. Society of Petroleum Engineers - University of Bergen, Noruega, 2015

[4] INOUE, N.; FONTOURA, S. A. B. - Answers to some questions about the coupling between fluid flow and rock deformation in oil reservoirs. SPE/EAGE Reservoir Characterization and Simulation Conference, 2009

[5] ALBUQUERQUE, R.A.C. - Simulação de Fluxo e Tensões em Reservatórios Aplicada a Casos Reais. Dissertação de Mestrado - Pontifícia Universidade Católica do Rio de Janeiro, Rio de Janeiro, 2014

[6] BIOT, M.A. - Mechanics of Deformation and Acoustic Propagation in Porous Media. Journal of Applied Physics 33, New York, 1962

[7] LAUTENSCHLÄGER, C. E. R-Efeitos do Desenvolvimento de Reservatórios sobre a Integridade de Poços de Petróleo: Uma Análise Parcialmente Acoplada e Multi-Escala. Tese de Doutorado - Pontifícia Universidade Católica do Rio de Janeiro, Rio de Janeiro, 2014

[8] DEAN, R., GAI, X., STONE, C., \& MINKOFF, S. - A Comparison of Techniques for Coupling Porous Flow and Geomechanics. Society of Petroleum Engineering Journal, 11 (1), 2006

[9] AZIZ, K.; SETTARI, A. Petroleum Reservoir Simulation. Applied Science Publishers, Londres, 1979

[10] FALCÃO, F. de O. L. - Simulação hidromecânica de reservatório carbonático de petróleo através de pseudoacoplamento. Tese de Doutorado - Pontifícia Universidade Católica do Rio de Janeiro, Rio de Janeiro, 2013 
[11] SETTARI, A.; VIKRAM, S. - Geomechanics in Integrated Reservoir Modeling. Offshore Technology Conference, Houston, Texas, 2008

[12] LACY, L. L. - Dynamic Rock Mechanics Testing for Optimized Fracture Designs. Society of Petroleum Engineers 38716. BJ Services Company, USA, 1997

[13] FJAER E.; HOLT R. M.; HORSRUD P., RAAEN A.M. \& RISNES R. Petroleum Related Rocks Mechanics - 2nd Edition. Editora Elsevier, Oxford, 2008. 490 p.

[14] DETOURNAY, E., CHENG, A. H. D. - Fundamentals of Poroelasticity. Em Comprehensive Rock Engineering. Vol. 2. (pp. 113-171). J. A. Hudson (Ed.), 1993

[15] WANG, Z. - Fundaments of Seismic Rock Physics. Geophysics, 66, no 2, 2001, p. 398-412, 2001

[16] ZIMMERMAN R. W. - Compressibility of Sandstones - 1st Edition. Editora Elsevier, Oxford, 1991. 174 p.

[17] HALL, H. N. - Compressibility of Reservoir Rocks. Petroleum Transactions of the AIME - vol.198, 1953.

[18] BIOT, M.A. - General Theory of Three-Dimensional Consolidation. Journal of Applied Physics 12, New York, 1941

[19] LI, C., CHEN, X., \& DU, Z. - A New Relationship of Rock Compressibility with Porosity. SPE Asia Pacific Oil and Gas Conference and Exhibition, Perth, Austrália, 2004

[20] SAMIER, P.; DE GENNARO, S. - Practical Iterative Coupling of Geomechanics with Reservoir Simulation. SPE Reservoir Simulation Symposium, Houston, Texas, 2007

[21] HOFMAN, R.; XU, X.; BATZLE, M.; PRASAD, M.; FURRE, A. \& PILLITERI, A. - Effective Pressure or What is The Effect of Pressure. The Leading Edge p.1256-1260, 2005

[22] TRAN, D., NGHIEM, L., \& BUCHANAN, L. - Aspects of Coupling Between Petroleum Reservoir Flow And Geomechanics. American Rock Mechanics Association, 2009 
[23] SEN V.; SETTARI, T. Coupled Geomechanical and Flow Modeling of Compacting Reservoirs. The Leading Edge, 2005

[24] ESPINOZA, C. E - A New Formulation for Numerical Simulation of Compaction: Sensitivity Studies for Steam Injection. SPE Reservoir Simulation Symposium, San Francisco, California, 1983

[25] TRAN, D., NGHIEM, L., \& BUCHANAN, L. - Improved Iterative Coupling of Geomechanics With Reservoir Simulation. SPE Reservoir Simulation Symposium, Houston, Texas, 2005

[26] ZIENKIEWICZ, O.; CHAN, A. H.; PASTOR, M.; SCHREFLER, B. A. \& SHIOMI, T. - Computational Geomechanics with Special Reference to Earthquake Engineering (1 ${ }^{\text {a }}$ ed.). England: John Wiley \& Sons, 1999

[27] SETTARI, A., \& MOURITS, F. M. - Coupling of Geomechanics and Reservoir Simulation Models. 8th International Conference on Computer Methods and Advances in Geomechanics. Morgantown, Viginia, Estados Unidos, 1994

[28] ASTM - D4543-09: Standard Practices for Preparing Rock Core as Cylindrical Test Specimens and Verifying Conformance to Dimensional Shape Tolerances, 2007

[29] LOBATO, K. C. R. - Simulação Física e Numérica de problemas de Estabilidade de Poços. Dissertação de Mestrado - Pontifícia Universidade Católica do Rio de Janeiro, Rio de Janeiro, 2009

[30] CHEN, H. Y., TEUFEL, L. W., \& LEE, R. L. - Coupled Fluid Flow and Geomechanics in Reservoir Study - I. Theory and Governing Equations. Society of Petroleum Engineers, 1995

[31] MAVKO, G.; MUKERJI, T. and DVOR KIN, J. - The Rock Physics Handbook: Tools for Seismic Analysis in Porous Media. Cambridge University Press, 1998

[32] NERY, G. G. - Perfilagem Geofísica em Poço Aberto: Fundamentos básicos com ênfase em petróleo. Salvador, 1990. 231p.

[33] CÔRTE, G. A. - Modelagem e Interpretação de Sísmica Time-Lapse em Modelos de Simulação Numérica de Reservatório: o Exemplo do Reservatório de Namorado. Dissertação de Mestrado - Unicamp, Campinas, 2014 
[34] PASSARELlA, C. A. - Integração de Dados de Poços e Métodos Geoestatísticos Para a Modelagem Geológica do Campo de Namorado. Dissertação de Mestrado - Unicamp, Campinas, 2014

[35] ROSA, H.; SUSLICK, S. B.; VIDAL, A. C.; SAKAI, G. K. - Caracterização de Eletrofácies Por Meio de Ferramentas Estatísticas Multivariadas. Revista Escola de Minas, $n^{\circ}$ 61, vol. 4, p. 415-422. Ouro Preto, 2008

[36] BORGES, Y. A. - Método de Inversão Mineralógica a Partir de Perfis Geofísicos de Poços do Campo de Namorado. Trabalho de Conclusão de Curso - Universidade Federal Fluminense, Niterói, 2012

[37] CRUZ, M. M. - Aplicação de Perfilagem Geofísica e Sísmica na Caracterização da Faciologia do Reservatório de Namorado. Dissertação de Mestrado - Universidade Federal Fluminense, Niterói, 2003

[38] EMERICK, A. A.; MORAES, R.; RODRIGUES, J. - Calculating Seismic Attributes Within a Reservoir Flow Simulator. SPE Latin American and Caribbean Petroleum Engineering Conference, 2007.

[39] GONZALEZ, S. P. - Estimativa de Saturação de Água Conata em Reservatórios Clásticos. Trabalho de Conclusão de Curso em Geofísica Universidade Federal Fluminense, Niterói, 2014

[40] SOUZA, R. M.; SANTOS, M. S,; SCHIOZER, D. J. - Petro-Elastic Parameters Effects on History Matching Procedures. EUROPEC Annual Conference and Exhibition, Viena, Áustria, 2011

[41] ROSA, M. C. - Modelo Petrofísico 3D do Arenito Namorado no Campo de Namorado - Bacia de Campos, RJ. Monografia de Conclusão de Curso Universidade Estadual Paulista, Rio Claro, 2011

[42] SOUZA, R. M. - Obtenção de Dados de Saturação e Pressão a partir de Atributos Derivados da Sísmica 4D. Dissertação de Mestrado - Universidade Estadual de Campinas, Campinas, 2010

[43] CASTAGNA, J.P.; BATZLE M.L.; EASTWOOD R.L. - Relationships Between Compressional-wave and shear-wave velocities in clastic silicate rocks. Society of Exploration Geophysics, Vol.50, n 4 - Dallas, Texas, 1985

[44] ClAVIER, C.; COATES, G.; DUMANOIR, J. - The Theorical and Experimental Bases for the Dual Water Model for the Interpretation of Shaly Sands. SPE Annual Fall Meeting, 1977 
[45] HASHIN, Z.; SHTRIKMAN, S. - A variational approach to the elastic behavior of multiphase minerals. Journal of the Mechanics and Physics of Solids, 11, 127-140, 1963.

[46] ARCHIE, G. E. - The Electrical Log as an aid in determining some reservoir characteristics - p. 54-62. Dallas Meeting, 1941

[47] MORAIS J. M. - Petróleo em Águas Profundas: Uma História Tecnológica da PETROBRAS na Exploração e Produção Offshore. Instituto de Pesquisa Econômica Aplicada- IPEA, Brasília, 2013. 424p.

[48] WINTER, W.R.; JAHNERT, R.J.; FRANÇA, A.B. - Bacia de Campos. Boletim de Geociências da Petrobras, vol.15, n², p.511-529, 2007

[49] BASTOS, G. - Bacia de Campos - Sumário Geológico e Setores em Oferta. $13^{\text {a }}$ Rodada de Licitações de Petróleo e Gás, 2015

[50] LEE, M. W. - Proposed Moduli of Dry Rock and Their Application to Predicting Elastic Velocities of Sandstones. Scientific Investigations Report 5119 - U.S. Geological Survey, 2005.

[51] NUR, A., MAVKO, G., DVORKIN, J., and GAL, D. - Critical porosity: the key to relating physical properties to porosity in rocks. 65th Annual International Meeting, Society of Exploration Geophysicists, vol. 878. Tulsa, 1995

[52] STUART, C.A. - Geopressures Presented at the Louisiana State University. Symposium on Abnormal Subsurface Pressure. Louisiana, USA, 1970

[53] READ, J. \& STACEY, P. - Guidelines for Open Pit Slope Design. CRC Press - 1st edition, 2009. 510 p.

[54] SEABRA, G.S. - Simulações Hidromecânicas Parcialmente Acopladas de um Reservatório Carbonático da Bacia de Campos. Dissertação de Mestrado - Pontifícia Universidade Católica do Rio de Janeiro, Rio de Janeiro, 2016

[55] GUTIERREZ, M.; LEWIS, R. W. - The Role of Geomechanics in Reservoir Simulation. SPE/ISRM Rock Mechanics in Petroleum Engineering, Trondheim, Noruega, 1998

[56] RIGUETTO, G. L.; LAUTENSCHLÄGER, C. E. R.; ALBUQUERQUE, R. A. C.; INOUE, N. \& FONTOURA, S. A. B. - A Smart Way to Build Geomechanical Models and Analyze Casing Collapse during the Petroleum Field Development. American Rock Mechanics Association, 2014 
[57] MAINGUY, M., \& LONGUEMARE - Coupling Fluid Flow and Rock Mechanics. Formulations of the Partial Coupling Between Reservoir and Geomechanics. Oil \& Gas Science and Technology - Revue d'IFP Energies Nouvelles, 2002

[58] PEREIRA, L. C. - Simulação de Fluxo em Reservatórios sob Efeito da Compactação. Dissertação de Mestrado - Universidade Federal do Rio de Janeiro, Rio de Janeiro, 2007

[59] GOODMAN, R.E. - Introduction to Rock Mechanics. Editora John Wiley and Sons, $2^{\text {a }}$ edição, 1989

[60] RODRIGUEZ, N. P. Y. - Avaliação de esquemas de acoplamento na simulação de Reservatórios de Petróleo. Dissertação de Mestrado - Pontifícia Universidade Católica do Rio de Janeiro, 2011

[61] ZIENKIEWICZ, O. C.; SHIOMI, T. - Dynamic Behavior of Saturated Porous Media: The Generalized Biot Formulation and Its Numerical Solution. International Journal for Numerical and Analytical Methods in Geomechanics, Vol. 8, 1984 


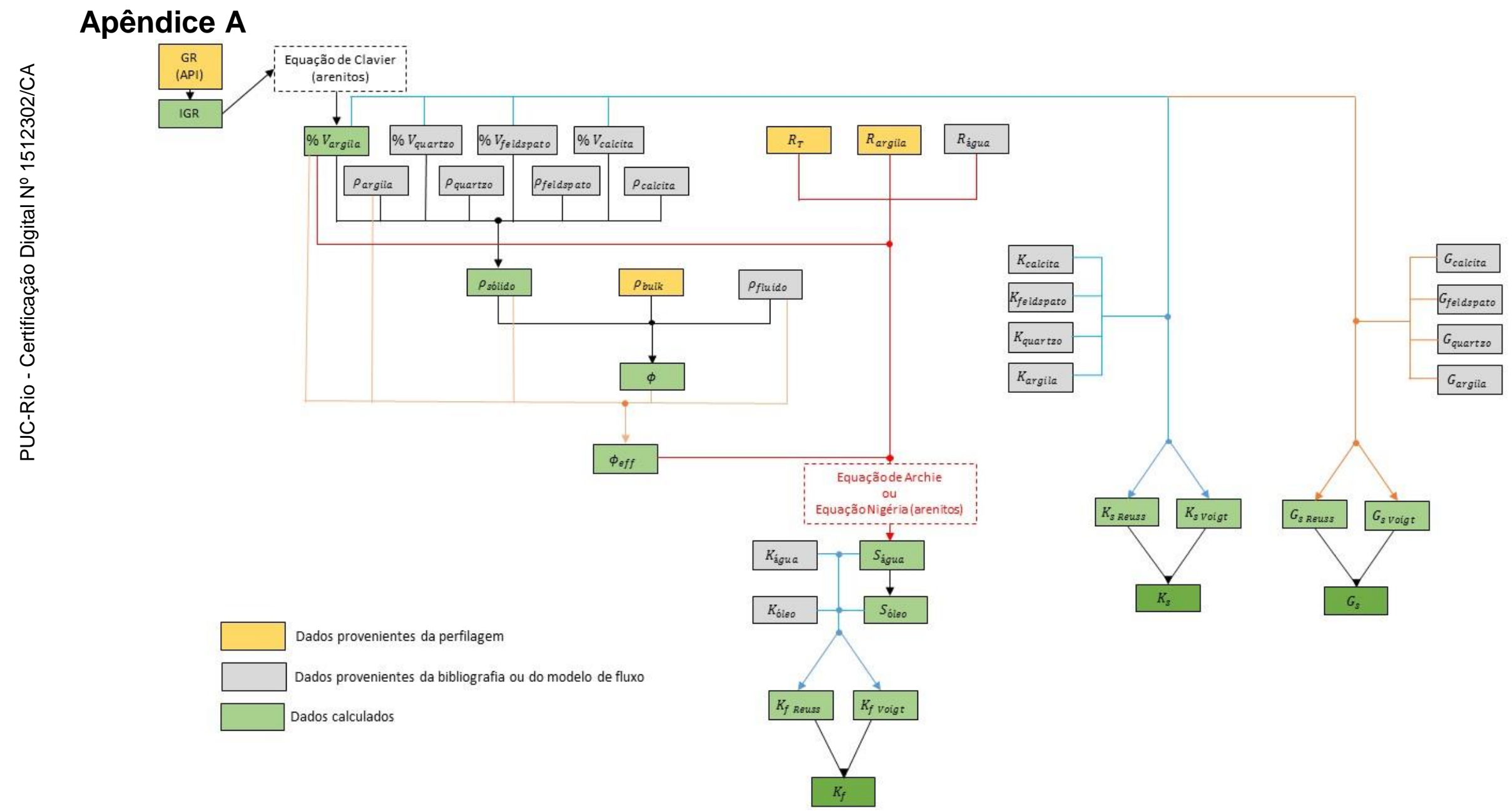

Figura A. 1: Fluxograma de definição dos módulos de compressibilidade e cisalhamento para as três fácies a partir de dados de bibliografia e de perfilagem de poços. 


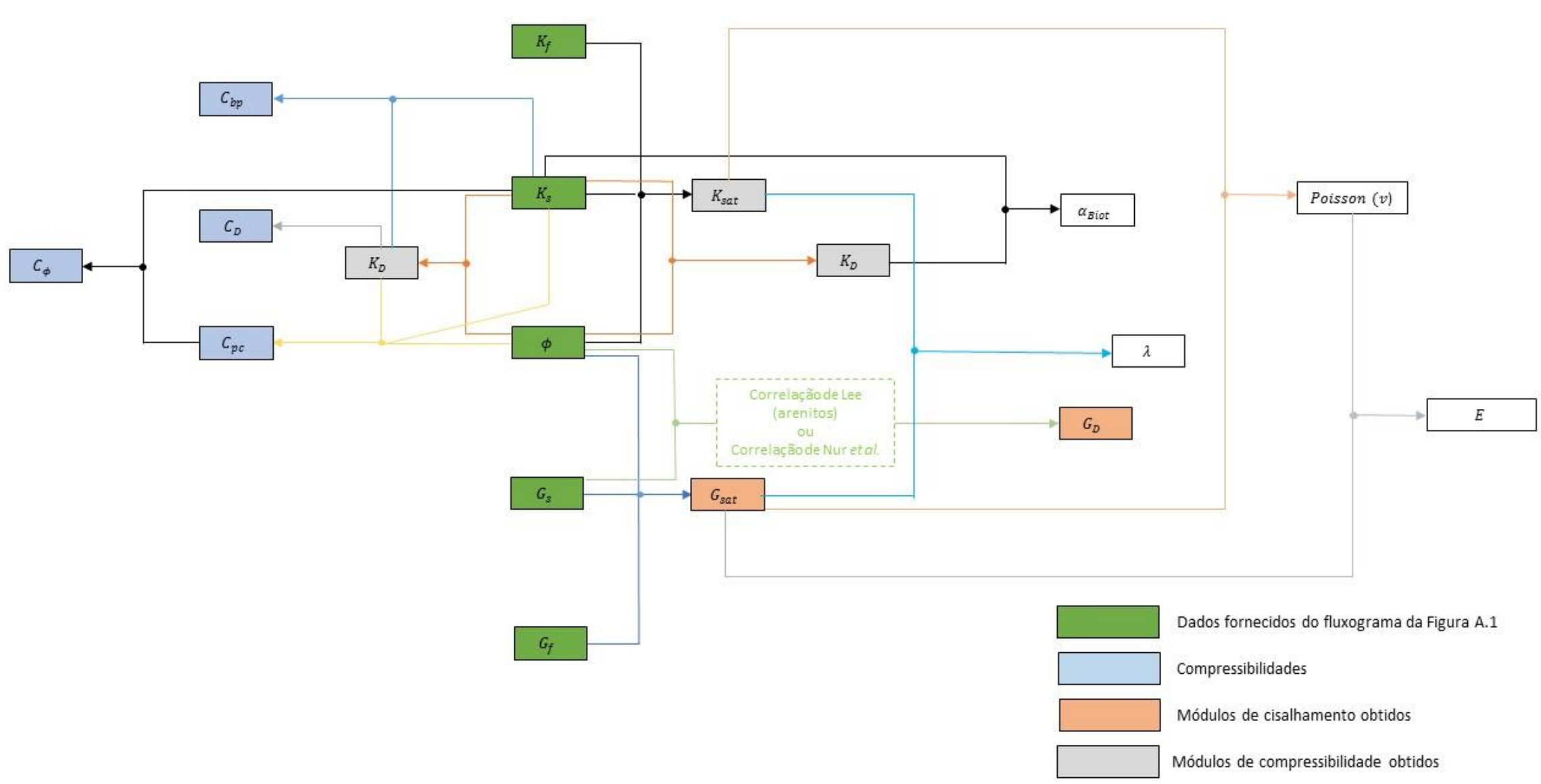

Figura A.2: Fluxograma de definição dos módulos elásticos e compressibilidades a partir de dados obtidos do fluxograma anterior. 


\section{Apêndice $B$}

Tabela B.1: Relação das fácies encontradas em cada poço perfilado. Adaptado de Passarella [34]

\begin{tabular}{|c|c|c|c|c|c|}
\hline \multirow{2}{*}{\multicolumn{2}{|c|}{ Fácies }} & \multicolumn{4}{|c|}{ Poços } \\
\hline & & \multirow[t]{2}{*}{ NA02 } & NA04 & \multirow[t]{2}{*}{ NA07 } & NA12 \\
\hline 1 & Interlaminado Lamoso Deformado & & & & \\
\hline 2 & Conglomerados e Brechas Carbonáticas & & & & \\
\hline 3 & Diamictito Arenoso Lamoso & & & & \\
\hline 4 & Conglomerados Residuais & & & & \\
\hline 5 & Arenitos Conglomeráticos & & & & \\
\hline 6 & Arenito Grosso, Amalgamado & & & & \\
\hline 7 & Arenito Médio Fino Laminado & & & & \\
\hline 8 & Arenito Médio Gradado ou Maciço & & & & \\
\hline 9 & Arenito Médio Cimentado & & & & \\
\hline 10 & Arenito/Folhelho Interestratificado & & & & \\
\hline 11 & $\begin{array}{l}\text { Arenito/Folhelho Finamente } \\
\text { Interestratificado }\end{array}$ & & & & \\
\hline 12 & Siltito Argiloso Estratificado & & & & \\
\hline 13 & Interlaminado Siltito Argiloso e Marga & & & & \\
\hline 14 & Folhelho Radioativo & & & & \\
\hline 15 & Interlaminado Arenoso Bioturbado & & & & \\
\hline 16 & $\begin{array}{l}\text { Interlaminado de Siltito e Folhelho, } \\
\text { Deformado, Bioturbado }\end{array}$ & & & & \\
\hline 17 & Marga Bioturbada & & & & \\
\hline 18 & Ritmito & & & & \\
\hline 19 & Arenito Glauconítico & & & & \\
\hline 20 & $\begin{array}{l}\text { Folhelho Siltico com Níveis de Marga } \\
\text { Bioturbada }\end{array}$ & & & & \\
\hline 21 & $\begin{array}{l}\text { Arenito Cimentado, com Feições de } \\
\text { Escorregamento }\end{array}$ & & & & \\
\hline 22 & Siltito Argiloso/Arenito Deformado & & & & \\
\hline 23 & Arenito Médio/Fino Laminado Cimentado & & & & \\
\hline 24 & $\begin{array}{l}\text { Interestratificado Siltito/Folhelho } \\
\text { Intensamente Bioturbados }\end{array}$ & & & & \\
\hline 25 & Marga Bioturbada & & & & \\
\hline 26 & Folhelho Carbonoso & & & & \\
\hline 27 & Arenito Maciço Muito Fino & & & & \\
\hline 28 & Siltito Areno-Argiloso & & & & \\
\hline 29 & Interlaminado Siltito/Folhelho & & & & \\
\hline
\end{tabular}




\section{Apêndice C}

A seguir, encontram-se os perfis dos 5 poços selecionados e utilizados ao longo da dissertação para obtenção de dados.

\section{- POÇO NA02}
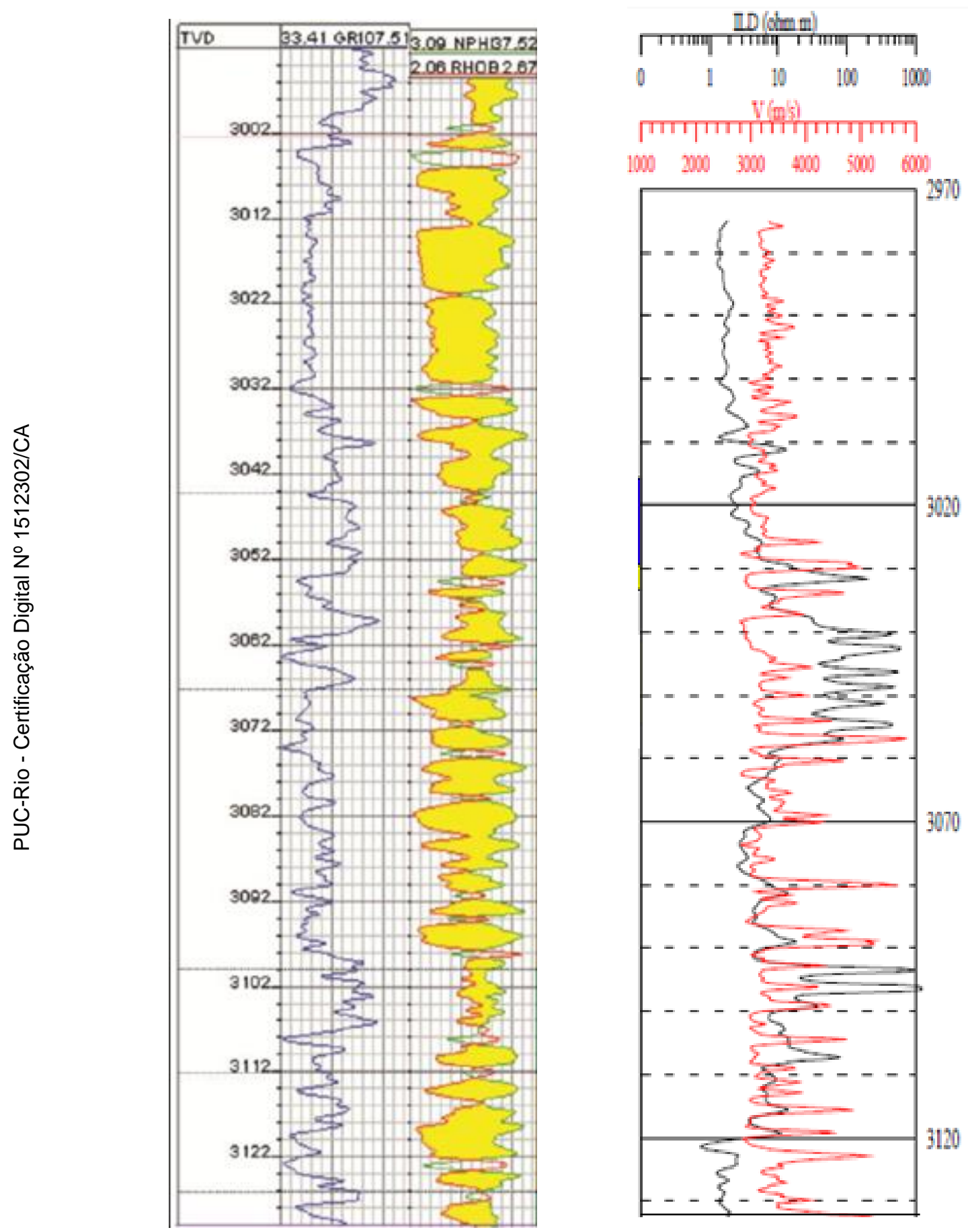
- Poço RJS0019
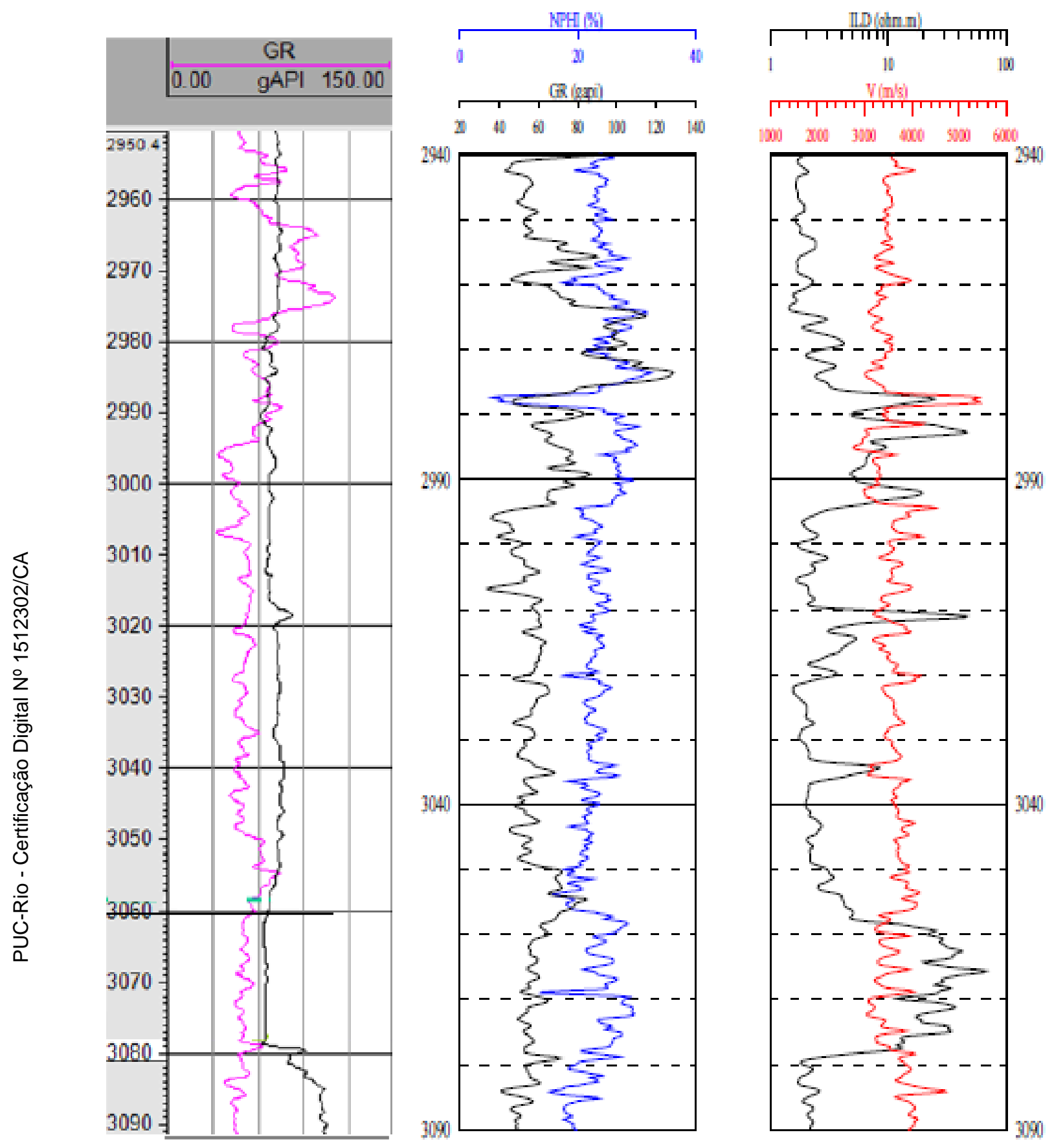
- POÇO NA04
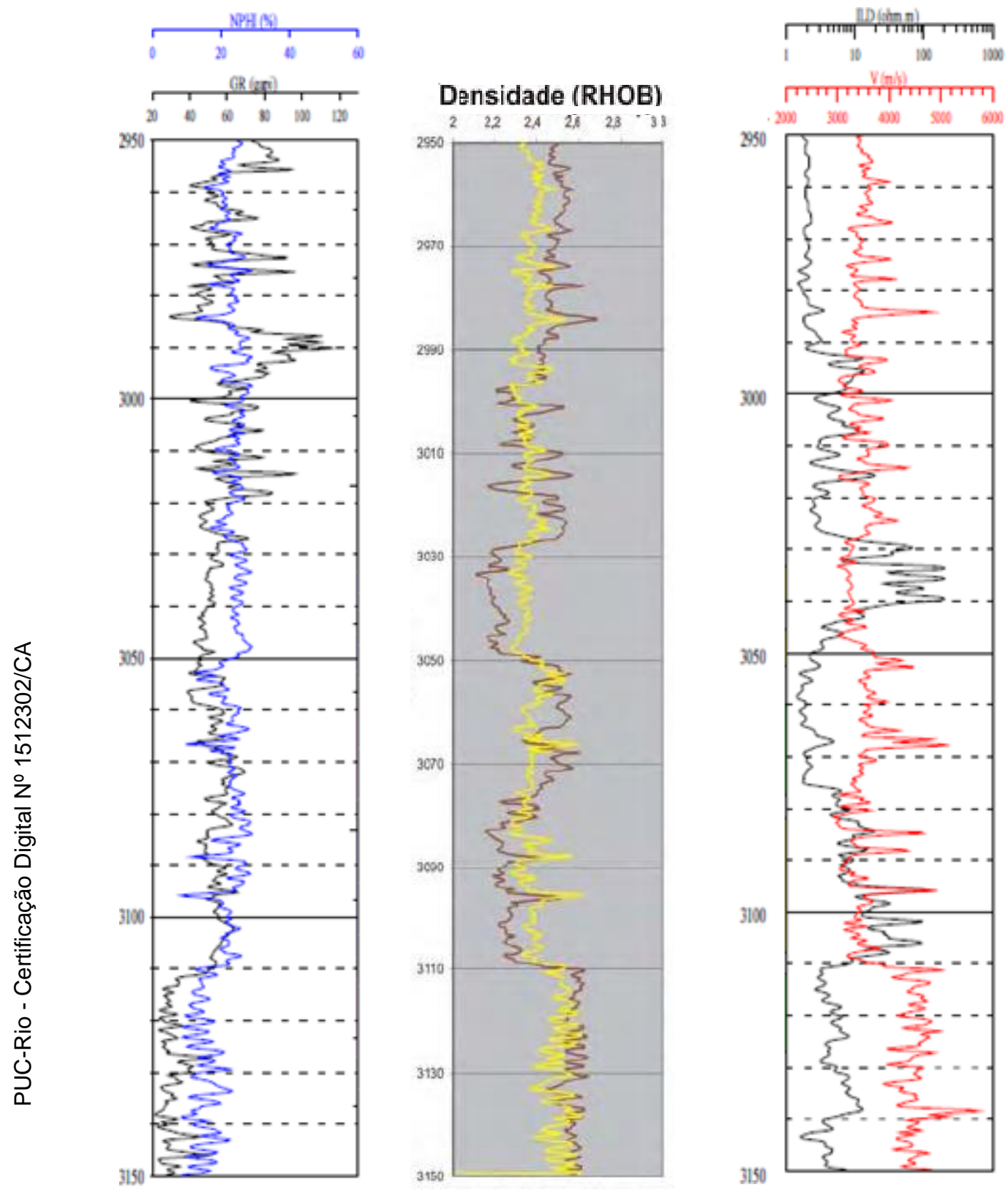
- POÇO NA07
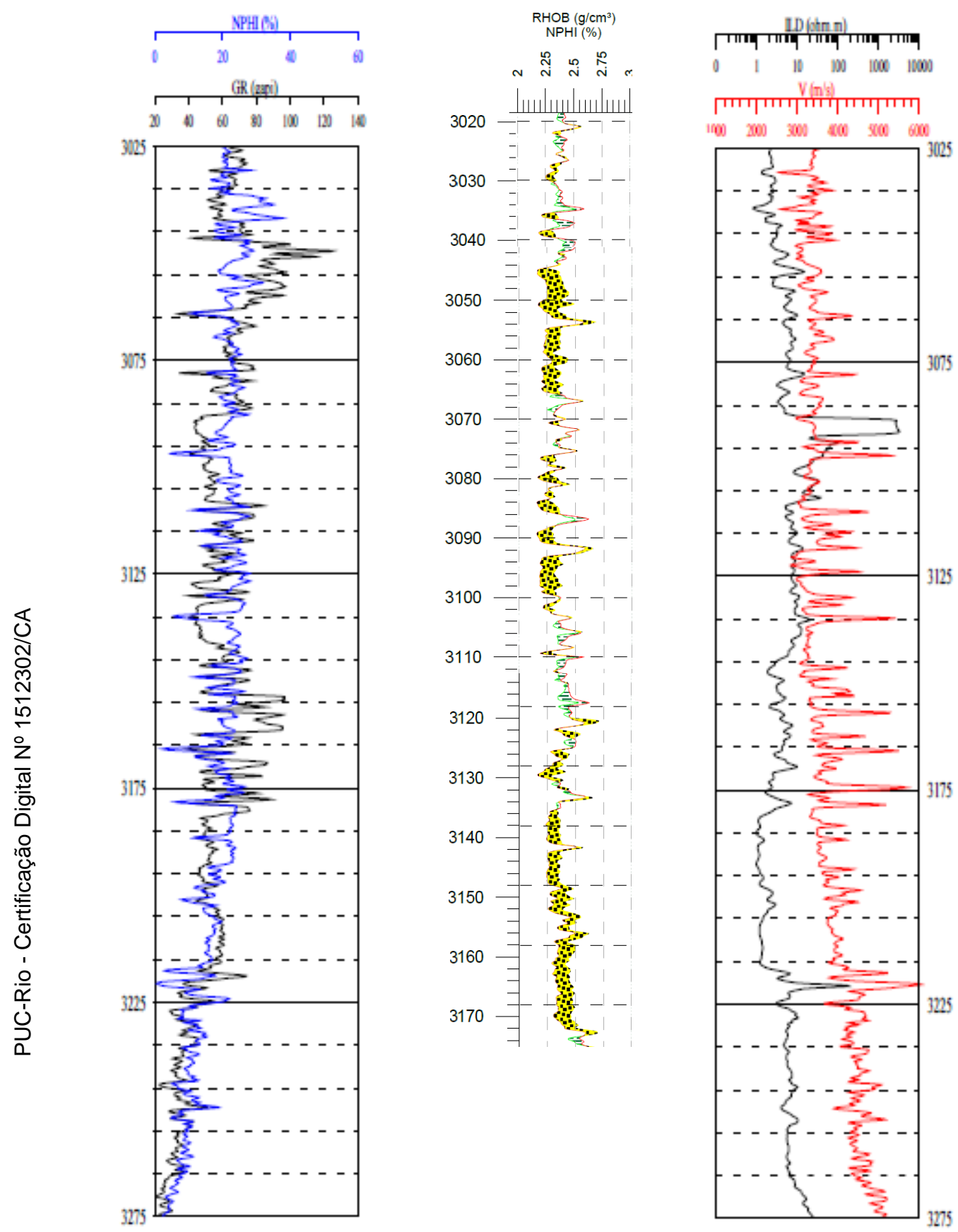
- POÇO NA12

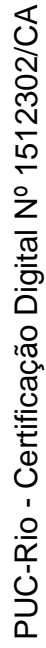

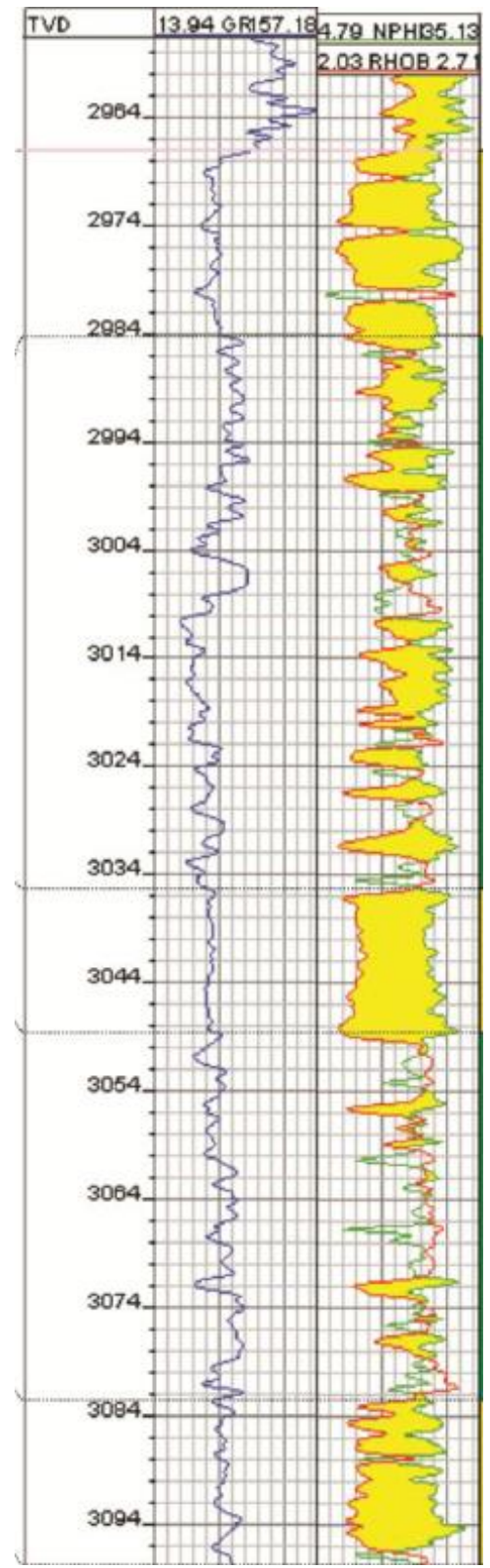

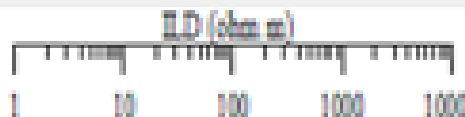

$\begin{array}{lllll}1 & 10 & 100 & 1000 & 1000\end{array}$

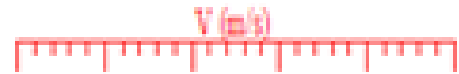
$1200 \quad 2000 \quad 3000 \quad 40005000 \quad 6000$

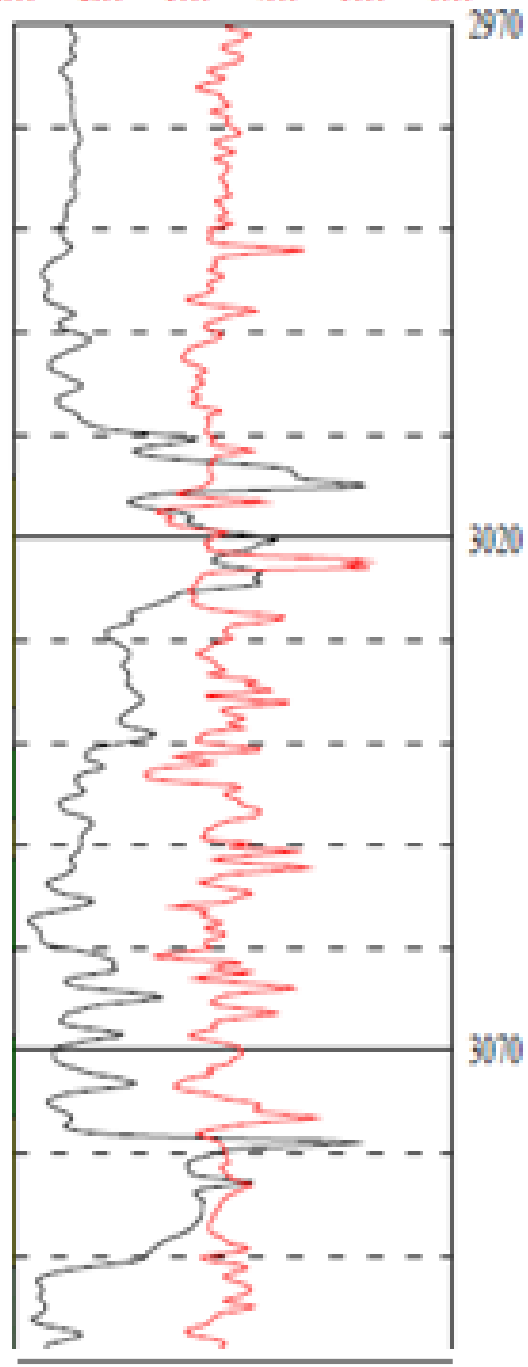

